\title{
Hawaii Zuteck Rotor Project: Compilation of Project Reports
}

M.D. Zuteck

MDZ Consulting

Kemah, Texas

M.W. Miller

Makani Uwila Power Corporation

Laie, Hawaii

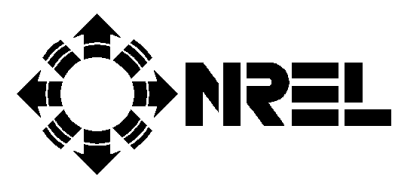

National Renewable Energy Laboratory 1617 Cole Boulevard Golden, Colorado 80401-3393

A national laboratory of the U.S. Department of Energy Managed by Midwest Research Institute for the U.S. Department of Energy under contract No. DE-AC36-83CH10093 


\section{Hawaii Zuteck Rotor Project: Compilation of Project Reports}

M.D. Zuteck

MDZ Consulting

Kemah, Texas

M.W. Miller

Makani Uwila Power Corporation

Laie, Hawaii

NREL technical monitor: D.A. Simms

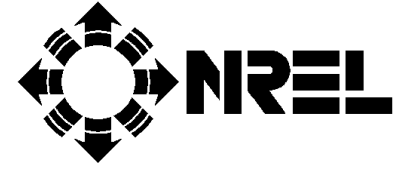

National Renewable Energy Laboratory 1617 Cole Boulevard Golden, Colorado 80401-3393

A national laboratory of the U.S. Department of Energy Managed by Midwest Research Institute for the U.S. Department of Energy under contract No. DE-AC36-83CH10093

Prepared under Subcontract No. HC-2-11101-04

November 1998 
This publication was reproduced from the best available copy Submitted by the subcontractor and received no editorial review at NREL

\section{NOTICE}

This report was prepared as an account of work sponsored by an agency of the United States government. Neither the United States government nor any agency thereof, nor any of their employees, makes any warranty, express or implied, or assumes any legal liability or responsibility for the accuracy, completeness, or usefulness of any information, apparatus, product, or process disclosed, or represents that its use would not infringe privately owned rights. Reference herein to any specific commercial product, process, or service by trade name, trademark, manufacturer, or otherwise does not necessarily constitute or imply its endorsement, recommendation, or favoring by the United States government or any agency thereof. The views and opinions of authors expressed herein do not necessarily state or reflect those of the United States government or any agency thereof.

Available to DOE and DOE contractors from:

Office of Scientific and Technical Information (OSTI)

P.O. Box 62

Oak Ridge, TN 37831

Prices available by calling (423) 576-8401

Available to the public from:

National Technical Information Service (NTIS)

U.S. Department of Commerce

5285 Port Royal Road

Springfield, VA 22161

(703) $605-6000$ or (800) 553-6847

or

DOE Information Bridge

http://www.doe.gov/bridge/home.html 


\section{Foreword}

The Hawaii Zuteck Rotor Project was not carried out as originally conceived and planned. The original objective was to provide aileron-controlled retrofit blades for the Westinghouse WWG-0600 wind turbines operating at the Kahuku wind farm on Oahu, Hawaii. The turbine's rotating hydraulic full-span pitch control system was problematic and required significant maintenance. It was hoped that the aileron concept would have eliminated the need for the full-span pitch control system, replacing it with smaller, simpler, electro-mechanical actuators to drive two flaps on each blade. It was also hoped that aileron control could be used to alleviate rotor loads and boost power production.

The technical feasibility of the aileron-controlled blades for the Westinghouse WWG-0600 turbine was demonstrated in Phase I of the project. An outboard section of the turbine blade was retrofitted with various aileron configurations and leading edge modifications and tested in the Wichita State wind tunnel. The most promising candidate aileron configuration was chosen from analysis of the resulting twodimensional test data. Technical rationale and resulting conclusions are reported in the Phase I final report "Wind Tunnel Test Report of the First LS-1 Airfoil/ Flap Model Test at the Beech Memorial Wind Tunnel, Wichita State University February 2 through 7, 1992" by M. D. Zuteck and M. W. Miller.

During Phase II of the project, a set of Westinghouse blades were retrofitted with the aileron modification. Two linear electro-mechanical actuators were mounted at the inboard section of each blade. Synthetic lines were run through the blade from the actuators to the two aileron sections. A considerable amount of testing was undertaken to find appropriate synthetic lines capable of withstand anticipated fatigue loading. Various mechanical links and other equipment were used to route the lines from the root actuators to outboard blade section ailerons. The aileron sections were built to be extremely flexible to accommodate blade flap motion, but were torsionally rigid so they would not twist when driven into position. Blade modifications, aileron configuration, and flap actuation system details are described in the Phase II final report entitled "Task 2 Report Hawaii Zuteck Rotor Project" dated December 7, 1994 by M. D. Zuteck and M. W. Miller.

Phase I and II were completed as required. Phase III was to encompass installation and testing of the retrofitted blades on the full-scale Westinghouse turbine in the field. Phase III was not undertaken due to the fact that operation of the Westinghouse WWG-0600 turbines at the Kahuku wind farm was discontinued. The wind farm was shut down and the project team dissolved. The proposed installation and test plan was described in the report entitled "Bold-On Rotor Test Plan for the Hawaii Zuteck Rotor Project at Site 9, Kahuku Hills, Hawaii" by M. D. Zuteck and M. W. Miller, June 17, 1992. Various other reports providing justification to proceed and other project rational were also produced.

The planned aileron configuration as reported in the Phase II final report was modified slightly during the blade retrofit construction process. The final configuration is reported in the appendix entitled "Final Flap Actuation System Configuration Overview" by M. D. Zuteck, August 18, 1998.

This publication contains a compilation of project reports submitted by the subcontractor during the course of the project. It documents the project rationale and objectives in a chronological manner, and summarizes technical conclusions. Upon termination of the Hawaii Zuteck Rotor Project, the aileronretrofit blades were transported to NREL and placed into long-term storage at the National Wind Technology Center.

D. Simms NREL Technical Monitor

Hawaii Zuteck Rotor Project

January 18, 1999 


\section{Contents}

Section $1 \quad$ Phase I Final Report

Section 2 Preliminary Test Plan

Section 3 Justification to Proceed

Section $4 \quad$ Preliminary Design

Section 5 Phase II Final Report

Section 6 Phase II Follow-Up
"Wind Tumnel Test Report of the First LS-1 Airfoil/ Flap Model Test at the Beech Memorial Wind Tunnel, Wichita State University, February 2 through 7, 1992" by M. D. Zuteck and M. W. Miller

"Bolt-On Rotor Test Plan for the Hawaii Zuteck Rotor Project at Site 9, Kahuku Hills, Hawaii" by M. D.

Zuteck and M. W. Miller, June 17, 1992

"Justification to Proceed to the Hawaii Zuteck Rotor Project Bolt-On Test at Site 9, Kahuku Hills, Hawaii" by M. D. Zuteck and M. W. Miller, August 24, 1992

"Preliminary Design Description for the Hawaii Zuteck Rotor Project Bolt-On Test at Site 9, Kahuku Hills, Hawaii" by M. D. Zuteck and M. W. Miller, September 16,1992

"Task 2 Report Hawaii Zuteck Rotor Project" by M. D. Zuteck and M. W. Miller, December 7, 1994

"Hawaii Zuteck Rotor Project, Final Flap Actuation System Configuration Overview" by M. D. Zuteck, August 18, 1998 


\section{Section 1}

\section{Hawaii Zuteck Rotor Project \\ Phase I Final Report}

"Wind Tunnel Test Report of the First LS-1 Airfoil/ Flap Model Test at the Beech Memorial Wind Tunnel, Wichita State University, February 2 through 7, 1992"

by M. D. Zuteck and M. W. Miller 


\section{INTRODUCTION}

\section{Purpose}

The wind tunnel test was intended to provide further knowledge of the ability of the flap system on the Westinghouse LS-1 airfoil to start, stop and control the Westinghouse WWG-0600 wind turbine without a full span pitch capability. Further, the test was to collect data on the effect of different nose and cusp configurations on the operating characteristics of the airfoil.

\section{History}

The Hawaii Zuteck Rotor Project was started to allow for a larger, more efficient rotor to be substituted onto the existing Westinghouse WWG-0600 wind turbines located in Kahuku, Hawaii. The goal is to replace the troublesome components of the Westinghouse hub design, namely the blade pitch spindles, the blade pitch hydraulics and the current bronze teeter bearings, with this larger rotor. Conceptual designs have been made, along with initial engineering calculations showing that it should be feasible to install a 160 foot diameter rotor using the existing 142 foot diameter blades as a starting point. To do this, many technical and financial hurtles had, and still have, to be overcome. A plan was made to overcome these technical hurtles in a single, controlled fashion, allowing the technical and financial risk to be mitigated as well as giving natural break points at which to evaluate the progress and feasibility of the project.

The first technical hurtle to be overcome was the understanding of the rotors behavior with flaps installed. It was decided that the best way to attack this problem was to install a model of the LS-1 airfoil in a wind tunnel and collect data to determine the ability to start, stop and operate the turbine with flaps. During discussion of the options for the wind tunnel test, various variables were brought forth that could be tested in the tunnel, allowing for fuller understanding of the behavior of the blade on the turbine. These included three types of flaps and two types of nose modifications (along with the unmodified nose) for the LS-1. (A third nose type was designed and tested at the tunnel.) One week of wind tunnel time was reserved at the Wichita State University (WSU) Beech Memorial Tunnel during the week of 
February 2, 1992. Testing involved three project engineers lone from HERS and two from NPS) at WSU along with off site support from MDZ Consulting.

THE WIND TUNNEL

The wind tunnel at Wichita State University was used for the testing of the model. "The wind tunnel is a low speed, horizontal, single return, closed circuit facility. Circuit length, measured around tube centerline, is 256 feet with a maximum diameter of 23 feet 4 inches.... The tunnel has a rectangular, 7 \& 10 foot, test section with triangular fillets in each corner. The tunnel tube is transformed from a rectangle to a circular cross section in the енit cone just upstream of the tunnel fan and remains circular around the circuit to the contraction cone."

"The test section is 7 feet high, 10 feet wide, and 12 feet long and operates at atmospheric pressure. Section velocity is variable from 0 to 264 feet per second (0 to 180 miles per hour). Special walls are available which may be installed to permit two-dimensional testing of 3 foot span models."

"The tunnel fan is a four blade, variable pitch propeller which is driven by a 1,000 hp continuous duty $(1,500$ hp intermittent duty), electric motor. Propeller pitch and motor rpm are adjustable from the control room."

"The main balance is an external pyramid type which is located in a room below the test section floor. The balance sets model angle of attack and angle of yaw, and separates and measures the aerodynamic forces and moments. This information is transmitted to the control room where it is displayed on a digital data system and reduced by the on-line computer to aerodynamic force, and moment coefficients." (Abstracted from the WSU wind tunnel description booklet)

The model was mounted in the tunnel using the below the floor balance and a new balance, designed and built for this test, that was added to the roof of the wind tunnel. This in-roof balance resolved loads in the down tunnel and cross tunnel directions. The model was restrained in the span-wise direction by the floor and ceiling, which 
were used to make the model act as a two dimensional model. The model was attached to the below floor balance by means of a metal meshed tooth coupling with a plastic insert. This allowed the balance below the floor to be turned, in turn rotating the model in angle of attack while the tunnel was on-line.

\section{MODEL DESCRIPTION}

The model used for the first HZRP wind tunnel test at WSU was built by Northern Power Systems (NPS). It consisted of the last seven feet (escluding the tip cap) of tip from a blade of a Westinghouse wind turbine, incorporating the same twist, taper, and cross-section as that of the turbine. The model was made from .1" Douglas fir ply sheets, laminated together with epory resin and sealed, inside and out, with a fiberglass shell. This piece was modified, by removing the aft section and by installing attaching hardware, to allow the installation of three different types of $30 \%$ chord flaps. The model was also fitted with an electro-mechanical actuator to allow the flaps to be moved to different deflection angles while the tunnel was operating.

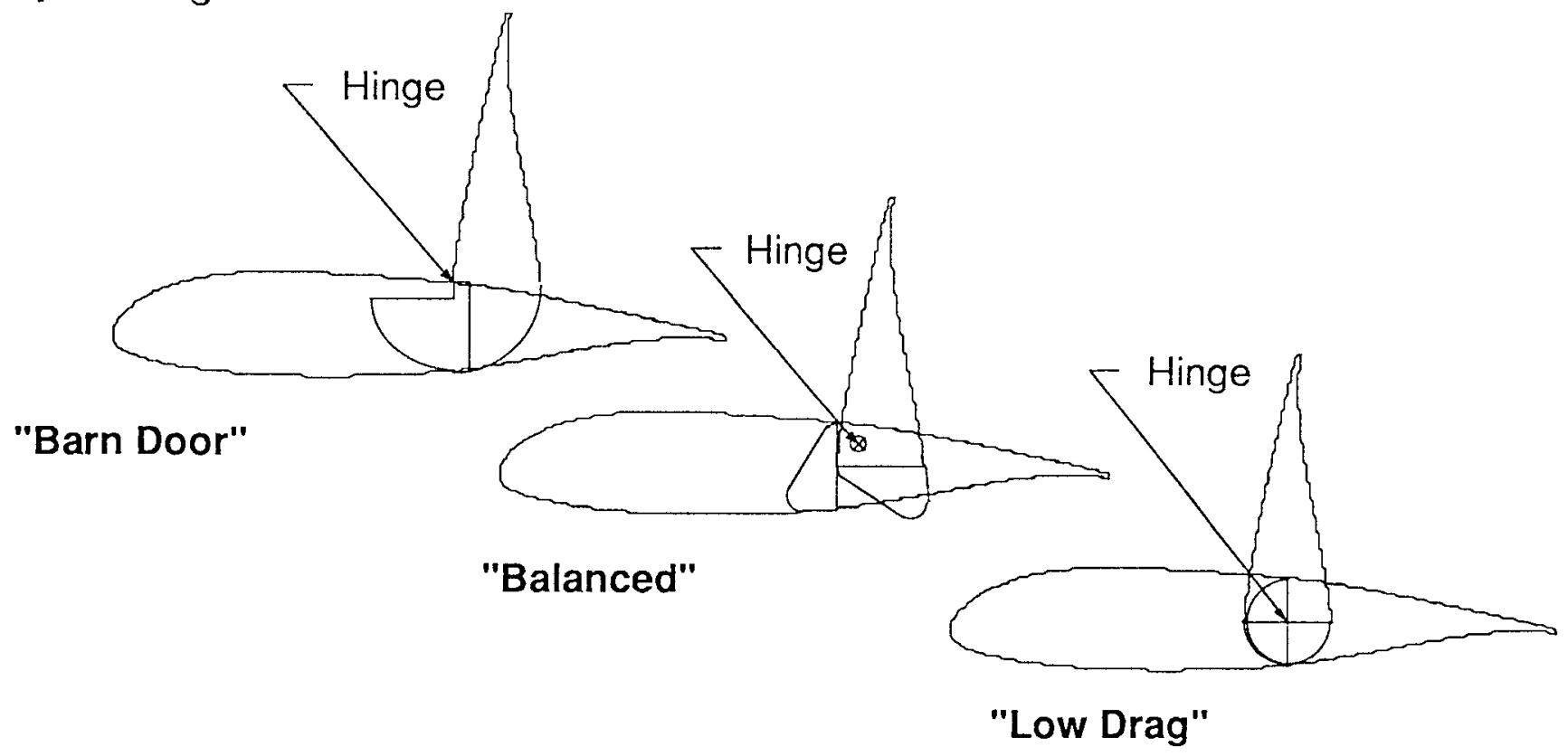

The flaps consisted of a single aft piece (made from the aft section that was removed from the blade tip) and interchangeable noses (made new) to accommodate the testing criteria. These flaps were designated the "Barn Door", the "Balanced" and the "Low Drag". 
Examples of these three flaps are shown above.

The Barn Door was designed to provide a good stopping ability by allowing the air on the high pressure side to round the corner and create a low pressure area aft of the deployed flap. The hinges in the model were located in the top and bottom end plates, as were the hinge points in all the other flaps. The intention of this model was to allow minimal, preferably no, airflow through a gap in the low pressure surface between the flap and the airfoil.

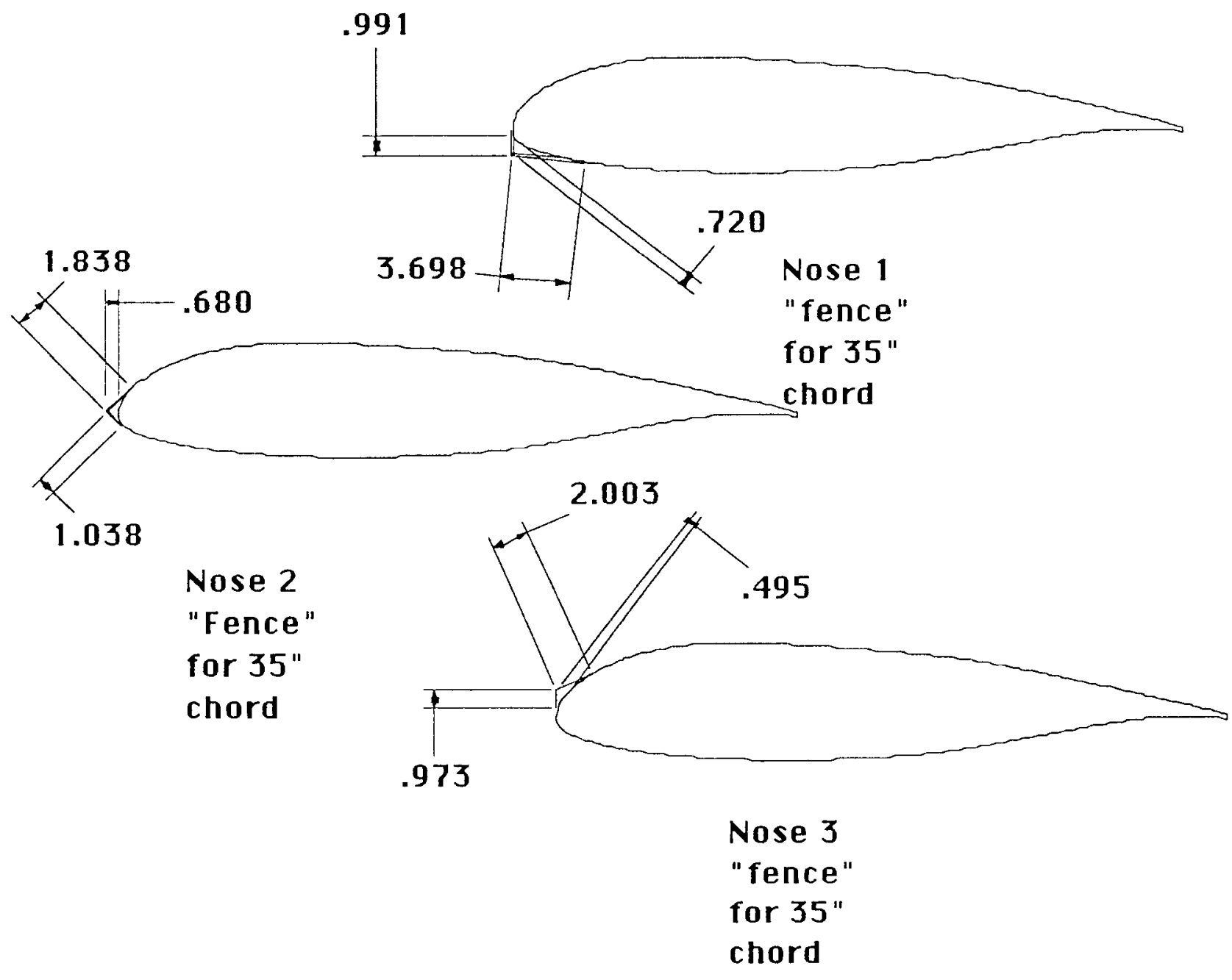

The Balanced was designed to give minimal actuator loadings as well as allow the venting of high pressure side air to the low pressure side in high flap deploy angle situations (greater than $-15^{\circ}$ ). This venting was to destroy any lift left on the airfoil in a shutdown situation. 
The Low Drag flap was designed to give the least drag in the operating condition and allow for no venting in the high flap deploy angle situation.

In addition, three different leading edge modifications were designed for use on the model. These noses provided a sharp corner to trip the flow over the model at different angles of attack. The drawing above shows the design of these three different noses as they would appear on a typical cross section of the model.

Each nose gave us the opportunity to investigate the characteristics of the airfoil in different stalled conditions. The intention of these trips was to reduce $C_{I m a x}$ for the airfoil to a value more realistic for stall limiting the wind turbine rotor.

WIND TUNNEL TEST PLAN

The wind tunnel testing was conducted from a plan allowing the investigation of the effects of the three different types of flaps and three different nose configurations on the start-up, shutdown, and operating modes. This plan was considered to be a starting point, but flexible enough to allow changes in the testing as the data indicated new directions which showed promise. This led to a very dynamic wind tunnel test, with runs being designed and modified while others were being completed. The third nose configuration was a major, and extremely important, result of this dynamic interaction during testing. The different configurations and conditions tested are shown in appendis $A$.

DATP

\section{Comparison with previous GA(W)-1 Data}

The data from the wind tunnel test included an angle of attack sweep that had the gap between the flap and the airfoil body taped to eliminate the bleed through of air from the high to low pressure area. There was also no nose modification attached to the leading edge of the airfoil. This run (Run 18 ) allowed us to compare the aerodynamic characteristics of the model to those reported by others on the GA(W)1 . 
Figure 1 shows the comparison of the model coefficient of lift with the published data for the GA(W)-1 tested by Wichita State University in the same tunnel. This graph indicates that there is a noticeable difference between the data collected from our test and that collected and accepted for the $G(\omega)-1$. Figure 2 shows the comparison of the model coefficient of drag with the published data from the same source. This data also indicates that there exists a difference between the model data collected and the published data.

These differences could have been caused by a number of factors. They could include incorrect model constants defined for the model, tunnel blockage and wall effects, inaccuracy in flap angle adjustment and setting, deviation of the airfoil geometry from that originally engineered for the published data, and tunnel turbulence. The magnitude that these different factors take in explaining the differences seen is difficult to quantify. The model constants, for esample were changed twice during the test in order to reflect reality a little more clearly. Yet the model, with it's complen geometry, defied easy definition of the model constants. The size of the model created tunnel blockage problems that contributed to differences in the operation of the model from the original plan and could have contributed to the differences seen.

That the curves have the same shape and are fairly close to the data shown in the literature is encouraging. As a gross look at the effects of the different variables being tested, especially as they compare one to another, this data will more than serve it's purpose. This data will not give three dimensional effects, nor will it indicate how the flaps will interact with the inner rotor, items that can only be resolved with a true 3-D test on a complete rotor.

\section{Starting Ability}

The ability to start the rotor is an important consideration in the overall usefulness of the flaps to operate the wind turbine. Figure 3 shows $C_{1}$ versus flap angle $(\delta)$ with the barn door flap and an angle of attack of $90^{\circ}$. The model was positioned in the tunnel with the high pressure side of the model facing the air stream $\left(\alpha=90^{\circ}\right)$, as would be roughly true of a blade in startup. This is considered the worst case 


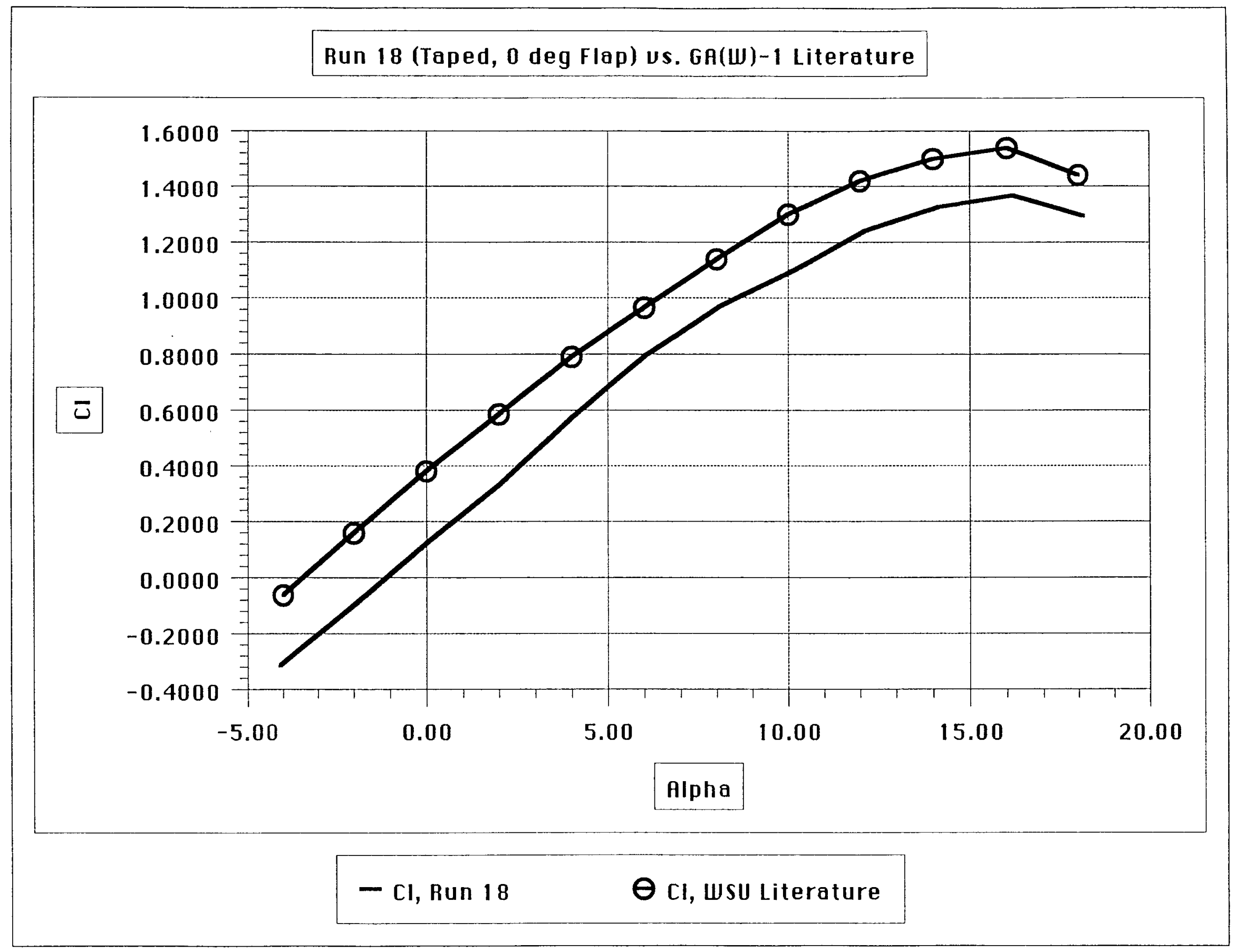

Figure 1 


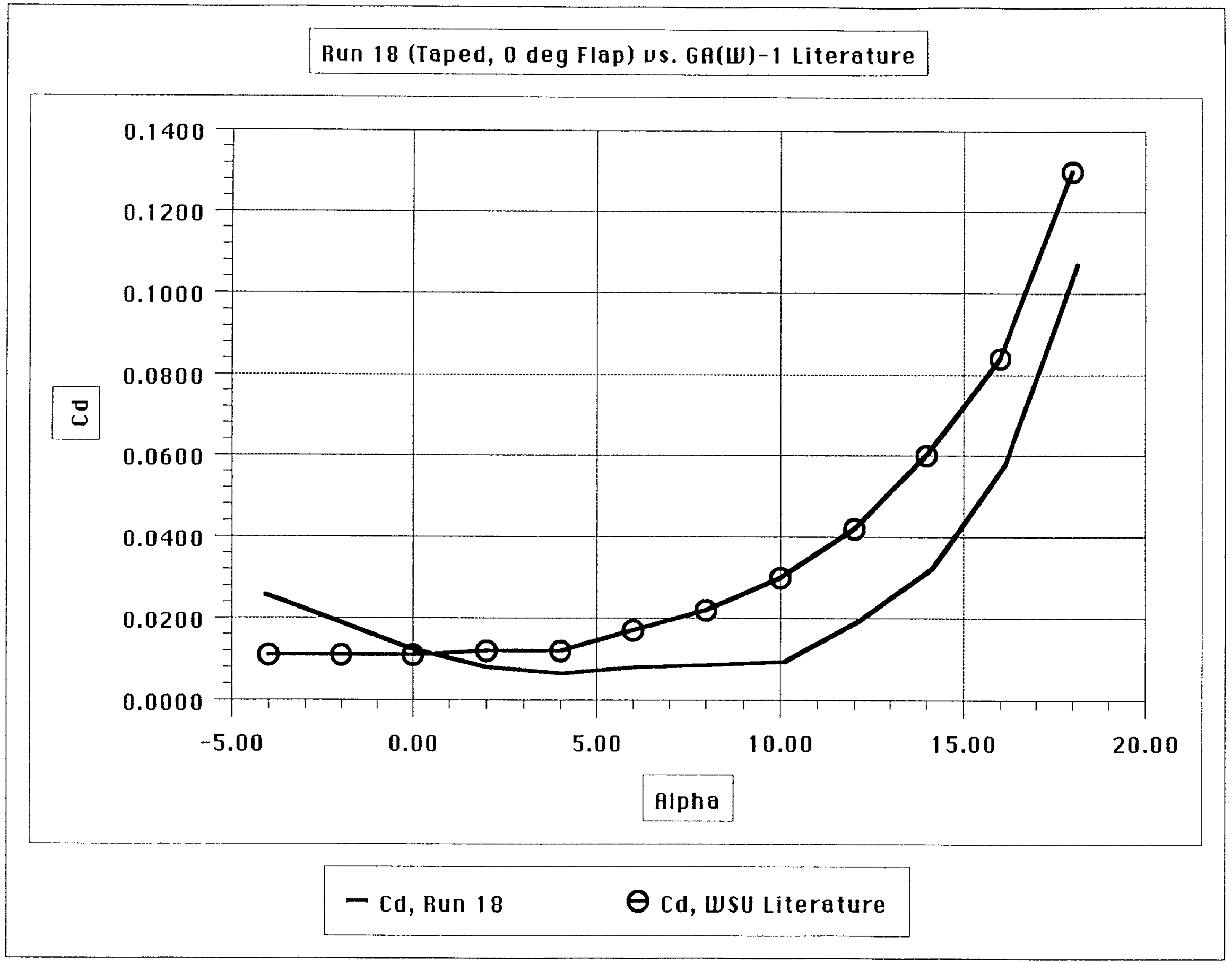

Figure 2 


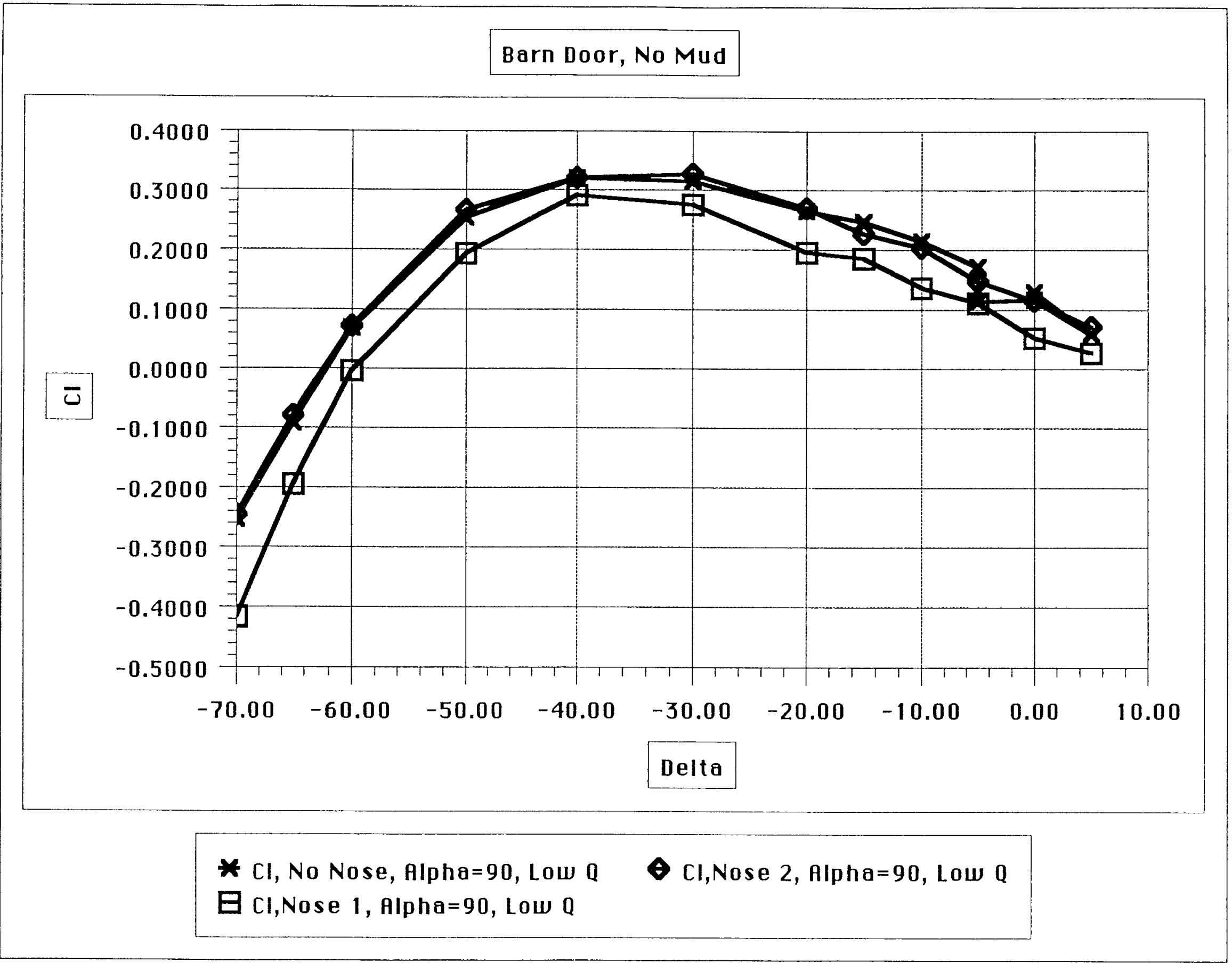

Figure 3 
for the HZRP rotor, as it is planned to operate at a pitch angle as much as $4^{\circ}$ into the wind. $C_{1}$ is measured toward the side wall of the tunnel and therefore, in this case is the force coefficient in the direction of rotation of the blade. Figure 3 shows that there is a maximum $C_{1}$ of almost .33 with nose 2 and $\delta=-30$ degrees. Looking at the raw data for run 36, this corresponds to a force of ouer? pounds in the direction of rotation for this 7 foot section. This translates to roughly 50 pounds at $15 \mathrm{MPH}$ in the direction of rotation if 24 feet of flap is presented to the wind on each blade. This should be sufficient to overcome the static friction of the rotor and cause it to turn. This also ignores any contribution of a positively pitched blade or of the inner rotor. The case for starting the rotor therefore looks promising.

\section{Stopping Ability}

The ability to stop the rotor is as important, if not more important, than the ability to start it. It has also proven to be more difficult to do with the LS-1 than startup has been. $C_{t}$, or thrust coefficient, is a measure of this stopping ability. It is the coefficient of force in the chordwise direction, referenced to the model. Figure 4 (note that this graph shows the aircraft nomenclature " $C_{a}$ ", which is equivalent to $-C_{t}$ ) shows that both the Barn Door with Nose 3 and the Balanced with Nose 3 flaps have a negative value of $c_{t}$ for all angles of attack. In other words, the rotor force is in the direction opposite of the direction of rotation. The Barn Door flap has an aduantage in that it has more stopping power, by as much as a factor of three, at angles of attack greater than 30 degrees. The Barn Door had a masimum flap angle of $70^{\circ}$ and the Balanced had a maximum flap angle of $80^{\circ}$ due to hardware constraints.

It can be seen from Figure 5 that the nose modification also has an

effect on stopping power. Nose 3 appears to aid stopping especially in the angle of attack range of $25^{\circ}$ to $60^{\circ}$. Measurements were not taken with nose 1 or 2.

The Effect of Nose Trips on the Airfoil Sections.

The ability to stall limit the rotor and have the rotor behave in a benign fashion in operation is of prime concern in this project. Although stall limiting is not essential, it is a goal worthy of much 
Balanced us. Barn Door, "Stopping Power"

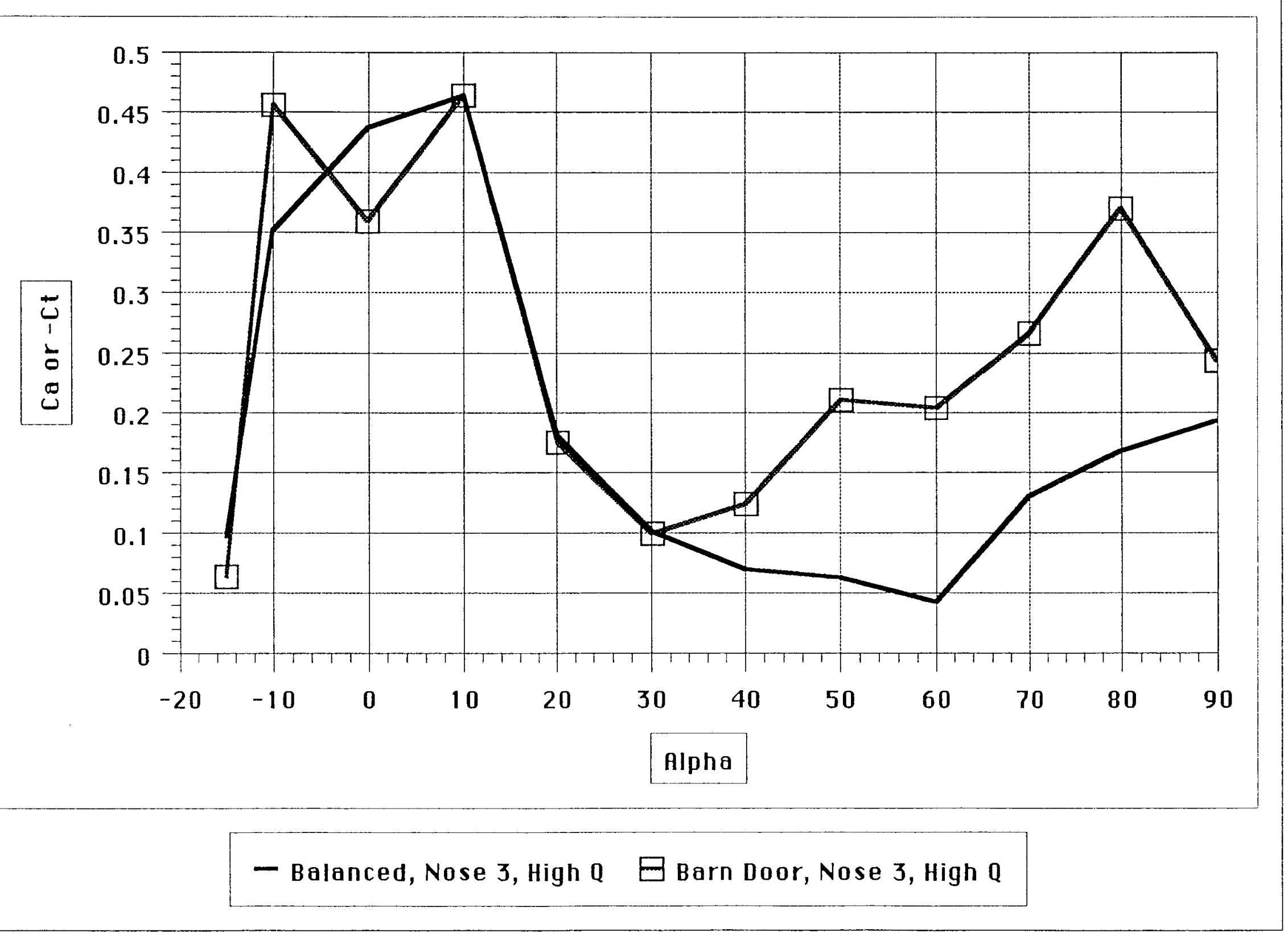

Figure 4 


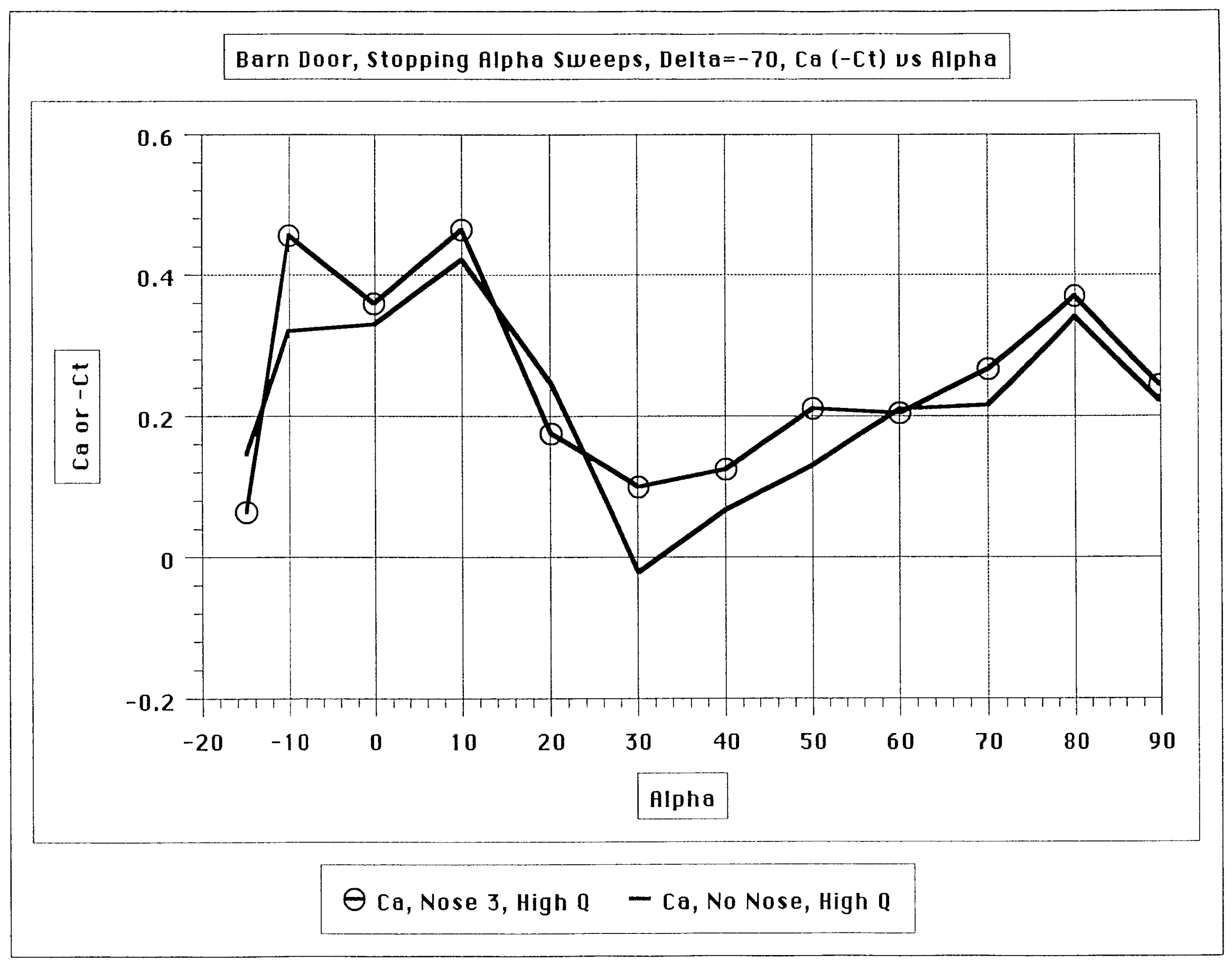

Figure 5 
effort to achieve. The intention of the nose modifications was to reduce $C_{1 m a r}$ to a value that would allow a better chance at achieving stall limiting behavior from the 160' rotor at $36 \mathrm{rpm}$. Each of the noses used is briefly described in the model section. In addition, testing with an unmodified nose was also done.

As the Barn Door flap seemed the most likely candidate for the Bolton Rotor Test and all the flaps behaved similarly in low $\delta$ settings, the leading edge modifications were all tested only on the Barn Door. The three modifications were also tested on the Balanced flap, but the unmodified leading edge was not. The results of the testing lead to some interesting conclusions.

The effects of the Noses on $C_{1}$ is reflected in Figure 6 . Nose 0 (the unmodified leading edge) and Nose 1 tended to give the nearly the same $c_{1}$ curve at all angles of attack. The only notable exception to this was that the sharper, but drooped, nose of Nose 1 gave a slightly higher (0.08 higher) $C_{\text {Imas }}$ that did Nose 0 . Nose 2 follows the Nose 0 curve to an $\alpha$ of $6^{\circ}$ and then drops off slightly. $C_{I m a r}$ for Nose 2 is 1.15 at an $\alpha$ of $14^{\circ}$ instead of 1.32 at an $\alpha$ of $16^{\circ}$ for nose 0 . Nose 3 matches nose $2^{\prime} s C_{1}$ curve until an $\alpha$ of $10^{\circ}$, which is $C_{I m a r}$ for Nose 3 , and then drops off. Nose 3 starts to increase $C_{1}$ beyond an $\alpha$ of $18^{\circ}$. Flap angle appears to do no more than shift the entire set of nose curves down and to the right, thus the basic relationships between the curves appear to be independent of flap angle. This shift appears to be about $3^{\circ}$ in $\alpha$ at $\mathrm{C}_{\text {Imar. }}$.

Figure 7 presents the results of $C_{d}$ versus Alpha for the different noses at $\delta=0$ and $\delta=-15$. The results presented here are a little different that those for $\mathrm{Cl}$. Where nose 3 reduces the $\mathrm{C}_{\mathrm{Im} \text { as }}$ of the airfoil, it increases $C_{d}$ enormously beyond a modest $\alpha$ of $4^{\circ}$. This can be seen, for example, as a more than four and one half times drag increase over the drag of the Nose 0 airfoil at an $\alpha$ of $15^{\circ}$. In high wind cases, where $\alpha$ can easily reach $15^{\circ}$ (roughly $44 \mathrm{MPH}$ with a pitch angle of $4^{\circ}$ on the $160^{\prime}, 36 \mathrm{rpm}$ rotor), this drag can significantly affect the rotor's ability to produce power.

Other conclusions that can be drawn from the graph are that nose 2 is also a high drag airfoil beyond an $\alpha$ of $10^{\circ}$, as compared to Nose 0 . 


\section{Barn Door, Cl us Alpha, Nose comparisons}

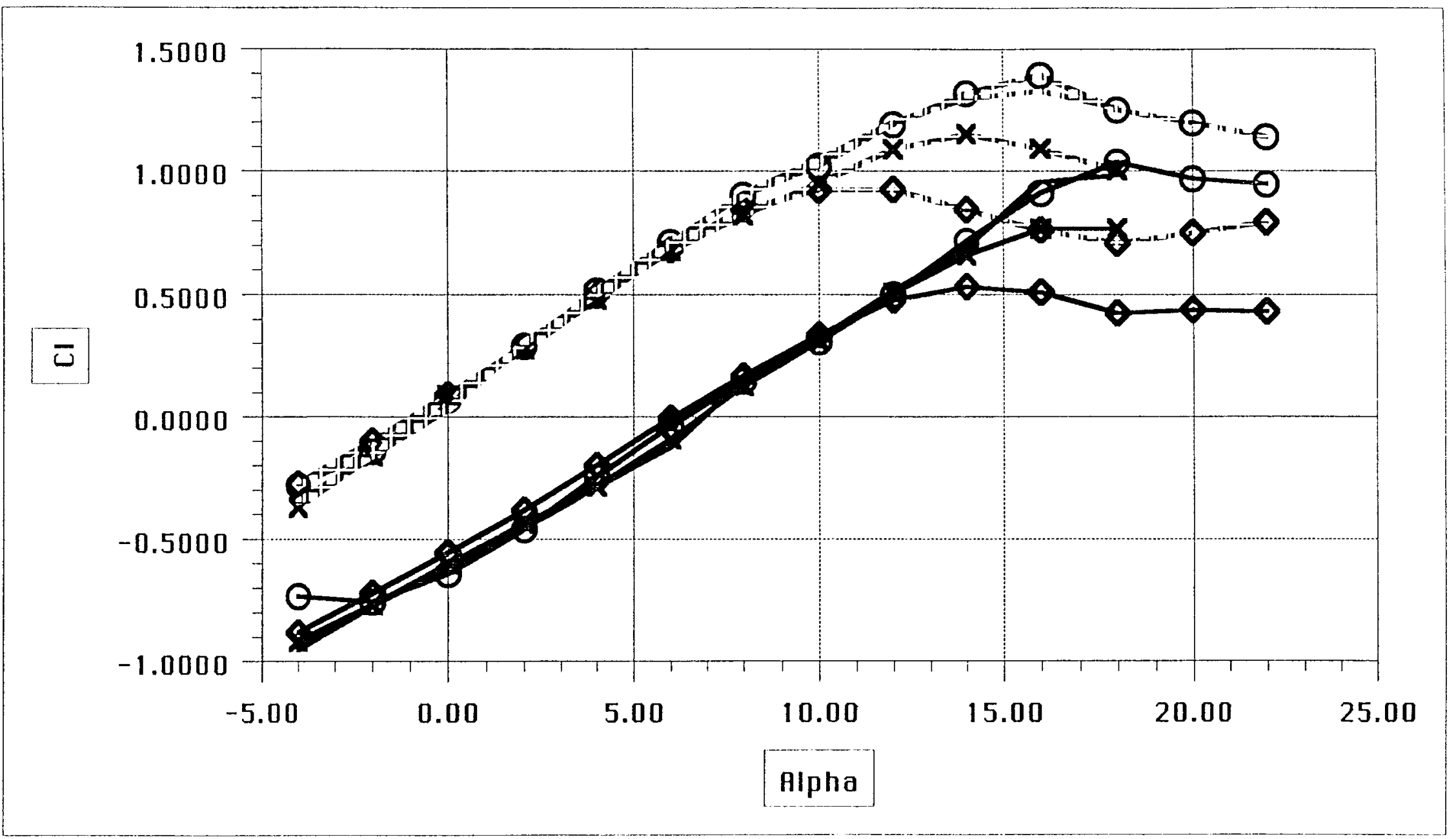

$\begin{array}{lll}\text { - No Nose, Delta }=-15 & \bullet \text { Nose 3, Delta }=-15 & \bigcirc \text { Nose 1, Delta }=0 \\ * \text { Nose 2, Delta }=-15 & ==\text { No Nose, Delta }=0 & \ominus \text { Nose 3, Delta }=0 \\ \Theta \text { Nose 1, Delta }=-15 & \times \text { Nose 2, Delta }=0 & \end{array}$


Barn Door, Cd us Alpha, Nose comparisons

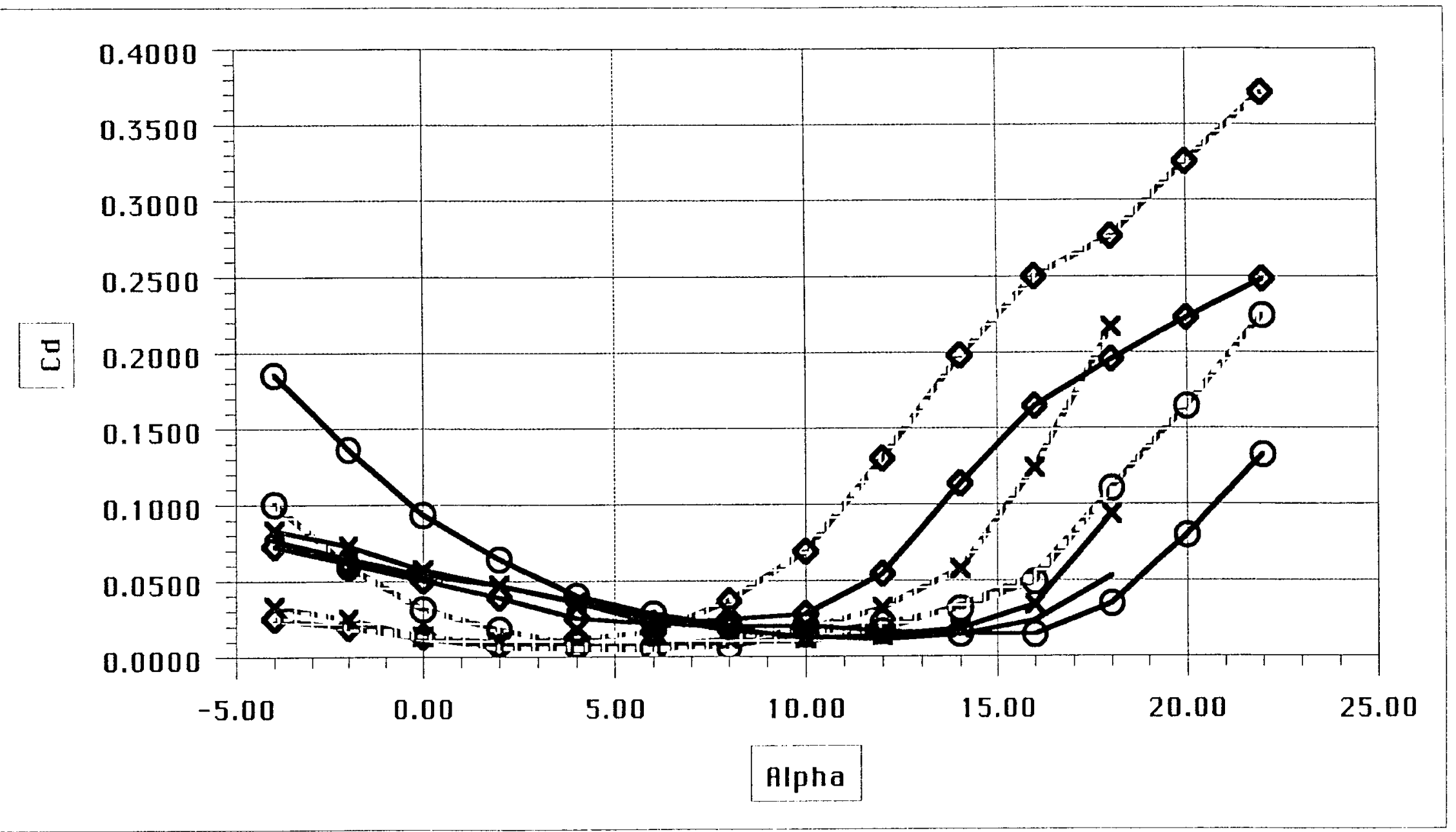

$$
\begin{array}{lll}
\text { - No Nose, Delta }=-15 & \bullet \text { Nose 3, Delta }=-15 & \bigcirc \text { Nose 1, Delta }=0 \\
* \text { Nose 2, Delta }=-15 & =\text { No Nose, Delta }=0 & \diamond \text { Nose 3, Delta =0 } \\
\ominus \text { Nose 1, Delta }=-15 & \times \text { Nose 2, Delta }=0 &
\end{array}
$$


The drag is twice that of Nose 0 at an $\alpha$ of $18^{\circ}$. Nose 1 again follows Nose 0 , except in the low $\alpha$ cases ( $\alpha$ less than $6^{\circ}$ ) where Nose 1 drag rises as Nose 0 drag continues fairly flat. Drag values for all noses are increased by increasing negative flap angle (flap deployment toward stop) up to between $\alpha=7^{\circ}$ (Nose 3) and $\alpha=11^{\circ}$ (Nose 1). At that point, increasing negative flap angle reduces the drag values at the same $\alpha$.

\section{The Effect of Flap Angle on Lift and Drag.}

It appears that flap angle and nose modifications cause changes in $C_{1}$ and $C_{d}$ independently of each other, at least as far as first, and possibly second, order effects are concerned. They will be treated therefore as separate issues in their effects.

The data indicates, in general, that changes in flap angle toward shutdown $\left(-90^{\circ}\right)$, cause the $C_{1}$ versus fipha curves to shift downward and to the right. In general, the same change in flap angle causes the $C_{d}$ versus Alpha curves to shift upward and to the right. This can be seen in Figure 8 . Note that the flap angle $(\delta)$ has not been shown beyond $-40^{\circ}$. This was the extent of the data collection for the operating angles of attack $\left(-4^{\circ}\right.$ to $\left.18^{\circ}\right)$. The curves appear smooth, even at high angles of attack and high angles of flap. Figure 9 shows that the same type of trend occurs with $C_{d}$ versus flpha. The $C_{d}$ curves shift upward and to the right, in an orderly manner, as $\delta$ increases toward shutdown.

\section{The Effect of Flap Type on Operating Alpha Range Data.}

The effect of flap type on $C_{1}$ and $C_{d}$ in the operating range of $\alpha(-4$ to $\left.+22^{\circ}\right)$ is shown in Figure 10. $C_{1}$ for both the Barn Door and Balanced flaps track each other well for deltas of 0 and $-5^{\circ}$. They start to diverge as $\delta$ increases beyond that. The $\delta$ equals $-10^{\circ}$ case could differ between the two types of flaps due to the early starting of venting in parts of the model or due to the difference in pivot location/nose shape (especially that the flap leading edge protruded into the airstream on the high pressure side on the Balanced flap). The $\delta$ equals $-15^{\circ}$ definitely shows the effect of venting on the Balanced flap. The curve for $\delta$ equals $-15^{\circ}$ crosses the $\delta$ equals $-10^{\circ}$ curve at an $\alpha$ of $14^{\circ}$. Yet the curve $\delta$ equals $-15^{\circ}$ is very close to that 


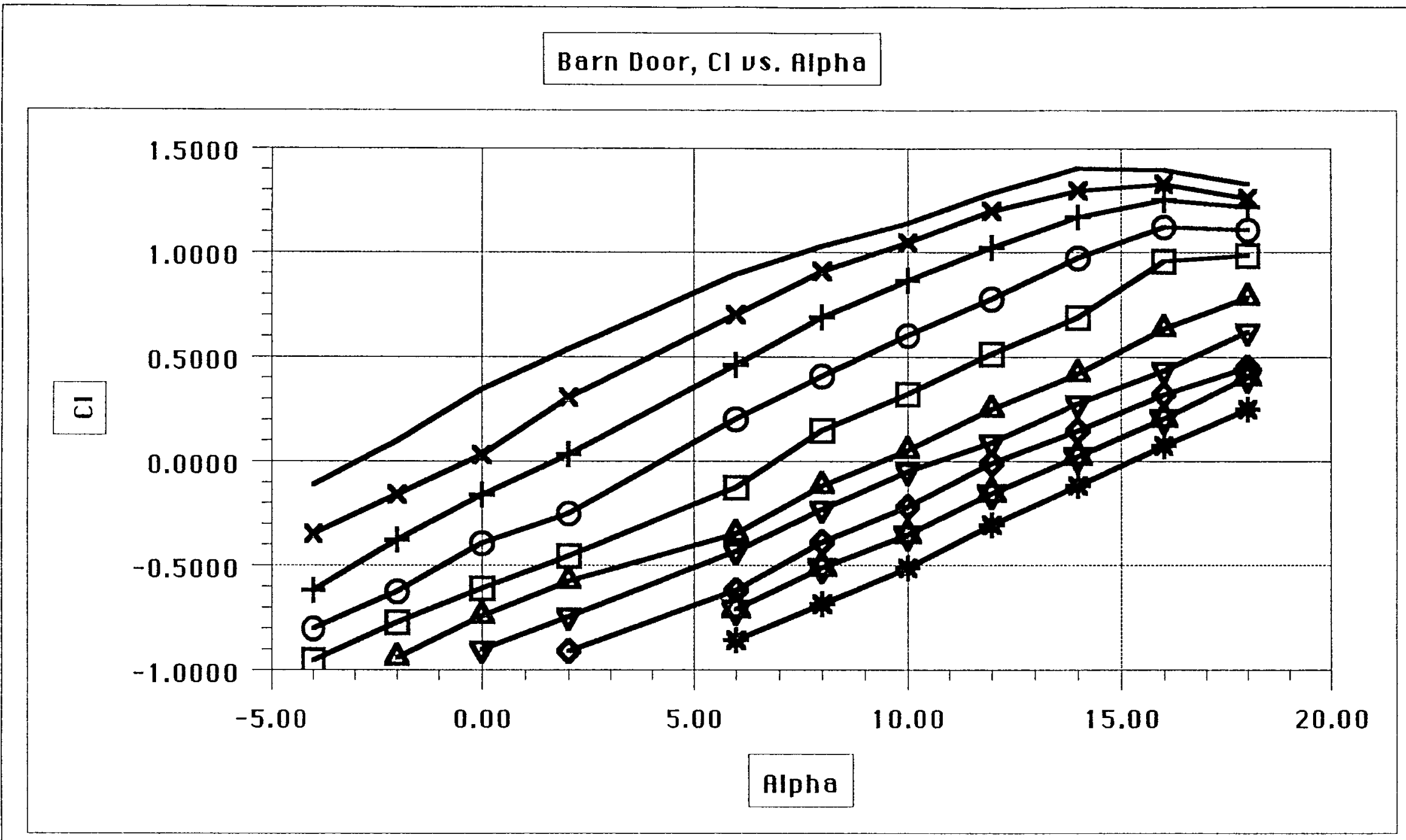

$\begin{array}{lll}* \text { No Nose, Delta }=-40 & \Delta \text { No Nose, Delta }=-20 & * \text { No Nose, Delta=0 } \\ * \text { No Nose, Delta }=-35 & \text { 日 No Nose, Delta }=-15 & \text { - No Nose, Delta }=5 \\ \Theta \text { No Nose, Delta }=-30 & \Theta \text { No Nose, Delta }=-10 & \\ \boldsymbol{\nabla} \text { No Nose, Delta }=-25 & \text { + No Nose, Delta }=-5\end{array}$




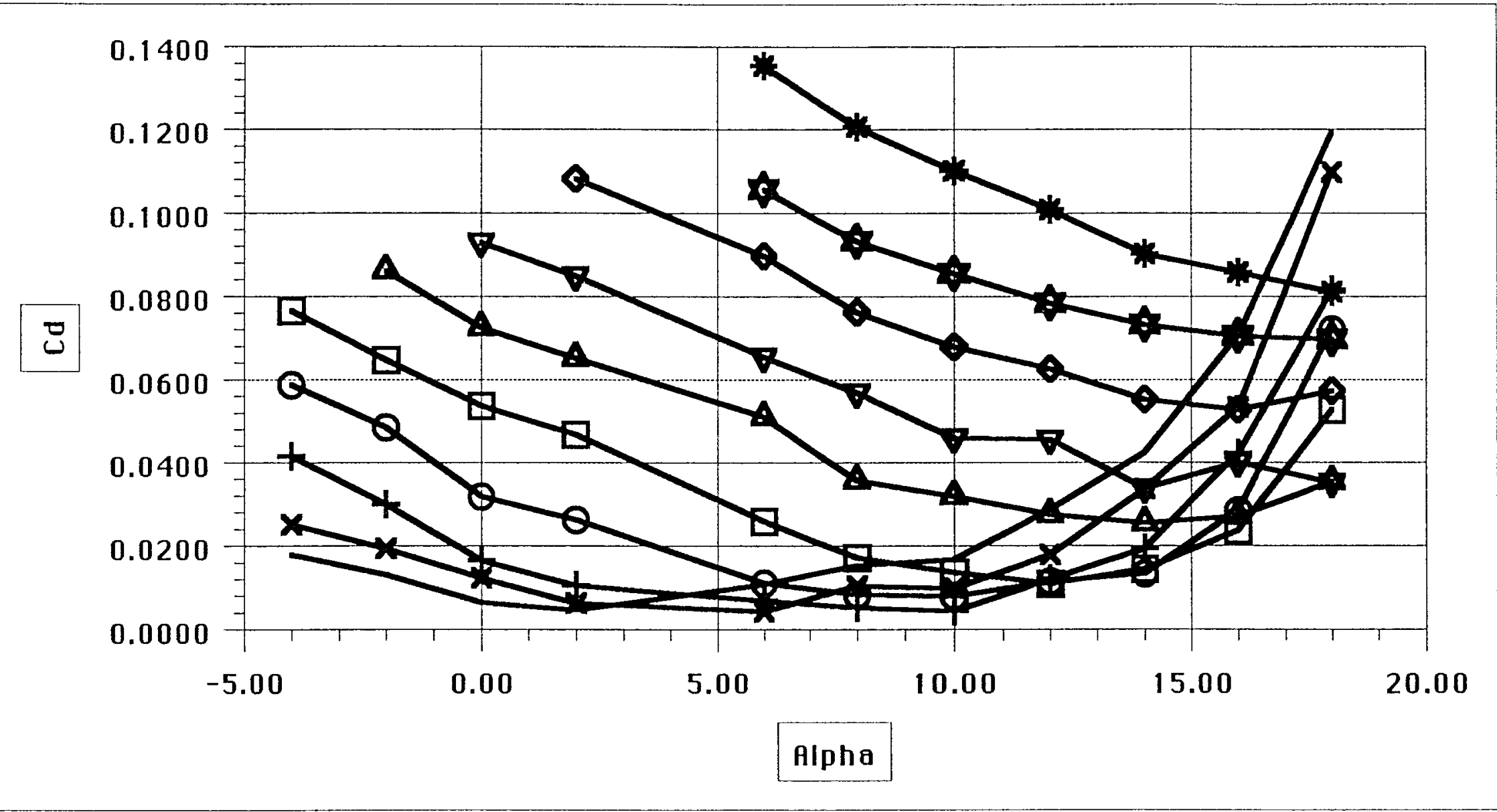

* No Nose, Delta $=-40$

A No Nose, Delta $=-35$

- No Nose, Delta $=-30$

$\nabla$ No Nose, Delta $=-25$
$\Delta$ No Nose, Delta $=-20$

日 No Nose, Delta $=-15$

$\Theta$ No Nose, Delta $=-10$

+ No Nose, Delta $=-5$
* No Nose, Delta $=0$

- No Nose, Delta $=5$ 


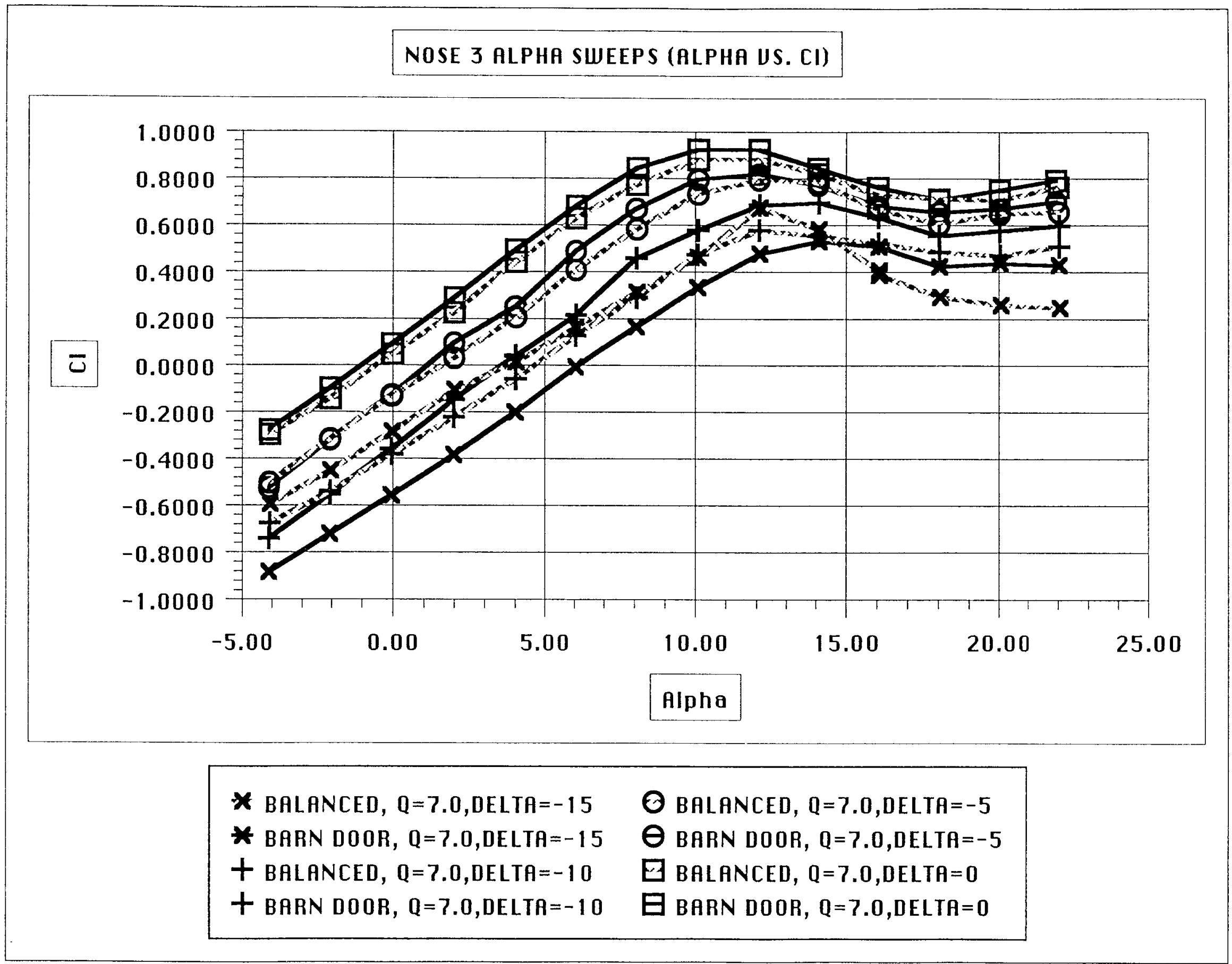

Figure 10 
of $-10^{\circ}$ below this point. This appears to indicate that venting, in this case, causes a rise in $C_{1}$ compared to non-venting at the lower angles of attack, but kills off the lift faster after $C_{I m a r}$ is reached.

On the $C_{d}$ curves, Figure 11 , it is clear that venting, as shown in the Balanced, $\delta$ equals $-15^{\circ}$ case, increases drag substantially. The drag for this case is higher at every angle of attack shown than the $\delta$ equals - 10 degree case. All of the other cases for drag appear to match fairly well between the Balanced and the corresponding Barn Door flaps.

One set of runs was done with no nose attached to the flap to give a .75 " gap between the airfoil and the flap. This data is presented in Figures 12 and 13 . The data shows that there really is not much effect for small deltas and alphas less than $18^{\circ}$.

\section{CONCLUSIONS}

\section{Summary}

The wind tunnel test conducted at wSU during the first week of February was a boon for data in order to show the ability to start, stop and operate the Hawaii Zuteck Rotor. It has been shown that the Barn Door flap will start and stop the rotor. It has been shown that $C_{1}$ can be trimmed and that there can be an associated increase in drag that will allow the real possibility of stall limiting the rotor. The effects of flap nose shape have been shown to have an effect on lift and drag which increases with increased flap deployment angle. Uenting has also been shown to change the characteristics of the lift and drag.

The use of leading edge modifications, by far, were the most important data gleaned from the test. It can be shown that without nose 2 or nose 3 , the rotor could not be stall limited without severe problems in startup due to the need for negative pitch angle settings.

\section{Future Testing?}

Some of the data and subsequent analysis has shown that there is yet 


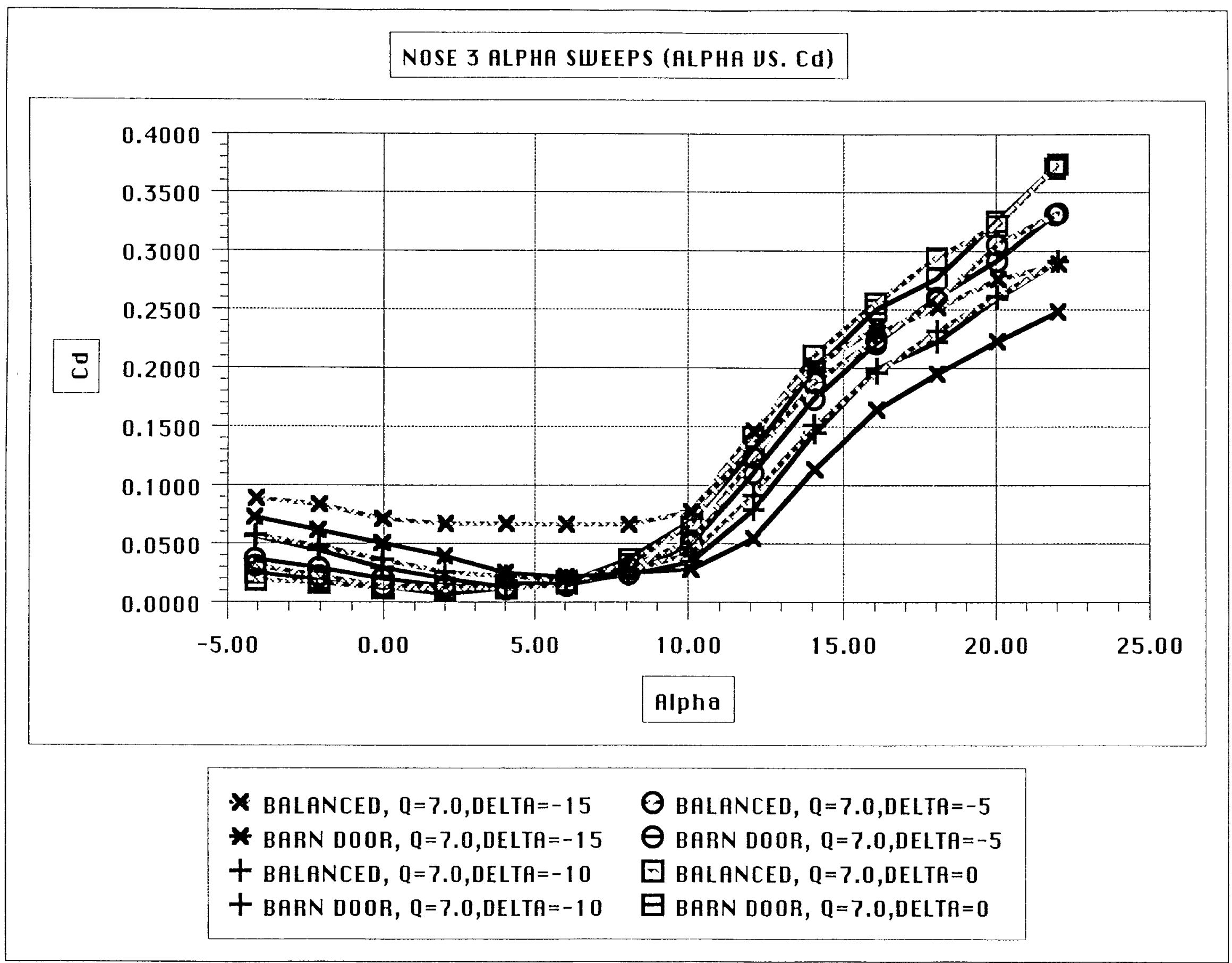

Figure 11 
Balanced, No Nose, Gapped Flap (No nose on Flap)

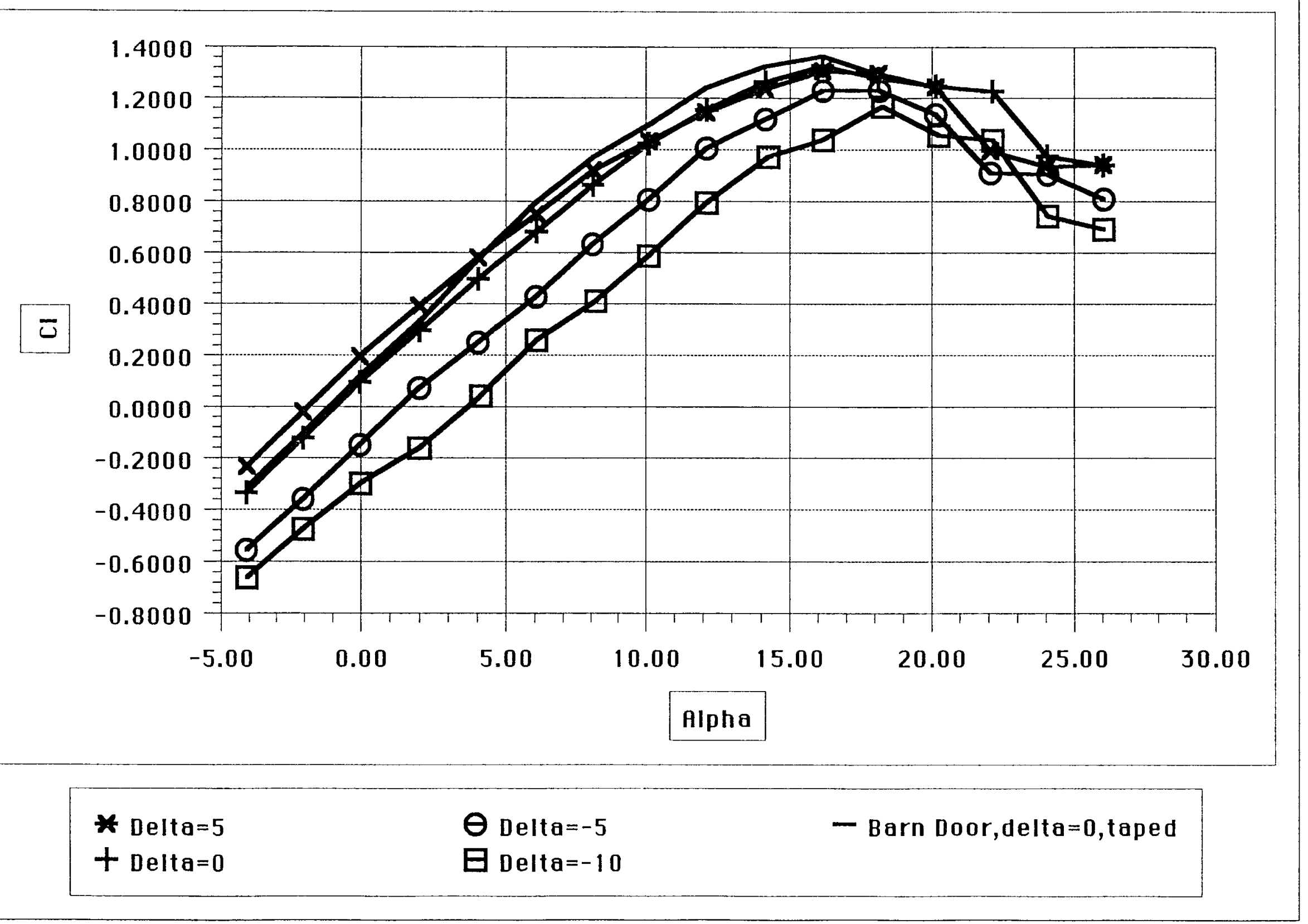

Figure 12 
Balanced, No Nose, Gapped Flap (No nose on Flap), Cd

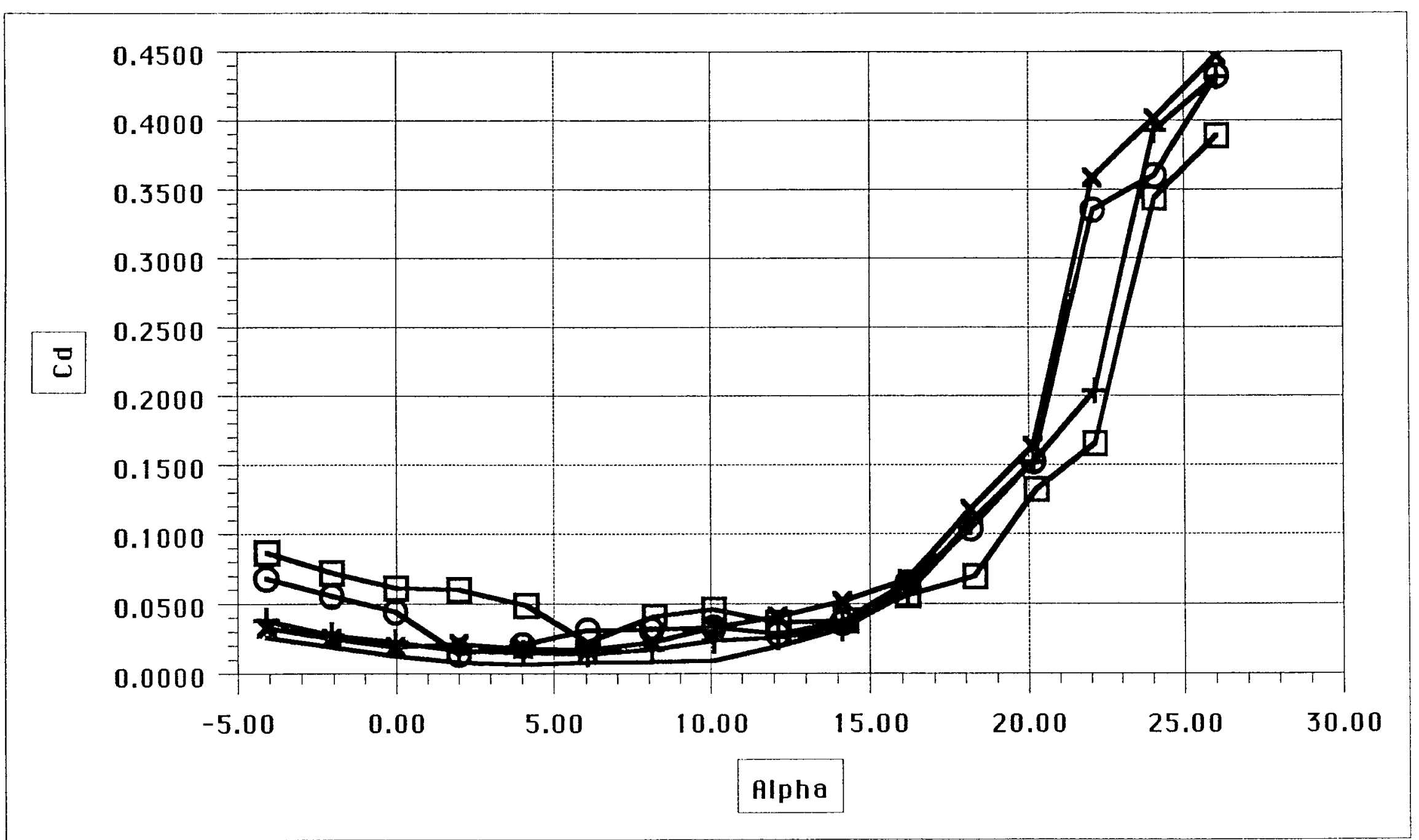

$\begin{array}{lll}* \text { Delta }=5 & \Theta \text { Delta }=-5 & \text { - Barn Door,delta=0,taped } \\ + \text { Delta }=0 & \text { 日 Delta }=-10 & \end{array}$


much to learn that could be profitably used in either the Bolt-0n Rotor test or the Full Rotor test. Testing of the free flap (without attaching the actuator) to show that the cusp will tend to drive the flap toward shutdown and testing of other leading edge modifications to refine the gross discoveries made during this test are but two of the possible areas were more data could be profitably gathered. Should there be data that could, or must, be used to make the field testing easier or safer, there is definitely a desire to return to Wichita. 
APPENDIH A

Wind Tunnel As Run Log 


\begin{tabular}{|c|c|c|c|c|c|c|c|}
\hline Run Number & Flap Type & Nose Type & Mud/No Mud & Alpha & Delta & $Q$ & Notes \\
\hline 1.00 & 3arn Door & No Nose & No Mud & 90.00 & Sweep $+5,-70$ & 0.54 & \\
\hline 2.006 & 3arn Door & No Nose & No Mud & 90.00 & Sweep $+5,-70$ & 4.85 & \\
\hline 3.001 & Sarn Door & No Nose & No Mud & Sweep 90,20 & -70.00 & & Sk10000 \\
\hline 4.001 & arn Door & No Nose & No Mud & 10.00 & Sweep $+5,-70$ & 7.30 & \\
\hline 5.008 & 3arn Door & No Nose & No Mud & 5.00 & Sweep $+5,-70$ & 7.50 & \\
\hline $6.00 \mathrm{E}$ & Sarn Door & No Nose & No Mud & -4.00 & Sweep $+5,-15$ & 9.00 & \\
\hline $7.00 \mathrm{E}$ & Barn Door & No Nose & No Mud & -2.00 & Sweep $+5,-20$ & 9.00 & \\
\hline 8.001 & 3arn Door & No Nose & No Mud & 0.00 & Sweep $+5,-25$ & 8.90 & \\
\hline $9.00 \mathrm{E}$ & 3arn Door & No Nose & No Mud & 2.00 & Sweep $+5,-30$ & 8.90 & \\
\hline 10.00 & Sarn Door & No Nose & No Mud & 4.00 & Sweep +5,-35 & 8.80 & [DValio \\
\hline $11.00 \mathrm{E}$ & 3arn Door & No Nose & No Mud & 6.00 & Sweep $+5,-40$ & 9.00 & \\
\hline 12.006 & 3arn Door & No Nose & No Mud & 8.00 & Sweep $+5,-40$ & 8.40 & \\
\hline 13.006 & Barn Door & No Nose & No Mud & 10.00 & Sweep $+5,-40$ & 8.50 & \\
\hline 14.008 & 3arn Door & No Nose & No Mud & 12.00 & Sweep $+5,-40$ & 6.20 & \\
\hline 15.00 & 3arn Door & No Nose & No Mud & 14.00 & Sweep $+5,-40$ & 5.70 & \\
\hline $16.00 E$ & 3arn Door & No Nose & No Mud & 16.00 & Sweep $+5,-40$ & 5.50 & \\
\hline 17.00 & 3arn Door & No Nose & No Mud & 18.00 & Sweep $+5,-40$ & 5.50 & \\
\hline 18.00 & 3arn Door & No Nose & No Mud & Sweep $-4,18$ & 0.00 & 19.60 & Taped \\
\hline 19.006 & 3arn Door & No Nose & No Mud & 4.00 & Sweep $+5,-35$ & 8.80 & \\
\hline 20.00 & 3arn Door & Nose 2 & No Mud & 90.00 & Sweep $+5,-70$ & 0.80 & \\
\hline 21.008 & Barn Door & Nose 2 & No Mud & 90.00 & Sweep $+5,-70$ & 5.70 & \\
\hline 22.006 & 3arn Door & Nose 2 & No Mud & 10.00 & Sweep $+5,-70$ & 7.20 & \\
\hline 23.006 & Barn Door & Nose 2 & No Mud & 5.00 & Sweep +5,-70 & 6.90 & \\
\hline 24.008 & 3arn Door & Nose 2 & No Mud & -4.00 & Sweep $+5,-15$ & 8.80 & \\
\hline 25.008 & 3arn Door & Nose 2 & No Mud & -2.00 & Sweep $+5,-15$ & 8.80 & \\
\hline 26.00 & 3arn Door & Nose 2 & No Mud & 0.00 & Sweep $+5,-15$ & 8.80 & \\
\hline 27.006 & Barn Door & Nose 2 & No Mud & 2.00 & Sweep $+5,-15$ & 8.90 & \\
\hline 28.00 & Barn Door & Nose 2 & No Mud & 4.00 & Sweep $+5,-15$ & 8.90 & \\
\hline 29.001 & Barn Door & Nose 2 & No Mud & 6.00 & Sweep +5,-15 & 8.90 & \\
\hline $30.00 E$ & Barn Door & Nose 2 & No Mud & 8.00 & Sweep $+5,-15$ & 8.80 & \\
\hline $31.00 \mathrm{E}$ & Sarn Door & Nose 2 & No Mud & 10.00 & Sweep $+5,-15$ & 7.60 & \\
\hline 32.00 & Barn Door & Nose 2 & No Mud & 12.00 & Sweep $+5,-15$ & 6.80 & \\
\hline 33.00 & Sarn Door & Nose 2 & No Mud & 14.00 & Sweep $+5,-15$ & 6.10 & \\
\hline 34.00 & Sarn Door & Nose 2 & No Mud & 16.00 & Sweep $+5,-15$ & 6.30 & \\
\hline 35.00 & Barn Door & Nose 2 & No Mud & 18.00 & Sweep $+5,-15$ & 6.30 & \\
\hline 36.00 & Barn Door & Nose 1 & No Mud & 90.00 & Sweep $+5,-70$ & 1.00 & \\
\hline
\end{tabular}




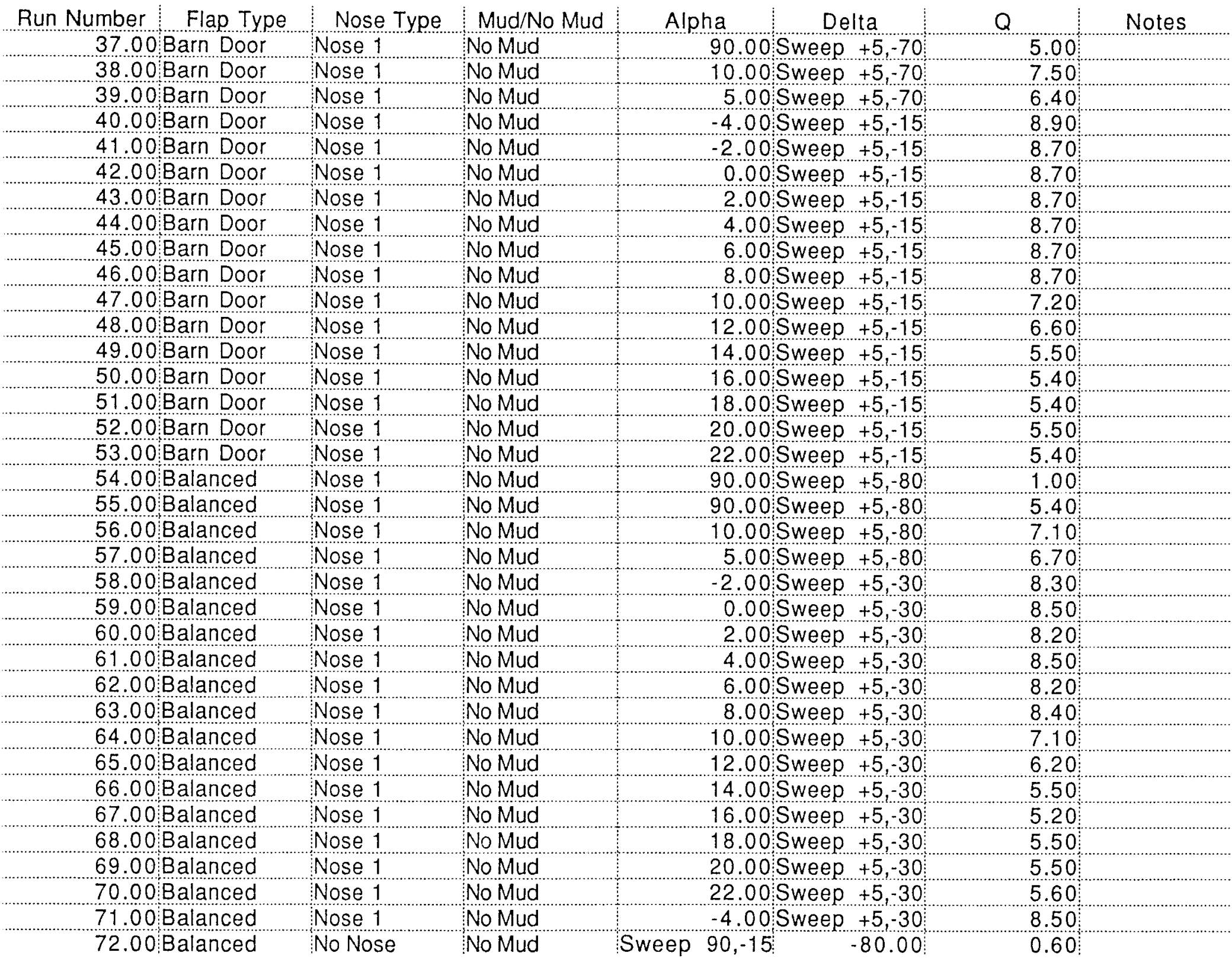




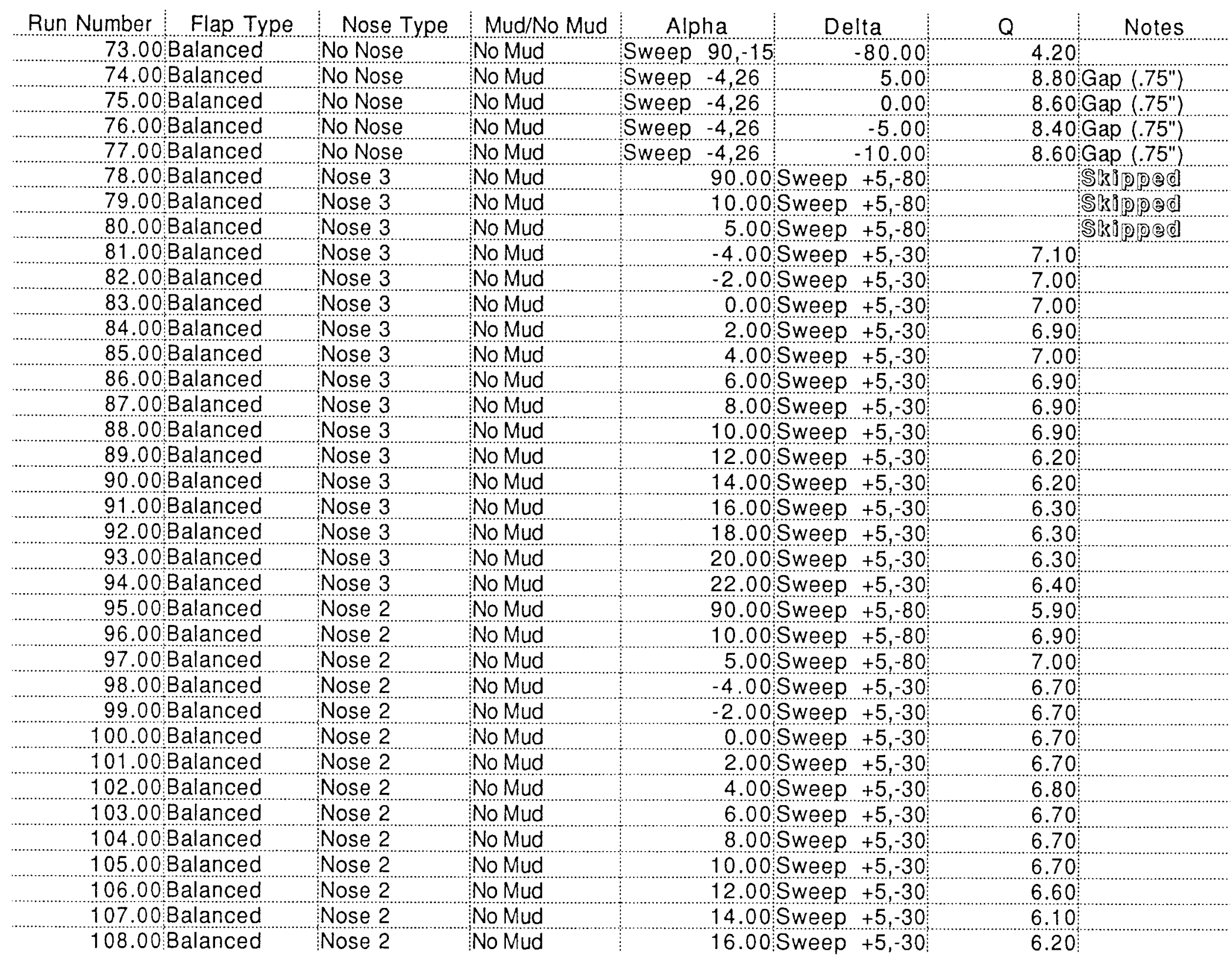




\begin{tabular}{|c|c|c|c|c|c|}
\hline Run Number & Nose Type & Mud/No Mud & Alpha & $Q$ & Notes \\
\hline 109.00 Balanced & Nose 2 & No Mud & 18.00 Sweep $+5,-30$ & 6.20 & \\
\hline 110.00 Balanced & Nose 2 & No Mud & 20.00 Sweep $+5,-30$ & 6.20 & \\
\hline 111.00 Balanced & Nose 2 & No Mud & 22.00 Sweep $+5,-30$ & 6.30 & \\
\hline 112.00 Balanced & No Nose & No Mud & 90.00 Sweep $+5,-80$ & 5.80 & \\
\hline 113.00 Balanced & No Nose & No Mud & 85.00 Sweep $+5,-80$ & 5.90 & \\
\hline 114.00Balanced & No Nose & No Mud & 80.00 Sweep $+5,-80$ & 5.80 & \\
\hline 115.00 Balanced & Nose 3 & No Mud & Sweep $90,-15 \quad-80.00$ & 0.60 & \\
\hline 116.00 Balanced & Nose 3 & No Mud & Sweep $90,-15$ & 5.10 & \\
\hline 117.00 Barn Door & Nose 3 & No Mud & -4.00 Sweep $0,-15$ & 6.70 & \\
\hline 118.00Barn Door & Nose 3 & No Mud & -2.00 Sweep $0,-15$ & 6.70 & \\
\hline 119.00:Barn Door & Nose 3 & No Mud & 0.00 Sweep $0,-15$ & 6.60 & \\
\hline 120.00 Barn Door & Nose 3 & No Mud & 2.00 Sweep $0,-15$ & 6.60 & \\
\hline 121.00:Barn Door & Nose 3 & No Mud & 4.00 Sweep $0,-15$ & 6.70 & \\
\hline 122.00Barn Door & Nose 3 & No Mud & 6.00 Sweep $0,-15$ & 6.70 & \\
\hline 123.00Barn Door & Nose 3 & No Mud & 8.00 Sweep $0,-15$ & 6.60 & \\
\hline 124.00Barn Door & Nose 3 & No Mud & 10.00 Sweep $0,-15$ & 6.70 & \\
\hline 125.00Barn Door & Nose 3 & No Mud & 12.00 Sweep $0,-15$ & 6.20 & \\
\hline 126.00 Barn Door & Nose 3 & No Mud & 14.00 Sweep $0,-15$ & 6.20 & \\
\hline 127.00Barn Door & Nose 3 & No Mud & 16.00Sweep $0,-15$ & 6.10 & \\
\hline 128.00Barn Door & Nose 3 & No Mud & 18.00 Sweep $0,-15$ & 6.20 & \\
\hline 129.00Barn Door & Nose 3 & No Mud & 20.00 Sweep $0,-15$ & 6.30 & \\
\hline 130.00Barn Door & Nose 3 & No Mud & 22.00 Sweep $0,-15$ & 6.30 & \\
\hline 131.00Barn Door & Nose 3 & No Mud & Sweep 90,-15 $\quad-70.00$ & 5.00 & \\
\hline 132.00:Barn Door & Nose 3 & No Mud & Sweep $90,-15$ & 5.70 & \\
\hline 133.00:Barn Door & No Nose & No Mud & Sweep $90,-15$ & 5.20 & \\
\hline 134.00Barn Door & No Nose & No Mud & Sweep $90,-15$ & 5.70 & \\
\hline 135.00 Low Drag & No Nose & No Mud & -4.00 Sweep $0,-45$ & 6.70 & \\
\hline 136.00 Low Drag & No Nose & No Mud & -2.00 Sweep $0,-45$ & 6.90 & \\
\hline 137.00Low Drag & No Nose & No Mud & 0.00 Sweep $0,-45$ & 7.00 & \\
\hline 138.00Low Drag & No Nose & No Mud & 2.00 Sweep 0,45 & 6.80 & \\
\hline 139.00:Low Drag & No Nose & No Mud & 4.00 Sweep 0.45 & 6.90 & \\
\hline 140.00Low Drag & No Nose & No Mud & 6.00 Sweep $0,-45$ & 6.80 & \\
\hline 141.00Low Drag & No Nose & No Mud & 8.00 Sweep $0,-45$ & 6.60 & \\
\hline 142.00Low Drag & No Nose & No Mud & 10.00 Sweep $0,-45$ & 6.70 & \\
\hline 143.00 Low Drag & No Nose & No Mud & 12.00 Sweep $0,-45$ & 6.00 & \\
\hline 144.00Low Drag & No Nose & No Mud & 14.00 Sweep $0,-45$ & 6.80 & \\
\hline
\end{tabular}




\begin{tabular}{|c|c|c|c|c|c|c|}
\hline Run Number & Flap Type & Nose Type & Mud/No Mud & Alpha & Q & Notes \\
\hline 145.00 & ow Drag & No Nose & No Mud & 16.00 Sweep $0,-45$ & 5.20 & \\
\hline 146.00 & ow Drag & No Nose & No Mud & 18.00 Sweep $0,-45$ & 5.10 & \\
\hline $147.00 \mathrm{~L}$ & Low Drag & No Nose & No Mud & 20.00 Sweep $0 .-45$ & 5.30 & \\
\hline 148.001 & ow Drag & No Nose & No Mud & 22.00 Sweep $0,-45$ & 5.40 & \\
\hline 149.001 & -ow Drag & No Nose & No Mud & Sweep $90,-15$ & 0.60 & \\
\hline $150.00 \mathrm{~L}$ & ow Drag & No Nose & No Mud & Sweep $90,-15$ & 4.50 & Skjppod \\
\hline $151.00 \mathrm{~L}$ & ow Drag & No Nose & Mud & -4.00 Sweep $+5,-45$ & 6.70 & \\
\hline $152.00 \mathrm{~L}$ & ow Drag & No Nose & Mud & -2.00 Sweep $+5,-45$ & 6.40 & \\
\hline $153.00 \mathrm{~L}$ & ow Drag & No Nose & Mud & 0.00 Sweep $+5,-45$ & 6.40 & \\
\hline $154.00 \mathrm{~L}$ & ow Drag. & No Nose & Mud & 2.00 Sweep $+5,-45$ & 6.40 & \\
\hline $155.00 \mathrm{~L}$ & ow Drag & No Nose & Mud & 4.00 Sweep $+5,-45$ & 6.60 & \\
\hline $156.00 \mathrm{~L}$ & ow Drag & No Nose & Mud & 6.00 Sweep $+5,-45$ & 6.70 & \\
\hline $157.00 \mathrm{~L}$ & ow Drag & No Nose & Mud & 8.00 Sweep $+5,-45$ & 6.70 & \\
\hline $158.00 \mathrm{~L}$ & ow Drag & No Nose & Mud & 10.00 Sweep $+5,-45$ & 6.70 & \\
\hline $159.00 \mathrm{~L}$ & Low Drag & No Nose & Mud & 12.00Sweep $+5,-45$ & 6.80 & \\
\hline $160.00 \mathrm{~L}$ & -ow Drag & No Nose & Mud & 14.00 Sweep $+5,-45$ & 6.60 & \\
\hline $161.00 \mathrm{~L}$ & -ow Drag & No Nose & Mud & 16.00 Sweep $+5,-45$ & 6.70 & \\
\hline $162.00 !$ & ow Drag & No Nose & Mud & 18.00 Sweep $+5,-45$ & 6.20 & \\
\hline $163.00 \mathrm{~L}$ & ow Drag & No Nose & Mud & 20.00 Sweep $+5,-45$ & 5.70 & \\
\hline $164.00 \mathrm{~L}$ & ow Drag & No Nose & Mud & 22.00 Sweep $+5,-45$ & 5.70 & \\
\hline $165.00 \mathrm{~L}$ & -ow Drag & No Nose & Mud & 90.00 Sweep $0,-70$ & 0.60 & \\
\hline
\end{tabular}




\section{Section 2}

\section{Hawaii Zuteck Rotor Project \\ Preliminary Test Plan}

"Bolt-On Rotor Test Plan for the Hawaii Zuteck Rotor

Project at Site 9, Kahuku Hills, Hawaii”

by M. D. Zuteck and M. W. Miller

June 17, 1992 


\section{Introduction}

The purpose of this test plan is to identify the specific tests that will be performed to meet the bolt-on test program goals. This testing will be performed in five basic areas, as outlined in the proposal statement of work. These are:

System Integration Test

Operations Test

Stall Control Test

Start and Stop Test

Production Integration Test

While the first and last of these must be performed in the time sequence shown, the other three may be run concurrently, to efficiently take advantage of conditions. For instance, if the wind is light and unsuitable for operations or stall control testing, this would nonetheless provide an ideal situation for early start-up and stopping tests, where the minimum start-up windspeed could be ascertained for various pitch settings, and stopping could be first attempted at low aerodynamic load and power conditions. In general, it makes good sense from a safety standpoint to begin with low wind tests, where the aerodynamic loads, blade bending, and rotor accelerations are reduced. This allows the most time to respond if something unusual does occur, and provides flap load and teeter excursion trends that can be extrapolated upward to higher wind, so that possible difficulties can be anticipated before they actually occur.

The test execution matrix for the three mid-list tests, which is given in the following, is intended to be run beginning on the low wind side, and progressing to higher winds. Since the winds probably won't appear in a nice orderly strength progression, discretion by the test manager is to be exercised in deciding how far beyond existing data one could reasonably go to make use of available winds, rather than waiting. This will clearly depend on the data trends already obtained at the lower windspeeds, but skipping ahead one or two windspeed brackets seems like a viable possibility, unless the data indicates otherwise. These considerations will apply for the initial 43 rpm testing, where loads and rotor response are first being observed. For the later 36 rpm testing, much less restrictive methods should be possible. 
System Integration Test

The objective of this test sequence is to completely exercise the flap hardware using the complete wind turbine control system with the rotor in the static condition. This testing shall include the following elements for each flap segment:

\section{1) Exercise Full Flap Motion Range (on ground and tower)}

Each flap segment shall be driven through its whole range of motion while unloaded. This includes exercising the end of range safety stops, as applicable. The flap angle sensors shall also be exercised, to record the flap response time. The speed to traverse the whole angular range shall be recorded manually via stop watch as a verification check.

\section{2) Measure Flap Positioning Accuracy (ground checkout)}

The control computer shall be used to command flap positions of $+5^{\circ}$ to $-30^{\circ}$ at $5^{\circ}$ increments. The flap position shall be measured with a suitable angle measuring device referenced to the blade shell forward of the flap. The flap angle sensor readings shall also be recorded. This procedure shall be executed and repeated for each flap segment, to ascertain reproducibility of the results. This shall include a test to demonstrate that blades one and two respond within a degree of one another.

\section{3) Demonstrate Flap Motion with Resistance (ground checkout)}

Using a system which applies at least half of maximum rated actuator capacity, flap motion in the presence of resistance shall be demonstrated. The loads may be applied with a temporary quadrant attached to the flap that is loaded elastically, or via weights and sheaves, or by another suitable method. A rate of deploy measurement shall be performed, as was done for item 1 .

\section{4) Demonstrate Emergency Stop Mode (on ground and tower)}

The emergency stop mode of the software shall be exercised, to demonstrate full response of all links (computer, electrical, and mechanical), for this critical mode.

5) Demonstrate Differential Deploy Mode (ground checkout)

The differential deploy mode shall be exercised, to verify that the flaps respond as intended. 


\section{Operations Test}

The objective of this test sequence is to investigate the capability of the flap system to control the turbine's output power in the power production mode. As a minimum, two blade pitch settings and associated control modes will be investigated in depth. These will be chosen to provide 1) a high flap activity mode whose goal is to maximize energy capture with little regard to flap duty cycle 2) a low flap activity mode, which will attempt to maintain high energy capture with much reduced flap activity.

As a basis for judging how to set up these in-depth tests, a preliminary blade pitch sweep from $0^{\circ}$ to $4^{\circ}$ in $1^{\circ}$ increments shall be performed using fully active flap control. It should be noted that a rapid shift in machine response will occur across this range. At the positive blade pitch side of this range, blade loads and bending will be lowered, but at the cost of high levels of flap activity to trim excess peak power. At the low angle end of the range, the reverse occurs, and there is reduced requirement for flap activity, but higher average blade loads and bending are anticipated.

\section{RPM Testing}

The initial testing at $43 \mathrm{rpm}$ will employ nose $\# 3$ for $30 \%$ of span, because this provides the simplest correlation to the wind tunnel data, and it is desirable to limit the peak power production we get at the high rpm condition. At least two flap response modes will be explored 1) uniform response, where all flap segments move together, and 2) differential deploy, where the most outboard flaps move either first or farthest. The differential deploy mode is expected to reduce blade loads and bending, while improving teeter stability, without loss of energy capture, but this needs to be shown. Data sufficient to define a power curve as well as basic machine response is required. Schedule constraints and wind conditions will of course impact the amount of data that can be gathered, but a minimum goal of ten hours for each mode seems reasonable. This should cover as wide a windspeed range as possible.

It should be noted that the ability to change blade pitch on the fly can be exploited to get samples of all pitch values during any period the wind is within a chosen range. This has the substantial advantage that similar turbulence conditions would prevail, making comparisons of blade / flap loads, power variations, and flap / teeter motions, all the more meaningful. Thus this is the preferred test mode for the preliminary pitch angle sweep. 
Once the preliminary blade pitch sweep is completed, blade pitch settings can be selected for the more in-depth study of high activity vs. low activity flap modes. Either the uniform or differential flap deploy mode should be selected for both types of test to simplify data comparison, unless there is a compelling reason to do otherwise. This is the time when fine tuning of the control algorithm in either mode can best be explored. Control algorithm experiments that do not prove to be beneficial need not be explored in great depth, but the most promising algorithm in each mode should get substantial data accumulation before passing from this phase. Again, it is an advantage to switch between pitch setting / activity modes on the fly, so that comparisons in like turbulence conditions can readily be made. It is felt that 20 hours of data in each mode is an appropriate goal for the final control algorithms.

\section{RPM Testing}

The preceding material was aimed specifically at the $43 \mathrm{rpm}$ portion of the testing, but would be repeated with little change for the $36 \mathrm{rpm}$ phase. Perhaps the main variation would be in the choice of nose trip used. Certainly it would make sense to repeat the nose \#3 testing at this new rpm, to get a direct assessment of the effect of rpm change. The whole sequence need not be repeated, but the initial pitch angle sweep portion should be. Once that is done, a modified nose trip based on what has been learned could be applied, and the most interesting parts of the angle sweep portion repeated. The timing of this would likely allow benefit from additional wind tunnel testing to also be applied, if such testing has been undertaken. More than one nose trip variation could be investigated, if the possible performance benefits warrant. Once a preferred nose trip configuration is identified, the more in-depth phase of operations testing would again be undertaken, with additional control algorithm experimentation if warranted.

The primary parameters for the operational mode testing are shown summarized on the following page. 
Summary of Operational Mode Tests

43 RPM Tests

Blade Pitch Sweep with Active Flaps

Nose $\# 3$ for outer $30 \%$ of span

Both uniform and differential flap deploy modes

Pitch angles $0^{\circ}, 1^{\circ}, 2^{\circ}, 3^{\circ}, 4^{\circ}$ (each flap mode)

High vs Low Activity Flap Investigation

Nose $\# 3$ for outer $30 \%$ of span

Either uniform or differential flap deploy mode

Control algorithm variation / optimization

Data collection for "best" high \& low activity modes

36 RPM Tests

Blade Pitch Sweep with Active Flaps

Nose $\# 3$ for outer $30 \%$ of span

Either uniform or differential flap deploy modes

Pitch angles $0^{\circ}, 1^{\circ}, 2^{\circ}, 3^{\circ}, 4^{\circ}$ (each flap mode)

Alternative nose trip testing - at "best" pitch angles

High vs Low Activity Flap Investigation

"Best" nose trip design

Either uniform or differential flap deploy mode

Control algorithm variation / optimization - optional

Data collection for "best" high \& low activity modes 


\section{Stall Control Test}

The objective of this test sequence is to investigate the ability of the nose trip and flap system to control the turbine's output power in the power production mode, with only occasional flap adjustment to improve energy capture, but without any need to actively respond to transient wind gusts. This test phase will draw on and extend data gathered in the operations mode testing.

Existing analysis of the $43 \mathrm{rpm}$ bolt-on rotor indicates that negative blade pitch will be needed to stall limit power to levels that the drivetrain and generator can handle. This will cause increased blade loads and bending, and if increased teeter excursions occur due to operation in stall, concerns of tower clearance could limit the $43 \mathrm{rpm}$ testing of this mode. Here the trends seen in the $0^{\circ}$ to $4^{\circ}$ blade pitch sweep during the operations mode testing will provide valuable background for the decision to proceed. If the trends indicate that a pitch with acceptable blade bending and teeter excursions will suffice for demonstrating a stall limited mode, then we need only extend the blade pitch angle sweep to the extent necessary to demonstrate the validity of these trends. Once that is done, and the appropriate pitch angle for stall limited operation is verified, unrestricted data gathering for this mode can proceed at $43 \mathrm{rpm}$. Otherwise, this will proceed only under selected wind conditions, or be postponed entirely to later testing at $36 \mathrm{rpm}$.

In order to correlate the stall limit mode data with that obtained for the high and low activity flap modes, it makes the most sense to swing into the exploratory pitch settings for this mode right after the $0^{\circ}$ to $4^{\circ}$ operational mode sweep is taken. If an acceptable stall limiting pitch setting is found, then the stall limiting data could be taken in the same wind and turbulence conditions, intermingled with the active flap control data, thereby getting the best comparative correlation to the other operational mode data.

The primary parameters for the stall mode testing are shown summarized on the following page. 
Summary of Stall Mode Tests

43 RPM Tests

Blade Pitch Sweep

Nose $\# 3$ for outer $30 \%$ of span

Both uniform and differential flap trim modes

Pitch angles $-1^{\circ},-2^{\circ}$ etc. as needed (each flap mode)

In-depth Investigation

Nose $\# 3$ for outer $30 \%$ of span

Either uniform or differential flap trim mode

Trim algorithm variation / optimization - optional

Data collection for "best" flap trim mode

\section{RPM Tests}

\section{Blade Pitch Sweep}

Nose $\# 3$ for outer $30 \%$ of span

Either uniform or differential flap trim modes

Pitch angles $-1^{\circ},-2^{\circ}$ etc. as needed

Alternative nose trip testing - at "best" pitch angles

In-depth Investigation

"Best" nose trip design

Either uniform or differential flap trim mode

Trim algorithm variation / optimization - optional

Data collection for "best" flap trim mode 


\section{Start and Stop Test}

The start and stop test is straightforward, as its purpose is to determine the start-up and shutdown performance of the flap system across the whole range of windspeeds. It again will make the most of sense to work from the low windspeeds to higher ones, so that trends of flap loads can be used to extrapolate to higher wind and loading conditions before they are actually experienced. Once sufficient preliminary data has been gathered to give confidence that the flap system will not experience excess loads during the start / stop sequence, all windspeed data can be quickly obtained. All that is required is to get a record of rpm versus time at appropriate windspeeds, while also recording the usual range of position and load variables for the rotor. Ideally, this should be done for each of the blade pitch / nose trip / rpm combinations, so that the broadest understanding of the effect of these variables can be obtained. Once confidence in the starting and stopping ability of the flap system has been obtained, this should be easily combined with the other testing, by simply using flaps for start and stop, and recording the time that it takes in each condition.

\section{Start-up / Shutdown Test Summary}

Obtain rpm vs time response

Whole windspeed range - progress from low to high

All pitch angle / nose trip / rpm combinations 


\section{Production Integration Test}

The objective of this test sequence is to generate representative data for fully automated operation. This will include start-up, shutdown, and power production. Provision shall be made to test up to three distinct pitch settings and control modes: fully active flaps, low activity flaps, and stall control. Some difficulty may be met in the stall control mode at $43 \mathrm{rpm}$, because it will require the most negative pitch setting, and this will lead to elevated blade loads, and also make start-up difficult. If this mode also exhibits increased teeter excursions due to operation in stall, the increased blade bending from the elevated loads might make it unwise to run extensively in this mode. To a lesser extent, the same considerations may apply to the low activity control mode. This situation will dramatically improve for $36 \mathrm{rpm}$ operation, because more positive pitch settings and lowered loads will result. Consequently, we will want to adjust our $43 \mathrm{rpm}$ goals to reflect the blade bending and teeter activity observed in test. At 36 rpm, we should get extensive data for all modes. A minimum of twenty hours for each control mode / RPM combination is sought.

The table below summarizes the possible data gathering windspeed restrictions for the various control mode and rpm combinations.

\section{Windspeed Range for Various Control Mode / RPM Combinations

Control Mode $\quad 43$ RPM $\quad 36$ RPM \\ Fully Active \\ Low Activity \\ Stall Limited \\ 43 RPM \\ Full range \\ Restricted? \\ ? ?? \\ Full range \\ Full range \\ Full range}

From the count of available slip rings, we can carry almost all of the desired data simultaneously. By this point in the testing, we may be able to eliminate a channel or two as relatively uninteresting, and thus be able to monitor everything else whenever the machine is in operation. This is the anticipated testing mode. Refer to the test data description for a discussion of the specific variables to be recorded. 


\section{Section 3}

\section{Hawaii Zuteck Rotor Project Justification to Proceed}

"Justification to Proceed to the Hawaii Zuteck Rotor Project Bolt-On Test at Site 9, Kahuku Hills, Hawaii"

by M. D. Zuteck and M. W. Miller

August 24, 1992 


\section{Aerodynamic Considerations}

There are three primary aerodynamic functions for the flap system: startup, operating mode, and shutdown. The wind tunnel data obtained at Wichita State has allowed good insight into each of these modes.

\section{Startup}

During startup mode, the flap will not provide as much start-up torque as the original full span pitch could. This was expected from the start. Actual startup wind speed will depend on details of final blade pitch setting and flap design, and is difficult to predict because it depends on the starting friction of the particular machine, and whether transient gusts and vibration help overcome that startup friction. Initial estimates indicate that aerodynamic startup should be possible whenever there is adequate wind to go on to generate meaningful power. A valuable result of the tests themselves will be to more accurately quantify this feature of performance in the real world environment. This is more an opportunity to learn, rather than a big problem.

\section{Operating Regime}

Here our highest hopes appear within reach of the bolt-on testing. While there was originally not much hope of stall-limited or low-activity control modes for the current $43 \mathrm{rpm}$ configuration of the machine, there was also some doubt this could be done, even after the planned reduction to $36 \mathrm{rpm}$. Here the wind tunnel data, used by HERS as the basis for PROP predictions of the operating mode performance, has been very encouraging. It now appears that appropriate blade pitch settings will allow both rpm choices to test stall limiting, low activity, and high activity flap modes, all with one test setup. This is shown in the following power curves, which use a flat $\mathrm{Cl}$ beyond stall to approximate stall hysteresis effects. Note that power curves for flap deflections beyond $-15^{\circ}$ are not included, because the nose \#3 wind tunnel data is unavailable beyond -15 . 


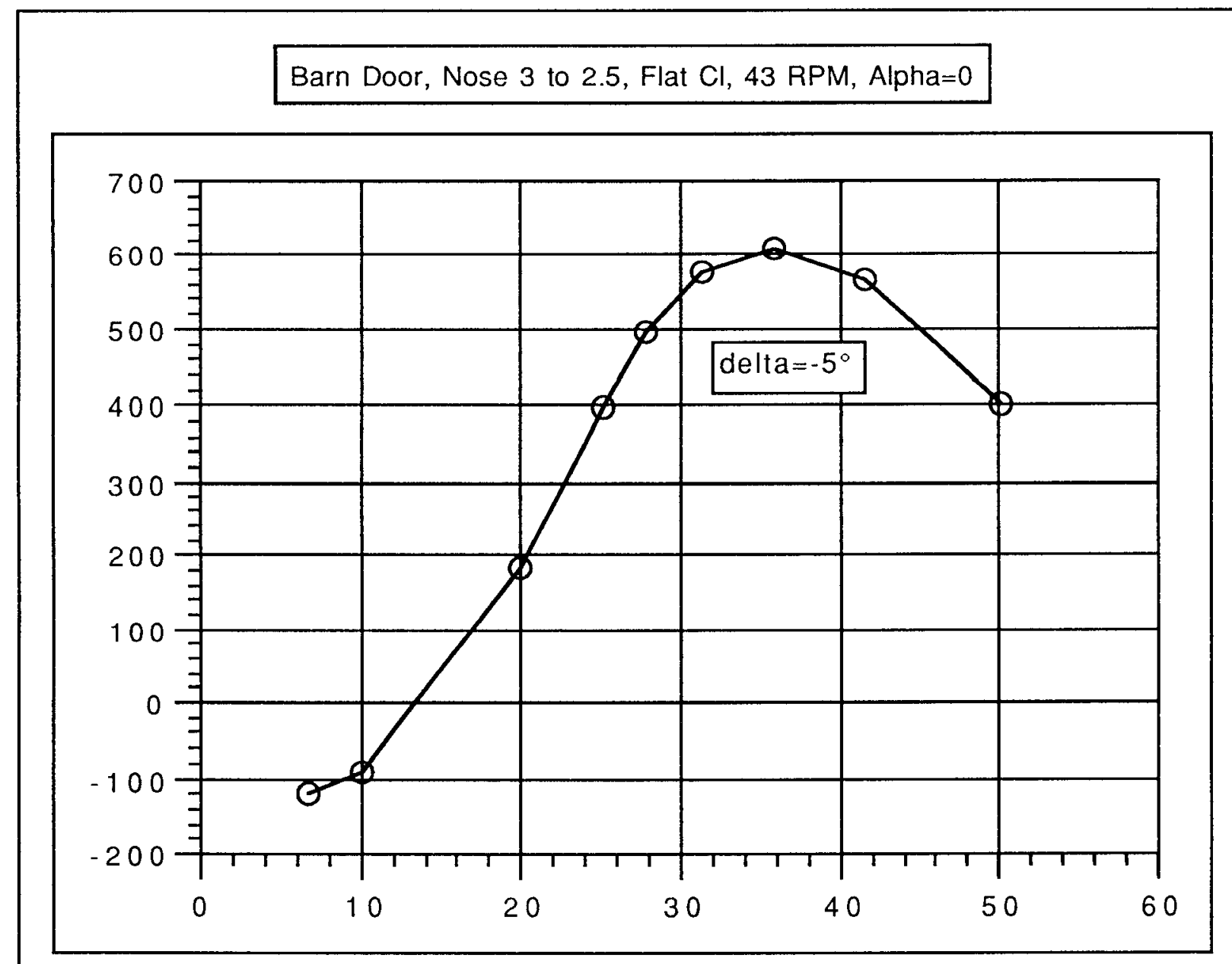

As is seen in the power curve above, using a $30 \%$ of chord (and span) barn door flap, with nose trip 3-2.5, at $0^{\circ}$ pitch setting and $43 \mathrm{rpm}$, gives the desired peak power of $600 \mathrm{Kw}$. The $-5^{\circ}$ flap deflection curve is shown, because it has the best performance below rated, but peak power is little different for flap deflections from $0^{\circ}$ to $-15^{\circ}$. While experience with predicting peak power would caution us that a somewhat more negative blade pitch angle may actually be necessary, this is still an encouraging result. It may indeed be possible to demonstrate stall limiting at $43 \mathrm{rpm}$ after all. 


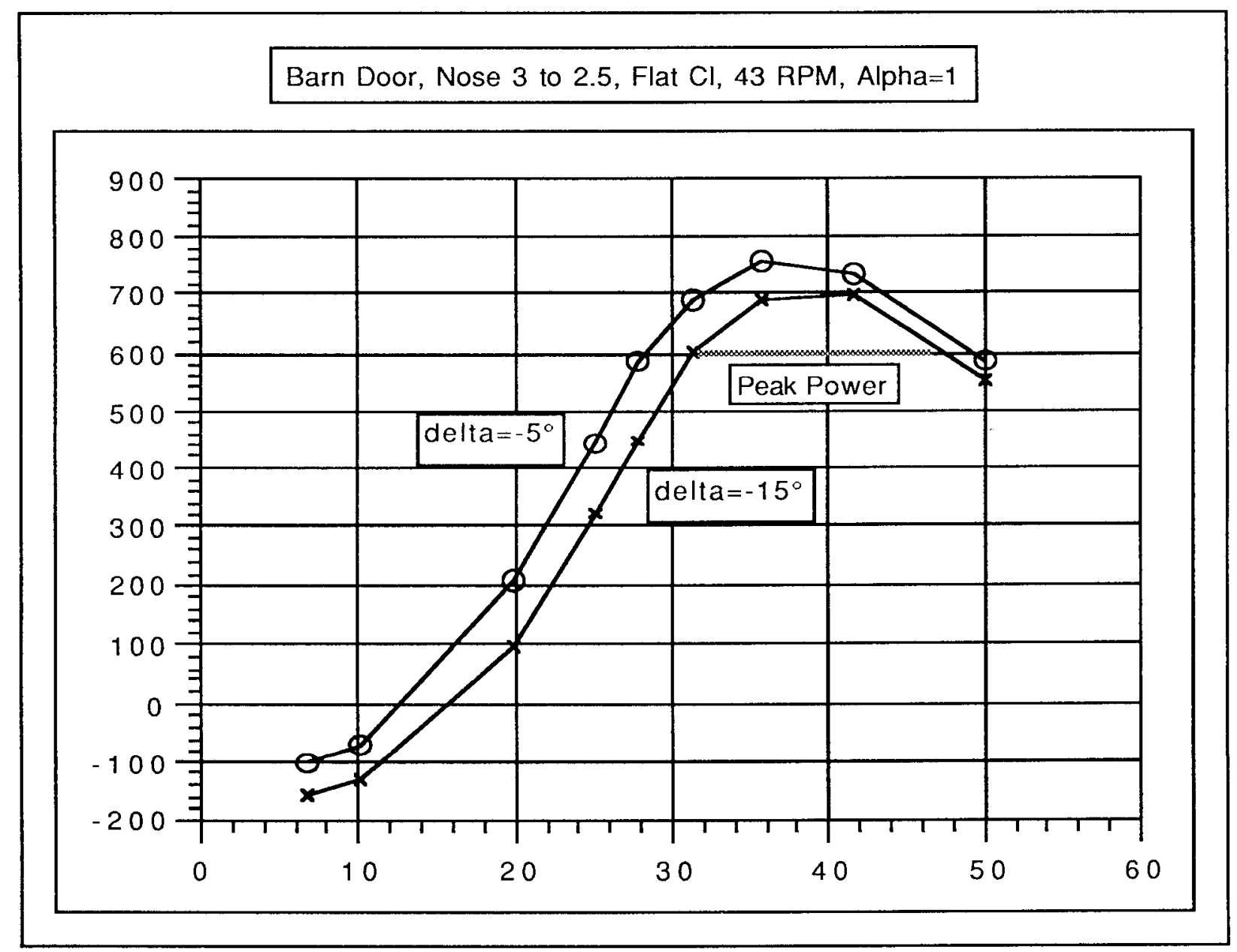

As is seen in the power curves above, pitching the nose into the wind to a $1^{\circ}$ setting increases the peak power to about $750 \mathrm{Kw}$ at delta $=-5^{\circ}$. Since this is in excess of the desired drivetrain limit, control of the flap angle in the higher winds is needed to trim peak power to the chosen level. As illustrated by the horizontal grey line on the graph, control would begin near $27 \mathrm{mph}$, and require $-15^{\circ}$ flap at about $32 \mathrm{mph}$. Due to accelerated power reduction at larger angles, something in the range of $-20^{\circ}$ to $-25^{\circ}$ of flap should be enough to trim peak power in the high windspeed range. Note that $20 \mathrm{mph}$ power output has increased by 30 to $40 \mathrm{Kw}$ compared to stall limiting, by accepting the required flap activity. 


\section{Barn Door, Nose 3 to 2.5, Flat Cl, 43 RPM, Alpha $=2$}

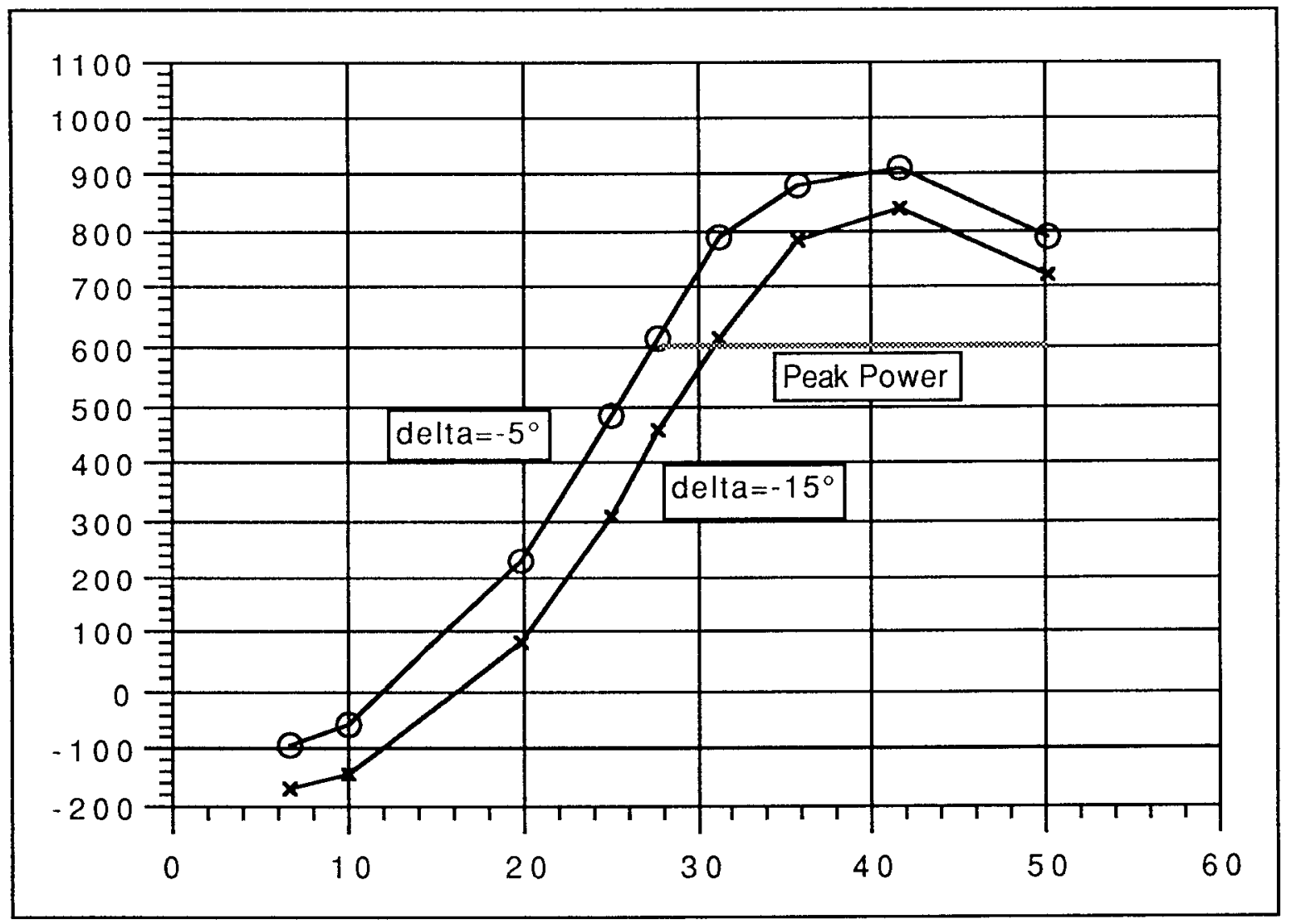

As is seen in the power curves above, pitching the nose into the wind to a $2^{\circ}$ setting increases the peak power to about $900 \mathrm{Kw}$ at delta $=-5^{\circ}$. As illustrated by the horizontal grey line on the graph, control would now begin near $26 \mathrm{mph}$, and require $-15^{\circ}$ flap at about $31 \mathrm{mph}$. Even with the accelerated power reduction at larger angles, something in the range of $-25^{\circ}$ to $-30^{\circ}$ of flap would probably be needed to trim peak power in the elevated windspeed range. Note that $20 \mathrm{mph}$ power output has increased at most another $20 \mathrm{Kw}$ compared to the low activity mode, so there is diminishing returns in accepting this further increase in flap activity. 


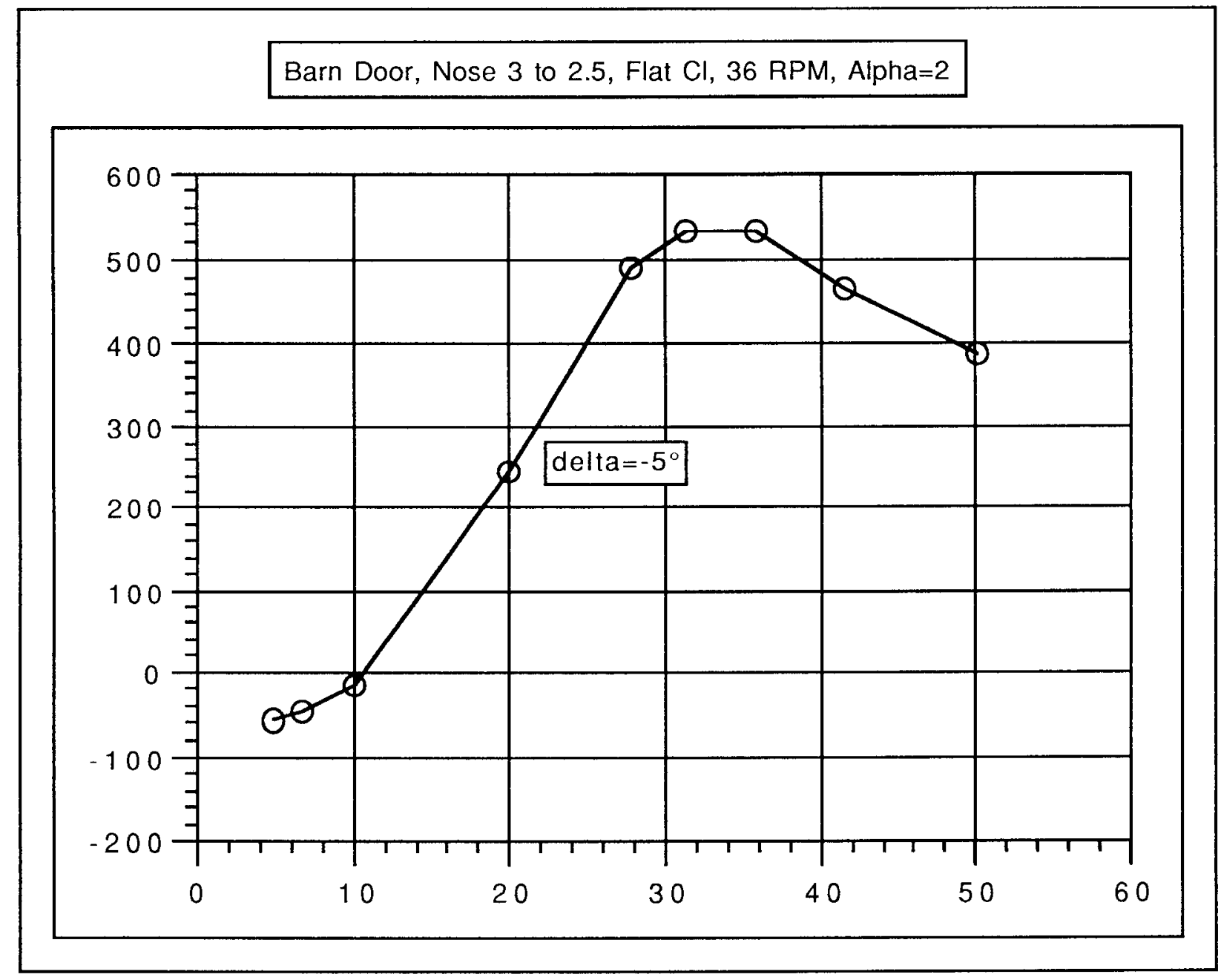

Again using a $30 \%$ of chord (and span) barn door flap, with nose trip $3-2.5$, but at $2^{\circ}$ pitch setting and $36 \mathrm{rpm}$, gives a peak power of $530 \mathrm{Kw}$, as seen in the graph above. The $-5^{\circ}$ flap deflection curve is again shown, but peak power is not much different for flap deflections from $0^{\circ}$ to $-15^{\circ}$. The lower peak power is chosen because gear box torque will limit peak power to such values, unless power spike limiting improves at $36 \mathrm{rpm}$. Even with a lower peak, power at $20 \mathrm{mph}$ is above all of the $43 \mathrm{rpm}$ cases, showing that the lower tip speed provides an efficient stall limited mode. This will provide an excellent follow-on to the $43 \mathrm{rpm}$ test, especially as regards load and power spikes versus rpm. 


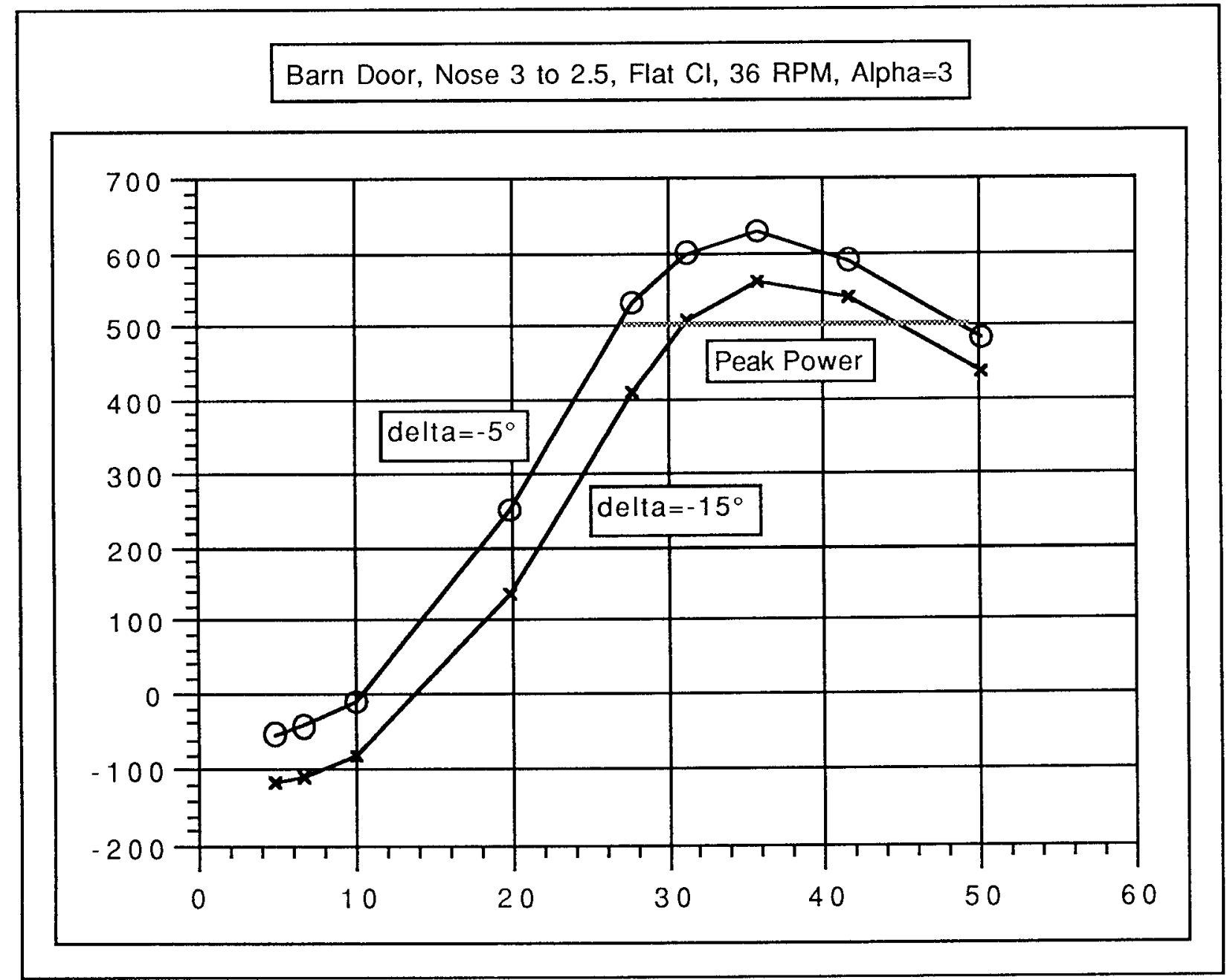

As is seen in the power curves above, pitching the nose into the wind to a $4^{\circ}$ setting increases the peak power to about $630 \mathrm{Kw}$ at delta $=-5^{\circ}$. As illustrated by the horizontal grey line on the graph, control would begin near $26 \mathrm{mph}$, and require $-15^{\circ}$ flap at about $31 \mathrm{mph}$. Due to accelerated power reduction at larger angles, possibly as little as $-20^{\circ}$ of flap would be enough to trim peak power in the high windspeed range. Note that 20 mph power output has increased by only about $20 \mathrm{Kw}$ compared to $36 \mathrm{rpm}$ stall limiting, by accepting the required flap activity. 
Barn Door, Nose 3 to 2.5, Flat $\mathrm{Cl}, 36 \mathrm{RPM}$, Alpha $=4$

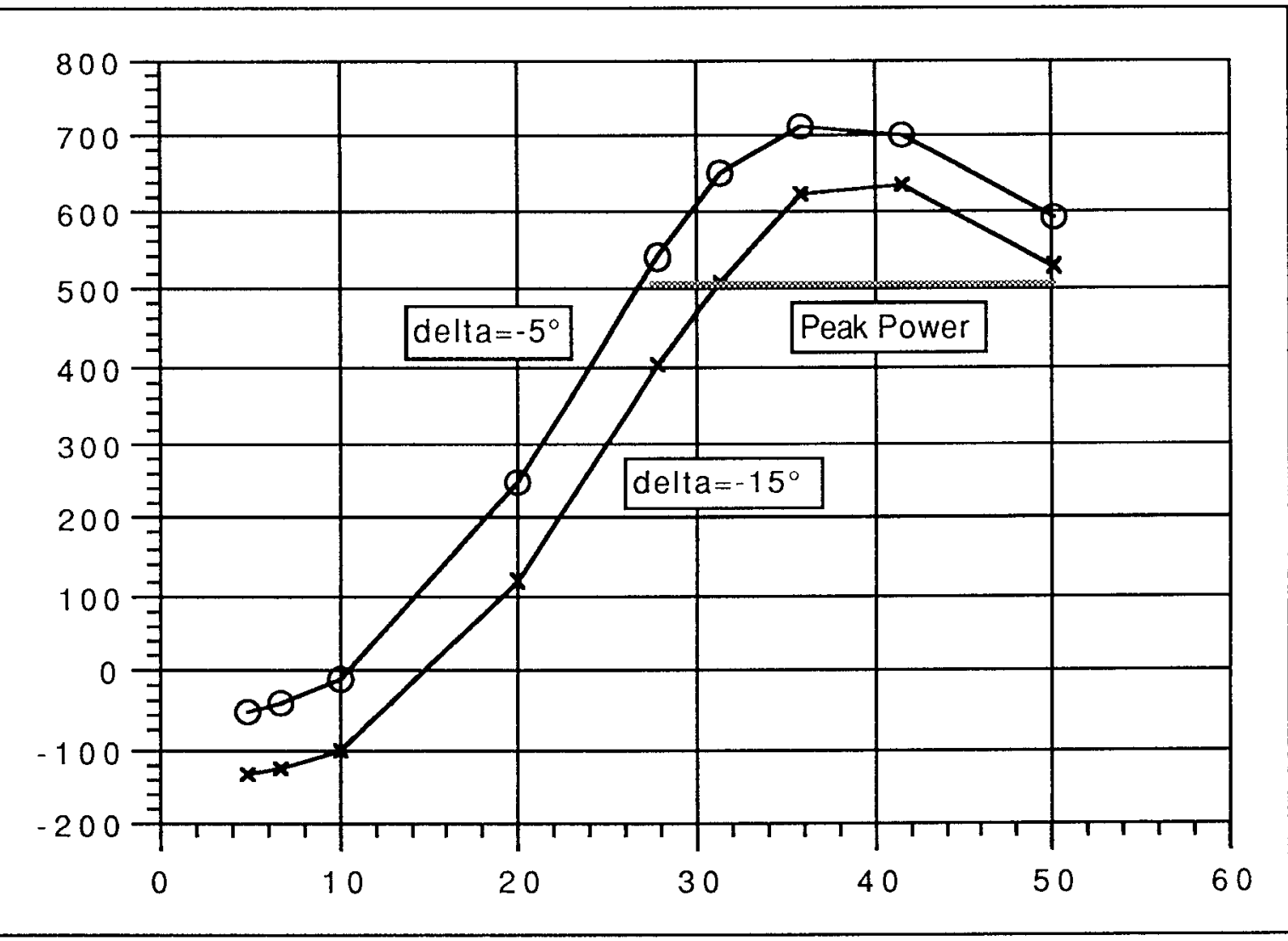

As is seen in the power curves above, pitching the nose into the wind to a $4^{\circ}$ setting increases the peak power to about $710 \mathrm{Kw}$ at delta $=-5^{\circ}$. As illustrated by the horizontal grey line on the graph, control would still begin near $26 \mathrm{mph}$, and require $-15^{\circ}$ flap at about $31 \mathrm{mph}$., but trimming the increased peak power would now likely require something in the range of $-20^{\circ}$ to $-25^{\circ}$ of flap. However, note that $20 \mathrm{mph}$ power output has now actually decreased somewhat compared to the low activity mode, so there is no benefit in accepting this further increase in flap activity. 
the existing full span pitch control hardware is a great advantage. This will allow the test hardware to compare key aspects of various control options. Power spike control, which will be a major factor in setting the peak power level that can be accepted, is an important example. Not only is there the immensely interesting basic scientific issue of how tripped airfoils behave in the real environment, this peak power level also affects energy capture and retrofit economics in a first order way. Fundamental insight on blade bending moments, which also affect retrofit cost, will be obtained at the same time. The whole spectrum from pure stall limiting to highly active flap control can be investigated and analyzed with the bolt-on test, just by varying the pitch setting. In the active control mode, various control algorithms and levels of flap activity can be compared, and their value in reducing power and blade load spikes directly assessed. This will provide a great deal of scientific insight, as well as practical engineering data to guide the retrofit decisions. To get this whole range of data from a single test setup is quite fortunate. To test two rpms that give tip speeds bracketing the final retrofit rotor is even more fortunate, and should yield a great deal of insight into the effect of tip speed on loads, power spikes, rotor dynamics, and control effects. This is really rather more than we initially dared hope, and seems a bit serendipitous, but that is the bonanza we appear poised to reap.

\section{Shutdown}

The balanced aileron does not provide an aerodynamic retarding force at all angles of attack in the presence of a leading edge nose trip, and so cannot provide pure aerodynamic stopping in that configuration. However, the barn door design was advocated precisely because it was expected to provide good stopping power even with separated upper surface airflow, and the wind tunnel data confirms it does provide a retarding force at all angles of attack when fully deflected. While it still must be shown that it can absorb all the power created by the inner rotor over the whole range of operational stopping conditions, the bolt-on does look well position to successfully address that issue, and lead the way to further evolution, if/as required. 
The bolt-on test will provide measurement of startup and shutdown times and loads over the applicable range of wind conditions, and allow optimum strategies to be assessed. Actuator loads and duty cycles for a variety of control strategies can be measured, and successful operation in the high $G$ force environment confirmed. Flap and attachment hardware adequacy in the real operating environment will also be demonstrated.

\section{Scientific Fallout}

Fundamental insight into the transient response properties of nose tripped airfoils will be available from the bolt-on test, via measurements of instantaneous peak power and blade bending moments. If the data is sufficiently interesting, comparative data without the nose trip might be justified, and could be easily obtained. Blade moment trimming by differential flap deployment in the high wind regime can also be studied. To a large degree, data in these areas is needed for purely engineering purposes, so that the eventual retrofit rotor can be properly designed. However, the eventual quest for an easily controlled, aerodynamically docile rotor may also benefit substantially, because nose trip / flap effects can be studied across a wide range of pitch and control system choices with modest effort. Getting such data at large scale, in the turbulent, 3D rotating frame condition would constitute an excellent experiment in its own right. While the intended scope of the bolt-on rotor testing cannot be structured to obtain the ultimate possible data due to its orientation toward practical goals, the very nature of the tests seems destined to provide substantial scientific fallout.

\section{Recommendation to Proceed}

The bolt-on rotor test appears poised to realize all of its goals in startup, operational, and shutdown modes, thereby providing a solid base for eventual rotor retrofit. Considerable scientific fallout on the nature of nose tripped airfoils, flap effects, and optimum rotor control appears almost inevitable. This project should certainly proceed to hardware test. 


\title{
Section 4
}

\section{Hawaii Zuteck Rotor Project \\ Preliminary Design}

\author{
"Preliminary Design Description for the Hawaii Zuteck \\ Rotor Project Bolt-On Test at Site 9, Kahuku Hills, Hawaii" \\ by M. D. Zuteck and M. W. Miller \\ September 16, 1992
}




\section{Hawaii Zuteck Rotor Project Preliminary Design Description}

The purpose of this writeup is to provide the preliminary design configuration for the Hawaii Zuteck bolt-on rotor test hardware. As will be seen, the design has evolved in both depth of detail, and in several basic design choices. That is discussed in some detail in the following.

\section{Continuous Upper Surface Hinge}

One of the first major departures from the earlier design concepts was the choice to pursue a continuous upper surface hinge right from the start. This possibility was suggested in previous writings, but was recognized as requiring more time and design work to implement. However, it presented the best possibility for controlling the flap to blade geometry to high accuracy, which was seen as holding potential benefits in both noise control and energy capture efficiency. The clean smooth joint on both top and bottom surfaces eliminates the gaps or protrusions that could lead to noise generation, while the ability to seal the joint eliminates power robbing airflow through the blade to flap joint. Since this is where the project was really aimed in the long run, the decision was made to save the lost time and expense which would occur by following other directions initially. The full length continuous hinge thus became the preliminary design baseline.

To locate a suitable hinge, products available off the shelf from industrial suppliers were reviewed via their catalog listings and descriptions. This showed that products with the right general dimensions were readily available, but did not really answer the question of which would likely be best for the flap hinging application. As a result, samples of two hinge types were procured, one of stainless steel, and the other of aluminum, so that more comprehensive hands-on evaluation could be performed.

The stainless steel hinge is made from .060" thick stainless steel wrapped around a .120" diameter steel pin. Its open width was $1.25^{\prime \prime}$. The aluminum hinge is a military standard extruded product, with .073" thickness, a .183" diameter pin, and an open width of $2.0^{\prime \prime}$. Since it is an extruded product, the pin is totally enclosed, rather than just wrapped from one side, as in the case for the steel hinge. 
The extruded aluminum hinge certainly looked stronger and better suited to this project, but to remove any doubt, it was decided to cut 3" wide lengths of both hinges, and pull them to destruction in Gougeon Bros. Inc's test lab. As would be expected, the wrapped flat plate construction of the stainless steel hinge began to unwind at a fairly low load of about $600 \mathrm{lbs}$., and its ultimate strength was only about $1500 \mathrm{lbs}$. The aluminum hinge went to about $2000 \mathrm{lbs}$. before the first yielding was observed, and its ultimate strength was also much higher, over $6500 \mathrm{lbs}$. for the 3 " long segment. These results, as shown in the load versus stroke plot provided below, settled all doubt about the issue. The military standard extruded aluminum hinge is baseline for preliminary design, and is depicted in the drawings included in this writeup.

\section{Load vs. Deflection Curves for Aluminum Flap Hinge and Steel Flap Hinge \\ 8/14/92}

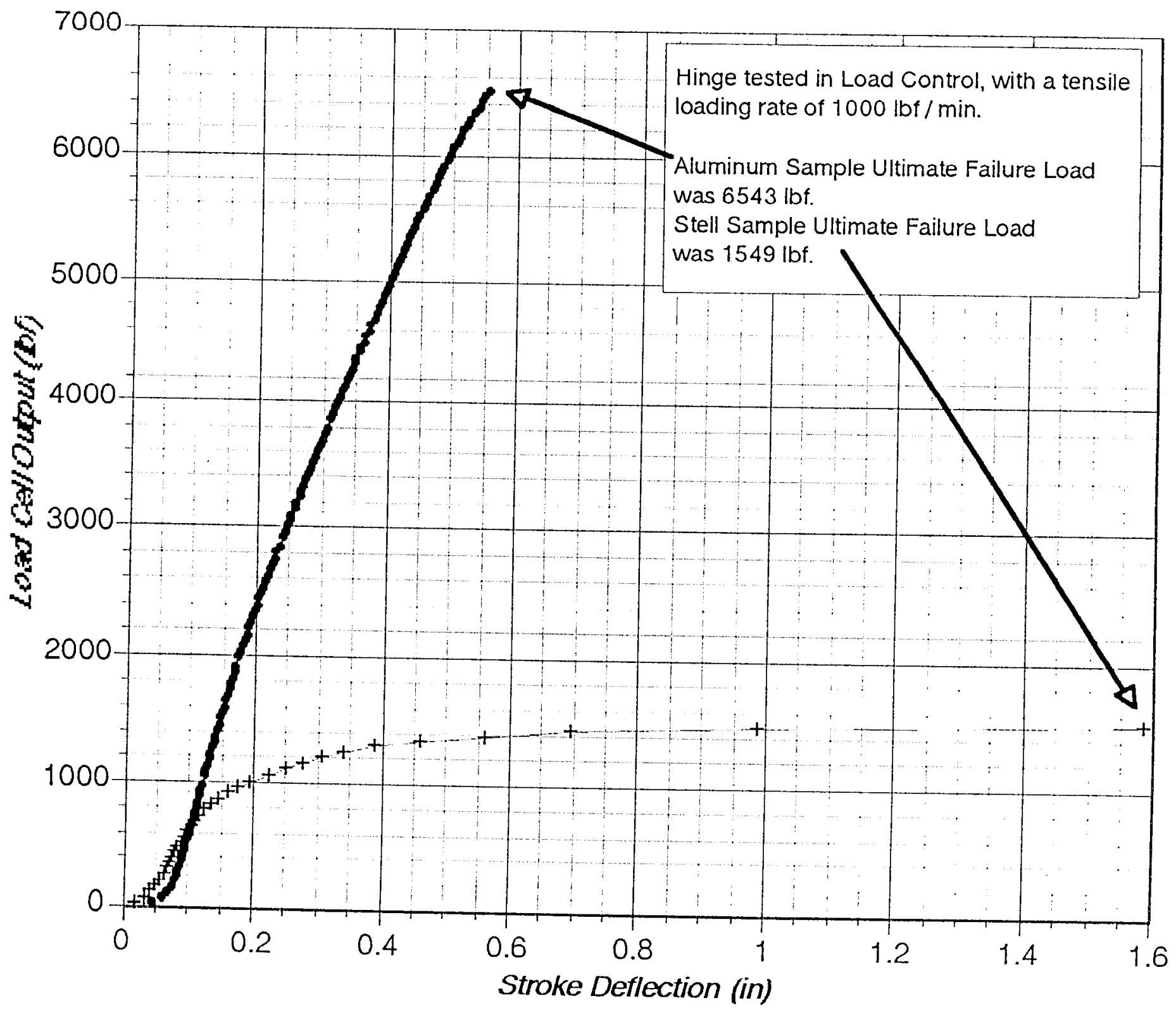




\section{Integrated "C" Section Aft Closure \& Flap Assembly}

The decision to pursue the distributed hinge meant that it would be necessary to come up with a reasonable, cost effective way to strengthen the aft portion of the upper blade shell, so that it could reliably support the loads transmitted through the hinge. This is not a trivial matter, because the upper shell must cantilever aft a substantial distance from the aft web closure, in order to provide space for the nose of the flap. Unfortunately, the blade shell is not strong against loads applied that way, because they must be reacted primarily by the crossgrain capability of the laminaled shell, with only a little help from the thin glass skins. Since the crossgrain strength of Douglas fir laminate is both low and rather variable, it was clearly not acceptable to just react the hinge loads into the unreinforced upper shell. Some method of providing a stronger, more reliable hinge support would have to be found.

It was obvious from the start that interior reinforcing with fiber in the chordwise direction could easily be added to the laminate inner surface during field installation, but that this would be insufficient, as the outer skin could still be subject to breakage. Reinforcing the outer skin was certainly possible, and if done with judicious amounts of carbon fiber, the deviation from the original airfoil contour could be kept quite small. However, this was going to entail a lot of time consuming and expensive preparation, application, and fairing to produce an acceptable result, and having to do that in the field would only make it more difficult and expensive. It was not a pretty picture.

Mike Miller (HERS) was a strong advocate of using a pre-fabricated assembly that could be bonded in place in a single operation. That had many obvious advantages, but the blade cutout required to accommodate such an assembly was so large that it created a difficult structural problem by removing too much load carrying blade shell. While we continued to wrestle with other ways to simplify the in-field installation work, without running afoul of that problem, Curt Dechow and Jack Anderson of GMC came up with a way to break through that barrier, by introducing a long low angle cut that allowed bonding in a " $\mathrm{C}$ " shaped structure that combines the aft web and aft shell reinforcing in one unit. This cut is really only at its most difficult just in a short region of the outermost blade, and they now feel completely confident that this can be efficiently executed in the field. 
The result of this is really a breakthrough, as it allows construction of a complete aft web, reinforcement, and flap subassembly at GMC. The aft web and reinforcement would be constructed of two " $\mathrm{C}$ " shaped glass laminations, with core in the web portion to provide a thick rigid web. This core will be replaced by solid wood at the actuation load reaction locations, so that hardware can be easily and securely attached there. The inner " $\mathrm{C}$ " will be shorter on the upper side, to form a natural indent for the hinge. The hinge is to be bonded and screwed in place, with the screw heads accessible from the inside, for hinge removal in the unlikely event of damage or long term wear. The upper leg of the " $\mathrm{C}$ " provides a strong direct mount for the hinge, that dissipates load into the upper shell along a long bond line. The connection to the web is strong, since it is constructed integral with the web. Because the path of strength goes directly from the hinge to the body of the " $\mathrm{C}$ " assembly, structural integrity would be maintained even if a crack of the outer skin were to occur. This provides a very secure hinge attachment method as a result, and allows installation of the assembly without the need for exterior shell reinforcement. Figures 1 and 2 show this concept at the innermost and tip flap stations, to illustrate the extremes of shape.
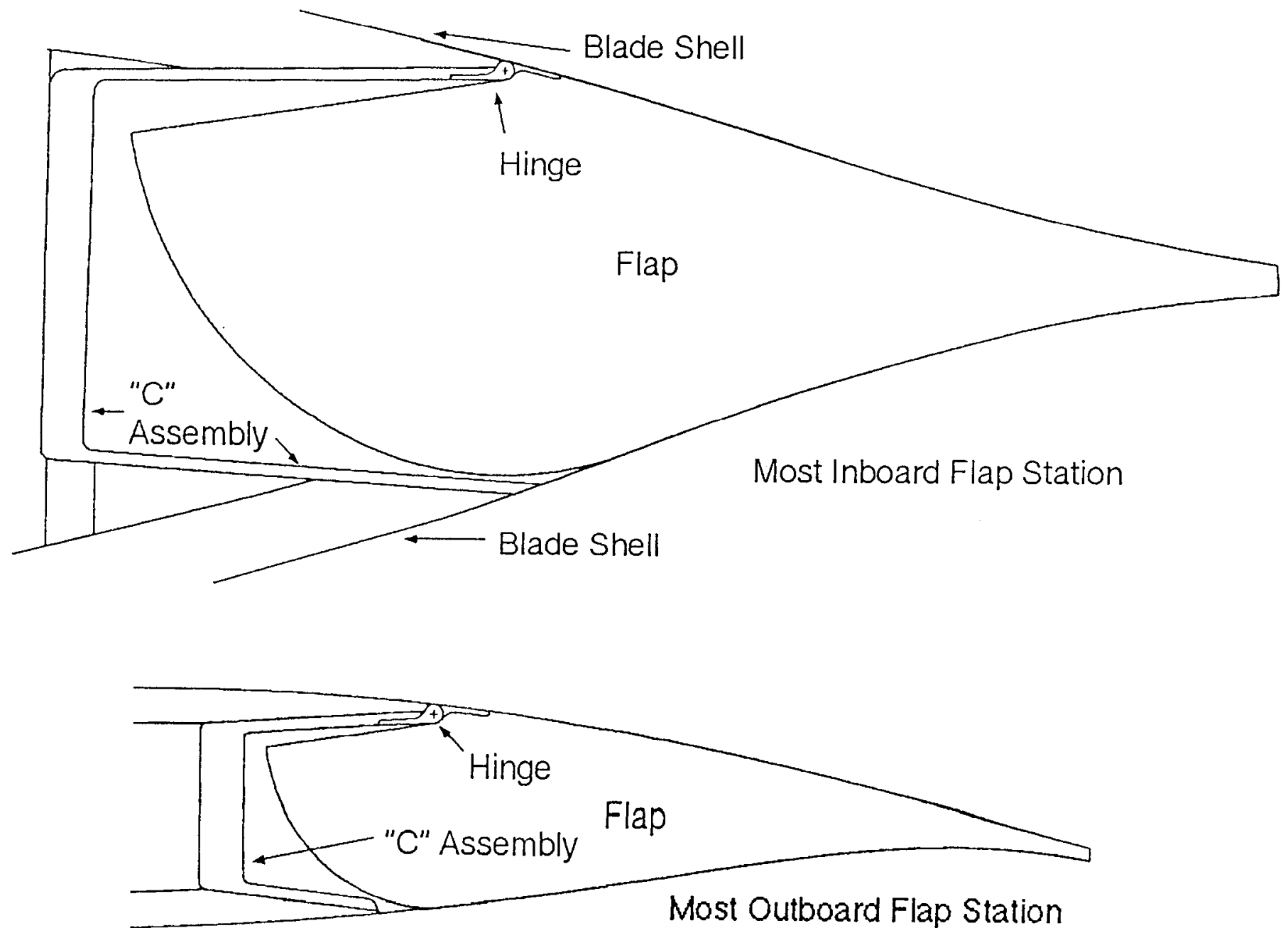
This approach will require a dedicated mold to manufacture this " $\mathrm{C}$ " shaped unit, but GMC is very good at that, and the shape is simple compared to the NREL blades. A little laminate is still lost, and there is some complexity at the inboard corner where the " $\mathrm{C}$ " must terminate and dump its loads into the blade shell in a smooth fashion. This looks manageable compared to the difficulties a large cutout would have caused, and there is no big concern about creating suitable structural detailing to handle this. Due to the combination of excellent structural integrity with minimum expensive field installation work, this " $\mathrm{C}$ " section assembly is the baseline for the preliminary design.

\section{Actuation Linkage Type}

Structural integrity, weight, and cost of the " $\mathrm{C}$ " assembly all argued for making it only deep enough chordwise to comfortably house the nose of the flaps. Any further increase in chordwise dimension beyond that would only add to the weight and cost, while reducing blade torsional stiffness, and making inboard termination more difficult. Since the region forward of the " $\mathrm{C}$ " would be hard to access once it is bonded in place, it was seen to be a big advantage to keep all the moving parts of the actuator linkage aft of the web unit. This would allow the easiest inspection and maintenance, and the simplest and strongest web assembly (free of access holes), and actuator linkage (free of unnecessary disconnection points).

The difficulty with the above set of goals was that the actuator linkage has to live in the fairly small cavity forward and below the leading edge of the flaps. While this eliminates a great many possibilities, a cable and sheave system, capable of driving the flap in both the power and stop directions, was shown to fit readily into this space. The following drawing accurately depicts the geometry at the center of the middle flap, and also shows locations for the primary actuation and reverse cables and sheaves. As is evident, the required components readily fit in the cavity behind the new aft web, at this location. While the dimensions change somewhat, preliminary layout drawings show that there is no difficulty fitting into the cavity at the other two flaps either. Note that the outboard flap will be actuated near its inboard end, to take advantage of the larger cavity and flap nose radius at that location. Consequently, the geometry at its actuation station is not very different than that depicted for the center flap. Of course, the inboard flap station has even more room than what is depicted here. 


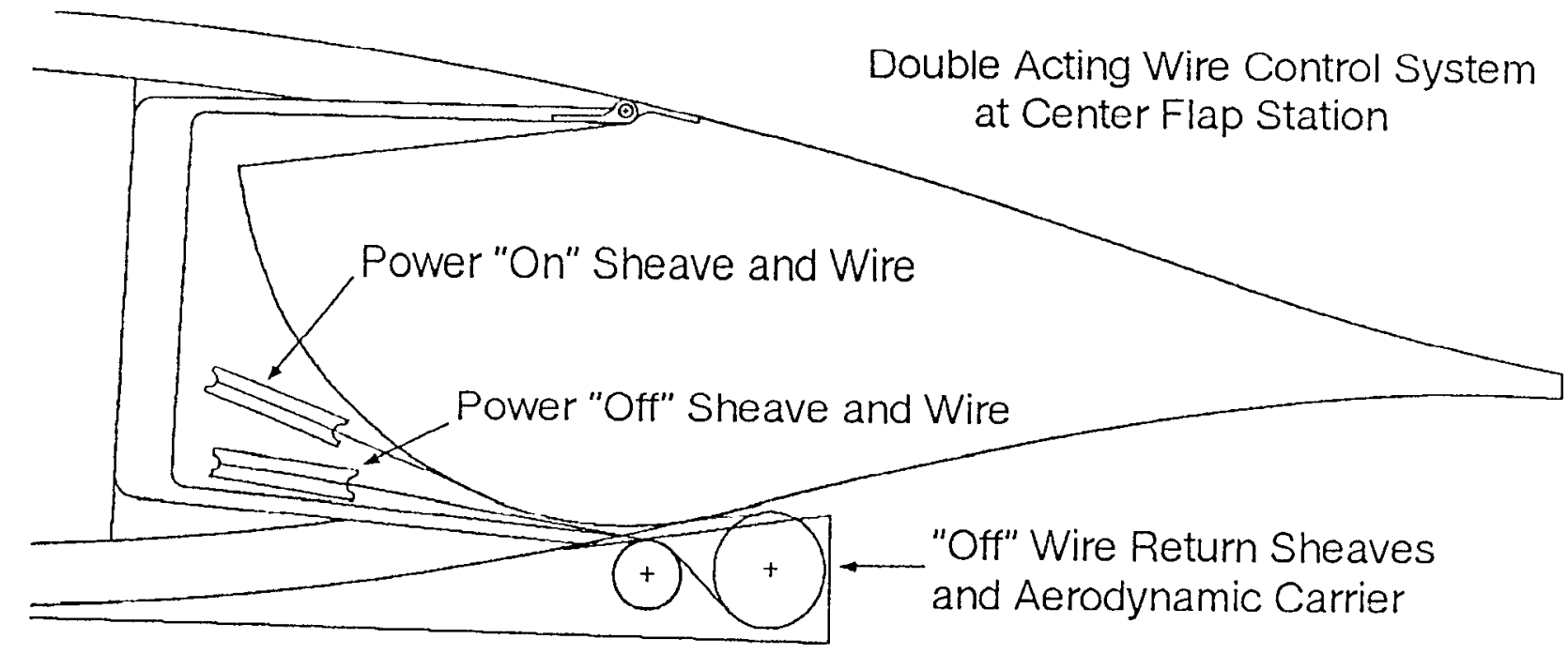

A major design philosophy for the flap control system is evident in the drawing, namely that the flaps shall be positively controlled in both directions of motion. The Wichita State wind tunnel data indicated that for the geometry tested, aerodynamic forces driving the flap toward the stop position existed for all flap angles measured. However, that may not be true for all possible conditions, and even if it were, we have to design to prevent uncontrolled flap motion, and possible resulting flutter instability. There are so many combinations of blade motion and bending, inflow turbulence, control input, unsteady aerodynamics, and so on, that we cannot assume the flap will always be loaded in a way that would prevent slack from occurring in the wires. Consequently, it is a feature of the preliminary design that the flaps shall have direct control in both directions, and be so constructed and preloaded that slack in the system is prevented by design.

As is seen in the drawing, the wire which pulls the flap into the power position uses the radius on the leading edge of the flap as a natural arc to deliver its forces. This guides the wire through the flap to blade shell gap in a clean way, while providing a constant radius of the maximum available size for the flap actuation. To keep the reverse wire system compact, and also route it through the blade / flap gap for easy removal and replacement, a compact double sheave arrangement, integrated into an aerodynamic U shaped channel/carrier, is shown. Since the reverse cable loads ought to be low, there should be no problem cantilevering this assembly the required distance aft, and only a small slot at the wire is needed for it to pass through the gap. This may still need some local outer skin carbon reinforcing or steel straps, but that need can be minimized by making the " $\mathrm{C}$ " stronger in the proper locations. 


\section{Actuator Choice}

Preliminary estimates of the actuator force requirements for the assumed $12^{\prime \prime}$ flap chord indicated a maximum steady aerodynamic load in the $300-400 \mathrm{lb}$. range, with the largest force required for the outermost flap, since it has the smallest nose radius. This does not include brief peaks from unsteady aerodynamics or structural dynamics, which are expected to be generally less than this primary aerodynamic component. To provide a comfortable reserve against unknown loading conditions, an actuator load capability of at least $600 \mathrm{lbs}$. seemed prudent.

To assess the availability and properties of off-the-shelf linear actuators in this load range, catalogs and recommendations were sought from three companies that supply such units: Thomson Saginaw, Warner, and Industrial Devices Corp. It was found that both Thomson and Warner offered low cost units with capabilities in the desired range. These used a ball screw for efficiency, a permanent magnet DC motor for low cost, and a mechanical brake to prevent back-driving when power is off. The brake is needed because the DC motor is not designed to be powered continuously, and is readily backdriven when power is removed.

Stepper motor units were also investigated, because they can be powered continuously and thus do not need a brake. They have the added advantage that they will automatically backdrive, and thereby allow the flaps to move to the stop position, when the power is removed. That is a very desirable characteristic, because it gives an automatic failsafe to the stop position when power is lost. The DC motor version will need either an electromagnetic latch, or a backup power supply to drive the flaps to the stop position, to provide that capability. Unfortunately, the stepper motor units were found to be tremendously more expensive. If periodic replacement is required, which may be the case for a highly active control strategy, then the cost penalty could become unacceptable. Reluctantly, we decided that economics dictated following the DC motor path, with the stepper motor approach as an alternative if the economics ultimately permit it.

The bolt-on rotor testing will provide vital information about the actual service response of the actuators employed. It will also provide the needed information about optimal control strategy, actuator duty cycle, and control system loads to make an informed decision on the best actuators for the final retro-fit project. Other actuators could be fitted and tested if that seemed warranted, but the low cost DC motor units are the chosen baseline for preliminary design. 


\section{Flap Sizing}

Previous writeups of the flap geometry have indicated that a constant $12^{\prime \prime}$ chord would be used with a $30 \%$ of span, three segment flap system. The $30 \%$ of span, three flap segment baseline has not changed, nor has the 12" flap chord at the tip. However, detailed physical layout work performed at Gougeon Manufacturing Corp. has shown that a 12 " inboard chord dimension is not sufficient for placing the chosen actuators in the most efficient position, if a location just inboard of the flaps is elected. Since it was desired to keep the option open for this outboard actuator placement, a study was undertaken to determine how much inboard flap chord would be required, to put the actuators where they could properly line up with the support structure and actuation force delivery system. It turned out that a 14" inboard chord satisfied the actuator placement needs nicely, without much loss of basic flatwise blade strength. While somewhat more reinforcing would be needed to carry loads around the inboard end of the larger required blade cutout, this was judged to be a manageable problem. A small benefit accrues, in that the larger flaps provide a bit more overall startup and braking power, and also a little more aerodynamic force taking the inboard segments toward the stopping position. Based on the above considerations, a 14" inboard flap chord dimension is the new baseline for the preliminary design.

\section{Actuator Selection and Placement}

Having deciding to focus the primary effort on the low cost DC motor actuators, steps were taken to learn more about the mechanical details of these units, and to procure at least one for initial evaluation. After considerable initial discussion, it was found that Thomson Saginaw had a $750 \mathrm{lb}$. unit that was well suited for this project. GMC made arrangements to pick up one of these, and to have a meeting with their engineering staff at the same time. The timing of this was quite fortuitous, and allowed Mike Zuteck to accompany Curt Dechow to that meeting, during which extensive discussions of the internal details and operating characteristics of the units occurred. Of primary concern was the ability of the units to provide a long lifespan of reliable operation in the high $\mathrm{G}$ field which exists in the outer blade, since they were not designed with that in mind. While this did not appear to be a problem in most respects, two areas of potential difficulty were identified:

1) the end bearing of the DC motor, and

2) the backdrive braking mechanism. 
On the Thomson unit, the outboard bearing of the DC motor is a self aligning plain bearing. The rotor is located axially by plastic tube spacers and steel shim washers. The steel to steel interface between the most outboard washer and the face of the plain bearing has an outside diameter of $10 \mathrm{~mm}$, and an inside diameter of $8.5 \mathrm{~mm}$, for a bearing area of about .05 square inches. The DC motor armature weighs about 10 oz., and in the outboard actuator location would see about $35 \mathrm{~g}$ 's, and so exert an axial force of about $20 \mathrm{lbs}$. This would result in a surface pressure of about $400 \mathrm{psi}$. at the interface, which would seem to be acceptable if this were kept lubricated. Since the self aligning bearing has a cylindrical end cavity aligned so that lubricant would tend to stay trapped in place, this might work fairly well. There is some chance that the motion could occur between the spacer washers, or between the spacer washers and the plastic spacer tube. Lubricant would probably not stay in those locations, because they are not sealed in any way, and any motion that did occur could result in wear, and accumulating tolerances. This would allow the rotor to move outboard slightly, feeding more lubricant up to the first washer to bearing interface. While this design was clearly not created for a high g axial field application, the conclusion was that it may well survive for a substantial period, if it is aligned to the $G$ field properly. However, with a $g$ field as high as that in the outboard blade, actual operating experience would be needed to reliably assess life performance of this bearing.

The Thomson back-drive braking mechanism is a unique device that uses axial load to create braking torque. It is sort of like a Chinese handcuff, in that it engages in proportion to load, always creating enough resistance to prevent backdriving. The actual mechanism is a complicated looking stack of bearings, spacers, and plates, surrounded by a wound spring that disengages it when motor torque is applied. There are two such backdrive assemblies, acting in opposite directions, to resist both pulling and pushing forces. The problem is that these assemblies are lubricated, and have to be kept lubricated in order to operate properly. They are not sealed, and by their nature have lots of little gaps through which lubricant could weep away. By the nature of the fabrication, the outer assembly is inaccessible. Fortunately, it is the one which resists pushing forces, which will rarely if ever occur in this application, so maybe it can survive as is. The other braking assembly is to the accessible side of the load reaction plate. That plate is only swaged in place at four discrete locations, but if it could be sealed, would form a cavity with the outer tube that could retain grease. This heavily used brake would probably not survive our application without such modification. 
As of this writing, a Warner unit has not been examined in sufficient detail to assess its suitability to long term operation in a high g axial field. However, it uses a different method to prevent backdriving, namely a brake mounted outboard of, and in line with, the DC motor. This brake may very well not require lubrication for its well being, but the motor housing pass-through required to drive the brake means the motor bearing would be open at its outboard end, so that it would be very difficult to keep it lubricated under simultaneous high rpm and high g's. The present plan is to procure an example of this unit, and examine it in further detail, but it does not look well suited to long term high g operation from what is known at this time.

Based on the above, Thomson 36 volt PPA linear actuator models 7821214 and 7821215 ( 8 " and 12" stroke for different flaps), are baseline for preliminary design. Because of the considerable uncertainty about their ability to tolerate the high g fields, the baseline location for these units will be in near the hub, where the centrifugally induced acceleration is much lower. The chosen cable actuation system permits such a choice with very little difficulty, beyond the need to drill some pass-through holes in the inboard trailing edge, and to provide a suitable blade mounted support structure. There will also be a need for sufficient stiffness to prevent excess linkage flexibility, and a way to keep the long unsupported cables from swinging and hitting each other or the blade shell, but reasonable methods have been proposed to address each of these requirements, and will be settled during final design.

Hawaiian Electric has already taken steps to procure one of the Thomson actuator units, and is studying the feasibility of mounting it to an existing blade, and driving it in concert with the existing blade pitch algorithm. This could indicate possible problems well before the bolt-on rotor is ready to fly, and the external location in near the root is ideal for changing to other actuators, if the Thomson units prove to be inappropriate. The inboard location is also best for periodic replacement, if that becomes part of the overall long term retrofit project. Given the combined weight of all of the preceding factors, inboard mounting of the low cost Thomson DC motor driven actuators is the preliminary design baseline for the Hawaii Zuteck rotor project. 


\section{Flap Skin Material}

Because the flaps necessarily work in the high g field of the outboard blade, keeping them light in order to minimize the magnitude of dynamic loads in the control system is a high priority. Keeping the flaps light also greatly reduces the amount of balance weight needed in the nose of the flaps for dynamic stability, which in turn takes a lot of centrifugal load off the continuous hinge and supporting blade structure. The flap structure also needs to be quite strong so that it can sustain its applied loads reliably over a long lifespan, and stiff and strong enough in torsion to move as a unit with the planned single point actuation. All of these factors point to the need for a high strength to weight construction technique.

The use of a continuous hinge introduces another somewhat unusual, but highly important design driver, namely that the flaps be relatively compliant in edge bending. This is important because flatwise bending of the primary blade structure under the operating thrust loads causes edge bending of the flaps as they are deflected toward the stopping position. In that case, edge stiffness creates large hinge and support structure loads, and also causes a torque that must be overcome to get the flaps to the stopping position. Both of these effects are undesirable, and the latter could interfere with emergence shutdown if the magnitude is too large. Even if this is not a problem, excess forces coupled into the actuator and linkage system could cause added expense and maintenance for those components.

Realizing the importance of simultaneously pursuing the above set of divergent goals, an experimental material properties assessment program was undertaken by the lab at Gougeon Bros. Inc., with samples fabricated by Gougeon Manufacturing Corp., and technical direction by M D Z Consulting. Three basic material types were tested: birch plywood, fiberglass, and carbon fiber. While fiberglass can supply high elasticity, its low modulus to weight ratio meant that it would be excessively heavy for a given level of flap torsional stiffness, compared to the other two materials, and it was soon set aside. Birch plywood proved a formidable competitor to carbon layups, for the very light panels which were desired - under $.5 \mathrm{lbs}$ per square foot, if possible. However, after considerable experimentation with a number of carbon fabric types, resin variants, and layup techniques, a highly desirable carbon based skin layup was obtained. This is now the baseline for the preliminary design. 


\section{Flap Construction Method}

The material used for the flap skins is only one facet of the overall flap design, albeit a very important one. To have suitable panel rigidity, the carbon fiber skins will require a core material of some sort. While a precise specification awaits final design, an expanded foam in the vicinity of $5 \mathrm{lbs}$ per cubic foot is the most likely candidate for the weight critical aft flap panels at the present time. Since balance weight will be needed anyway in the forward flap region, heavier core material, or even fiberglass construction, could be used for that portion. Certainly a strong web that can distribute forces from the hinge will be required under the hinge, and the same sort of birch ply web with top and bottom stringers that is used in the blade construction is a leading candidate for that critical role. All of these details await final choice during the detailed design tradeoffs that will lead up to the final design configuration. What is given here is just a snapshot of the thinking as it exists at this time, so that the level of base building and conceptual definition that has already been achieved can be properly understood. 


\section{Summary}

\section{Flap Design}

1) NASA barn door with LS-1 trailing edge cusp

2) Three independently actuated flap segments

3) "Flap chord: linear from $12^{\prime \prime}$ at tip to $14^{\prime \prime}$ inboard

4) Variable length flap segments $\left(7^{\prime}, 8^{\prime}, 9^{\prime}\right.$ - longer inboard)

5) Mating flap edges (no static flap separators)

6) ${ }^{\star}$ Continuous upper surface hinge:

*(Military standard aluminum extrusion)

${ }^{*}\left(2\right.$ " open width, $.073^{\prime \prime}$ plate, .183 dia. pin)

7) ${ }^{\star}$ Cored carbon fiber aft panel construction

8) *Integrated glass/epoxy " $\mathrm{C}$ " section flap assembly

\section{Flap Actuation System}

1) *Low cost DC motor ball screw linear actuators

2) *Thomson 36 volt PPA models 7821214 and 7821215

3) *Actuator location inboard near blade root

4) *Pre-tensioned double acting cable link to flaps

\section{Nose Trip Design}

1) Tunnel nose \#3 (defining angles held constant)

2) $30 \%$ spanwise extent

3) Trip end fairing

New Blade Tips

1) Tangler (ESI-80) type (or evolution thereof)

2) For $36 \mathrm{rpm}$ testing

Note:

Items with leading * have been created or changed since conceptual design, and are discussed in the present writeup. The other items have been carried over unchanged from conceptual design, and were covered in the previous conceptual level material. 


\section{Section 5}

\section{Hawaii Zuteck Rotor Project \\ Phase II Final Report}

"Task 2 Report Hawaii Zuteck Rotor Project"

by M. D. Zuteck and M. W. Miller

December 7, 1994 


\section{Makani Uwila Power Corporation}

\section{TASK 2 REPORT \\ Hawaii Zuteck Rotor Project}

Table of Contents

Page

Section $1 \quad$ Introduction to This Report 1

Section II $\quad$ Project Background 3

$\begin{array}{lll}\text { Section III } & \text { Overview of Rotor Modifications }\end{array}$

$\begin{array}{lll}\text { Section IV } & \text { Flap System } & 13\end{array}$

$\begin{array}{lll}\text { Section } V & \text { Aft Blade Structure } & 22\end{array}$

Appendix V-1 Supplemental Detail Drawings 31

$\begin{array}{lll}\text { Section VI } & \text { Attachment Hardware } & 36\end{array}$

$\begin{array}{lll}\text { Section VII } & \text { Actuation Link System } & 43\end{array}$

Appendix VII-1 Supplemental Detail Drawings

Section VIII $\quad$ Actuation Drive System 60

Appendix VIII-1 Ball Screw Actuator Data 68

Section IX $\quad$ Turbine and Rotor Flap Control 74

Appendix IX-1 Parker Compumotor Controller 79

$\begin{array}{lll}\text { Section } X & \text { Test Plan } & 82\end{array}$

Appendix X-1 Strain Gage Installation Details 89

Appendix X-2 Safe Operating Procedures 96

December 7, 1994

NREL Subcontract HC-2-11101-4

State of Hawaii DBED\&T Contract 32396 


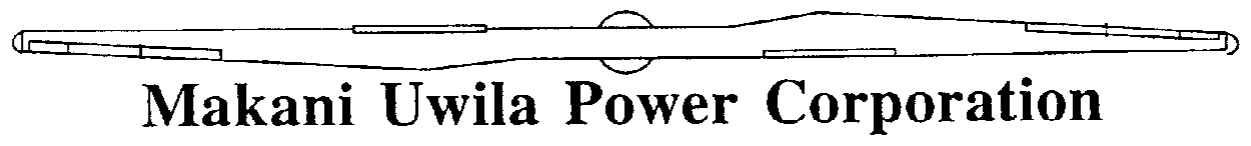

TASK 2 REPORT

Hawaii Zuteck Rotor Project

\section{SECTION I}

INTRODUCTION 
This report records the design and hardware modification activities under Task 2 - WWG-0600 Wind Turbine Modification - of the Hawaii Zuteck Rotor Project.

Task 1 of the project concluded with a report on the wind tunnel tests of a WW-0600 rotor blade section that had been modified with prototype aileron-type flaps.

The goal of Task 2 was to develop a full scale retrofit rotor package for installation on a turbine in Hawaii to test the effectiveness of flaps in enhancing the operating characteristics of the unit.

The report incorporates the following program deliverables:

- Final hardware design for the bolt-on rotor test, including detailed description of the aileron flaps and the turbine system modifications.

- As-built drawings.

- Test plan with instrumentation diagrams and Safe Operating Procedure.

Sections II and III of the report provide background and overview information and drawings. Sections IV through IX detail specific aspects of the flap and control systems. Finally, Section $X$ includes the test plan and supporting documents.

As the modified blades have not yet been shipped to Hawaii and installed on the test turbine, there may be final detail changes prior to commencement of the operating tests. An interim or supplemental report describing any such changes and the reasoning behind them will be submitted in conjunction with the Task 3 deliverable, an onsite "demonstration to NREL technical monitor of operation of modified machine components, instrumentation and data acquisition systems".

A short video tape of the modified blades is available as a supplement to this report: The tape illustrates the structural modifications to accommodate the aileron flaps, the completed flaps, and operation of the flaps when mounted on the blades. 
TASK 2 REPORT

Hawaii Zuteck Rotor Project

SECTION II

PROJECT BACKGROUND 


\section{CONCEPTUAL APPROACH}

The Hawaii Zuteck Rotor Project was conceived to adapt two previously successful concepts, the structural flow-through rotor and trailing edge flap control, in developing a new rotor for the Westinghouse WWG-0600 wind turbine.

The flow-through rotor concept allows the primary blade bending loads to "flow" across the inner hub portion of the rotor without passing through any bolted joints. This effect results in:

- a more uniform load distribution for the inner rotor.

- lighter weight due to elimination of many of the steel forging and components necessary to attach and pitch the blades as well as the in-blade build-ups required to transfer load to the steel components.

- elimination of the large hydraulic system.

- reduction of the number of electrical control cables passing through the low speed shaft.

- lower maintenance due to hub component elimination and simplification

- Increased tower clearance due to the lighter rotor being placed further forward of the tower.

- increased rotor diameter due to the increased tower clearance.

- increased annual energy capture due to increased rotor diameter and decreased maintenance requirements.

Many different rotor control ideas were explored prior to commencement of the project, including pitchable tips, stall limited airfoils, and flap control (ailerons). The last option was chosen as being the most practical for adaptation to the existing rotor. Pitchable tips would be too heavy and partially defeat the flow-through concept. Stall limited airfoils would require the expense of building and installing new airfoils on the existing machine. Flap control eliminated these disadvantages. NASA, in its Performance and Power Regulation Characteristics of Two AileronControlled Rotors and a Pitchable Tip-Controlled Rotor on the Mod-O Wind Turbine. (Corrigan, Robert B., et. al. NASA TM-100136, DOE/NASA/2032073.p. 10), reported that both aileron configurations tested "...provided acceptable power regulation within the wind speed ranges for which the control surfaces were effective." They also noted that the larger aileron was "effective over a wide wind speed range." (ibid., p. 9) 


\section{WORK APPROACH}

The program was divided into two principal phases. The first phase is intended to demonstrate the feasibility and effectiveness of retro-fitting flaps into an existing blade set. The major steps in this phase are:

- A Wind Tunnel Test to provide design and verification of the power control, start and stop characteristics of the LS-1 airfoil with flaps. This test was completed in February, 1992.

- The Design, Modification and Operation of a Blade Set to demonstrate the flap design, verify the loads, and demonstrate the start-up, stopping, stall limiting, and operating characteristics of the configuration to verify wind tunnel data.

The second principal phase, which is optional depending on Phase 1 results, would incorporate a flow-through rotor design, increased swept area (160 ft diameter versus $142 \mathrm{ft}$.), retrofit flaps and reduced rotor speed $(36 \mathrm{rpm})$ to reduce tip speed.

This overall program is projected to substantially improve the WWG0600's performance, efficiency, reliability, and cost competitiveness as well as demonstrate concepts with direct application to other wind turbines, both in new and retrofit applications.

\section{FIELD DEMONSTRATION OF BOLT-ON CONFIGURATION}

Upon successful completion of the wind tunnel test, engineering work began on refinement of the flap and actuator designs as well as detailed design of all other components to be incorporated in the Bolt-On Test Article (including hinges, fail safe devices, and molds). The final flap design was based on the data gathered in the wind tunnel and other research. An existing set of Westinghouse WWG-0600 blades were modified for the addition of flaps. The studs at the root end of the blade were retained to allow the blades to be bolted to the existing pitch spindles. The fact that the existing pitch capability is retained allows safer test operation of the turbine. Should there be a failure of the flap system during testing, the machine can be stopped using the existing pitch system. A secondary benefit is that the optimum blade "pitch" can be determined by setting the spindles at different pitch angles and recording the operating characteristics of the turbine. The blades and flaps will be instrumented to record critical data during testing. 
TASK 2 REPORT

Hawaii Zuteck Rotor Project

SECTION III

OVERVIEW OF ROTOR MODIFICATIONS 
The drawings in this section illustrate in sequence:

- The baseline Westinghouse WWG-0640 Wind Turbine.

- The turbine rotor hub assembly.

- The baseline rotor blade prior to any modifications.

- The plan of a modified blade with flaps indicating important dimensions and the station locations of detail drawings included in other sections of this report.

- The blade section shapes in the area of the flaps. 


\section{Westinghouse WWG-0640 Wind Turbine}

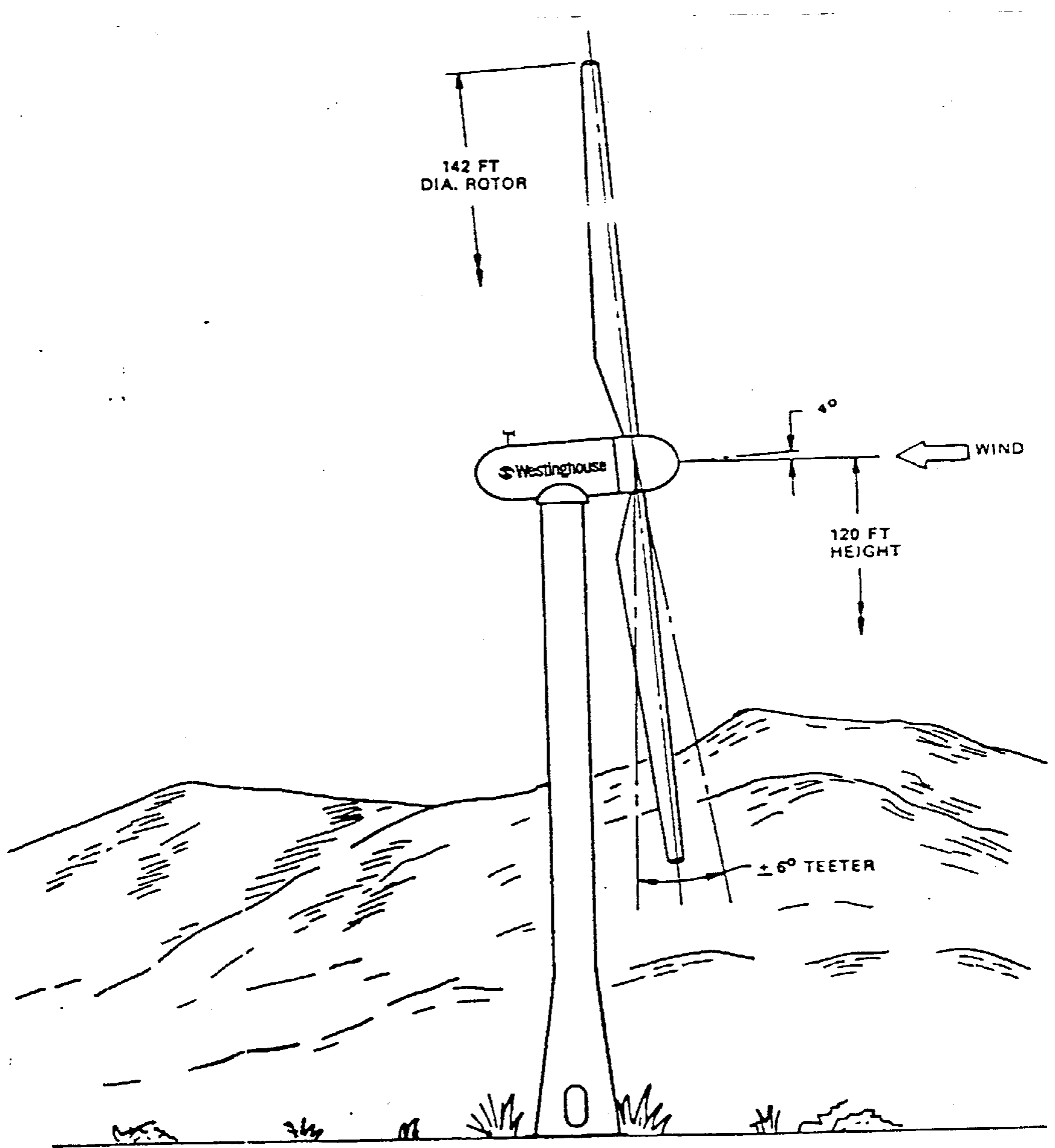




\section{Westinghouse WWG-0600 Wind Turbine Hub Assembly}

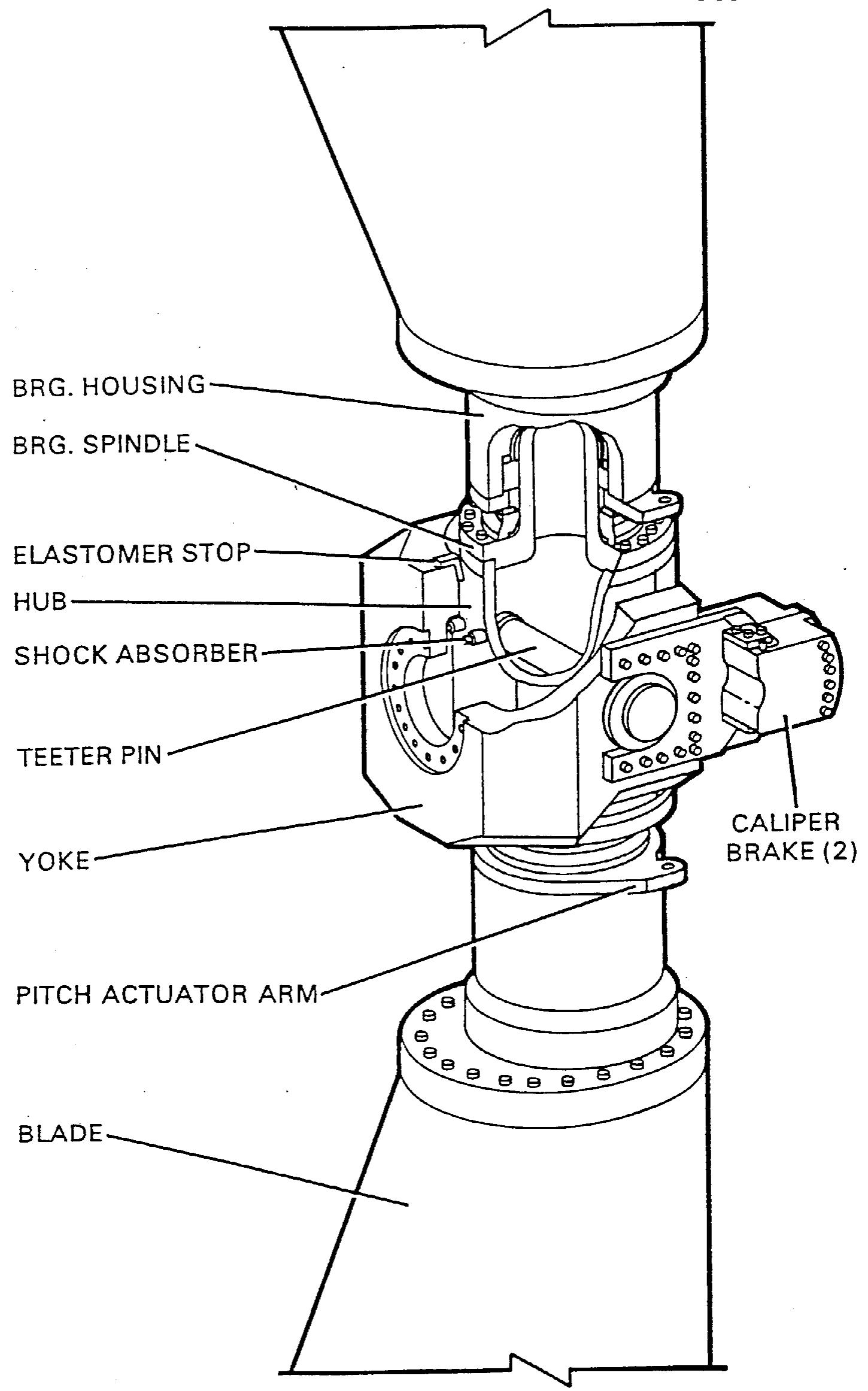




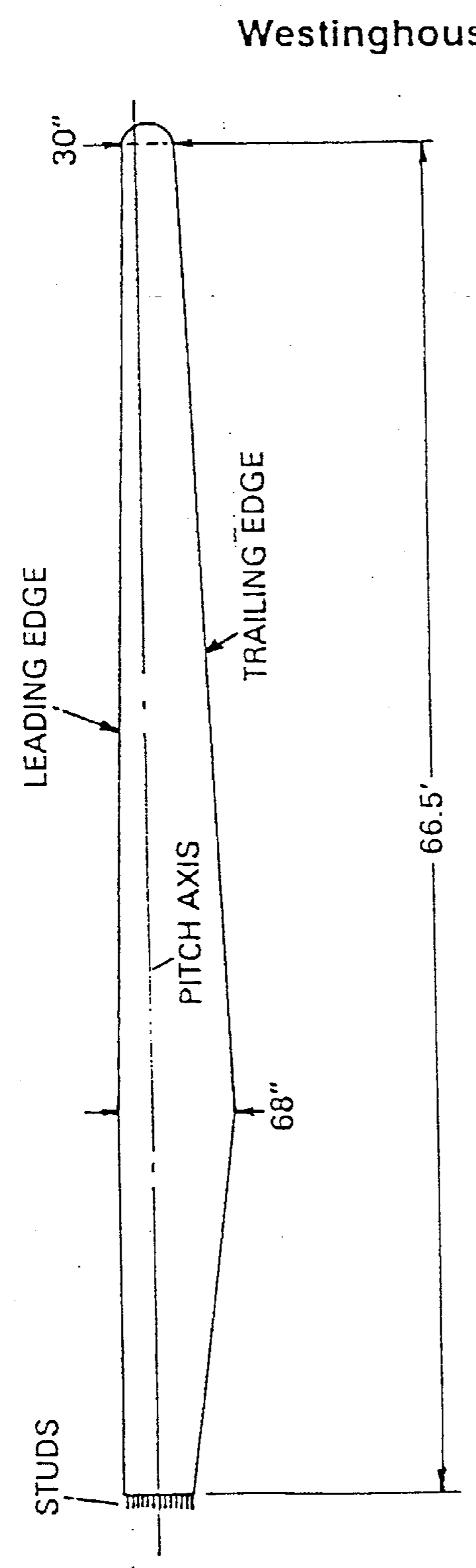




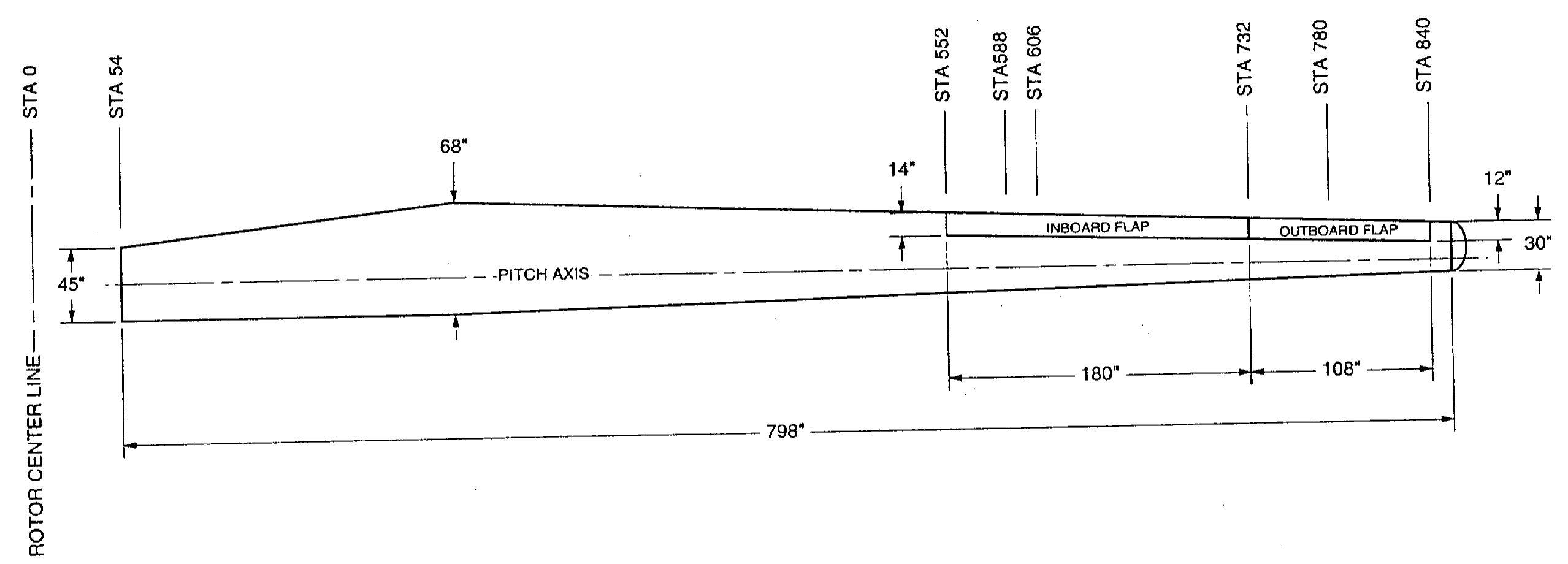

PLAN VIEW-MODIFIED WWG-0640 WIND TURBINE BLADE HAWAII ZUTECK ROTOR PROJECT

MAKANI UWILA POWER CORP.

7 DEC. 1994 


\section{Hawaii Zuteck Rotor Project \\ WWG-600 Rotor Blade \\ $11 / 18 / 93$}

\section{SECTION SHAPES OF THE OUTBOARD BLADE}

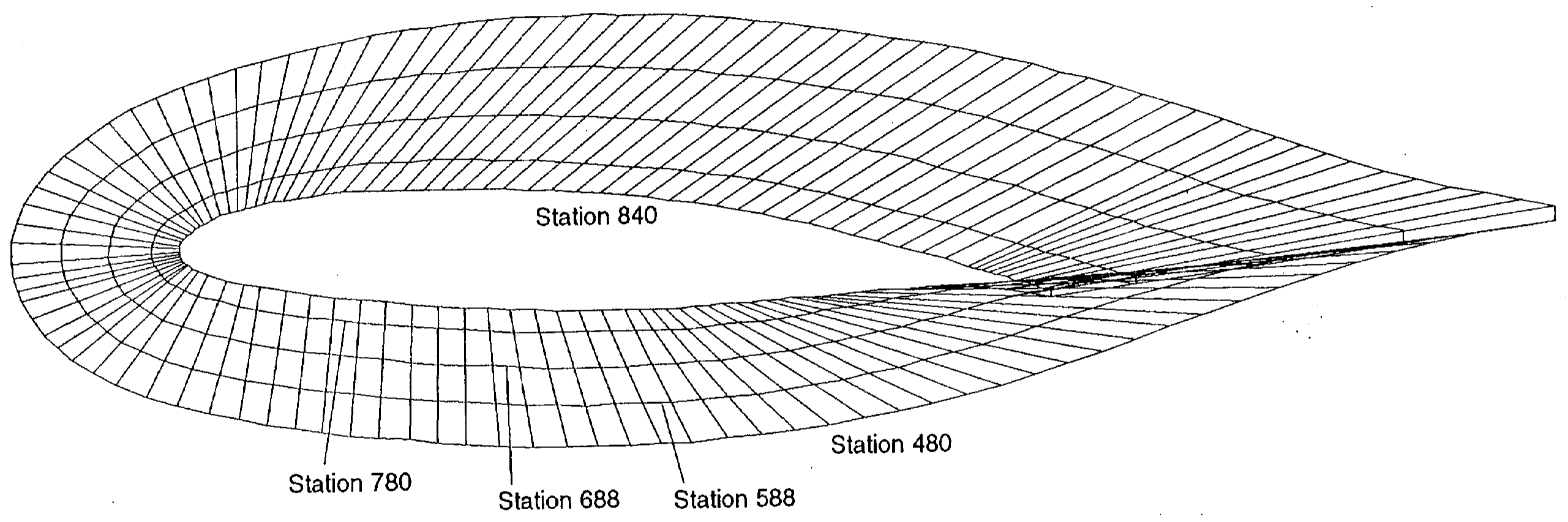




\section{Makani Uwila Power Corporation \\ Makani Uwila Power Corporation}

\section{TASK 2 REPORT}

Hawaii Zuteck Rotor Project

\section{SECTION IV}

FLAP SYSTEM 


\section{GOALS:}

In designing the flap system for the Hawaii Zuteck Rotor Project we looked toward the goals of:

- providing aerodynamic control of the machine from startup to near shutdown

- decreasing the noise produced by the flap system to a minimum

- reducing the structural loads on the blade

- keeping the actuation loads small

- producing a flap that will drive itself toward stop in the event of an actuation failure

- keeping the structure "soft" in comparison to the blade stiffness

\section{DESIGN CONCEPT \& MATERIAL SELECTION:}

The flap system for the Hawaii Zuteck Rotor was a major driver within the Hawaii Zuteck Rotor Project. As such there were many hours spent proposing, discussing, studying, testing and modifying the flap system before it was finally completed. Most of the early activity was in basic research, including a wind tunnel test and subsequent PROP runs. Most of this activity is sufficiently described in relation to the flap system in the wind tunnel test report and the preliminary design report, both of which have been previously submitted. Once the general aerodynamic parameters of the flap system were decided, we proceeded to detailed design of the structure of the flap system. During design, we started on construction of the flaps for the project. We have built six flaps, three each of the outboard and inboard flaps. Two pairs were intended for the modified blades and one pair was intended for the demonstration/test article. This last pair can also serve as a spare set for those that will be flown in Hawaii. Lastly, we have performed some limited testing on the flaps to verify their design properties and provide data for the design of other components.

The general aerodynamic parameters decided on for the flaps are listed in table IV-1 below. 
Table IV-1. Aerodynamic Parameters of the HZRP flap system.

Aft body airfoil shape: No changes from the LS-1 shape of the original blade.

Nose shape:

Quarter Cone, linearly tapering from a 3.0 inch radius at the tip end to a 6.2 inch radius at the root end of the flap system.

Flap chord: Approximately 12 inches at the tip end and 14 inches at the root end of the flap system.

Hinge location: At upper surface of the airfoil (low pressure side).

Number and size:

Two flaps per blade. Outboard flap 9 foot span. Inboard flap 15 foot span.

Note: For further details, refer to figure IV-1.

After review of the wind tunnel data and the PROP runs, we decided that the this shape, which we referred to as a "Barn Door" would give us good stopping capability as well as the desired self deployment (toward stop) capability. The effect of the nose was not an issue at small angles as all of the flap shapes performed about equally near the power position.

Design of the flap system was approached from an iterative design philosophy that allowed us to keep as many options open as possible while allowing mold construction to start while the structural design details evolved. This philosophy is described in more detail in the previous section. Design started with decisions about the method for producing the external shape of the flap. A few different methods were suggested, such as lay up on a mandrel, molding (with the mold from a "plug") and hand construction. Molding was chosen as the fastest, least expensive and most reliable method for creating the flaps.

With the method of construction decided, testing of materials and preliminary design of the flap structure was started. We tested skin materials in the Gougeon Brothers Inc. Materials Test Laboratory, including carbon, fiberglass and wood samples. We also tested off the shelf hinge materials in the same laboratory. The results of these tests were presented during our preliminary design review. 
Preliminary design of the flap started with the recognition of the basic structural facts that would have to be dealt with during design. Total weight aft of the hinge was recognized early as a critical factor to the design, especially in the outboard flap, in order to keep nose balance mass requirements and thus total weight within reasonable limits. The low span wise stiffness of the flap as compared to that of the blade supporting it was also recognized as a critical factor. By limiting the stiffness we limited the hinge loads and the coupling of blade bending into actuator loads. Use of materials that are substantially different in both properties and use from the typical blade manufactured by Gougeon Brothers was also recognized, leading to a desire to have a small, dedicated crew building the flaps.

Determination of the basic loads for the flaps structure was the next task undertaken. These loads were sufficiently small that the design of the structure was deemed to be more of a mass and stiffness design than a strength design. As thoughts and ideas for the structure began to take shape, discussion of the methods of construction were carried out with the shop. There were many times that the flap structural detailing was changed due to shop construction methods. There were also many new methods of construction designed to accommodate the needed structural details. Some of the details of these shop construction considerations will be discussed in the next subsection. Details of the flap materials and construction are shown in figure IV-1 and figure IV-2.

Testing of the flaps consisted of bending the flap and pulling on it to document the torque/flap-bend coupling of the flap structure. A symmetrical, 1 " maximum depth arc was cut into the thin edge of a 2 " $x$ $8^{\prime \prime} \times 15^{\prime}$ piece of lumber. A flap hinge was then installed on one of the $15^{\prime}$ inboard flaps and attached to this arc. The flap was moved through $90^{\circ}$ of motion with the flap chord perpendicular to the long axis of the wood (flap bent flat wise) being $0^{\circ}$ and parallel the long axis of the wood (flap bent edge wise) being $90^{\circ}$. The force required to maintain various intermediate angles was measured at the trailing edge. Data was also taken with no arc (hinge dead straight). A summary of the data is shown in table IV-2 below: 
Table IV-2. Flap forces to Hold a Specific Position, Straight and Arched. (Force measured at the trailing edge of the flap.)

Flap Position

$0^{\circ}$

$15^{\circ}$

$30^{\circ}$

$45^{\circ}$

$60^{\circ}$

$75^{\circ}$

$90^{\circ}$

Peak Load
Arched

0.0

6.2

13.7

19.7

26.3

23.0

19.1

31.0
Straight

0.0

3.5

5.5

6.0

7.0

6.0

5.5

This testing shows that the forces needed to move the bent flap are not large in comparison with the actuator capability. The flap is extremely "soft" in the span wise direction and therefore bend/torque coupling will have only a small impact on actuator loads, as was intended in the design.

\section{CONSTRUCTION CONSIDERATIONS}

Consideration was given to many different aspects of the flap design due to construction constraints. These include:

- Distribution of the power direction attachment forces. These forces are the result of the lines that pull the flap into the operating position. Each line introduces a concentrated load that must be distributed to the flap structure without unduly increasing the local stiffness of the flap. If the last were not a requirement, we would have installed ribs at the attachment points, which were considered a possible necessity at one point in this design. Instead, we have replaced the foam core in the region of the attachment points with balsa core in the general area, a balsa doubler over the previous where the attachment occurs as well as two layers of glass for added strength. This effectively distributes the loads from actuation into the flap skins with out a heavy and stiff rib.

- Molding the closure of the trailing edge of the flap. This little detail proved to be a very difficult problem to solve elegantly. The main constraints were that the joint had to be as strong and as light as possible, as it was the closure of the aft structure/torque tube 
and it was farthest from the hinge, where weight would do the most harm. After days of discussion and proposals for closure methods, the solution was indeed elegant. The internal carbons skins penetrate the aft bond line, transferring their loads into a glass tape which forms the bond between the two halves. The advantage of this is that the joint generates the most strength where it is most needed without the use of heavy materials or fussy dimensional tolerances across a 24 foot piece.

- Installation of the flap shear web and sequential low pressure side close-out. Due to the very low bending stiffness of the low pressure panel, the shear web was first bonded into the high pressure flap shell while the latter was still in its mold. This was to keep the high pressure side rigid during installation. The low pressure aft panel was then supported at intervals with mold spanning ribs that held its position, so that both it and the flat ply upper nose pieces could be bonded in place. The result was a beautifully controlled final shape, with very little excess bonding material.

- Installation of the DB carbon reinforcements for the stop line attachments. This took a lot of thinking on the part of the shop crew. They finally devised a long stringed hammock that was passed through the nose of the nearly completed flap, which was then lowered and carefully pressed into place. It was then rolled down and allowed to cure, thus reinforcing these critical regions of the nose. 


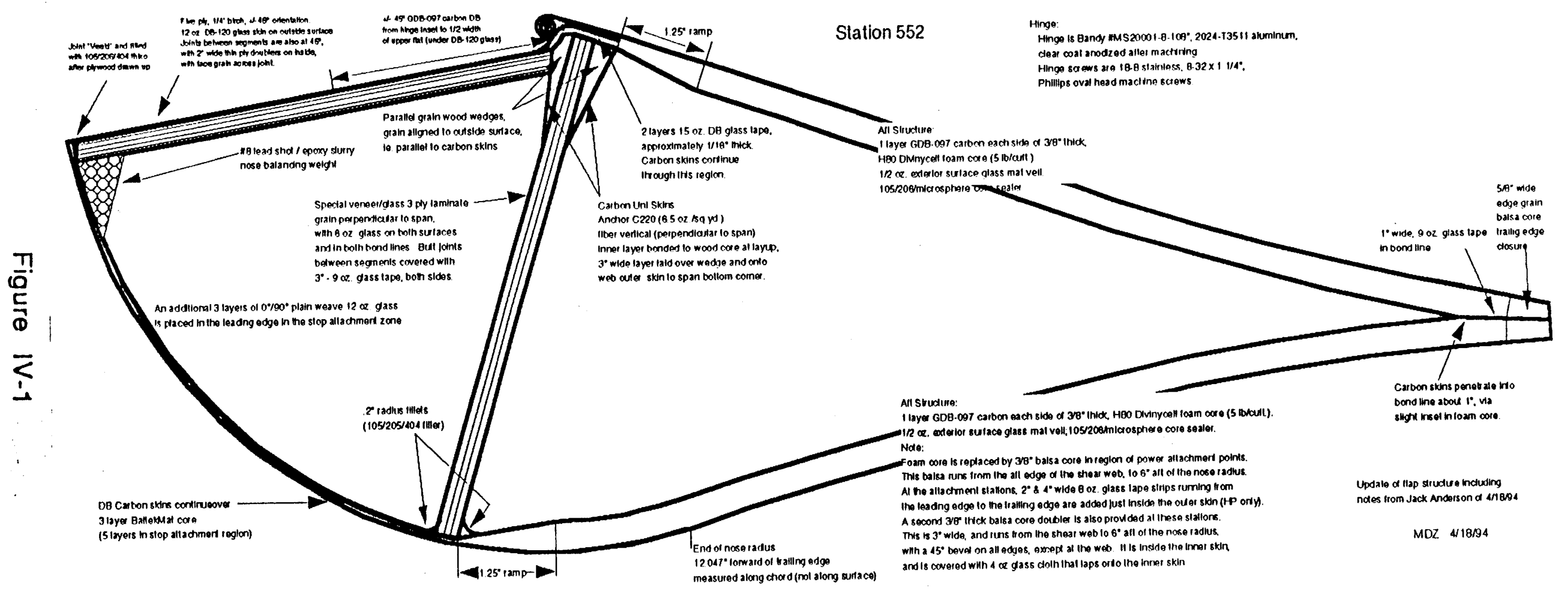




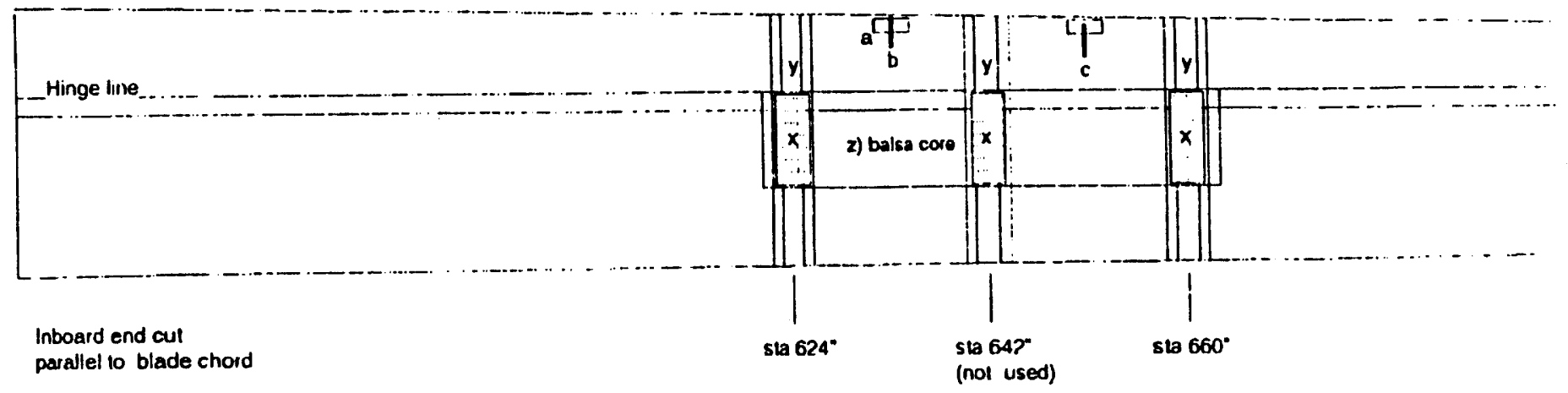

Innter Flap Acluation Pull Poinls

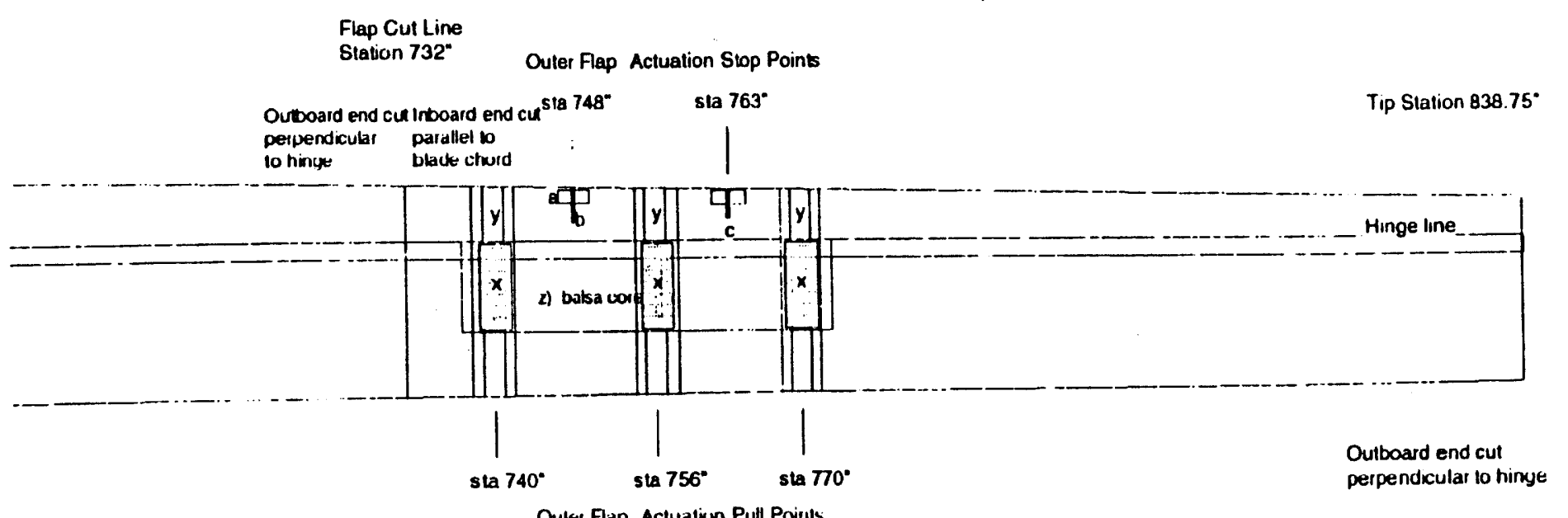

Stop Attachment Point Notes:

a) To reinforce where the stop lines will go around small slots in the nose, a $3^{\circ}$ by $3^{\circ}$ patch of DB carbon is put into the interior at the stop points.

lapping $1^{\circ}$ onto the nose ply, $1^{*}$ acrocs the balancing weight, and $1^{*}$ onto the nose radius.

b A reinforcing strip is created at the stop attachment groove.

Carbon uni is laid into the groove, tapering to end haltway across flat and down radius.

The groove is linished with a small patch of DB carbon. Final details TBD.

c A small groove. $1 / 2^{\circ}$ wide and $.1^{\circ}$ deep is routed into upper flal ply to provide clearance for the stop line end titting. Final dimensions and detaits (BI).
Pull Point Attachment Notes:

2) Foam core is replaced by $3^{\prime} 8^{\circ}$ balsa core in region of power attachment points. This balsa runs trom the aft edge of the shear web, to $6^{\circ}$ att of the nose radius.

y) At the attachment stations, $2^{\circ} \& 1^{\circ}$ wide 9 oz glass tape strips running from the leading edge to the trailing edge are added just inside the outer skin (HP only). x) A second $3 / 8^{\circ}$ thick balsa core doubler is also provided at these stations. This is $3^{*}$ wide, and runs from the shear web in $6^{\circ}$ ath of the nose radius, with a $45^{\circ}$ bevel on all edges, except at the web. It is inside the inner skin. and is covered with 4 oz glass cloth that laps onto the inner skin.

Flap End Rib Notes:

These are composed of DB carbon over $3 / 8^{\circ}$ foam core, just like the att panels. The inner cap skin and core are routed away to tit withing the flap end, and the tap shear 
Station 552"

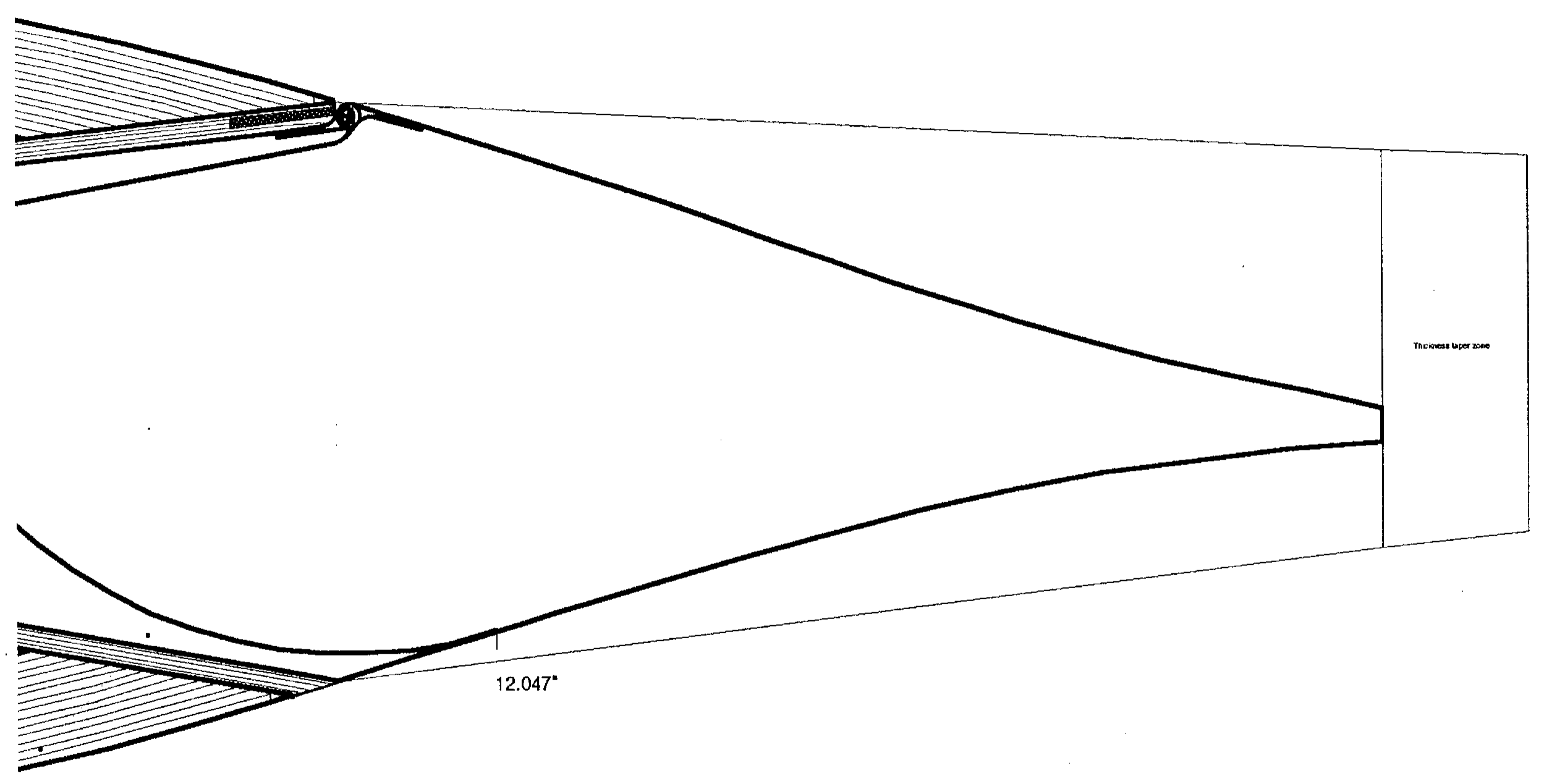

MDZ 2/22/94

$1 / 2$ scale 


\section{TASK 2 REPORT}

Hawaii Zuteck Rotor Project

\section{SECTION V}

\section{AFT BLADE STRUCTURE}




\section{GOALS:}

In designing the aft blade structure for the Hawaii Zuteck Rotor Project we had the following goals:

- Ease of installation and maintenance.

- Structurally integrity, particularly in regard to closing the open aft end of the airfoil.

- Validation of the barn door design, especially in regard to sealing of gaps for superior aerodynamics and noise reduction.

- Good load transfer characteristics from the flap to the airfoil.

- Good load shedding at the inboard cut point of the flaps.

- Minimization of field work through shop fabrication, integration and testing.

\section{DESIGN CONCEPT \& MATERIAL SELECTION:}

The aft blade structure for the Hawaii Zuteck Rotor has been the part of the project that has absorbed the most effort, both in design and execution. There were two major structural alternatives explored in the design of the aft blade structure. The first alternative was denoted the "C" structure, to reflect its shape. The second alternative was a shopretrofit, multi-piece system.

The " $C$ " structure was initially conceived as a way to reduce the amount of field work required to modify the blades in Hawaii. Basically the " $C$ " structure concept was a fiberglass and carbon structure that integrated all of the pieces needed to install flaps onto a Westinghouse blade, into a single, shippable unit. The plan being that the crew in the field would only have to perform a few saw cuts to remove the aft structure of the blade and epoxy the " $\mathrm{C}$ " into the resulting cavity. The structural reinforcement, the actuation hard points, the hinges and the flaps would all be installed with this bonding operation. As the program progressed it became clear that the " $C$ " structure would be very difficult to reliably install in the field and would require significant fabrication tooling before the design was field proven. These realizations led to a careful reassessment of the 
requirements and benefits of the "C". These two factors combined to replace the "C" with another structure that was easier to build than the "C", structurally superior and also avoided tooling costs for molds that would have to be frozen in design rather early in the overall design effort. This was the multi-piece system, which is shown in cross-section in

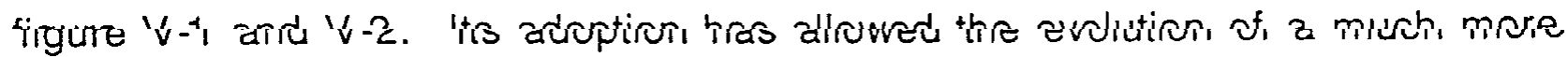
sophisticated and longer lived actuation system than originally proposed as discussed elsewhere in this report.

The multi-piece system was designed and built into the blades being used for the bolt-on rotor test. (For the following discussion, please refer to figures $V-1, V-2$ and $V-3$.) This system consisted of sawing away the trailing edge of the blade in the flap region with highly acute angled cuts (referenced to the outer blade surface). Fitted to these cuts are two planes of material making up the high pressure and low pressure braces. These braces are designed to heal the cuts in the skin of the blade, carry the cross-grain loads out of the blade structure and act as mounting surfaces for the hinge (low pressure brace) and the actuation blocks (high pressure brace). The low pressure brace terminates on the interior of the blade at the existing shear web throughout the flap region. The high pressure brace also terminates at the existing shear web in the outboard flap region of the structure, but terminates at the aft web over the span of the inboard flap. This was done partly to save work, as the brace can effectively dump loads into the aft web and connecting ribs in this area, and partly to allow more space for the line guide tubes that run forward of the aft web. This entire structure is supported every 14 to 18 inches, depending on span wise station, by ribs between the shear web and aft web. There are also tabs of these ribs that extend between the braces and the blade shell. The ribs support the other structural pieces, especially the aft web, as well as supporting the blade shells. The tubing that guides the lines for controlling the flaps are also supported by the ribs. Since there was no easy way to readily add cross grain reinforcing to the low pressure blade shell to carry the hinge loads, these ribs provide the most readily fabricated way to distribute those loads into the blade structure.

Some of the ribs, those that are at the end of flaps, are extended to serve as air dams between the flaps. These were added to the project to allow for differential flap deployment (up to $30^{\circ}$ from full power) without the high pressure side of one flap bleeding air to the low pressure side of the other. This will reduce noise and increase the effectiveness of the flaps 
by limiting the span wise migration of the airflows as well. The inboard air dam is further integrated into the blade structure via na external carbon "belly bond" that reacts substantial cross grain loads which arise from the open cavity needed for link access. Reinforcement of this cavity is outlined in figure $\mathrm{V}-4$.

The major purpose of all of this structure is to heal the load carrying capability of the blade after the aft structure has been removed. Other loads carried by this structure are the aerodynamic and actuation loads of the flaps. Most of the structures in the aft blade structure are made from laminated wood panels sandwiched between layers of either fiberglass and resin or carbon and resin. The major exceptions to this, for strength and space reasons, are the areas of the high pressure brace near the flap actuation points. These were made from FRP, which allowed for a thinner piece of material with better strength and load shedding capabilities from the attached blocks, while providing more room for large, long life blocks and line. Another area where FRP was used is in the exposed end of the low pressure brace, where the flap hinge attaches. This was done to give the bolts and screws holding the flap hinge to this structure a reinforced retention plate (as discussed in the next section), rather than taking the chance of shearing the wood laminate. The FRP was installed by routing a groove down the middle of the edge of the wood brace and bonding the FRP into the slot. An added benefit to this method is that the hinge line can be made very straight by bonding the FRP after the brace is installed.

\section{CONSTRUCTION CONSIDERATIONS:}

During construction of the aft blade structure, there were many design decisions that were influenced by construction considerations. Examples of these are:

A major concession that was made to space requirements and construction details was that the outboard low pressure brace panel effectively acts as a cantilever in supporting the flap loads, since it was not designed for to support flaps. The low pressure shell is basically too weak to support much of these loads, and adding chord wise reinforcement would require too much labor. In contrast, the inboard brace forms a triangle section with the shear web, aft ribs and the thicker inboard blade shell to support the flap loads. This would have been preferable in the outer blade as well, 
but was not possible without major construction and space sacrifices. Chief among these sacrifices would be a much reduced angular range where the flap would seal on the high pressure side. Since that was unacceptable, a very stiff and strong low pressure brace, that was easy to fabricate externally was chosen.

Differences between the as-build blades and the drawings of the original blades. These differences manifested themselves in everything from large globs of glue around the shear web supports to offsets in the position of the shear web to changes due to creep in the blade from the field. Three dimensional Computer Aided Design capability was used to generate aft rib patterns customized to the interior geometry of each blade to reduce hand fitting work and assure higher dimensional accuracy, in spite of these variations.

One unplanned difference that took some work to correct was that the blades sent to the shop from the field were the last of the old, thinner shell, design rather than the first of the new, augmented shell, design. These blades did not match the late model blade already largely modified for the project at the Gougeon Brothers shop. We added carbon pultrusions to the inside of the blade to increase the span wise stiffness and added weight to the nose to better match the flat wise stiffness, weight and CG between the old and new blades. 
Station 780
LP Shell Inner Skin Reinforcement:

G300 E-glass uni (8.8 oz./sqyd. Q.011" thick) one tull width layer - shear web onto sawn face one half width layer - midshell onto sawn face.

$$
\text { one half width layer }
$$

Standard high strength thixo fillets.

Cover with GDB.097 graphite fabric.

Lap $1^{\circ}(\mathrm{mm})$ onto blarte shall

and up faces of shear tab.

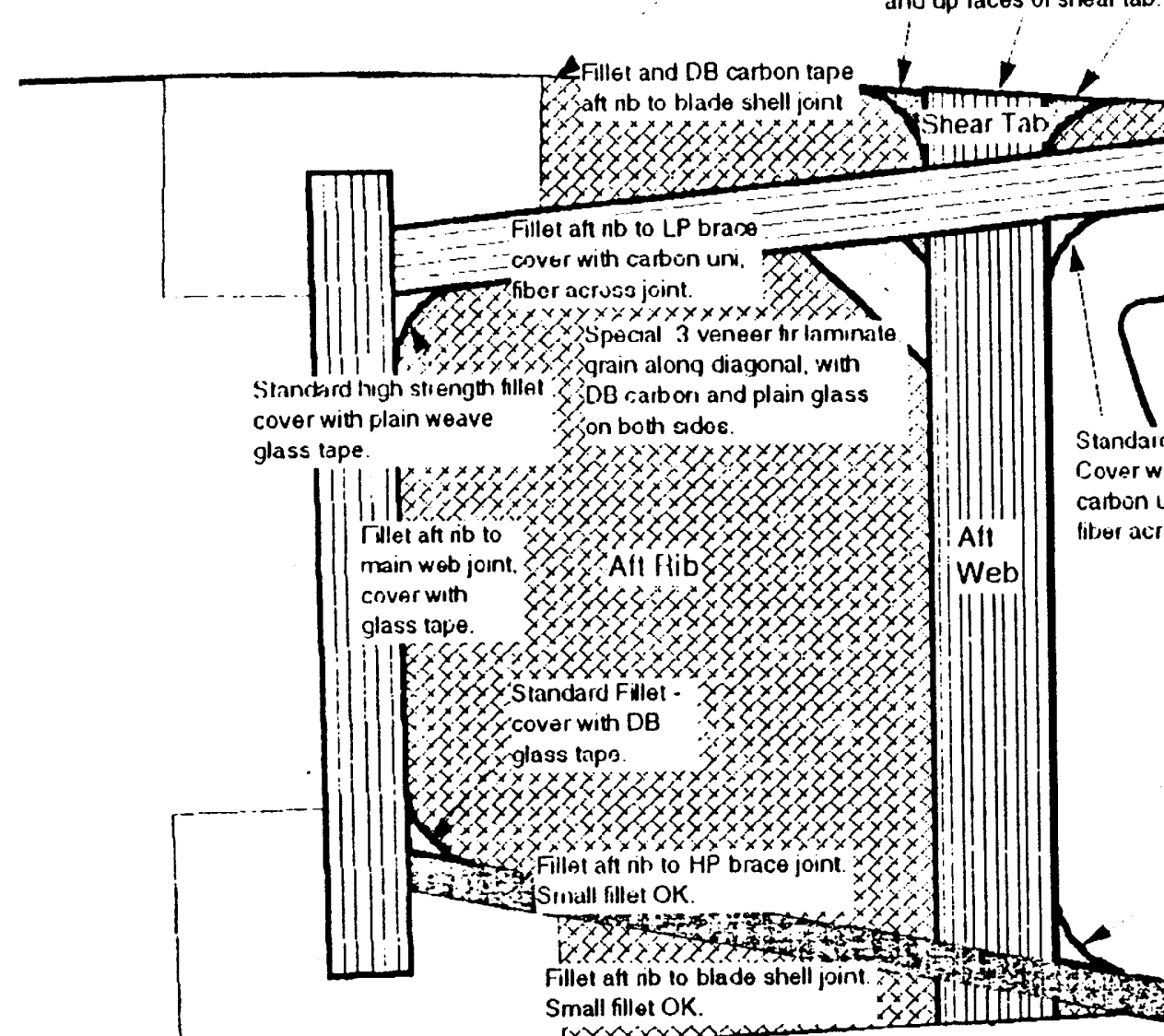
(x)

GDB-097 double bias cartion stip from mid cavity

to sawn surface, covering half of HP shell interior. and passing under bottom of lower shear tab. This carbon can end where shear tab plays out.

Cover with DB' glass tape

(except at she ave stations)
This reinforcement detailing applies to the outboard llap region,

where the HP brace continues

forward to the main shear web.

ie. from slation $724^{\prime \prime}$ in the tip.

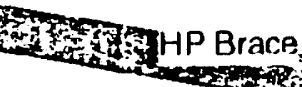

Hinge brace is composed of $1 / 4^{*}$ birch ply with face grain cherdwise. covered on both sides with chordwise $C^{2} 2^{2}$ ') uni grapinte labric

FRP spline is 1/8" Ganulite G 10,FH4 ylassiopuxy mialerial. scall juined.

Aft web and shear tabs are composed of $1 / 2^{*}$ birch ply, face grain vertcal. covered on both sides with GDB-09/ Jouble blas graphite tabnc Adelional reinforcing at access holes near thieaves may be specified

Aft ribs are composed of $1 / 4^{*}$ birch ply with faco grain chordwis. covered on buth sides mith DB.120 duible bias glass labnc HP brace is composed of $1 / 4^{\circ}$ tircl ply with face grain chorawise. covered with plain glass bath sides, except in flap actuation reguon (station $723^{\circ}$ to sta bon $771^{\circ}$ ). Where it is replaced by $1 / 8^{\circ}$ thick Garnlite G-10/RF4 glass/epmxy FRP. scartecl and glassad in the turch at each end. Lecal DB carbon reinforcement at the sheave locavons mar also be ajded.

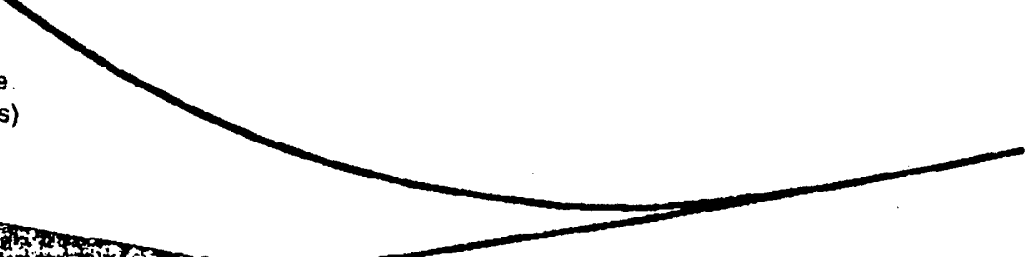
at stavon $724^{\circ}$, it is acceptable to use plain wenve all the way to tie tip

MDZ 4/27/94

full scale 


\section{Aft Web Exit Slot and Access Hole Layout}
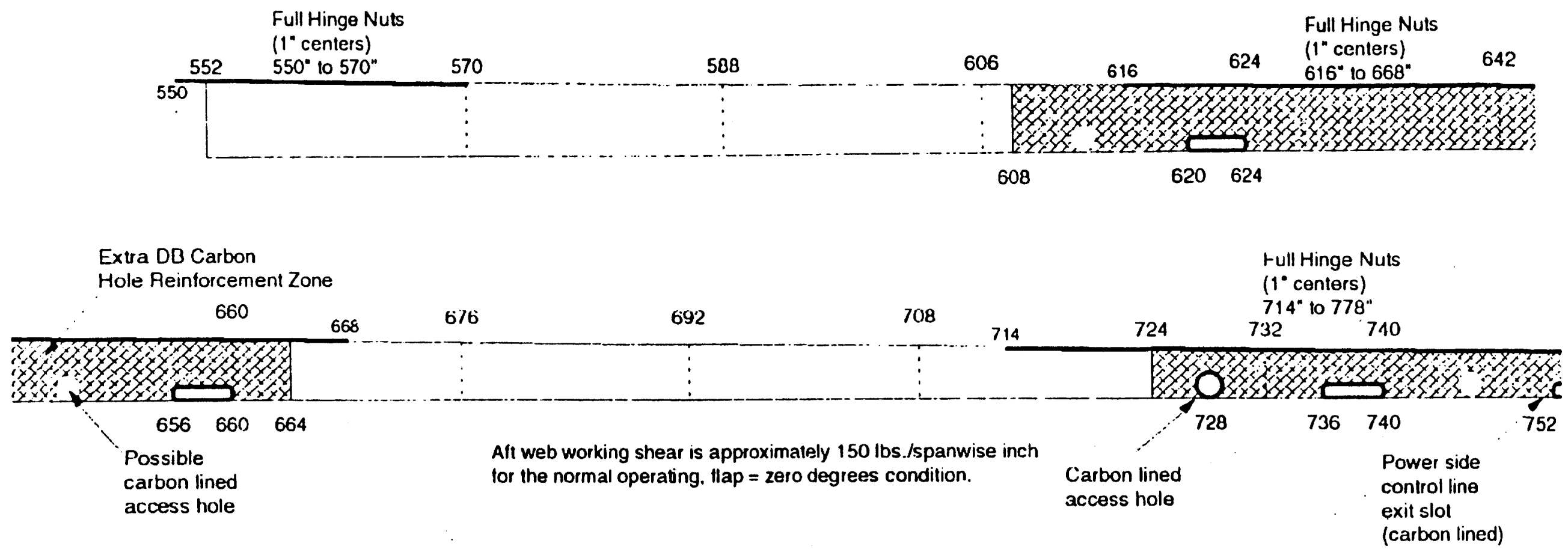

\begin{tabular}{|c|c|c|c|c|c|c|c|}
\hline \multirow[b]{2}{*}{756} & $\begin{array}{l}\text { Extra DB Carbon } \\
\text { Hole Reintorcement Zone }\end{array}$ & \multicolumn{2}{|c|}{ all rib locations } & \multicolumn{3}{|c|}{$\begin{array}{l}\text { Full Hinge Nuls } \\
828^{\prime \prime} \text { to } 840^{\circ}\end{array}$} & \multirow[t]{2}{*}{$\stackrel{?}{>}$} \\
\hline & $\begin{array}{l}770 \\
100 \times 10\end{array}$ & 781 & 798 & 812 & $\begin{array}{r}826 \\
\quad 828 \\
\end{array}$ & $\begin{array}{r}839 \\
840 \\
\end{array}$ & \\
\hline & 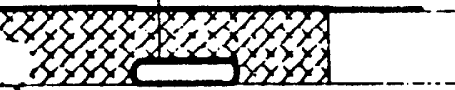 & $\vdots$ & $\vdots$ & : & & & 选 \\
\hline
\end{tabular}

Possible

carbon lined access hole

\section{Aft Web Exit Slot and Access Hole Layout}

The lower layoul shows the aft web exit slots for the power side control lines, as well as the possible access and inspection holes. The aft rib stations and local hole reinforcements arc also shown. A circular viewing and access hole is shown at station 728 to assure that the lines can be passed through the station 732 aft rib properly.

bult these would be added later it needed. once the position of the return side rigging is finalized, and their best positions are decided. 
1) The first reinforcement into the cavity is G-300 glass uni. The fiber is oriented chordwise, and extends from the main web, up onto the angle sawn cavity opening, to the aft shell edge. The spanwise extent of the glass uni is from station 552, to the veneer step at about $515^{\prime \prime}$.

2) The next reinforcement into the cavity is a double layer of 6" wide Fortafil FAW-150 carbon uni. This extends diagonally from the station 552" rib to the trailing edge joint. The aft edge of the uni aligns with the slanted inboard portion of the cavity aft edge. This puts the forward edge of the uni into the corner formed by the station 552" aft rib, and the main shear web.

3) The next reinforcement into the cavity is a double layer of CBX 1000 DB carbon. This is similar to the GDB-095 used for the flap construction, but was obtained from a different source due to lead time requirements. One layer of this reinforcement goes from the station $552^{\prime \prime}$ ib about 36" inboard, and extends about $3^{\prime \prime}$ up onto the cavity sides, while the other layer extends about $30^{\prime \prime}$ inboard from station $552 "$, and laps about $2^{\prime \prime}$ up onto the cavity sides.

4) Once the braces have been completed into the cavity region, a double layer of the $3^{\text {" wide }}$ Fortafil FAW-150 is to be run along the face of the braces, diagonally up into the trailing edge joint. The forward edge of this carbon is to run near the diagonal edge of the brace, to the corner where the aft web ends. The aft edge will touch the cavity edge in its curved region. The outboard end of the carbon will end in a long diagonal cut along the brace to aft web joint, and the inboard end will end in a long diagonal cut at the trailing edge joint. One of these two new layers will be stopped about an inch shorter to stagger the ends.

5) Once the aft web has been completed up to the cavity region, a double layer of CBX-1000 DB carbon is to run from the face of the aft web, down the face of the station $552^{\prime \prime}$ aft rib, and out onto the main web. One of these layers is to lap about $12^{\prime \prime}$ onto both the main and aft webs, while the other is to lap about $8^{\prime \prime}$ onto each.

6) After all of the above reinforcement is in, a 3/8" radius fillet (standard stir stick) will be made at the joint between the layers of carbon uni where they meet at the trailing edge joint. This will be overlaid with a double layer strip of $C B X-1000$ carbon DB, that will cover the fillet, and lap onto the carbon uni for a minimum of $3^{\prime \prime}$, with one layer lapping an inch further than the other to stagger the layer endings.

7) The aft facing sawn edge of the cavity is to be covered with a single layer of plain weave glass cloth or tape, just to bind the open end grain. 
Makani Uwila Power Corporation

\section{TASK 2 REPORT}

Hawaii Zuteck Rotor Project

\section{APPENDIX V-I}

\section{SUPPLEMENTAL DETAIL DRAWINGS BLADE STRUCTURE}


Blade 35 Internal Spanwise Carbon Reinforcing Details

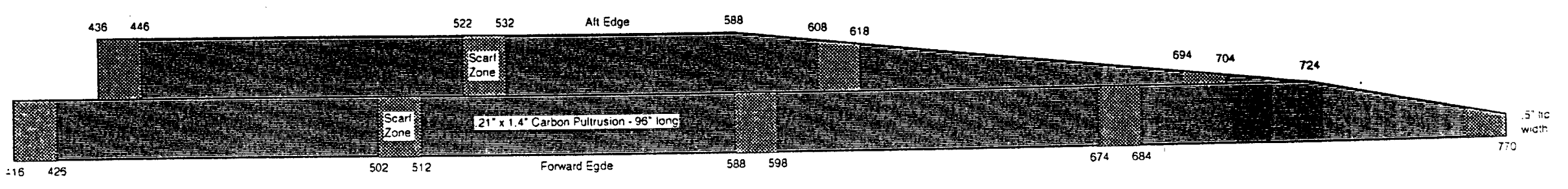

Blase Shell Side

Construction Notes

1) Carbon pultrusion is $.21^{\circ} \times 1.4^{*}$ unidirectional malerial obbained trom Spectra Corp. in $96^{\circ}$ sections.

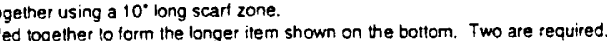

4) The shorer item shown toward the lop is $1 / 2$ of a 5 section scarf poined length. Since this lotal length

may be inconvenient to handle and cut. the center three sections can be scarled together first

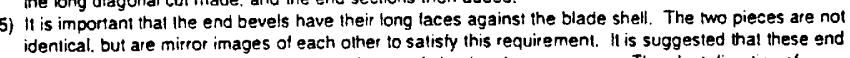

bevels be cul aner joining 10 reduce any chance of slanting the wrong way. The slanl direction of

6) Atter each ilem is scarled to lengith and surlace orep d. they are 10 be edge bonded together, and

MOZ 5/16/94 
Representative As-Built Illustration:

Air Dams at Station 840, 732, and 552

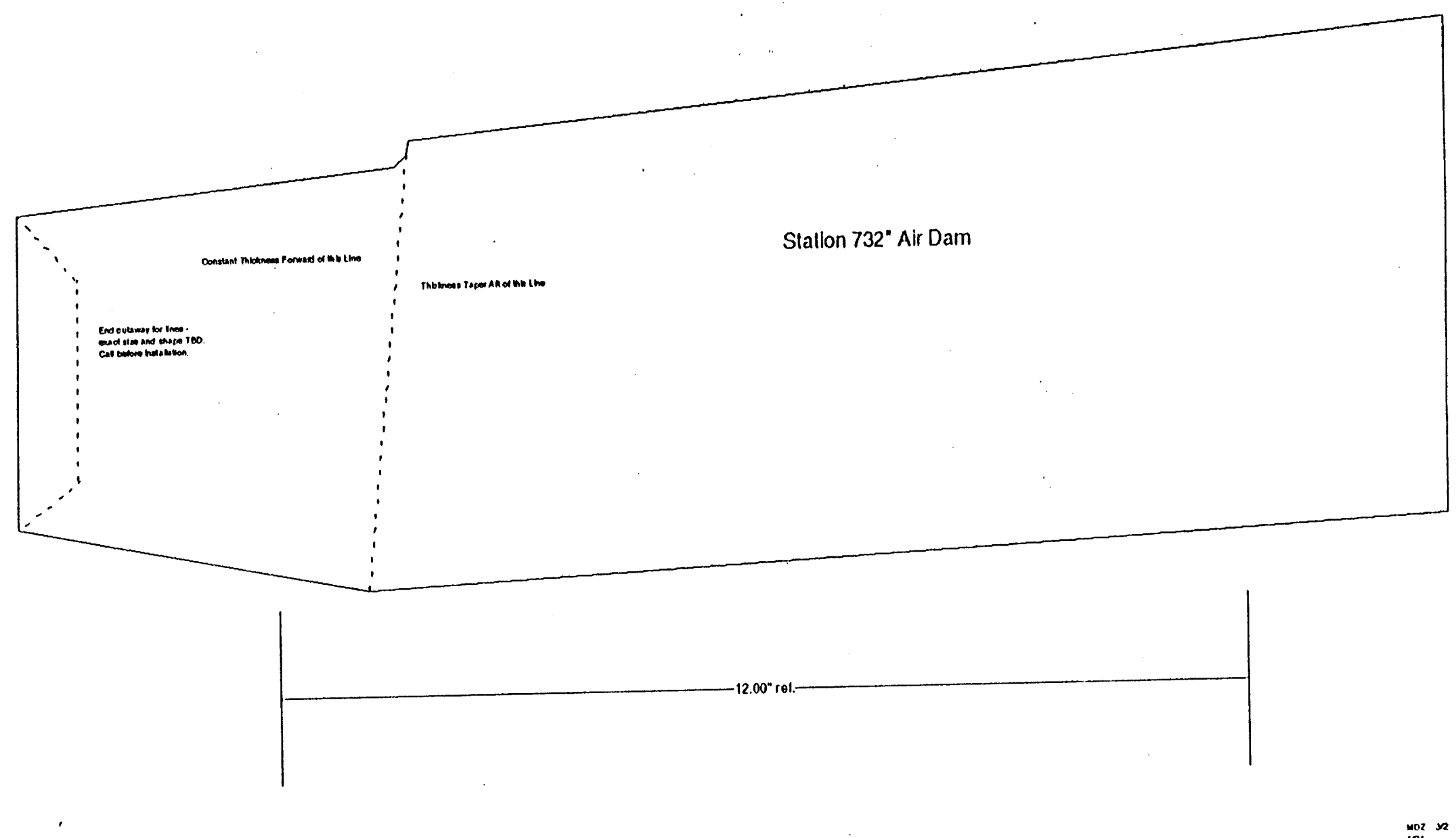


Station 780 Aft Rib Pattern

Comparing As-Built Blade

Structure to Design Parameters

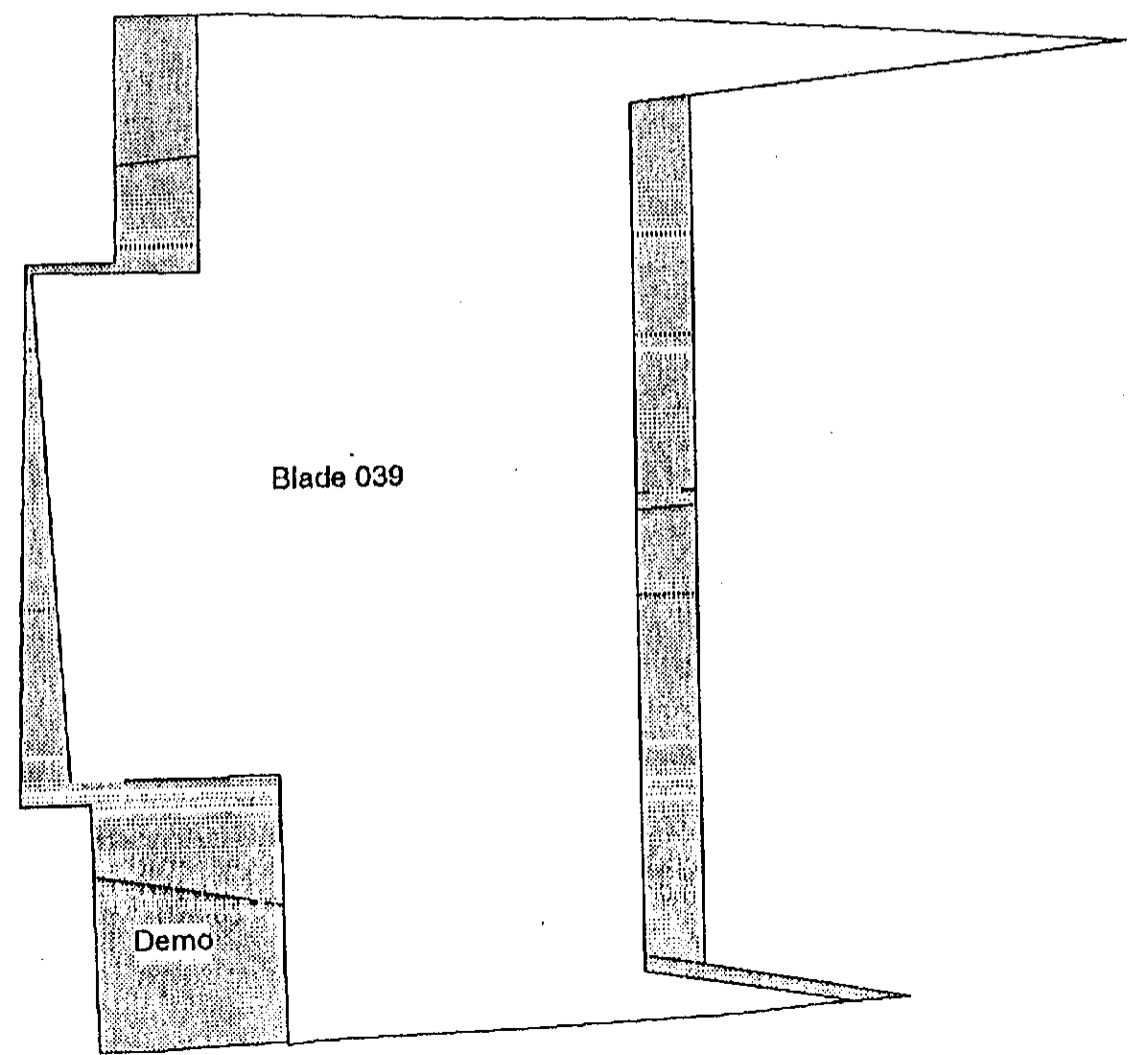




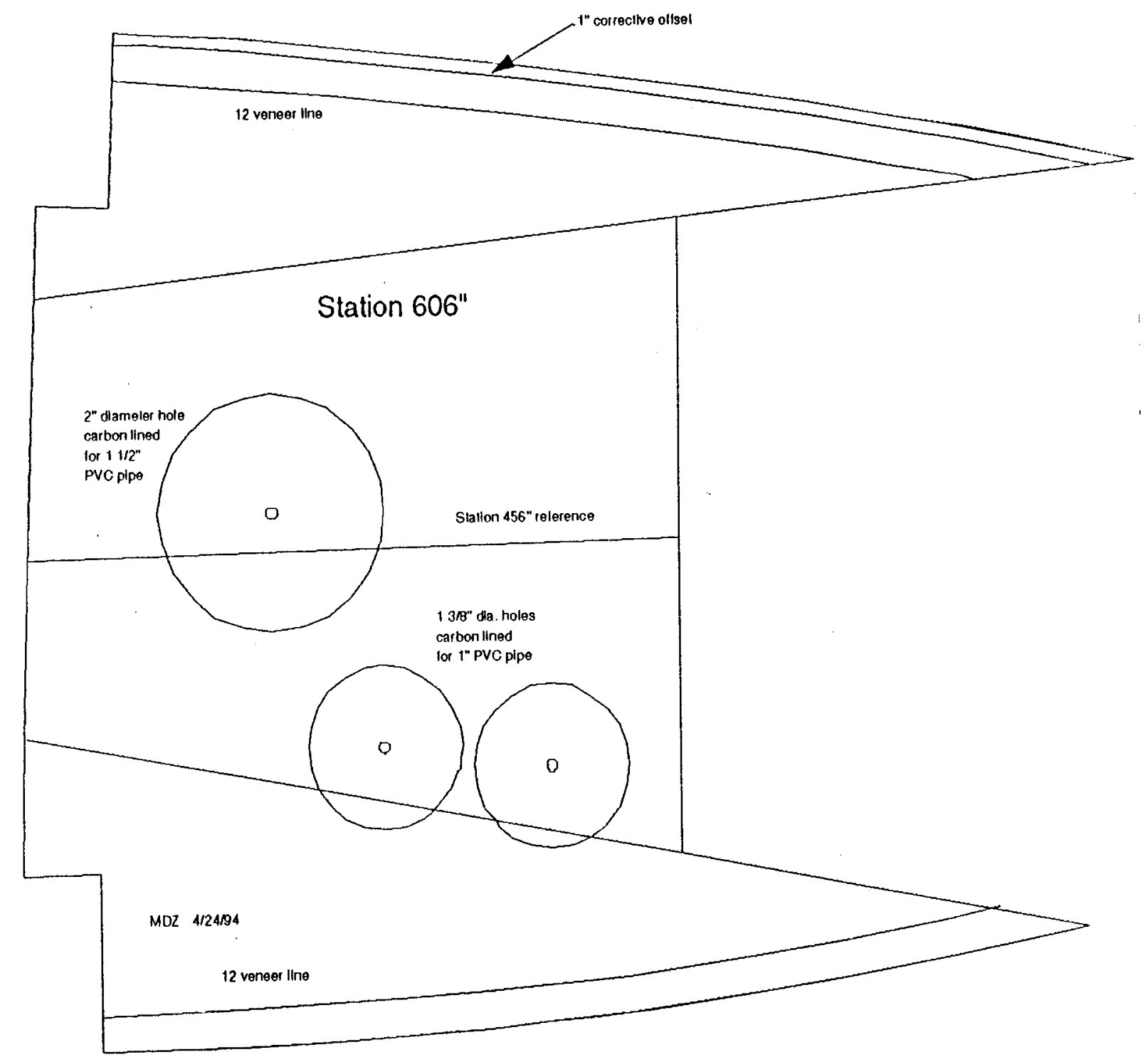




\section{Makani Uwila Power Corporation}

\section{TASK 2 REPORT}

Hawaii Zuteck Rotor Project

\section{SECTION VI}

\section{ATTACHMENT HARDWARE}


In designing the attachment hardware for the Hawaii Zuteck Rotor Project we looked to achieve the following:

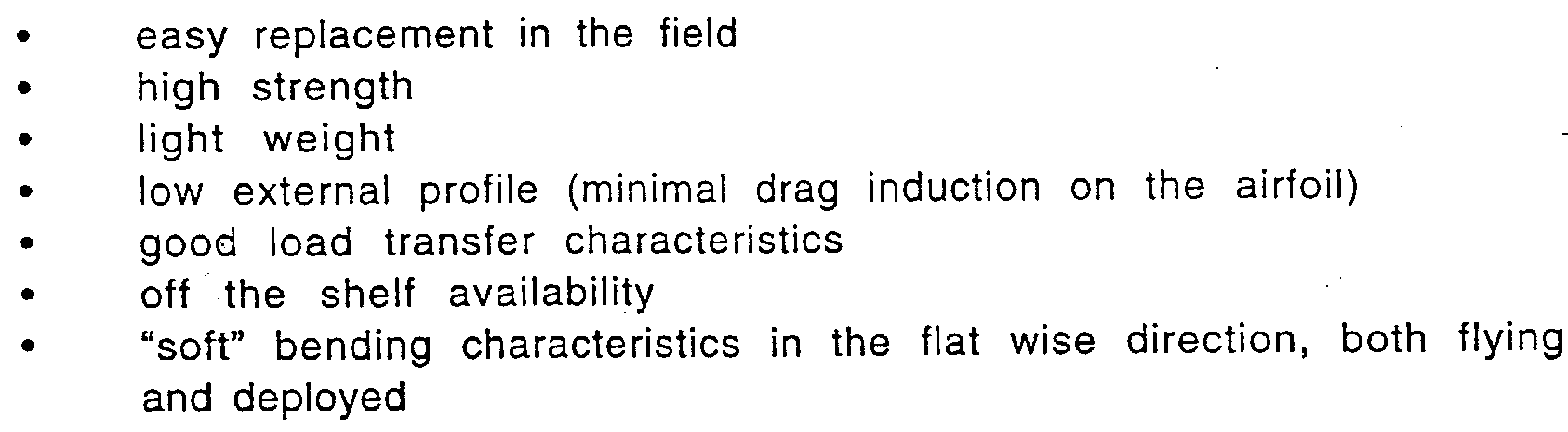

\section{HINGE \& FASTENER SELECTION}

The attachment hardware for the Hawaii Zuteck Rotor Project consists mainly of the hinge and fasteners to hold the hinge in place. Other fasteners used in the system are standard engineering specified hardware which will not be described in great detail as part of this write up.

During the initial design of the flap system, we looked at different types of flaps, each of which lent itself to a specific type of hinge arrangement. The "barn door" variant of the flap was chosen as the candidate for our flap system. This variant lends itself well to the use of a continuous or "piano" type hinge, although consideration was also given to discrete point, distributed "door" hinges and even a flexible fabric reinforced rubber strip hinge for the project. The first two types of hinges were rejected as we wanted to force the flap to conform more closely to the shape of the flat wise bent blade, which reduces the need for large tolerances in the flap to blade interface area as well as reducing the airfoil shape distortion, which would increase noise. The discrete and distributed hinges also allowed more air to escape through the slot between the low pressure surface of the blade and the nose of the flap, reducing the effectiveness of the "barn door" flap, especially in stopping conditions. Sealing this gap would have been harder with either of these systems. While the flexible strip hinge held some promise, the $90^{\circ}$ deflection requirement, large centrifugal and actuation forces, and soft position control were clearly going to introduce research requirements we 
did not wish to address. Thus the "piano" hinge was baselined for this project.

We are sealing the gap between the blade and flap on the high pressure side with a sealing strip on the aft edge of the blade shell. The high pressure will tend to press the seal home, reducing the ability of air to escape through this opening, thus reducing power loss and noise. We also have the option of sealing the hinge itself with a rubberized tape, though this is not planned.

We selected hinges based on the goals shown above, selecting two main candidates. Each hinge was mil. spec., although they differed quite a bit from one another. One contender was a stainless steel "piano" type hinge with the hinge pin retention formed by rolling alternating tabs around the pin. This configuration had the advantage of being stainless steel, but did poorly in our load testing (as shown in our preliminary design document) because of the rolled pin retention. The hinge we selected was extruded aluminum with a drilled hinge pin retention. This proved to be about three times stronger than the rolled retention. We also reversed one leaf of the hinge to expose less of it to the flow fields on the blade and to make the retention easier to design. We have had the hinges anodized to resist corrosion damage to the hinge.

The fasteners used to secure the hinge were also the subject of testing, this time to see which head style and length would be reasonable to remove from a simulated flap web. This was done to allow field replacement of the flap hinge if it were ever damaged or worn. Candidate screws were prepared and bonded into samples of flap web material. Each screw was allowed to cure for four days at 105 degrees $F$ and then removed from the rib material. All screws came out except a 1.5" nonlubricated screw. Testing showed that the best head configuration was a Phillips oval head, which had the least damage to the flutes as the oval head gave more gripping area to the driver. Our choice of lubricant was Pam, the spray cooking oil. It slightly outperformed AMS/Oil. Pam was also easier to apply. It should be pointed out that there is no perceived danger of the screws backing out in use. They are still quite difficult to remove. Similar "anti-seize" treatments have been used successfully for years with similar bonded fasteners in marine applications, without problems. 
As seen in the aft structure drawings (figures $V \mid-1$ and $V \mid-2$ ), a FRP spline was inset into the hinge brace to provide greatly increased strength for the hinge to blade attachment, whose screws must be quite short due to geometry constraints. In high stress regions at the ends of the flap segments and in the actuation load introduction regions, the fastener pullout strength is further increased by the use of buried nuts behind the FRP. (See figure V1-3) While at one time the limited size for fasteners on this side of the hinge was seen as a potential weakness int he design, and was the subject of much debate and several detailing concepts, the final design is. far stronger than the anticipated loads, and is believed to be fully "bullet proof" against long term fatigue. Yet the design allow for hinge removal and replacement if needed.

\section{CONSTRUCTION CONSIDERATIONS:}

The retention of the hinge and therefore the flap is of utmost importance to the project. We have taken great care to assure that the hinge will serve its purpose. Special consideration was given to the choice of hinge and the molding of that hinge shape into the flap. We purchased blank pieces of hinge from the manufacturer that allowed us to precisely mold the shape of the hinge into the flap, reducing the drag caused by this hinges exposure to the flow field. We also counter sunk the attachment holes in the exposed surface of the hinge and purchased new hinge pin stock to insure that the pin was in two pieces for ease of removal in the field. All of these steps will allow the hinge to work properly and be easily maintained in the field. 


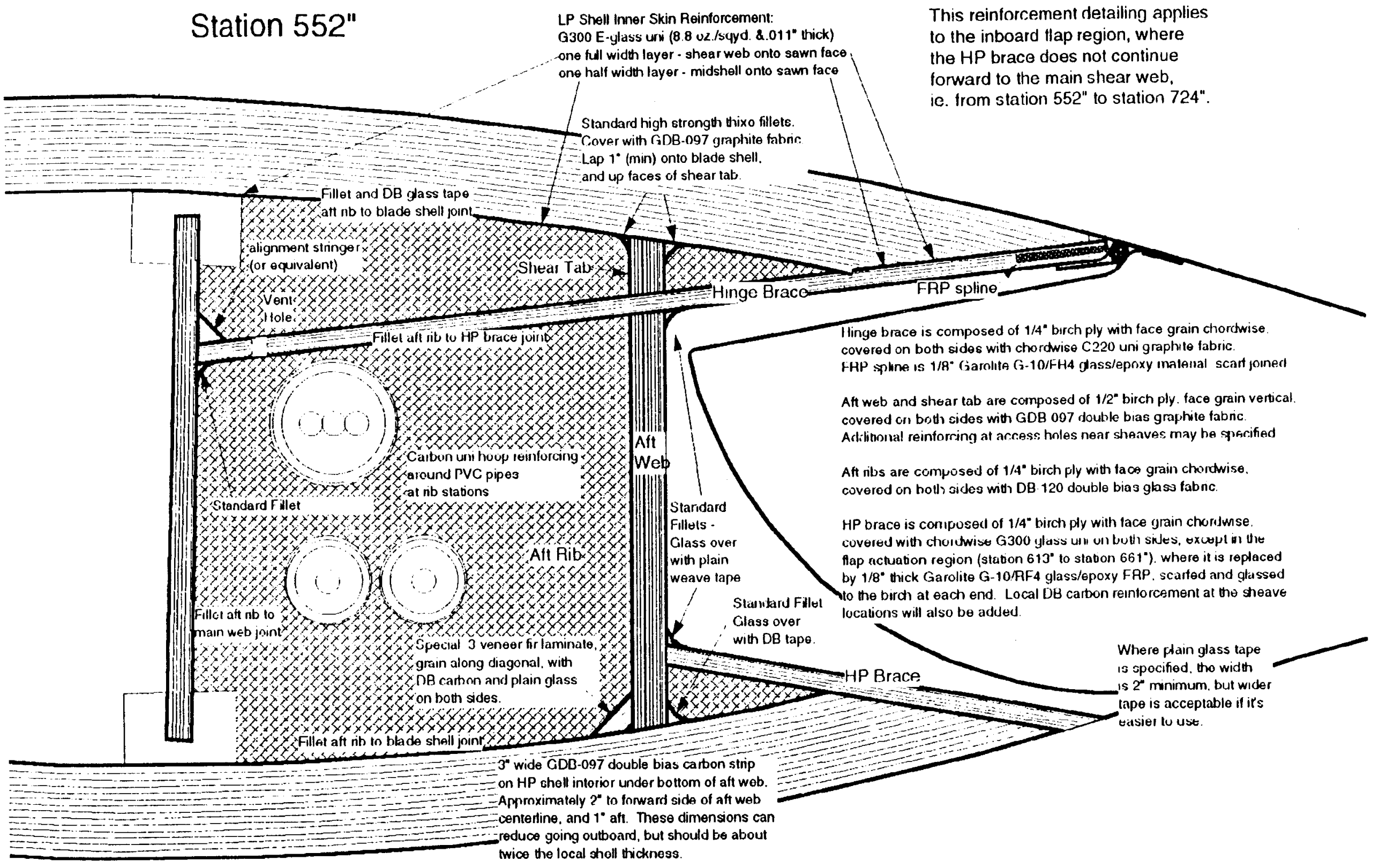

MDZ 5/15/94

1/2 scale 
Station 780
LP Shell Inner Skin Reinforcement:

G300 E-glass uni ( $8.8 \mathrm{oz}$./sqyd. \& $011^{*}$ trick)

one tull width layer - shear web onto sawn face

one half width layer - midshell onto sawn face.

Gtandard hight strength thixo fillets.

Cover with GDB-097 graphite fabric.

ap $1^{\circ}(\mathrm{mm})$ onto blade shell.

and up faces of shear tab.

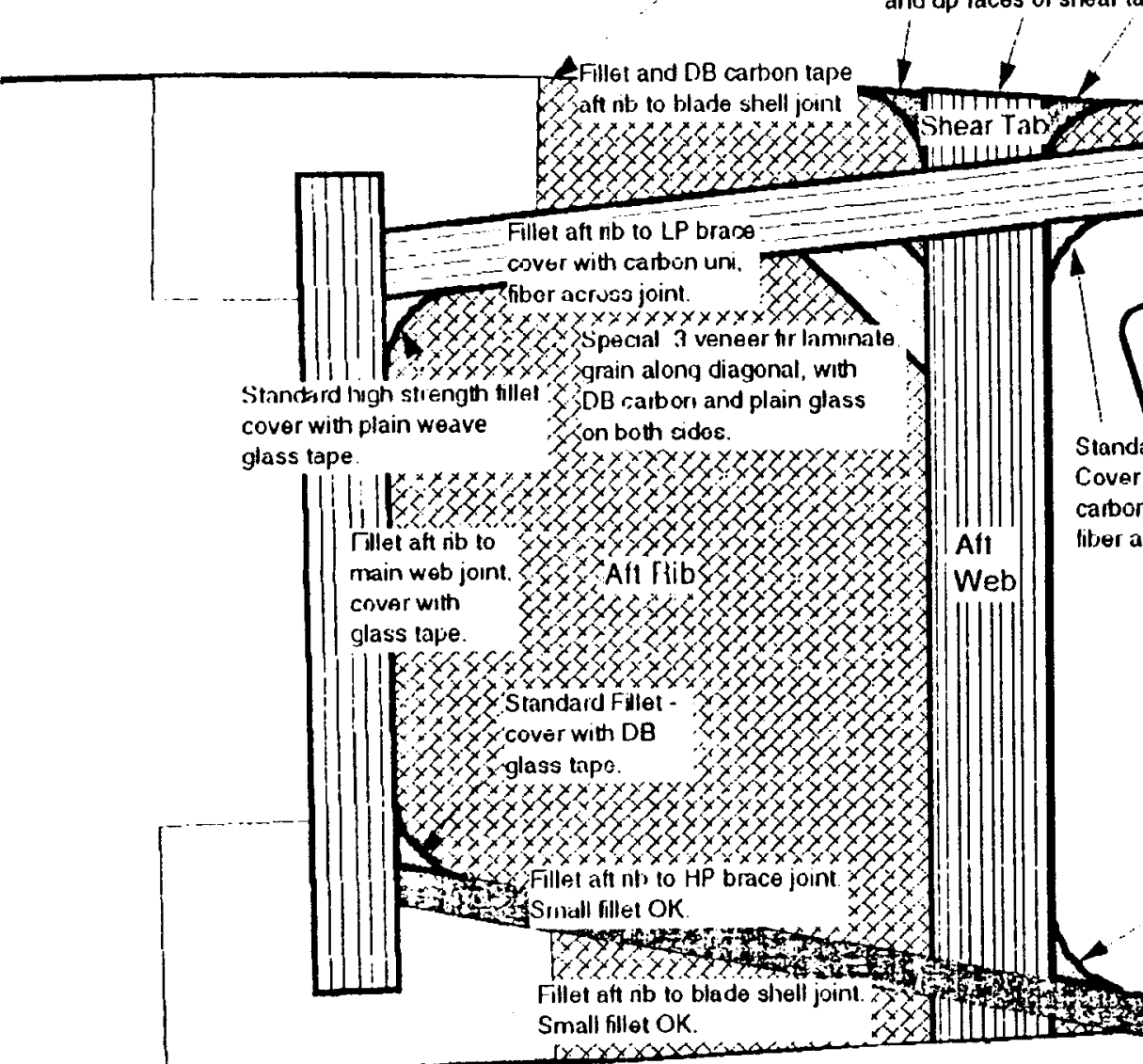

GDB-097 double bias carton slip from mid cavity to sawn surface, covering half of HP shell interior. and passing under boltom of lower shear tab.

This carbon can end where shear tab plays out.

Cover with DA" glass tape.

(except at sheave stations)

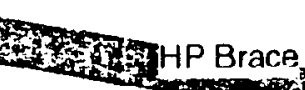

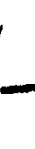

This reintorcement detailing applies to the outboard flap region, where the HP brace continues forward to the main shear web. ie. from slation 724 " in the tip.

covered on both sides with chordwise CLZU uni graphite labric.

FAP spline is 1/8" Garelite G 10iFi4 ylass/epuxy material, scart juined

FAP spline

Aft web and shear tabs are composed of 1/2" birch ply, face grain vertical covered on both sides with GOB-09/ double bias graphite tabnc Additonal reinforcing at access holes near stieaves inay be specilied.

Aft ribs are composed of $1 / 4^{\circ}$ birch ply with face grain chordwise. covered on both sides mith DB-120 double bias glass labnc. HP brace is composed of $1 / 4^{*}$ birch ply with face gratn chordwise. covered with plan glass both sides, except in flap actuation regon (station $723^{*}$ to station $771^{\circ}$ ). Where it is replaced by $1 / 8^{\circ}$ tuck

Garnlite G-10/RF4 glass/epoxy FRP. srartarl and glassad in the birch at each end. Local DB carbon reinforcement at the sheave locabons may also be added.

- If you wish to avoid switcting from plain weave to DB at station $724^{\circ}$, it is acceptable to use plain wenve all the way to the tip

MDZ 4/27/94 full scale 


\section{Aft Web Exit Slot and Access Hole Layout}

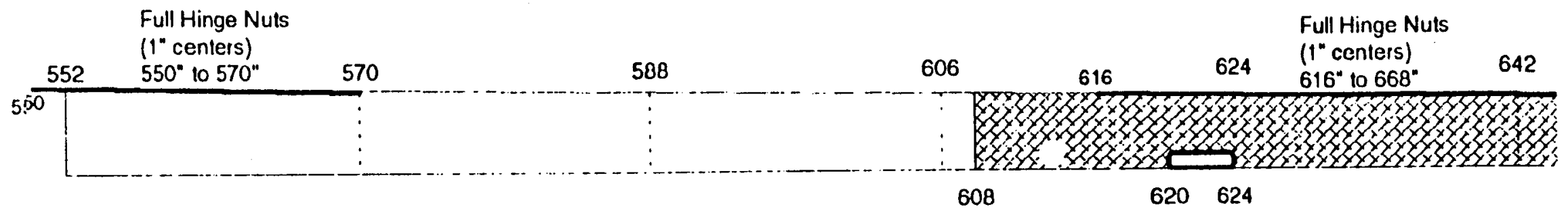

$\begin{aligned} & \text { Exira } \mathrm{DB} \text { Carbon } \\ & \text { Hole Reinforcement Zone }\end{aligned}$
$\begin{aligned} & \text { Possible } \\ & \text { carbon lined } \\ & \text { access hole }\end{aligned}$

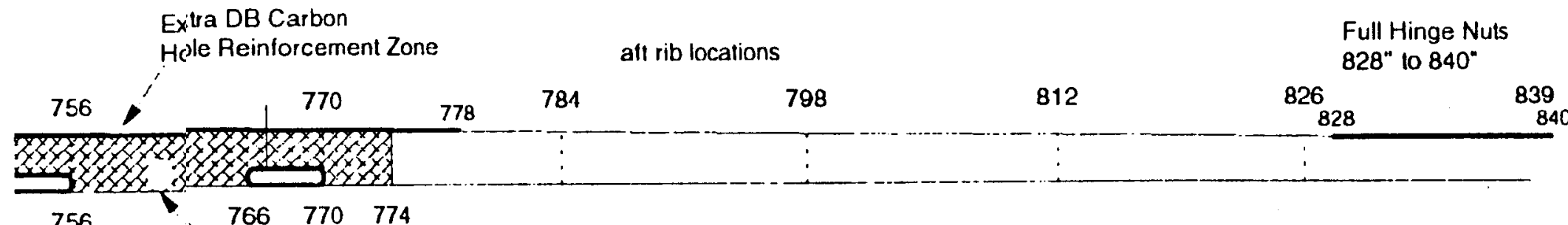

Possible

carbon lined

access hole

\section{Aft Web Exit Slot and Access Hole Layout}

The lower layout shows the alt web exit slots for the power side control lines, as well as the possible access and inspection holes. The aft rib stations and local hole reinforcements are also shown. A circular viewing and access hole is shown at station 728 to assure that the lines can be passed through the station 732 aft rib properly.

but these would be added later it needed, once the position of the return side rigging is finalized, and their best positions are decided. 


\section{TASK 2 REPORT}

Hawaii Zuteck Rotor Project

\section{SECTION VII}

\section{ACTUATION LINK SYSTEM}


In designing the actuation link system for the Hawaii Zuteck Rotor Project we pushed for completion of the following:

- ease of replacement in the field, without removal of the blades from the machine,

- long life components, allowing for many years of use between replacement of components.

\section{SYSTEM SELECTION AND TESTING:}

The actuation link system for the Hawaii Zuteck Rotor has gone through several iterations due to the evolving nature of the project, as the actuation link system was mostly driven by other considerations within the project rather than being a major driver. We selected these systems based on the goals previously described, research and experience of the investigators and the recommendations of our consultants and the manufacturers.

During the design of the Hawaii Zuteck Rotor Project we considered many different types of actuation link systems. Other than the direct drive systems, which are described in the next section, these systems can be broken down into two types.

Torque Tube drive systems: There were three types of torque tube drive systems considered for the project. The general idea of the torque tube
drive was to run a torsional member span wise through the blade to transmit the power to move the flaps. The three types differed in their connections to the power source and the flaps. The first consisted of a motor with a gear reducer, both located inboard, attached to the torque tube which drove a drive belt moving the flap. The second was similar, except that gears replaced the drive belt to move the flap. There was some torque multiplication via speed reduction at the flap attachment point on both systems. The third system considered would have the torque tube driven by the motor and the gear reducer located at the outboard end. The general problems with these systems were the size of the gear boxes, the torsional rod supports and questions of dynamic stability. These systems, as a class, were removed from consideration for the project in 
1993 as technically too complex in the existing blade envelope.

Actuation Rods or Cables: Actuation rods or cable systems were also considered as the means of moving the flaps. These systems consisted of transmitting either tension or compression forces to the flaps to change their position. The rod systems would use a single metal or FRP rod for moving the flap in both directions. Translation of the forces from span wise to chord wise would be accomplished by the use of bell cranks, which would also allow for multiplication of force or displacement by differential positioning of the two rods in relation to the rotation point on the bell crank. The cable system would require, in most cases, two full circuits to move the flaps in both directions. Blocks would be used to turn the lines and thus the forces from the span wise to the chord wise direction. One proposed system, which we called open return, used a gas filled snubber (similar to those used on lift gates on cars) and spring to keep tension on the shutdown side of the system. This would compensate for a broken line by keeping constant tension on the return side and driving the flap to shutdown if the power side line broke. A hybrid of these systems was also discussed that would use rods for the long runs and cables to make the turns. A cable based system was ultimately chosen for the project. A schematic of the current system is shown as figure VII-1.

After we discarded the idea of direct link systems (discussed in the next section), we baselined a cable or line driven flap system with full return circuit. We have also allowed in the design for modification of this system to an open return type once we are convinced of the stability and loads on the full circuit system.

Once this actuation system was chosen, we began a search for data that would increase our engineering understanding of both wire rope and synthetic line life. Data for the load carrying capability for these is readily available along with engineering practices for the safe design of a static tension system. On the other hand, we devoted many hours to researching data on fatigue, with little success. The data either did not exist or was not available publicly. With no other choice, we decided to carry out a very aggressive test to gather the data we needed. Attached as figure VII-2 is a schematic of the test rig, which allowed us to test concurrently four different samples. Testing was carried out at 500 pounds tension in each line. Many candidates were put forth. The results of the testing are shown in table VII-1 below. 
TABLE VII-1: Line fatigue test results.

Line Type
Marlow KT3 Kevlar Core
Dacron Cover
Stainless Steel $7 \times 19$ wire
Stainless Steel $6 \times 42$ wire
New England Ropes (NE) K-90
Kevlar/Spectra Core
Marlow Super pre-stretch
8-plait All Dacron
NE StaSet All Dacron $\quad(\# 1)$

$(\# 2)$
$(\# 3)$
$(\# 4)$
$(\# 5)$

NE SpecSet, Spectra Core/
Dia. Rated Load

$3 / 16^{\prime \prime}$

$1 / 8^{\prime \prime}$

$3 / 16^{\prime \prime}$

$3 / 16^{\prime \prime}$

$3 / 16 "$

$3 / 16 "$

$(3 / 16$

Dacron Cover

Samson UltraTech Technora

Core/Dacron Cover (\#1) 3/16" (\#2)

Pure Technora Core (Stripped from 3/8" Samson)
$3 / 16^{\prime \prime} \quad 2,800$

2,300

0.27
Total Cycles

to failure

382

4,170

6,003

7,727

14,893

22,867

13,359

14,512

13,543

12,084

90,055

111,643

160,416

182,276

Notes:

1) that the NE StaSet All Dacron (\#1) was from a different batch of line than all the other NE StaSet All Dacrons tested (a single batch), including those used for the high cycle testing below.

2) The Pure Technora Core was run without the cover to test a technora sample as soon as possible. It was too large for the $3 / 16$ " sheave we were running, yet proved itself to be very tenacious in the test. It got very frayed during the testing, to the point of looking like it would fail at any moment, yet it lasted for quite a long time.

We have also done testing at lower loads to establish a fatigue curve. These results are shown in tables VII-2 and VII-3 below. 
TABLE VII-2 Line Fatigue Test (400 pound load shown)

\begin{tabular}{|c|c|c|c|c|}
\hline \multicolumn{2}{|l|}{ Line Type } & \multirow{2}{*}{$\frac{\text { Dia. }}{3 / 16^{\prime \prime}}$} & \multirow{2}{*}{$\frac{\text { Rated Load }}{1,200}$} & \multirow{2}{*}{$\begin{array}{c}\text { Total Cycles } \\
\text { to failure } \\
31,149\end{array}$} \\
\hline NE StaSet All Dacron & $(\# 6)$ & & & \\
\hline & $(\# 7)$ & & & 31,594 \\
\hline & (\#8) & & & 31,604 \\
\hline
\end{tabular}

TABLE VII-3 Line Fatigue. Test (250 pound load shown)

\begin{tabular}{|c|c|c|c|}
\hline Line Type & & Dia. & Rated Load \\
\hline NE StaSet All Dacron & $\begin{array}{l}(\# 9) \\
(\# 10)\end{array}$ & $3 / 16^{\prime \prime}$ & 1,200 \\
\hline
\end{tabular}

Total Cycles

$\frac{\text { to failure }}{165,987}$
273,238

A fatigue curve using the above data is attached as figure VII-3.

In general, the data shows that synthetic cordage (rope) has a much longer life than wire rope in the small diameter sheave environment that we must use due to envelope constraints. We have also discovered that less rigid, high lubricity fibers (i.e. Spectra) tend to last longer than their opposites (i.e. Kevlar). Fatigue rates with respect to increasing loads are lower than expected, meaning that the lines will last longer in higher load environments than we expected. Thus we have decided to use a mixed Spectra/Technora core with Dacron sheath line (New England T-900). This line, which was not tested, is available in continuous lengths, whereas the Sampson UltraTech (which was tested) comes in internally spliced lengths, which could cause weak points in the line. The Sampson line will be used as a backup to the New England, should some unexpected problem show up in the T-900.

We also used the testing to gather more information about the turning blocks we were proposing for the design. The two inch blocks (Harken 309) we initially specified are not made for the loads and continuous cycle rates to which we subjected them. The blocks were rated at 2000 pounds maximum load, and while we were running one half of that, we were constantly moving them back and forth over a one inch throw. Little pieces of white material came out of the blocks, which we assumed was 
bearing material. They also suffered from increased end play and high temperatures. Testing also included a three inch block (Harken 005) with ball bearings. The Harken 005 block was audibly distressed and was quickly removed from testing. We then tried a three inch Harken 504 block, which lasted much longer but ultimately suffered a similar fate as the first three inch block. Our final choice for a three inch block was the Harken 691 narrow halyard sheave, the three inch cousin to the two inch test blocks, which performed satisfactorily under the severe test regimen.

During design of the actuation system, we also discussed two methods of line guides. The less complex method, long fixed tubes, caused some concern due to a lack of knowledge on their wear characteristics in relation to lines rubbing. During the testing, we installed wear samples of PVC tubing to quantify this unknown. The results showed no perceivable wear at loads up to 100 times those expected in operation. Testing was done at 40 times expected load for 243,100 cycles and 100 times expected load for 8,821 cycles. The PVC tubing has therefore been used as internal line guides through the outer blades. This will allow for easy stringing of the flap connections and will control any contact of the lines within the confined outer blade cavities. This concept is shown in figure VII-4.

\section{BLADE INTEGRATION CONSIDERATIONS:}

Blade integration of the actuation link system includes such considerations as:

- The stretch of the line through the 50 feet of travel between the actuator and the flap. The calculations based on data supplied by the manufacturer, data gathered in our testing and loads estimated for the system indicate that the stretch of the line over this distance will result in a flap elastic float angle of less than $\pm 0.4^{\circ}$ for flap load fluctuations of $\pm 33 \%$, which we feel is acceptable. Thus we saw no problem with running the actuation system from the root to the flap. If the actual elastic float error is much greater than the estimate, we have the option of putting larger diameter line in the long run, effectively reducing the error. One of the tradeoffs of such a replacement is that there is a longer vibration damping time on a larger, heavier line, which is why we have specified the $3 / 8$ inch 
diameter line for the design. Another option would be adding motion doubler blocks for the long runs, to effectively double the link stiffness with the same line size. Although we do not anticipate a need for these options, we mention them to demonstrate the flexibility that we have built into the system.

- Fitting the lines and blocks into the existing cavities and new structures. Careful consideration of the integration of the block was a key issue, as fatigue life dictated the use of the three inch blocks with their attendant need for more space in an already cramped environment. This, and the fact that the line diameter makes the runs between the aft rib and flap nose crowded, let to the decision to run the power side lines in the cavity between the aft rib and the shear web. There are some access problems that had to be resolved, most of which went away with the introduction of the tube guides, but this "split run" was the most effective way to get all the controls in the blade at one time, while using components sized for long term, trouble free fatigue operation. Two components which benefitted from this change were the line itself and the block. The line size increase gave the line an operating load which is $3.5 \%$ of the rated strength. The block operates at approximately the same small percentage of rated load.

- Transferring the loads to the structure from the lines and blocks. This detail took careful consideration from a design and maintenance standpoint. Transfer of the loads from the lines to the flaps required a "soft" attachment point within the flap structure, which was accomplished with a balsa mat imbedded in the skin on the high pressure side of the flap just aft of the flap shear web. (See the flap design section for details.) We also had to spread the loads in the line to three different power side attachment points on the outboard flap and two on the inboard flap. This distributed the loads into the soft structure of the flap, avoiding point loading of the structure and hinge.

To transfer the loads from the line to the attachment point, an end fitting was required on the line. In a novel approach, we have tested and are using a bonded end fitting on the lines. This technique has proven itself strong enough, when properly executed, to withstand forces that will deform the steel fittings bonded to the line. 


\section{Electric Actuation Schematic Layout Root Mounted - Outboard Flap}

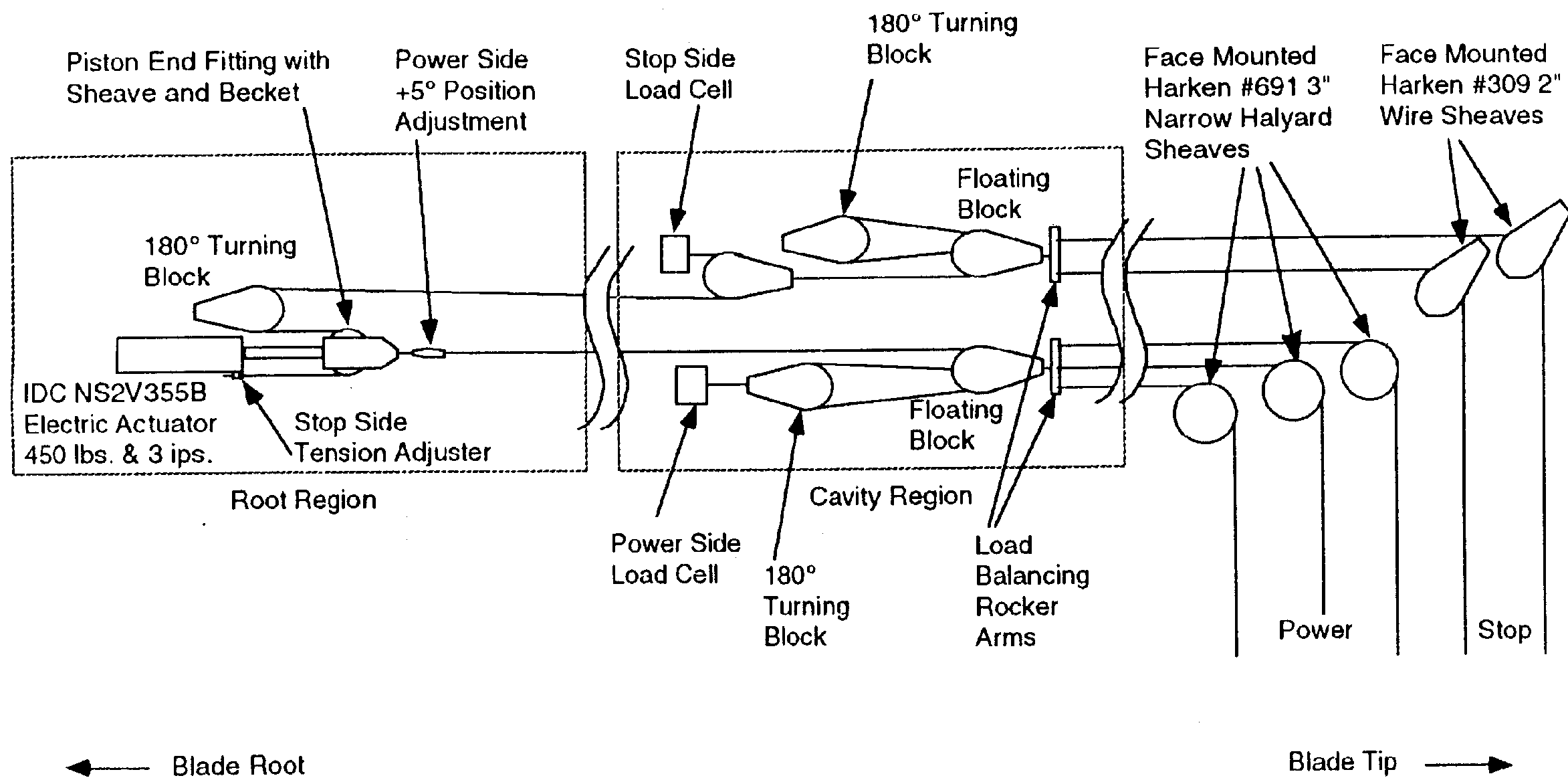




\section{Multiple Item Chordage \\ Test Apparatus Schematic}

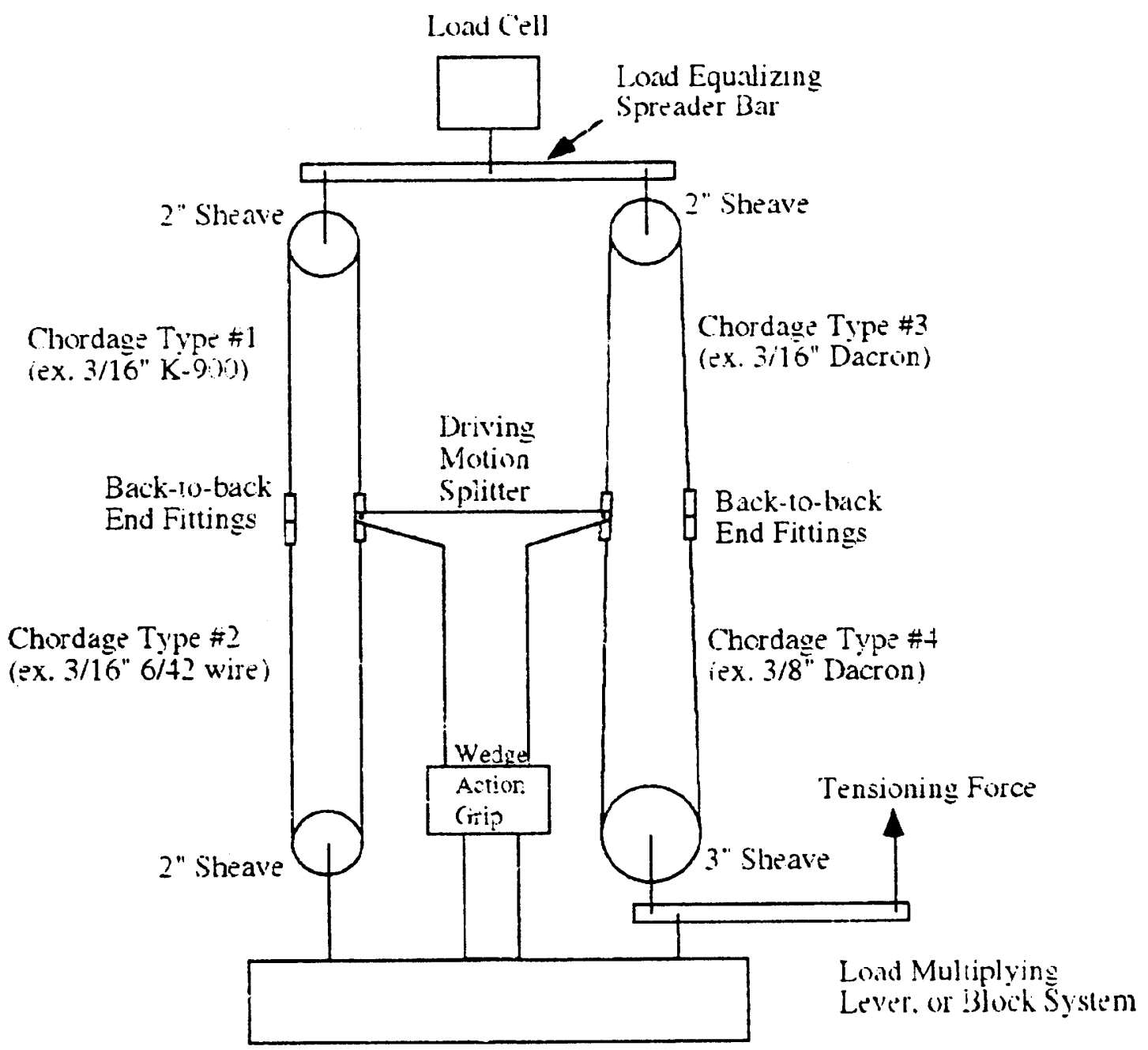

notes:

1) Initial test at $500 \mathrm{lbs}$. line tension.

(Full sequence $500 \mathrm{lhs}$. $400 \mathrm{lts.} .3 \mathrm{l}) 0 \mathrm{lbs..}$ if needed)

2) Stroke amplitude to be 1".

3) Cycle rate $1 \mathrm{~Hz}$. for shakedoinn. ? $\mathrm{Hz}$. thereafter.

4) Failure of any one line type ol sheave will stop test.

5) Bowline knots provide zero cist end fillings for line. standard end filling lised for wire. 


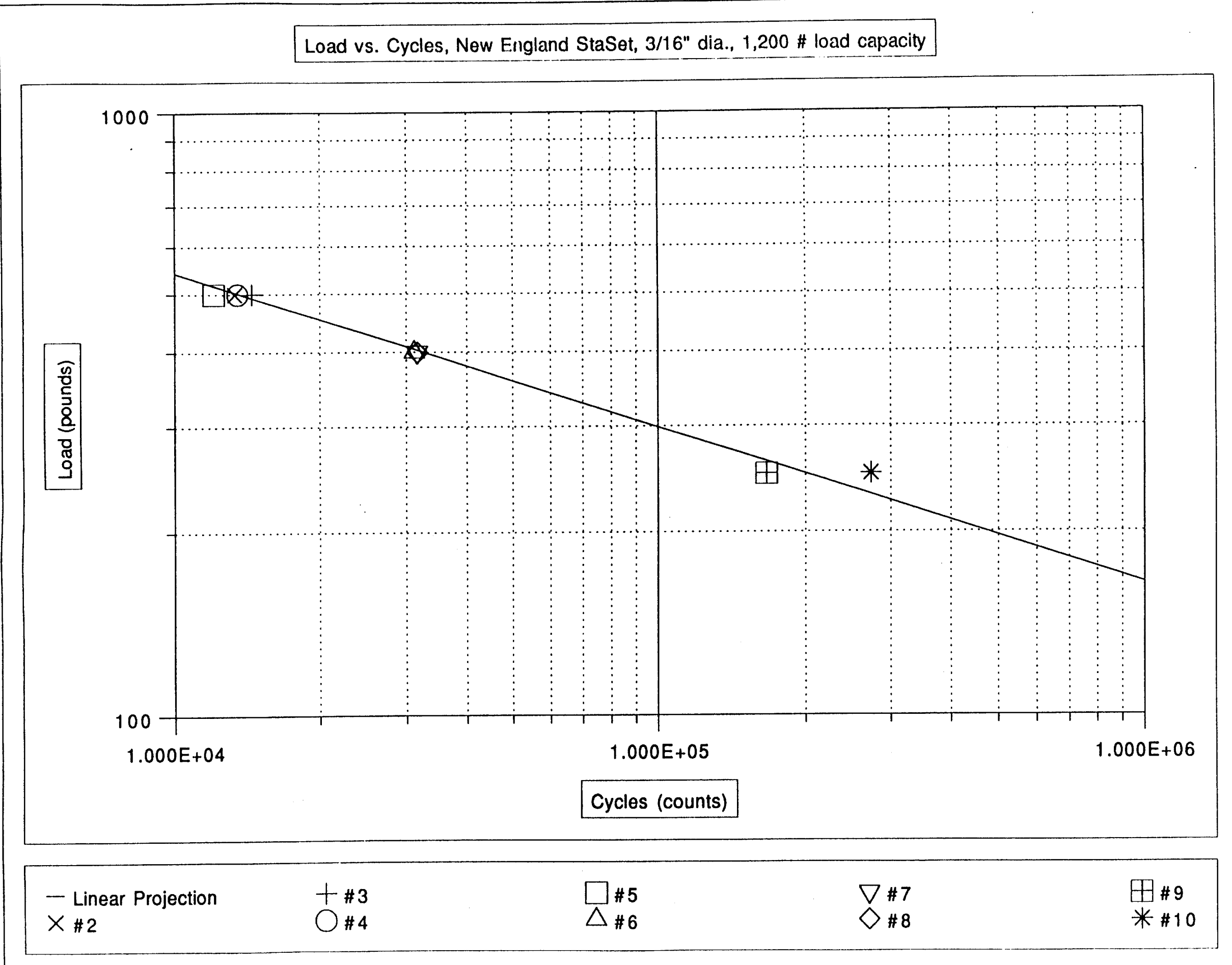

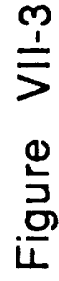


Station 552"

$.578^{\circ}$ reference wist

$.752^{\circ}$ rotahon from statoon $456^{\circ}$

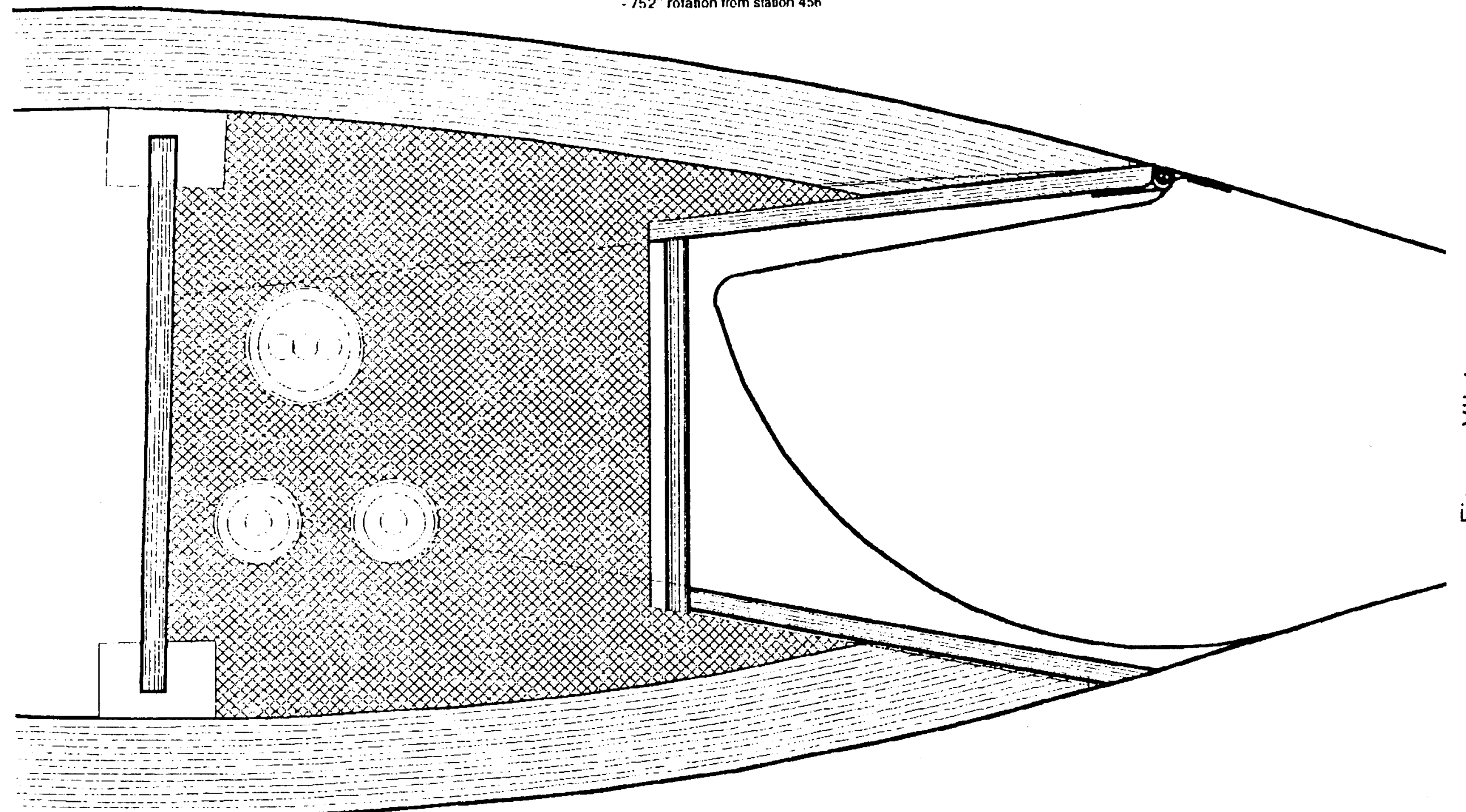

$\stackrel{+}{5}$
$\stackrel{5}{5}$
$\stackrel{0}{9}$

MDZ 4/17/94

$1 / 2$ scale 
Makani Uwila Power Corporation

\section{TASK 2 REPORT}

Hawaii Zuteck Rotor Project

\section{APPENDIX VII-I}

\section{SUPPLEMENTAL DETAIL DRAWINGS ACTUATION LINK SYSTEM}




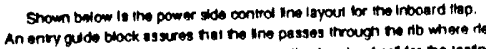

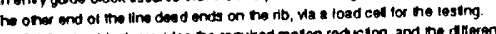

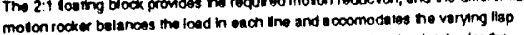

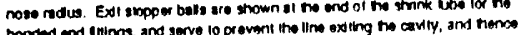

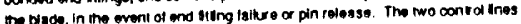

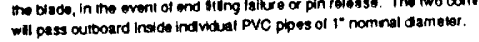

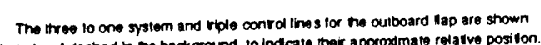

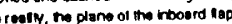

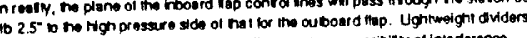

tis

MO2 42394

\section{LAYOUT: OUTBOARD ACTUATION LINKS}

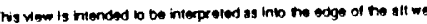

The

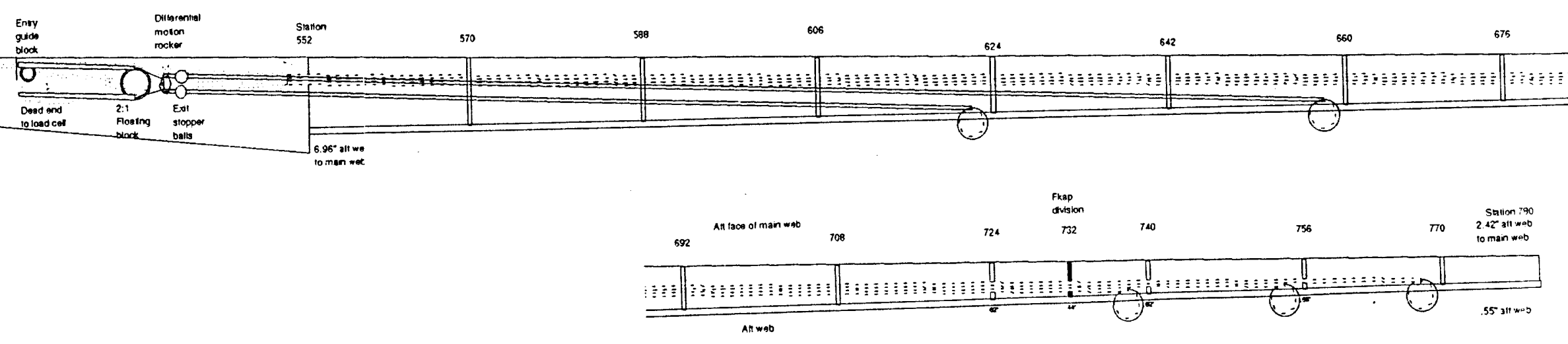




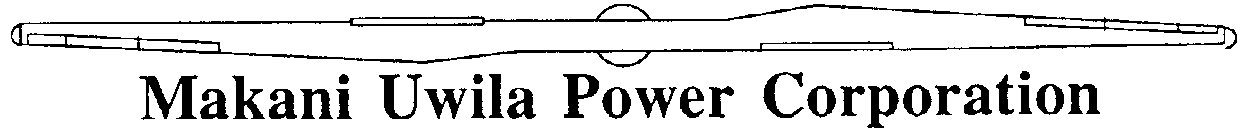

TASK 2 REPORT

Hawaii Zuteck Rotor Project

\section{SECTION VIII}

\section{ACTUATION DRIVE SYSTEM}




\section{GOALS:}

In designing the actuation drive system for the Hawaii Zuteck Rotor Project we tried to achieve the following goals:

- long life,

- low maintenance,

- moderate cost,

- sufficient flap movement speed (20-30 degrees per second),

- at least $30 \%$ to $50 \%$ over power capability.

\section{SYSTEM SELECTION AND TESTING:}

The actuation drive system for the Hawaii Zuteck Rotor has gone through several iterations due to the evolving nature of the project and the increase in technological capability of electro-mechanical drives, as the actuation drive system was both driven by other considerations within the project and was itself a major driver. We selected these systems based on the goals previously described, research and experience of the investigators, and the recommendations of our consultants and the manufacturers.

During the design of the Hawaii Zuteck Rotor Project we considered many different types of actuation drive systems, most in conjunction with actuation link systems (see the previous section). These systems can be broken down into two types.

Fluid Powered Systems: There were two types of fluid powered drive systems considered for the project. The general idea of the fluid powered drive was to move a linear actuator using gas or liquid. This linear motion would be transmitted by the actuator link system to move the flaps. The gas system considered was the use of compressed air to move an air piston mounted just inboard of, or directly forward of, the flaps. Because air is highly compressible, we thought that the constantly changing forces on the flap system would act to move the cylinder in and out.. This would cause inaccurate positioning of the flaps and could cause oscillations in the flap system. This might even lead to aeroeleastic instability, and serious damage. We rejected air driven actuation for this reason. The liquid system considered was based on hydraulic oil. This system had the 
same two actuator locations mentioned for the air system, but was a stiffer, more stable system due to the highly incompressible nature of oil. On the negative side of hydraulic systems are the oily mess created by the inevitable leak and the cost of the components, which are fairly expensive for the type of control system we were investigating. Despite these drawbacks, we baselined this type of system for quite some time in the project as the only system powerful enough to move the flaps and still be compact enough to fit entirely within the blade envelope. Technological advances in electro-mechanical actuators, the total cost of hydraulics and changes in the project finally swung the baseline away from the hydraulic option.

Electrically Powered Systems: Electrically powered systems were also considered as the means of moving the flaps. These systems consisted an electric motor either turning a torque tube, gear box or ball screw to change the position of the flaps. No direct-to-the-flap application of an electrically powered system was considered. (See the previous section for a discussion of how electrically powered systems would move the flaps.) A cable based system was ultimately chosen for the project, with actuation power delivered by a ball screw driven by a geared stepper motor. A description of the current ball screw actuator is attached as appendix VIII-1. This system allows us to meet our goals with enough flexibility to face increased loads or higher speed requirements. It is also a fairly new system that was not available off-the-shelf when we started the project.

Six actuators, IDC model NS2N355B24MXCFT1EMW, were ordered. They are off the shelf 24" ball screw linear actuators with geared stepper motors and weather proofing. After obtaining the actuators from the manufacturer, we performed several tests with them to better understand their operational characteristics and limitations. Testing consisted of operating each actuator with its driver to verify wiring and speed, then connection of two drivers to the Parker Two Axis Controller to verify that the controller would operate properly with two actuators. Testing was carried out with each actuator moving synchronously as well as independently. Measured rates were as much as 3.2 in per second with no load in both the retract and extend directions. The capabilities of the controller to accelerate, decelerate and otherwise control the actuators was investigated. Each controller is capable of many different functions as well as being programmable to execute various steps on command. It is 
a quite flexible system. We also tested the actuators with live loads, using the Gougeon Brothers, Inc. materials test machine as our driver. We first tested the actuator's ability to back drive under load. Graphs of the results are attached as figure VIII-1 and figure VIII-2. As can be seen from the graphs, the actuators back drive (power off) at approximately 90 pounds in retraction and 30 pounds in extension. We then set the test machine to load control, hoping to expose the actuator to a constant load while we cycled the actuator. The test machine performed acceptably, giving us the ability to load follow within 50 pounds of the set point while the actuator moved. We also attempted to verify the speed vs. load characteristics of the actuators. While we did not accomplish this task, we did find that when the stepper motor slips, the ball screw back drives until there is very little load on it. The motor did not retard the motion at load. Because of this undesirable slipping of the actuator when overloaded as well as a perceived need for faster deployment of the outer flap during shutdown, we returned two of the actuators to the manufacturer for retrofit with a larger NS3 motor and a 1.5 to 1 gearbox. Thus, two of the actuators are now IDC model NS3N155B24MXCFT1EMW and are used for the outboard flaps. This change doubled the speed and power available from the actuator. See figure VIII-3 for a comparison of the NS2 and NS3 actuators.

\section{BLADE INTEGRATION CONSIDERATIONS:}

Blade integration of the actuation drive system includes such considerations as:

The acceleration forces and size constraints on the actuator system. Many of the early decisions on which system to use for motive power in the blade were driven by a desire to mount these actuators at the root end of the flaps, in a cavity internal to the blade. This created size and load constraints on the actuators. The centrifugal forces at this location were approximately 35 times those of gravity. Size constraints were aggravated by the desire to operate the three flaps independently on each blade. This necessitated mounting three different actuators (and in the fluid power cases their servo valve controls) within the cavity. These constraints were the major drivers toward the small and powerful hydraulic system, as the ball screw actuators of that time were not powerful enough, yet small 
enough, to meet all of these requirements. The manufacturer and the project team were also worried about loss of lubrication on the bearings and ball screw due to the large induced gravity loads.

The decision to reduce the number of flaps to two, as well as the availability of new and more powerful ball screw actuators allowed renewed discussion of electro-mechanical actuators, as the space in the cavity was sufficient for two of the newer type. These newer types also appeared to be better sealed, although the doubts still remained about the life of these actuators in this location. Later discussions which reduced the concerns of long line runs through the blade allowed for removal of the actuators to the much more benign environment of the blade root, with the side benefit of relaxed size constraints.

- And running of control lines (electrical) and power transmission lines (fluid or electrical) to the actuators. While we considered mounting the actuators in the cavity just inboard of the flaps, we also had to consider different methods for routing control wiring and hydraulic (later electrical power) cables to that location from the hub. Many different ideas were presented, including running externally along the trailing edge, routing channels in the skin of the airfoil and running the lines inside the blade (which is hollow). The leading candidate, until we eliminated this requirement by moving the actuators to the root, was to run the lines along the trailing edge (which is flat, as the airfoil is an LS-1). This solution provided limited space for wiring and tubing without disrupting the flow over the aiffoil. Running lines through the interior of the blade presented problems of entering the blade at the root and securing the lines against movement within the blade. Routing the structure of the blade presented strength and fatigue problems for the blade. None of the solutions were very attractive, which was one of the drivers toward moving the actuators to the root. 

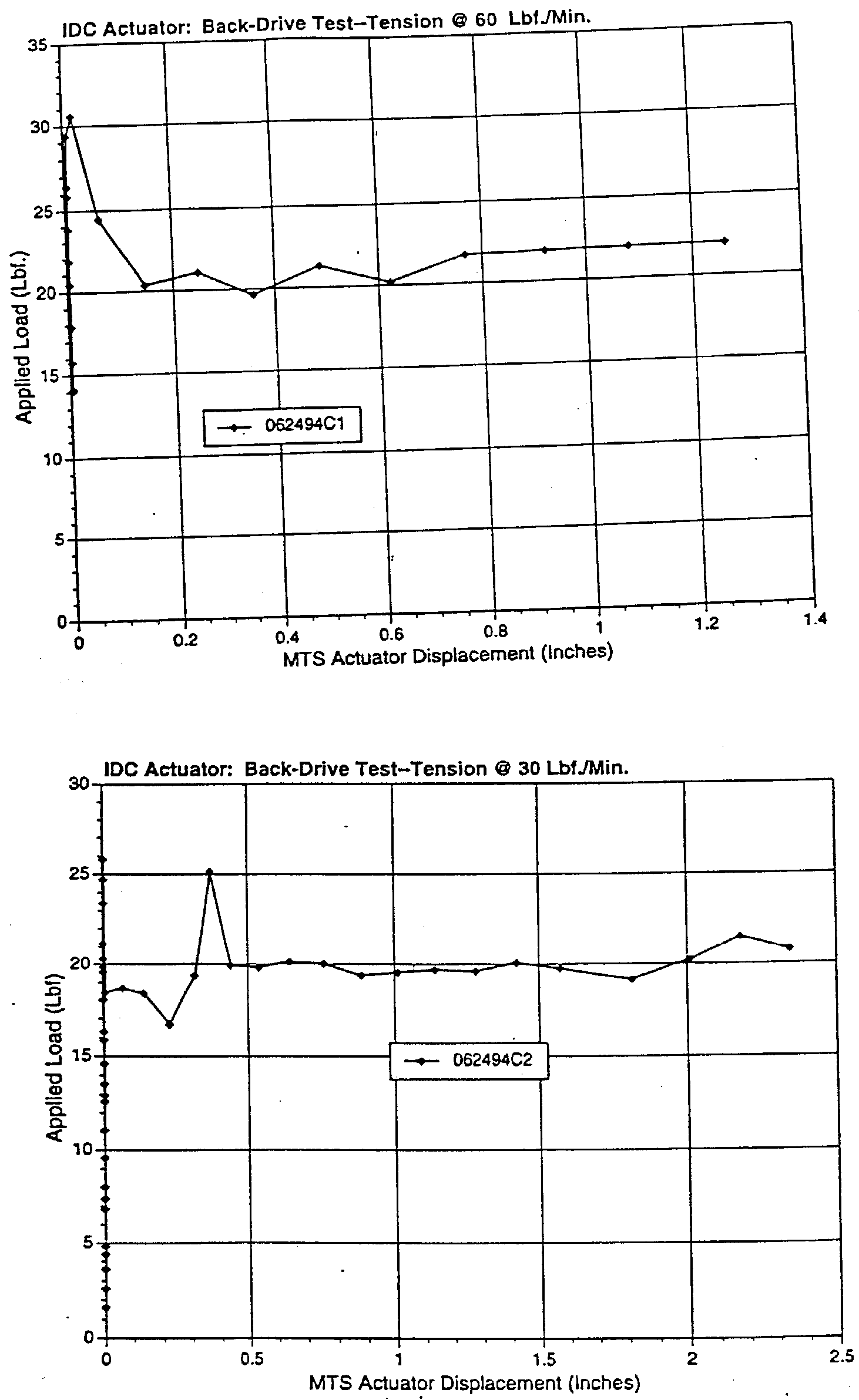

Figure VIII-1 

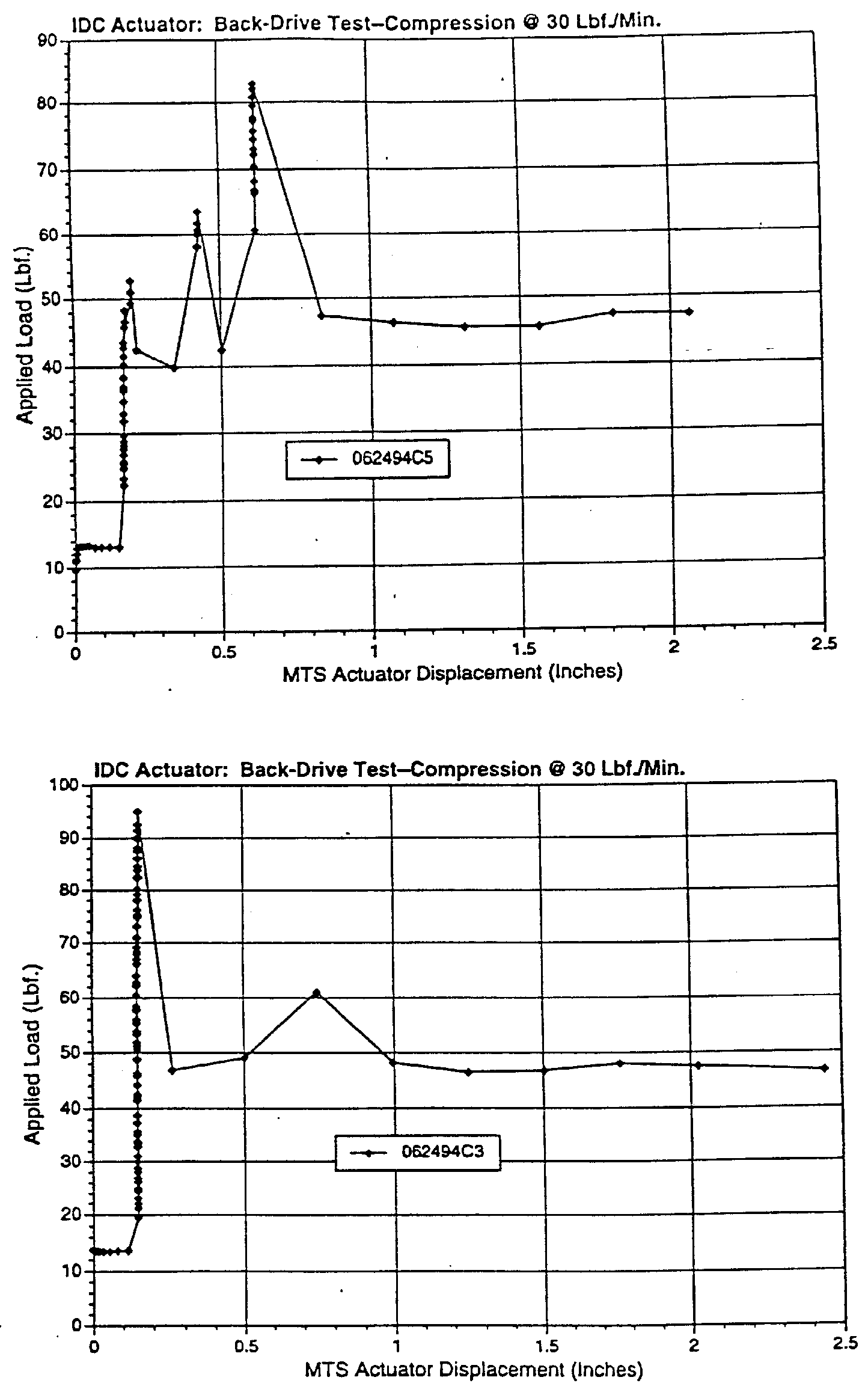

Figure VIII-2 
Speed vs. Thrust for IDC Actuators used in the Hawaii Zuteck Rotor Project

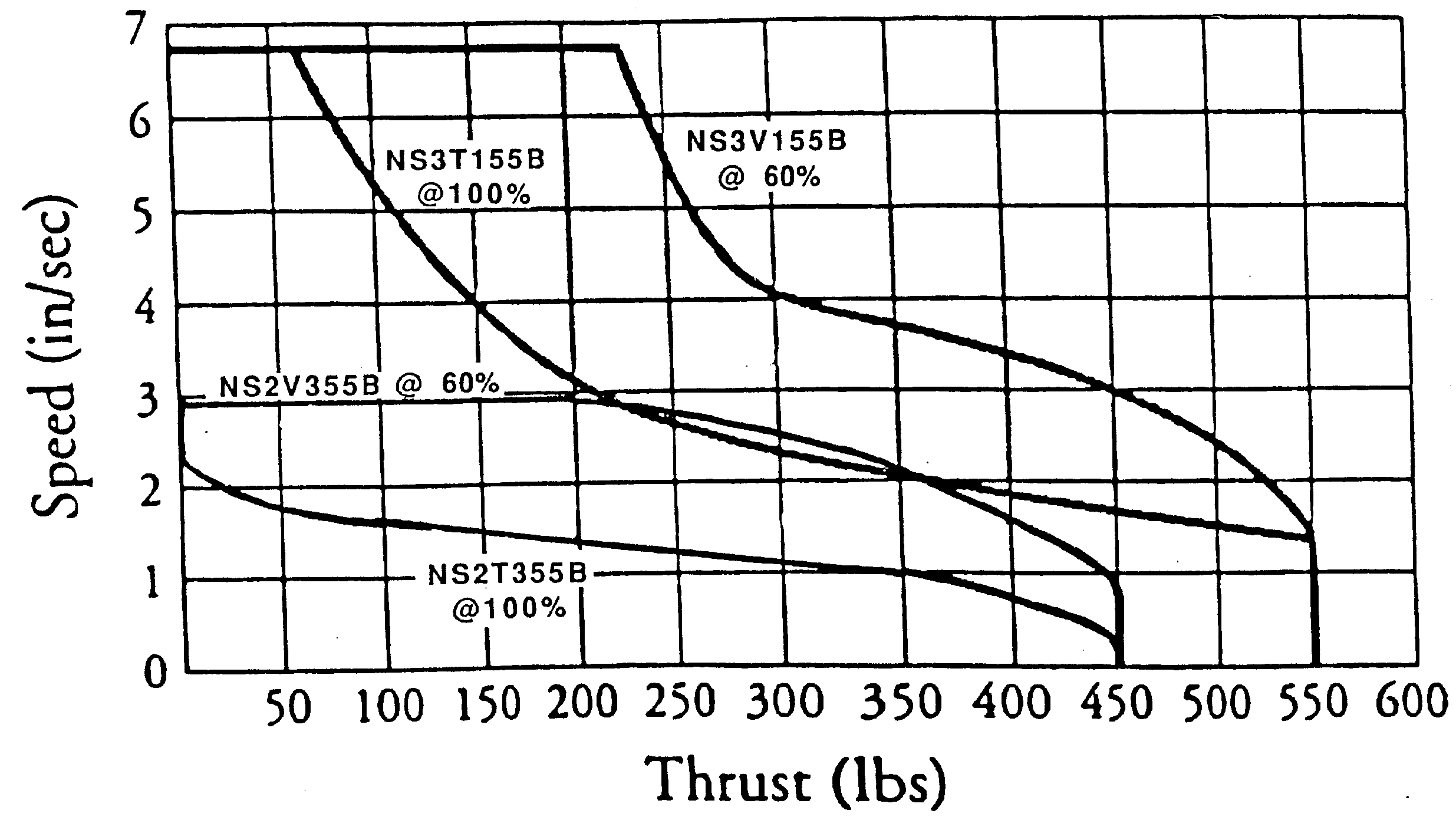




\section{TASK 2 REPORT}

Hawaii Zuteck Rotor Project

\section{APPENDIX VIII-I}

BALL SCREW ACTUATOR DATA 
N SERIES: STANDARD STROKE LENGTHS FROM 2 TO 24 INCHES. CUSTOM LENGTHS AVAILABLE TO 48 INCHES. UP TO 800 LBS OF THRUST.
T SERIES: STANDARD AND CUSTOM STROKE LENGTHS TO 60 INCHES. UP TO 2,4OO LBS OF THRUST. (SEE INSET BELOW.)

STANDARD MOTOR MOUNTING CONFIGURATIONS INCLUDE PARALLEL IAS SHOWN). IN-LINE, AND REVERSE PARALLEL

WIPER SEAL ON POLISHED STAINLESS STEEL OUTPUT TUBE KEEPS CONTAMINANTS OUT AND LUBRICANTS IN

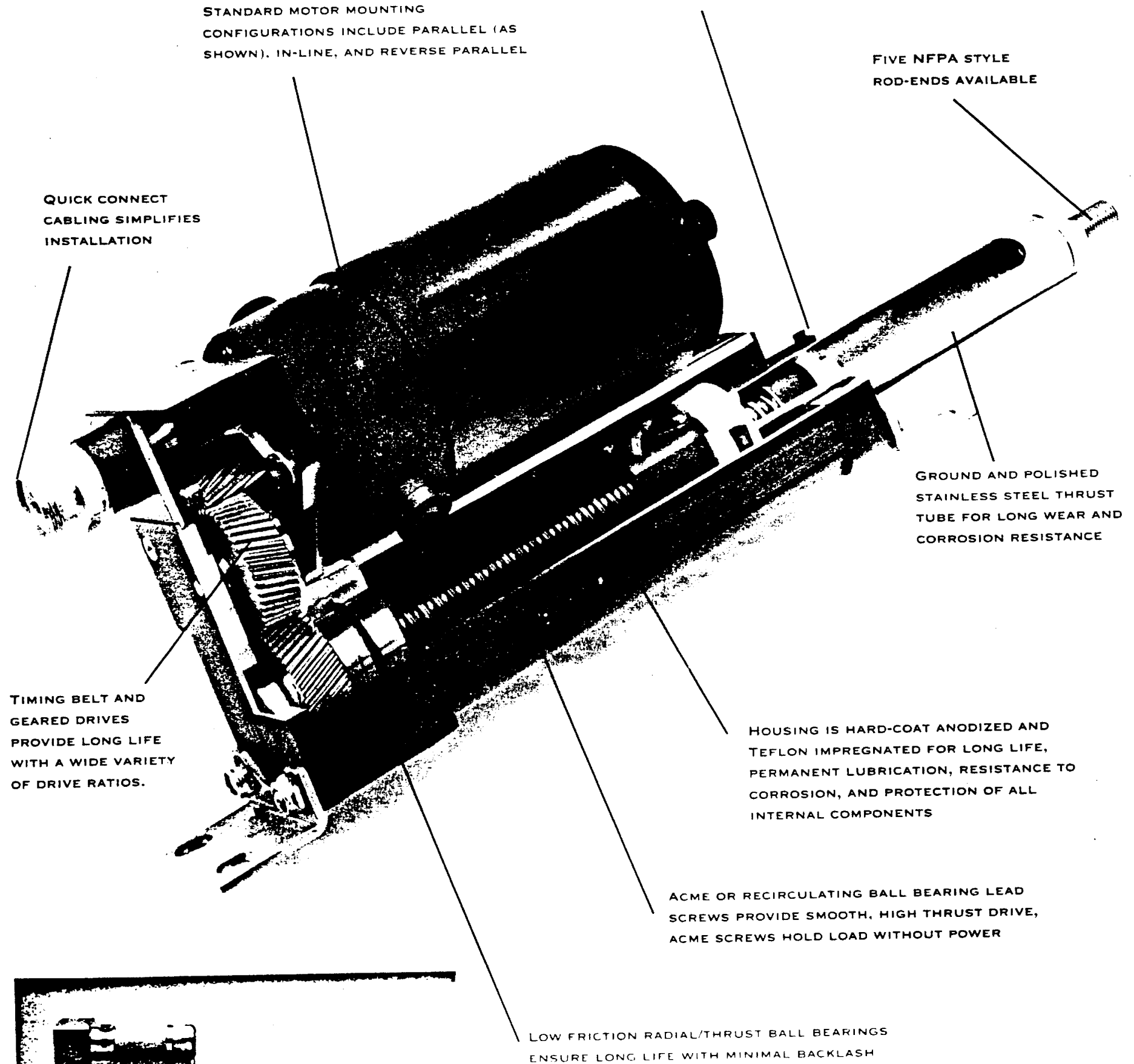


For many applicalions, lyclraulic or pneamatic linear cylinclers are a betler

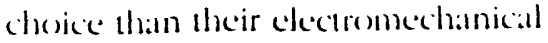
allernatives. For example, when exiremely heary loads must be moved, hydraulic cylinders are the best solution.

\section{CYLINDERS VS}

HYDRAULICS

AND

\section{PNEUMATICS}

"WHERE FLEXIBILITY, ACCURACY AND RELIABILITY ARE IMPORTANT, THE SOLUTION IS CLEAR."
Or, when very light kads must be moved rapidly and repeatedly from one fixed loc:allion to another fixed location, pneumatic cylinders may be the most economical solution.

But, when simplicity, flexibility, programmability, accuracy and reliability are imporant and loads are within the economical capacity of the technology, electromechanical solutions are the most desirable.

Further, electronechanical sy'stems are inherently more compatible with today's computer controlled automation.

\section{INDUSTRIIIL DEVICES

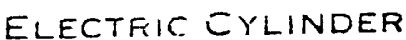

INSTALLATION

All electric operation recpuires simple wiring: directly compatible with oxher clectronic controls

PRECISE

POSITIONING

CONTROL

SPEED

RELIABILITY

VERSATILITY

CyCLE LIFE

ENVIRONMENT

\section{COST}

Cost-eflective, repe:ulable, multistop capabilities ( $\pm .005 " \mathrm{D}$ Series; $\pm 0.001 "$ B Series)

Solid-state microprocessor-based controls enable atuomatic operation of complex motion Simooth, variahle speced capabilities from $0 .(1) 21040 \mathrm{in} / \mathrm{sec}$

Repeatable, reproducible performance throughout useful life of product; no maintenance recpuired

Diverse selection of lead screws,

Up (o) millions of (ycless at rated load

Available with watler-tight seats, designs. Standard models ratled for $-20^{\circ}$ in $1+0^{\circ} \mathrm{F}$

Moclerate initial cost: bery low $\pm .001 " \mathrm{H}$, and $\pm .0005^{\prime \prime} \mathrm{S}$ Series sequences

\section{HYURAULic \\ CYLINDER}

Recutures expensive plumbing, filtering, pumps, etc. Must pay close attention to compatibility of components.

Requires expensive possition sensing and precise valving to implement; has tendency to creep

Requires electronic/fluid interfaces and sometimes exotic valve designs. Hysteresis, dead zone, supply pressure and temperature changes complicate control.

Difficult to comtrol accor:ately. drive mechanisms, mountings, etc. subfrecting operation, and special maintenance cost
Varies with temperature and wear. Stick slip can be a problem

Fluid sources require maintenance. Seals are prone to leak. Good reliability with diligent maintenance

Can be more powerful

Dependent on clesign and seal wear; usually good

Temperalture exitemess can he ad major problem. Seats are pronc to leak

Components often cosit less, but installation and maintenance are increased. Hyclraulic power unit cost is high if not pre-existing

\section{PNEUMATIC CYLINDER}

Reçuires expensive plumbing, filtering, pumps, etc.

Recyuire's expensive position sensing and precise valving to implement; has tendency to creep

Inherently non-linear, compressible power source complicates servo control. Compressibility can be an advantage in open loop opcration

More susceptible to stick slip and varying load

Air sources require proper filtration. Good reliability

Suited for high-speed applicaltions. Cleaner than hydraulics

Dependent on seal wear, usually good

Temperalure extremes can be a major prohlem. Seals prone to leak

Components often cost less, but installation and maintenance are increased 
Industrial Devices' NS Series rod-type cylinders are ideally suited for automated motion applications requiring high load and duty cyck, precise positioning, or full torque at rest with an open loop system. The NS Series can answer a variety of motion control needs, including open or closed loop positioning, simple or very complex motion profiling, PLC or computer interfacing, and multioperation programs.

As a replacement for troublesome hydraulic and pneumatics, NS Series systems are cleaner and easier to maintain, and are often less expensive.

These rod-type cylinders incorporate a 5 pitch ( 5 turns per inch) or 8 pitch acme screw, or a 2 or 5 pitch ball bearing screw to provide a variety of speed and thrust capabilities with a maintenance free $1.8^{\circ}$ hybrid step motor as the mechanical power source. Ball screw models are used in applications that require higher speed and duty cycles. Acme screw models generally perform best in applications with up to $60 \%$ duty cycle, and where backdrive is not acceptable. Acme screws also provide faster stopping because of their frictional damping qualities. Because they are self locking, no movement occurs when an external force is applied. Another appeal of acme models is their slightly lower cost. The life expectincy of a thall screw is genclally belled than :m acme screw.

Timing belt and gear reductions between the motor and the lead screw further widen the performance range of NS Series models. Parallel motor mounted models can have many ratios, while in-line models are always direct driven, with the motor directly coupled to the screw.

NS Series Cylinders are available with several time proven options for application in industrial enviromments. Options include holding brakes, encoders for position feedlatck, special materials for high or low temperature environments, linear potentiometer feedback for use with user supplied controls, dual rod-end bearings to increase side load capacity, and more. Industrial Devices will also discuss unicpue modifications at the customer's request.

\section{FEATURES}

- $100 \%$ duty cycle with ball screw models

- Speed to 25 inclies per secomd

- Thrust to $800 \mathrm{lbs}$

- Standard travel lengths to 24 inches. Custom lengths available.

- NFPA style mounting configurations provide direct replacement for hydraulic or pneumatic cylinders

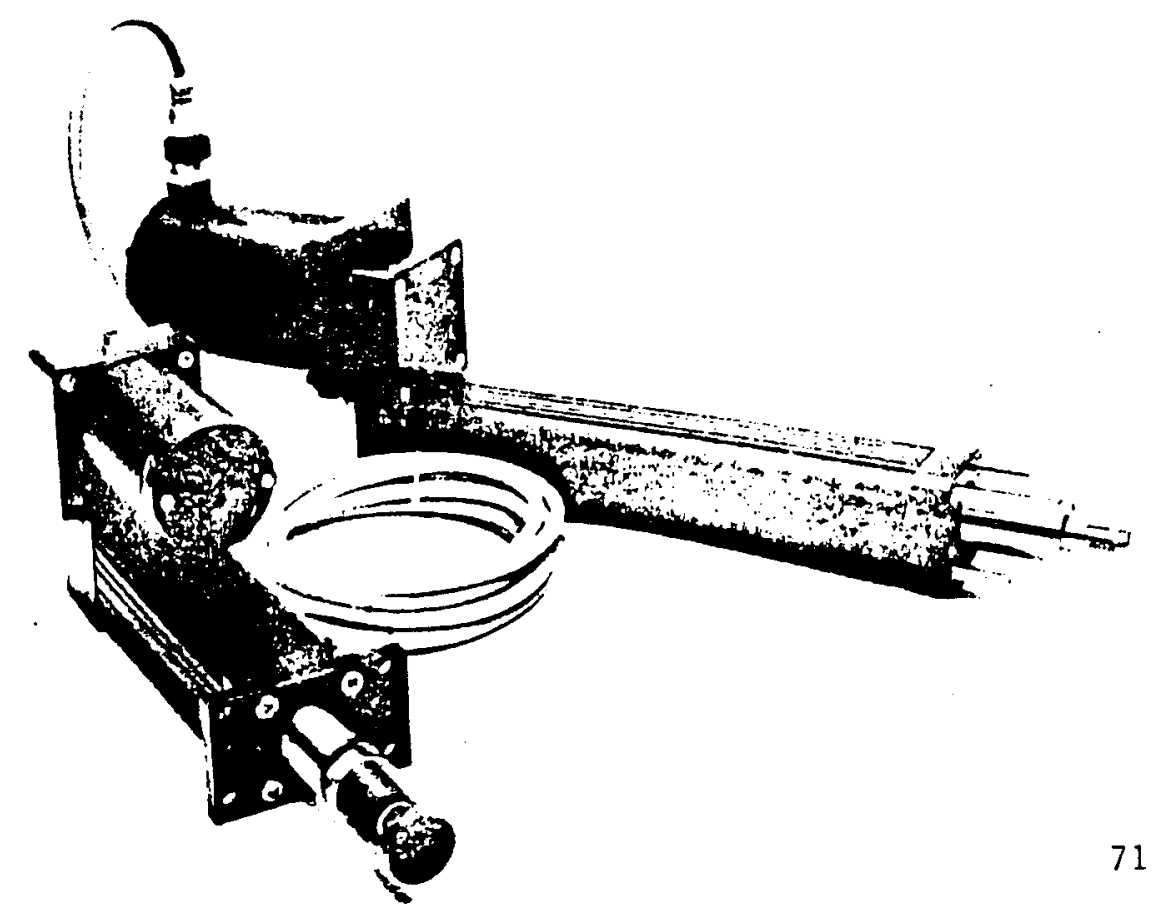

- Five rod end couplings facilitate a variety of loads

- Three motor mounting options optimize installation space

- Parallel

- Reverse Parallel

- In-line Models external aluminum surfaces, and stainless steel thrust tube provide corrosion protection

- Acme and ball screw models for application flexibility 23 or 34

- Optimized for use with $\$ 5000$ controls, offering:

- virtually unlimited programming capability

- very high position resolution

- repeatability to $+/-.0005$ inches

- integral control/drive/power supply package

- integral operator interface

- see page 195
- Ancolized and fused epoxy

- High performance step motor size 


\section{COMMON SPECIFICATIONS}

Specifications are defined in the Engineering Section.

$\begin{array}{ll}\text { Thrust Load } & 800 \mathrm{lbs} \max \\ \text { Speed } & 25 \mathrm{in} / \mathrm{sec} \max \text {, at no load } \\ \text { System Backlash } & 0.015 \mathrm{inch}\end{array}$

Thrust Tube

Side Load Moment

Rotation

Standard Travel Lengths

See load curves on page 257

Does not rotate. Note: applying a rotation torque to the thrust tube may damage unit

$2,4,6,8,12,18$, and 24 inches

\section{CONSTRUCTION MATERIALS}

Bearing Housings

Cylinder Housing

Thirust Tube

Wiper Seal

Lead Screw

Support Bearings

Acme Screw; drive nut

Ball Screw; drive nut
Type 380 die cast aluminum, epoxy coated

6063 T-6 aluminum, hard-coated anodized and teflon impregnated

Type 304 stainless steel, 1/4 hard, ground and polished

Polyurethane

Ball bearings

0.625 inch diameter, carbon steel screw; lubricated bronze drive nut

0.625 inch diameter, carbon steel screw; alloy stecl, heat treated ball nut

WEIGHT (approximate, without options)

2 inch stroke unit-NS2:

2 inch stroke unit-NS3:

$5.8 \mathrm{lbs}$, add $0.25 \mathrm{lbs}$ per additional inch of stroke

$9.6 \mathrm{lbs}$, add $0.25 \mathrm{lbs}$ per additional inch of stroke

\section{MOTOR SPECIFICATIONS}

Type

Inductance

HIPOT breakdown

Static Torque

$1.8^{\circ}$ permanent magnet hybrid step motor

S2T $8 \mathrm{mH} ; \mathrm{S} 2 \mathrm{~V} 2 \mathrm{mH}$

S3T $6.2 \mathrm{mH} ; 53 \mathrm{~V} 1.5 \mathrm{mH}$

$750 \mathrm{VAC}$

S2T 135 oz-in $\max$

S3T 300 oz-in $\max$

Connections

S2N, S3N: 8 leads, 8 inch length

S2T, S2V, S3T, S3V: 5 contact quick disconnect receptacle in anodized aluminum shell, includes $12 \mathrm{ft}$ cable with molded plug

Temperature

$212^{\circ} \mathrm{F}\left(100^{\circ} \mathrm{C}\right)$ Maximum allowable motor case temperature

Actual motor case temperature is ambient, duty cycle and speed dependent. Refer to speed vs. thrust peformance curves for system duty ratings.

\section{ENVIRONMENTAL OPERATION}

For applications beyond standard allowable environmental conditions, see the Options and Accessories section.

Temperature Range

Moisture

Contaminants $32^{\circ}$ to $140^{\circ} \mathrm{F}$,

-H high temperature option allows $32^{\circ}$ to $160^{\circ} \mathrm{F}$

-F sub-freezing temperature option allows $-20^{\circ}$ to $+105^{\circ} \mathrm{F}$

Humid, but not direct moisture contact

-W water resistant option allows some direct moisture contact

Non-corrosive, non-abrasive

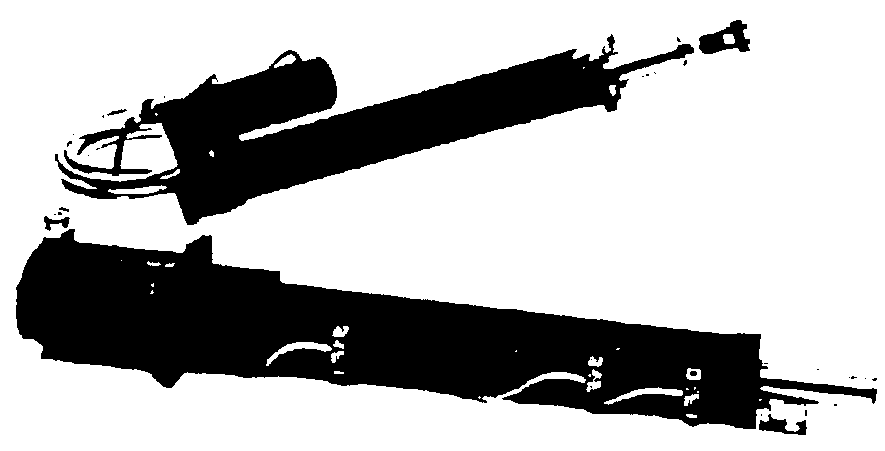


INDIVIDUAL MODEL SPECIFICATIONS-BALL SCREW MODELS

$\begin{array}{cccccccccc}\text { NS2N102B } & \text { NS2N105B } & \text { NS2N15213 } & \text { NS2N155B } & \text { NS2N20513 } & & \text { NS2N355B } & \text { NS2N12051B } & \text { NS2N992B } & \text { NS2N995B } \\ \text { NS3N102B } & \text { NS3N105B } & \text { NS3N152B } & \text { NS3N155B } & & \text { NS3N25513 } & & & \text { NS3N992B } & \text { NS3T995B } \\ \text { NS2T102B } & \text { NS27105B } & \text { NS2T152B } & \text { NS2T155B } & \text { NS2T205B } & & \text { NS2T355B } & \text { NS2T1205B } & & \\ \text { NS3T102B } & \text { NS3T105B } & \text { NS3T152B } & \text { NS3T155B } & & \text { NS3T255B } & & & \text { NS3T992B } & \text { NS3T995B } \\ \text { NS2V102B } & \text { NS2V105B } & \text { NS2V152B } & \text { NS2V155B } & \text { NS2V205B } & & \text { NS2V355B } & \text { NS2V1205B } & & \\ \text { NS3V102B } & \text { NS3V105B } & \text { NS3V152B } & \text { NS3V155B } & & \text { NS3V255B } & & & \text { NS3V992B } & \text { NS3V995B } \\ \text { Timing } & \text { Timing } & \text { Timing } & \text { Tining } & \text { Timing } & \text { Helical } & \text { Helical } & \text { Spur } & \text { In-Line } \\ \text { Belt } & \text { Belt } & \text { Belt } & \text { Belt } & \text { Belt } & \text { Gear } & \text { Gear } & \text { Gear } & \text { Flex Coupled } \\ \text { 1:1 } & 1: 1 & 1.5: 1 & 1.5: 1 & 2: 1 & 2.5: 1 & 3.5: 1 & 12: 1 & 1: 1 & 1: 1 \\ & & & & & & & & & \end{array}$

Drive Ratio
(motor:screw)

Screw Pitch

25

25

$5 \quad 5$

5

5

2

5

(rev/inch)

\section{SYSTEM PERFORMANCE USING S5O0O SERIES CONTROLS}

$\begin{array}{lccccccccccc} & \text { Stroke } & & & & & & & 2.9 & 0.8 & 25 & 10 \\ \text { Max. } & 2-18 \text { in } & 25 & 10 & 16.7 & 6.7 & 5 & 4 & 2.9 & 0.8 & \mathbf{1 8} & 10 \\ \text { Speed } & 24 \text { in } & \mathbf{1 8} & 10 & 16.7 & 6.7 & 5 & 4 & 2.9 & \end{array}$

(ips at no load)

When applying NS cylinders with yreater than 18 inch stroke, maximum speed may be limited by critical screw speed, as sbown bere in bold. The individual model perfornance curves sboun on the following pages bave been qualified (burizontal black lines) for critical speed limitations in 24 inch lengths.

\begin{tabular}{lcccccccccc}
\multicolumn{2}{c}{ critical speed limitations in } & 24 inch lengths. & & & & 450 & 800 & 65 & 165 \\
Maximum S2 & 65 & 165 & 99 & 248 & 330 & - & 450 & - & -145 & 365
\end{tabular}

(lbs at rest)

Repeatability (inches) Repeatability values achievable with $\$ 5000$ controls in open-loop configuration $\pm 0.0005 \pm 0.0005 \pm 0.0005 \pm 0.0005 \pm 0.0005 \pm 0.0005 \pm 0.0005 \pm 0.0005 \pm 0.0005 \pm 0.0005$

A COMPARISON OF SPEED VS. THRUST PERFORMANCE

Using S5101 or S5201 control, at 100\% duty cycle-see individual performance curves on page 150 .

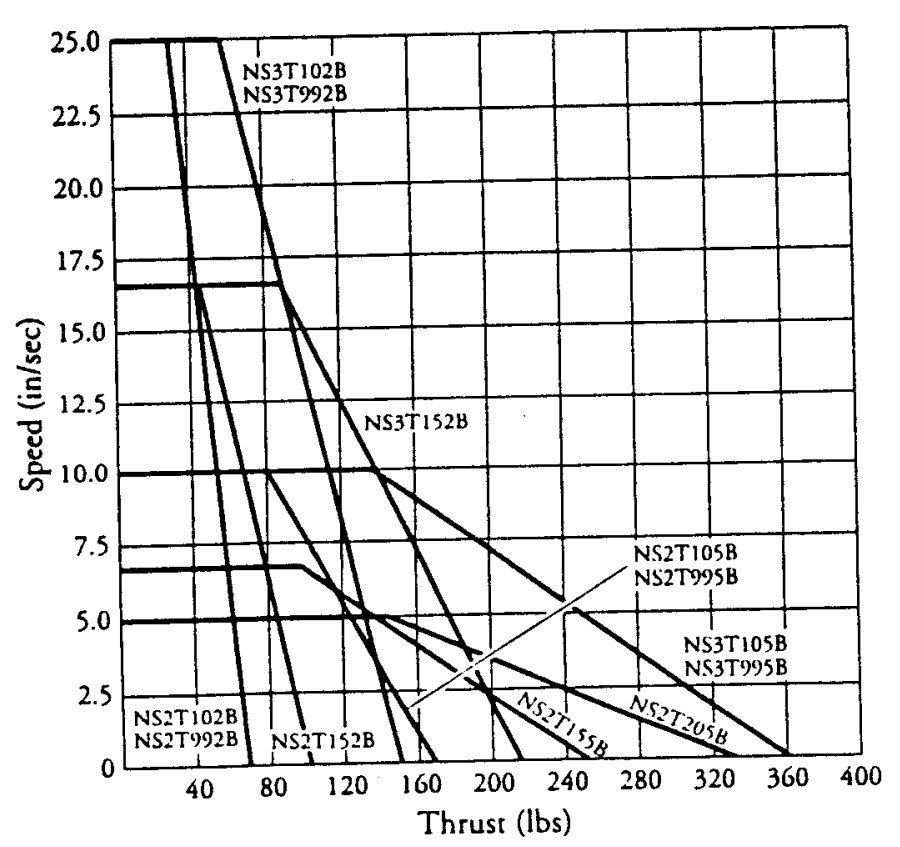

HIGHER SPEED MODELS

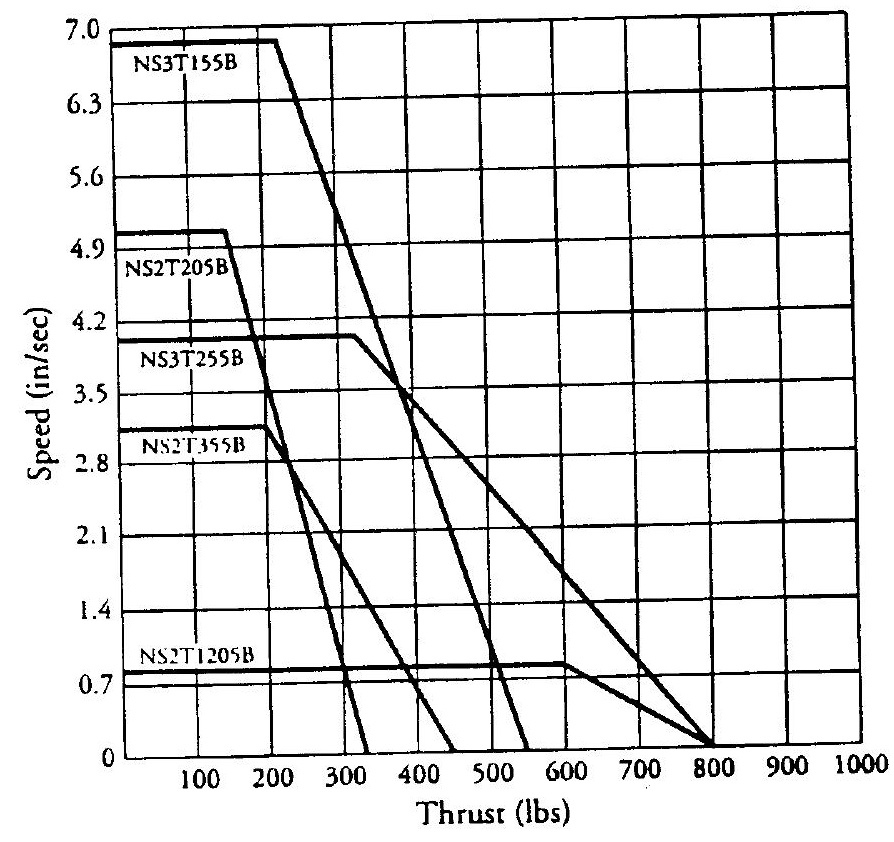

HIGHER THRUST MODELS 
TASK 2 REPORT

Hawaii Zuteck Rotor Project

\section{SECTION IX}

\section{TURBINE AND ROTOR FLAP CONTROL}




\section{GOALS:}

In designing the control system for the Hawaii Zuteck Rotor Project, the following goals were used:

- easy adaptability to changes in testing procedures,

- easy and quick integration into the existing wind turbine control system,

- minimal continuous signal requirements through the low speed shaft slip ring interface,

- complete and safe control of the wind turbine in all phases of testing,

- dual redundancy in critical shutdown systems.

\section{OVERVIEW OF THE CURRENT METHOD OF CONTROL}

The current control system for the Westinghouse WWG-0600 wind turbine consists of an Intel Single Board Computer System which interfaces through various analog, digital and serial communications boards with the turbine. The system is actually quite sophisticated for a wind turbine controller, allowing for many subtle methods of tweeking the production and operation of the wind turbine. We have not concerned ourselves with these subtleties, except where the flaps interact with the system.

The controller hardware is based on the Intel 8086 microprocessor running at $12 \mathrm{MHz}$ and the Intel 8087 co-processor running at $8 \mathrm{MHz}$. The wind turbines operate using the RMX86 operating system and the control software is written and compiled in PLM. The program is approximately $180 \mathrm{k}$ bytes long, taking up the majority of the space in ram (the computer has $256 \mathrm{k}$ bytes) and quite a bit of space on the bubble memory (permanent, non-volatile storage at $512 \mathrm{k}$ bytes size) The system is capable of handling 32 analog $1 / O$ signals and 48 digital $1 / O$ signals. We currently use approximately half of each.

Basically, the current controller software functions by reacting to the various inputs it receives in a preprogrammed manner. There are several different states of operation for the controller, which affect its responses to the same data coming into it. The main areas of concern for this task are those of start up, operation and shutdown. Each of these 
areas contains control logic that will be modified to work with the flap system. Unless otherwise stated, the following discussion assumes there are no faults that would cause a shutdown of the turbine.

The controller starts operation with the turbine in the shutdown mode, which is to say that the turbine is ready to operate if the sensors indicate that wind speed and direction will allow operation. When the controller calculates that these two criteria are met, it checks to see that there are no faults that would prevent start up and then shifts to the start up mode. in this mode, the turbine checks various sensor inputs, mostly from the pitch hydraulic system and commands the blades to start pitching toward operation. The hydraulic system drives the actuators for each blade by an amount determined continuously by the controller until the machine reaches synchronous speed. At this point, the controller commands blade pitch movement in relation to generator rpm error signals (analog) and gives permission to the auto-synchronizer to close on synchronization. Once the auto-synchronizer commands closure of the main bus breaker, the controller shifts to operate mode.

In operate mode, the controller controls blade pitch (to regulate power production) and yaw direction (to keep the machine in the wind). If a gust of wind should pass through the rotor, the controller will sense the increase in production, compare it against its current maximum power set point and, if the production exceeds the set point, command the feathering of the blades to dump the excess power.

The controller is also checking continuously for faults in the system. Most faults will cause the wind turbine controller to enter the shutdown mode. Negative power production for a preset period of time is considered a fault, which is how the system handles a low wind shutdown. Once the controller enters the shutdown sequence, the blades are commanded to pitch toward feather, which reduces the load on the generator. As the load goes negative, the main bus breaker is commanded open by the controller. The blades continue to progress toward feather until they have reached their locking mechanisms. The hydraulic pump is then shut down and the controller enters either the shutdown or safety shutdown state. From the shutdown state, the turbine can repeat the start up, operation and shutdown sequence at the next opportunity. From the safety shutdown mode, the failures that caused the shutdown must be cleared by human intervention before the turbine can enter the shutdown mode. 


\section{Description of the Modifications and Their Anticipated Interaction:}

The wind turbine controller provided us with two ways to control the flaps during testing of the Hawaii Zuteck Rotor Project. The first was to modify the existing turbine control software (for which we have a license) to accommodate the use of flaps on the wind turbine. The second was to modify the control system to communicate with the flap two axis controller (see appendix IX-1 for a brief description of the controller) and have the actuator controller make the calculations and give commands to the actuators. We decided that the latter was probably less difficult and have proceeded based on that assumption. Accordingly, a signal (modified from the watt transducer) is introduced into the flap controller joy stick port to indicate to the controller whether the turbine is over or under power and by how much. This input, a voltage, indicates that rated power has been reached by achieving a zero volt state. Negative values indicate the turbine is under rated power and positive values that the turbine is over rated power. The magnitude of the signal indicates how far under or over the set point the turbine is producing. The controller's reaction to an over rated power event will be to move the flaps in a predetermined fashion, which will change as part of the testing, toward feather. The opposite is true of an under rate power event, with the exception that deployment to the positive flap angles will be done only in light winds as sensed by very large under rated power events. Through one of two digital signals available on the same joy stick input, the main controller will indicate when it has sensed the need for shutdown to occur. When this happens, the flap controller will move the flaps toward feather in various predetermined algorithms, which will be part of the testing. These algorithms will all cause the eventual flap deployment to the full stop position. The second digital input will be used to indicate a trip of the emergency shutdown system, which will cause all flaps to drive toward stop at 20-30 degrees per second.

If the opportunity permits, we will be testing other methods of controlling the flaps, mostly having to do with direct wind turbine controller interaction with the flaps. This would entail the use of position feedback to the controller and determination by the controller of the optimal position for each flap, which it would then command. Such changes would be in addition to the above described method, or would replace that method should it fail to provide adequate control. 
It is expected that the flap system, along with the nose trip, will be able to reduce the spiking of the wind turbine (currently capable of more than $80 \%$ overshoot). We also anticipate that there will be flap control modes that will allow the reduction of flat wise bending loads due to differential deployment of the flaps. In other words, we expect to demonstrate a control mode that will turn off the outer rotor first, reducing the tip loads and thus the bending loads.

Another concern for the control system interaction will be those of the rotating environment. to which the flap controller will be exposed. Although the manufacturer indicates that the controller is capable of taking such loads, we will be observing it closely to determine any deterioration of the controller.

Finally, the ability to stop the machine will require careful testing to find the optimum flap angle for each tip speed ratio as the machine comes to a rest. Wind tunnel data indicates that this should be somewhere near 60 degrees for most tip speeds, and moving toward 90 degrees (stop position) as the rotor rpm reduces.

Although not strictly part of the machine interaction or the control software, there will be a capability to manually control the flaps through the use of a potentiometer box. It would take the place of the wiring that interfaces with the flap controller at the joy stick input. This box will be used for calibration, testing of flap systems in static conditions and, in a limited way, small deflection testing of the flap system while the turbine is running. 
TASK 2 REPORT

Hawaii Zuteck Rotor Project

\section{APPENDIX IX-1}

PARKER COMPUMOTOR CONTROLLER 


\section{C $\quad H \quad A \quad P \quad T \quad E \quad R \quad$ (1) \\ Introduction}

The information in this chapter will help you understand the 6200's basic functions \& features.

The Compumotor 6200 is a stand-alone, microprocessor-based, two-axds indexer. The 6200 provides sophisticated multi-axis control of any Compumotor motor/drive or any standard full-/half-step or microstep translator compatible with step \& direction signals.

Using the 6000 Series Programming Language. you can program the 6200 via a PC or a dumb terminal. User programs are stored in the 6200's batterybacked RAM.

The 6200 also provides operator interface capabilities when used with the Compumotor RP240 Front Panel.

The 6200 comes standard with support software for the Microsoft Windows ${ }^{\mathrm{TM}}$ and DOS operating environments:

- Motion Architect ${ }^{\mathrm{TM}}$ is an innovattve, easy-to-use Microsoft Windows $^{\mathrm{TM}}$ based programming adde to help you caslly create and implement complex motion programs. For more information, refer to the Motion Architect User Guide.

- The 6000 DOS Support Disk contains a DOS-based program edttor and terminal emulator package. Also included are sample 6000 Command Language programs.

Refer to 6200 Features below for a list of the 6200 's I/O capability. 


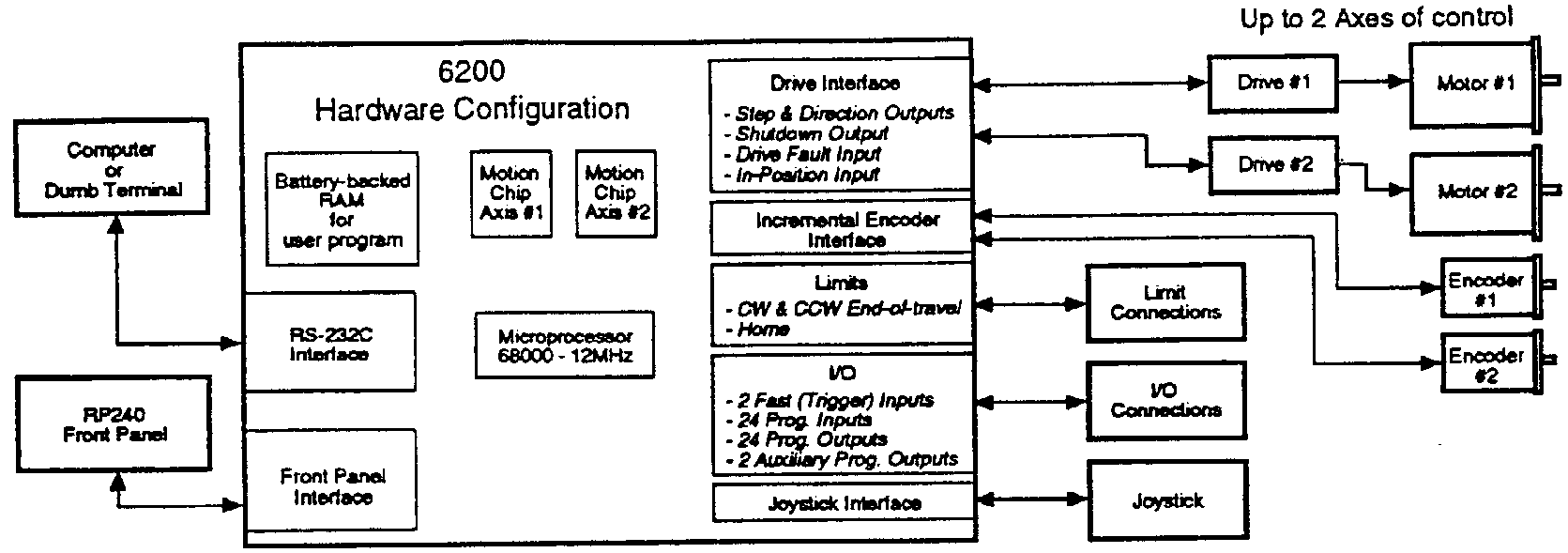

\section{Features}

D 1 to 2 axes of step and direction control with encoder feedback

DOS Support Disk provided

口 40,000 bytes of non-volatile memory for storing programs and paths

a Capability to interrupt program execution on error conditions

- Encoder and motor position capture (using the trigger inputs)

- Registration (using the trigger inputs)

2-axts linear interpolation standard

- 2-axds circular interpolation optional (6200-C)

a Vartable storage, conditional branching, and math capability

- Program debug tools - single-step and trace modes, breakpoints, error messages, and simulation of $1 / 0$

Internal power supply

口 Direct interface to RP240 Front Panel

- Operates stand-alone or interfaces to PCs \& PLCs

a Communication with PC or dumb terminal vla 3-wire RS-232C interface

- Encoder channels configurable as hardware up/down counters

a 1/O capabllities (all 1/O are 1solated):

- Step \& Direction output (up to 2 axes)

- Shutdown output (up to 2 axes)

- Drtve Fault and In-Position inputs (up to 2 axes)

- Incremental encoder input (up to 2 axes)

- CW \& CCW end-of-travel limit tnputs (per axis)

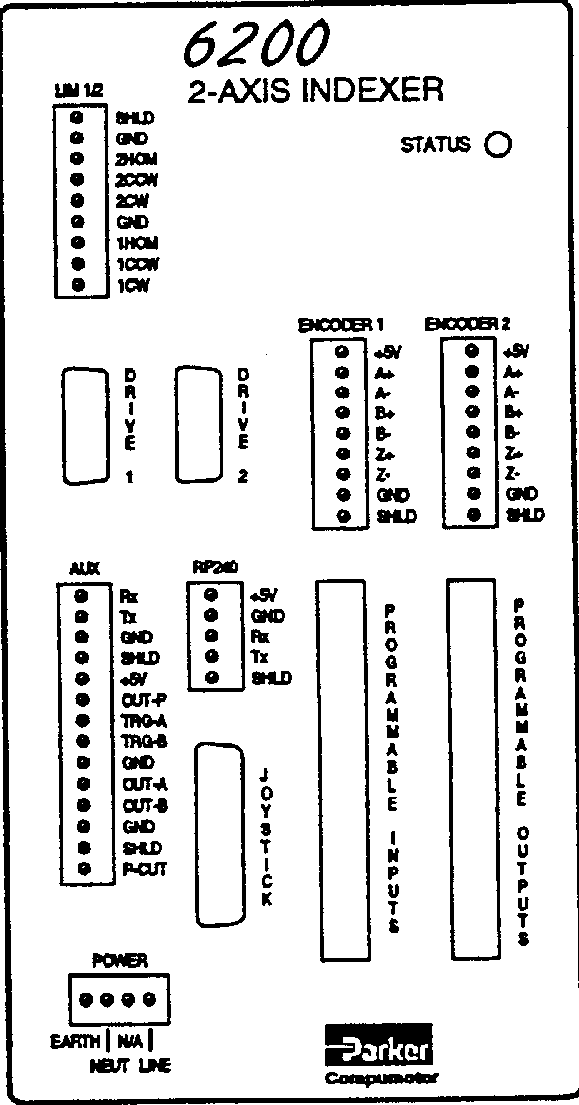

$\approx 00$ Front Panel

- Home limit input (per axds)

- 3 analog inputs for joystick control and vartable input

- 2 fast (trigger) tnputs - use with encoder capture

- 24 programmable inputs (Opto-22 compatible)

- 24 programmable outputs (Opto-22 compatible)

- 2 audiliary programmable outputs 


\section{FI \\ Makani Uwila Power Corporation}

\section{TASK 2 REPORT}

Hawaii Zuteck Rotor Project

\section{SECTION X}

\section{TEST PLAN}




\section{TEST PLAN}

Westinghouse WWG-0600 Wind Turbine

Rotor and Control Modifications

Hawaii Zuteck Rotor Project

\subsection{TEST OBJECTIVES}

The goals of the bolt on rotor test are to:

- Verify the aerodynamic control ability of the retrofitted flap system along with the effect on turbine power output.

- Validate the load and life calculations of the final hardware design and assess basic operational reliability.

- Increase the data base of flap controlled wind turbine operations, especially at start-up, during normal wind speeds, and at shut down.

\subsection{SAFETY ISSUES}

All testing will be carried out in accordance with the Safe Operating Procedure specific to this project (see Appendix); with Northern Power Systems Quality Assurance Standards QA200 (Rev 08-25Nov91); and with applicable OSHA regulations.

Scaffolding and turbine nacelle mounted work platforms will be required to carry out the test program. All personnel will descend from the scaffolding to ground level whenever the turbine is yawed toward or away from the scaffolding. During these operations personnel will move outside of the scaffolding fall radius until the operation is complete.

Two fixed work platforms will be installed on the outside of the nacelle. Technicians shall be connected by safety lines to appropriate points on the nacelle structure, not the platform or rotor, when working on the platform.

\subsection{TEST ARTICLE}

Testing will be carried out on a modified Westinghouse WWG-0600 wind turbine. Primary system modifications will be to the rotor assembly, secondary modifications will be to the turbine control system. Additional minor system modifications will be required to accommodate the test program. 
The test rotor blades will be the two original Westinghouse turbine blades that have been retrofitted with aileron flaps and actuation system under this development program at the Gougeon Manufacturing facility in Bay City, MI.

\subsection{TEST SITE \& LAYOUT}

The modified rotor blades will be evaluated in bench testing at Gougeon prior to shipment to Hawaii.

In Hawaii the blades will be installed on the WWG-0600 turbine at Site 9 of the Kahuku Hills wind farm. All other modifications and tests will be performed on the same turbine. Preparation for such work may occur at the central facility of that wind farm.

\subsection{TEST SCHEDULE}

Testing is planned for early spring of 1995. Sequence of the tests is provided in 8.0 below.

\subsection{TEST INSTRUMENTATION \& FUNCTION}

The following sensors are to be employed in the test program:

Strain gages will be mounted at various positions on a blade to measure flatwise bending, edgewise bending and blade torsion. These gages will be used for both bench testing at Gougeon and during operational testing in Hawaii. The accompanying drawing indicates the designated locations of the strain gages on a blade. See Appendix X-1 for strain gage installation details.

Load cells will be used at anchor points of the cable runs in the actuation system to measure the forces in the power and return lines. These forces will be used to validate the design loads and to determine that the ball screw loads are not excessive.

Flap angle will be measured using magneto-resonant sensors. These sensors will be mounted forward of the flap nose, with each flap being connected to a dedicated sensor.

Actuator motor position will be measured with an optical encoder mounted directly to each motor. These sensors will be used to compare 


\section{BLADE STRAIN GAGE LOCATIONS}

1. EDGEWISE ARE TWO PAIRS CONNECTED TOGETHER TO MAKE A FULL BRIDGE.

2. OUTBOARD EDGEWISE INSTALLATIIONS HAVE TWO GAGES ON THE AFT WEB FORWARD OF THE AILERONS.

3. FLATWISE PLACED AS CLOSE AS POSSIBLE TO THE BLADE NEUTRAL AXIS.

4. FLATWISE GAGES ARE ONE PAIR EACH ON THE UPWIND AND DOWNWIND SURFACES.

5. TORSIONAL AND AFT WEB SHEAR SETS CONSIST OF FOUR GAGES IN A CROSS.

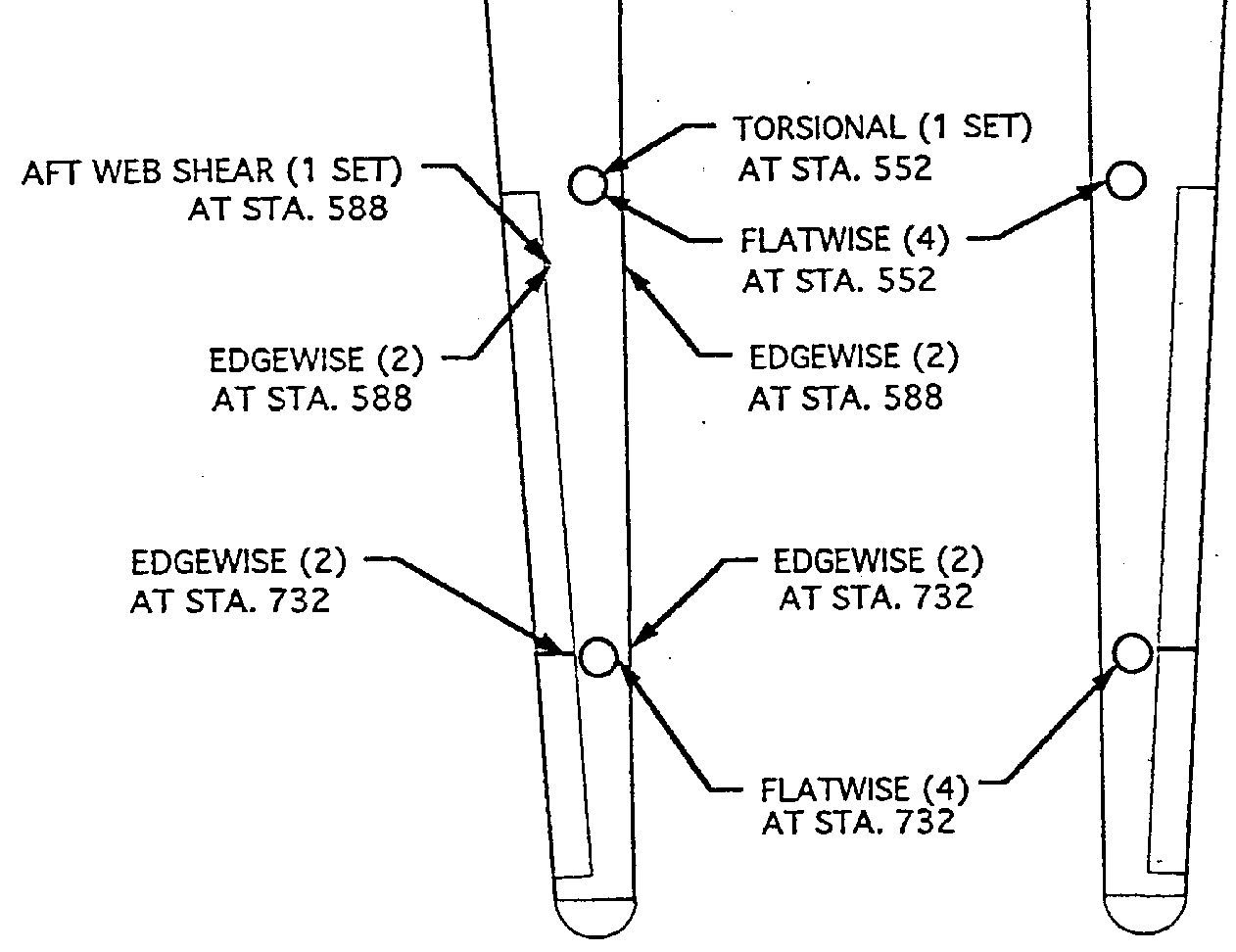


with the flap angle sensors, assuring that the flaps are moving as intended.

A standard cup anemometer and wind vane mounted on the met tower up wind of the wind turbine will sense wind speed and direction.

Prior to the commencement of any testing, all sensors, instrumentation, and data acquisition subsystems will be calibrated against known and verifiable standard measures and otherwise checked for proper operation. The results of this calibration process will be recorded and included in the test report. As appropriate, periodic checks of calibration and function will be carried out on each device.

\subsection{DATA COLLECTION \& PROCESSING}

The NREL-provided Zond data acquisition system (DAS) will be used to collect the output of the sensors listed in Section 6.0. A power transducer will be mounted in the switch gear of the turbine to feed signals to the DAS. This transducer will not be the one used in turbine control.

Global Labs data analysis software will be used to process the data on a PC computer system.

\subsection{DESCRIPTION \& SEQUENCE OF TESTS}

\subsection{Bench Testing}

\section{System Verification}

After the sensors, actuation system and flaps have been installed, all sensors will be calibrated individually and operation of all subsystems will be confirmed. The sensors, actuator systems and data collection system will then be integrated to test each blade system as a whole. Static Load Tests

When each blade system is operational and calibrated, the blades will be subjected to different load gradients to measure stresses, test the structural interactions of the flap system, verify the load and bending design calculations, and confirm that the data system operates in conjunction with the rest of the system.

\subsection{System Integration}

After the blades arrive in Hawaii, they will be attached to the turbine hub at ground level. When all of the connections and attachments are made, the actuation system and the data collection system will be tested from the nacelle side of the slip ring. When these checks are 
satisfactorily completed, the rotor assembly will be raised to the towerhead and installed. After all turbine control system integration and modification is complete, the final static test sequence will occur and full system readiness for dynamic testing will be demonstrated to the NREL technical monitor. The final step in commissioning of the modified turbine system will be operation in light winds to verify basic dynamic control.

\subsection{Operational Tests}

This testing shall examine the operational characteristics of the blade/flap systems and their relationship to turbine power. The major variables affecting data collection will be:

- wind speed and turbulence

- blade pitch angle

- flap angle

The dynamic test results will be used to verify earlier program calculations and predictions.

Hardware Evaluation

Throughout the dynamic test period there will be observation and measurement of flap system operation, and physical inspection of components. Flap actuation link loads, retention of system pre-load, possible link load oscillations, flap angular float, and flap loads in operation and at shutdown will be recorded.

Starting Torque Evaluation

Identify the optimum flap angle and blade pitch for lowest cut-in wind speed of the rotor.

\section{Stopping Evaluation}

Determine the ability of the flaps to slow down or stop the rotor when deployed to $-90^{\circ}$.

Determine the shut down equilibrium tip speed ratio at different wind speeds.

Modulation of Flaps for Rotor Control

Determine the effect on turbine power of various flap angles, and the ability of the flap system to limit power spikes. The blade pitch will be set to the optimum pitch determined during the start/stop evaluations. Aerodynamic stall characteristics will be identified. 
Determine the maximum sustainable RPM, up to synchronous speed, at different flap angles in different wind speeds.

Once startup and shut down parameters are determined, flap loads and power curves will be collected at fixed flap angles. This procedure will be carried out up to the rated power of the turbine, with flap angle controlled manually. The intention of these tests is to provide input data for the control algorithm of an automated system to control the flaps.

Automated testing of the flap control system will start with modification of the control algorithm to reflect the understanding gained in the previous tests. This testing will verify that the modified system can control the turbine in normal unattended operation.

\title{
9.0 TEST REPORT
}

The results of the test program will be compiled and analyzed in a test report. This report will include a section for each designated test with tabulated load and/or performance data as well as a summary log with narrative description of major events, findings, and problems. Each section will end with a conclusion in which the findings of that series of tests are summarized. Supporting graphs, charts, or comparative data will be generated and included as appropriate.

The test report will provide the information used in the final project report for an overall assessment of the turbine modifications. As such, care will be taken to generate data that can be used in evaluating:

\author{
-Affect on Electrical Production \\ -Design Suitability \\ -Reliability \\ -Control Effectiveness
}




\section{TASK 2 REPORT}

Hawaii Zuteck Rotor Project

\section{APPENDIX X-I}

\section{STRAIN GAGE INSTALLATION DETAILS}



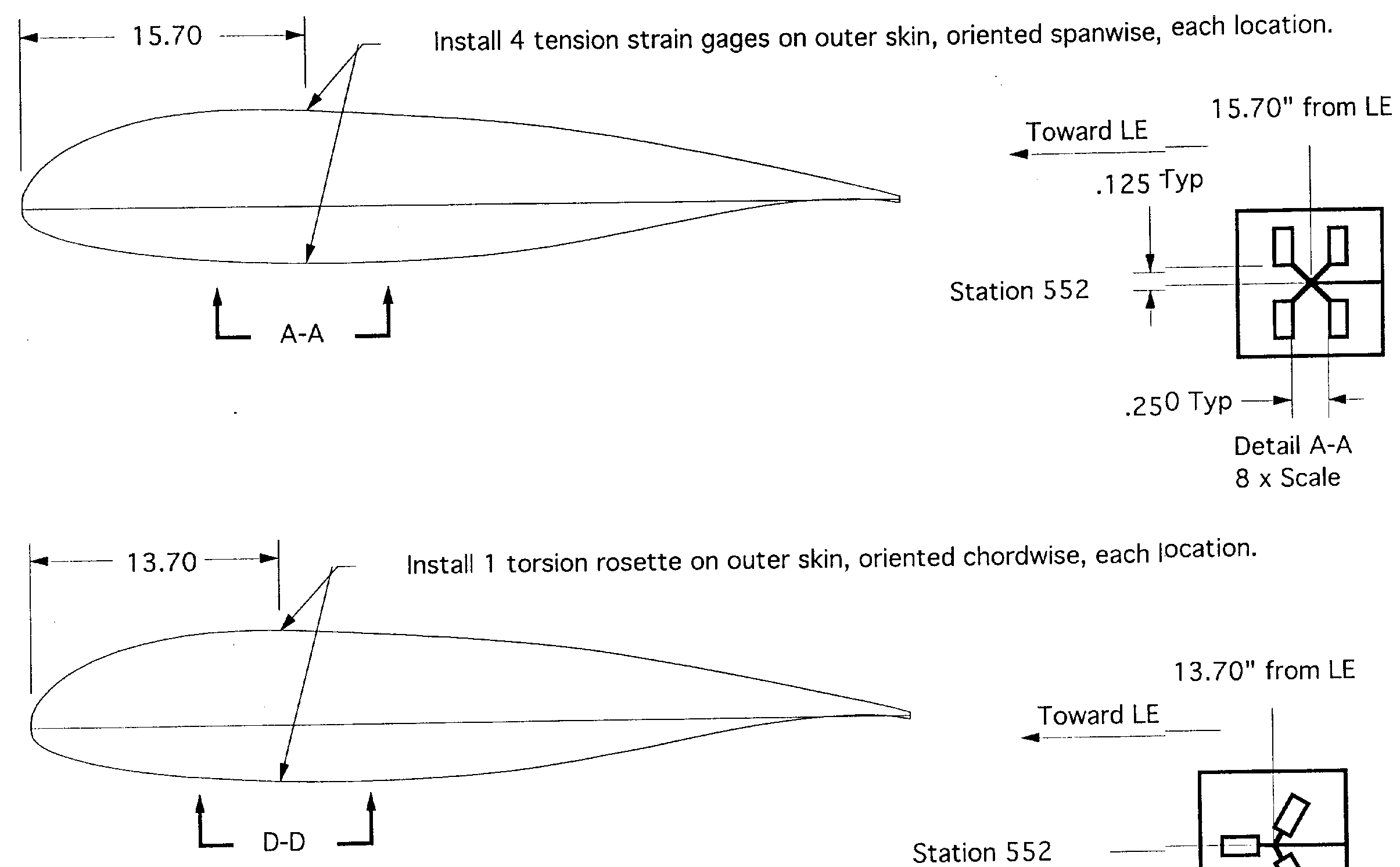

Station 552

13.70" from LE

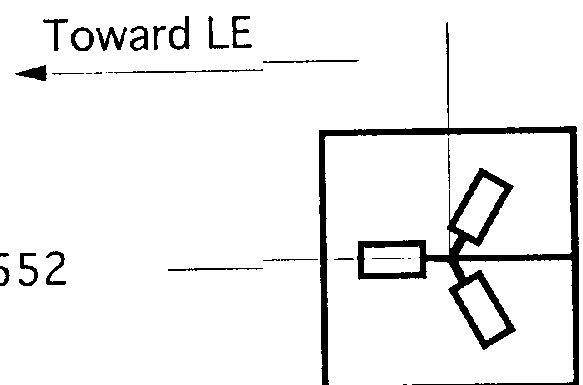

Detail D-D

$8 \times$ Scale

STRAIN GAGE DETAILS, Station 552 


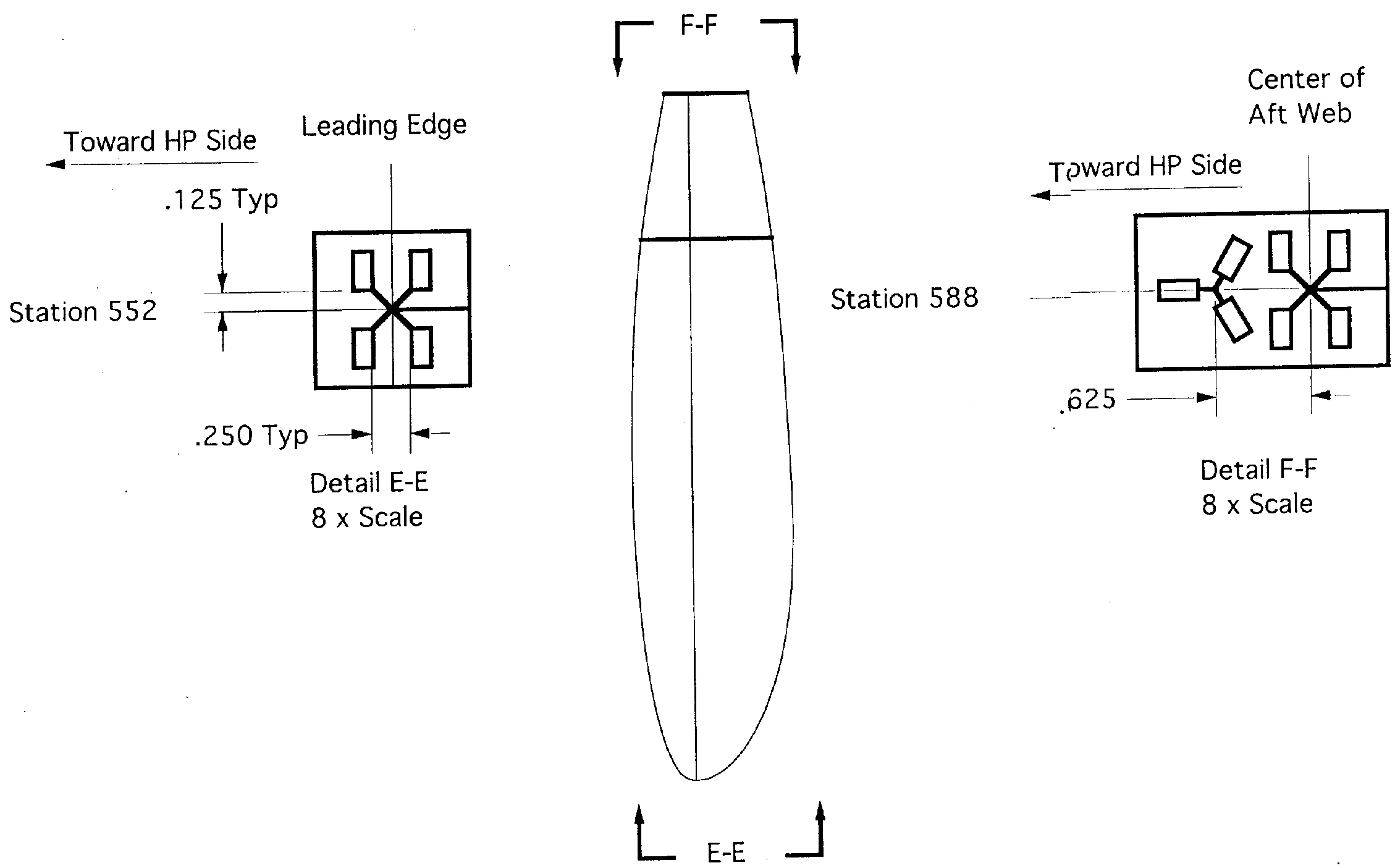

STRAIN GAGE DETAILS, Station 588

- Page 1 of 1 , Scale $1 "=8 "$ 


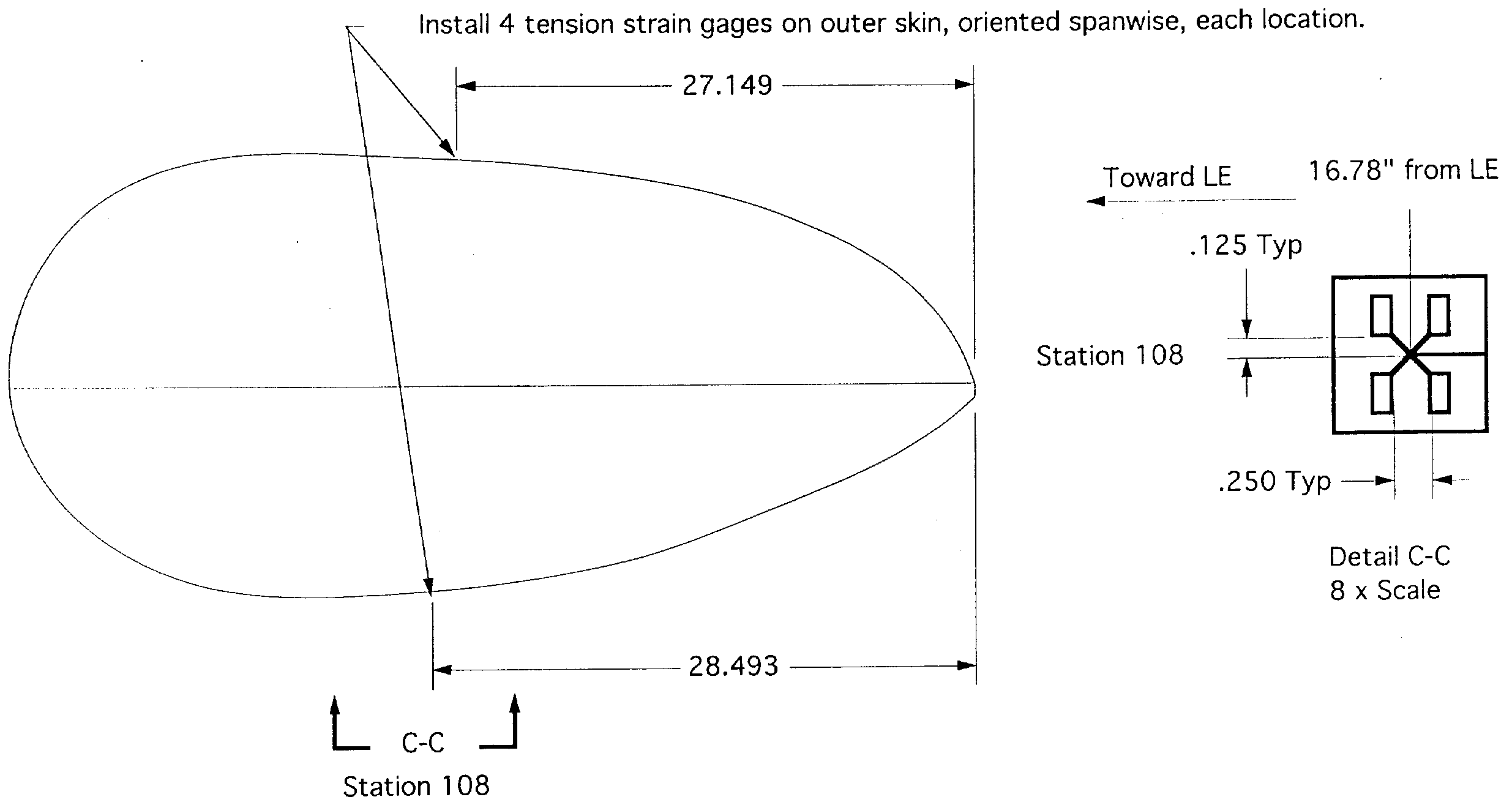




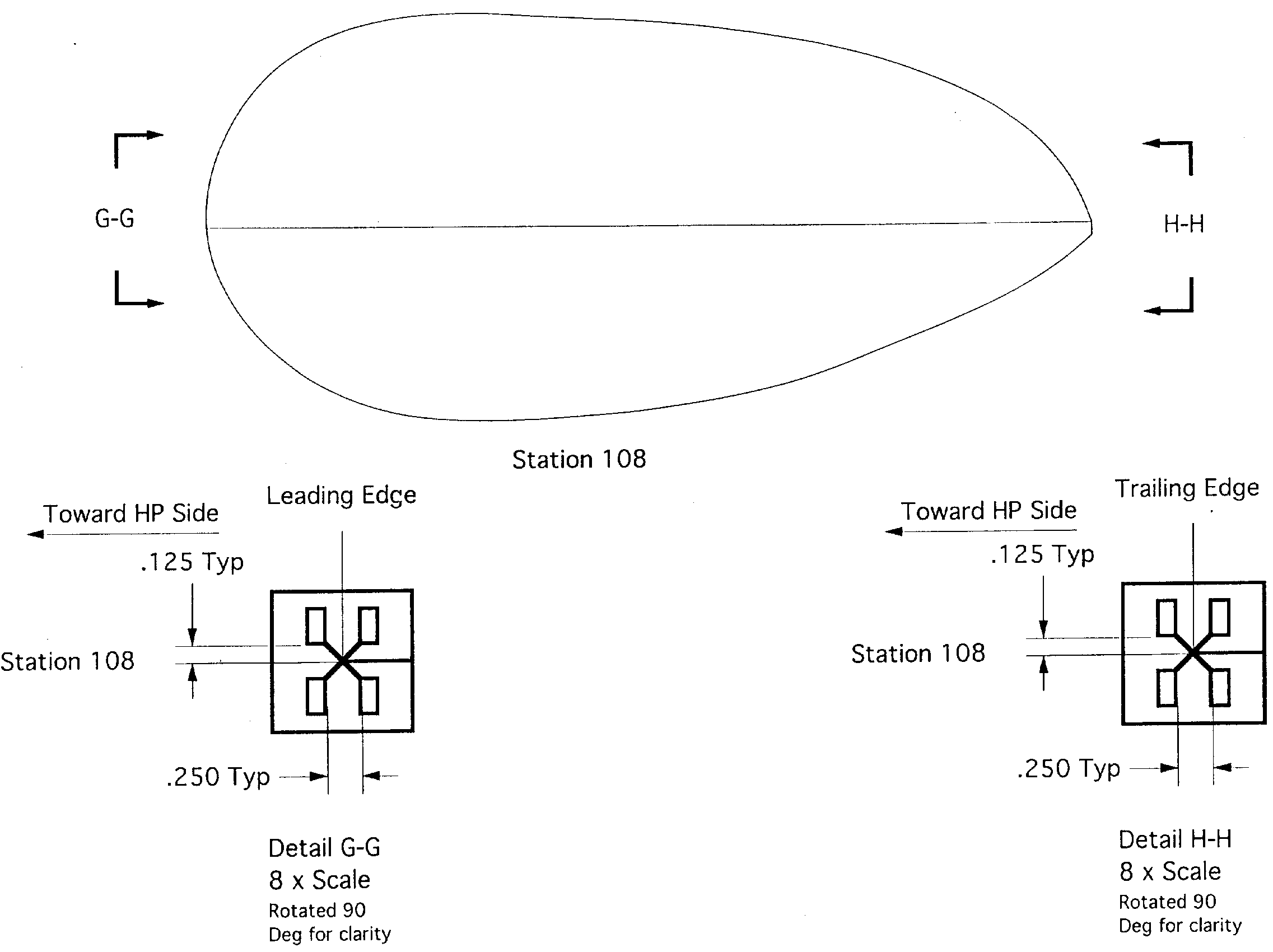

STRAIN GAGE DETAILS, Station 108

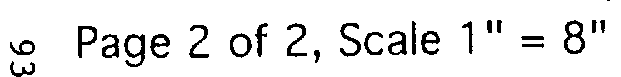




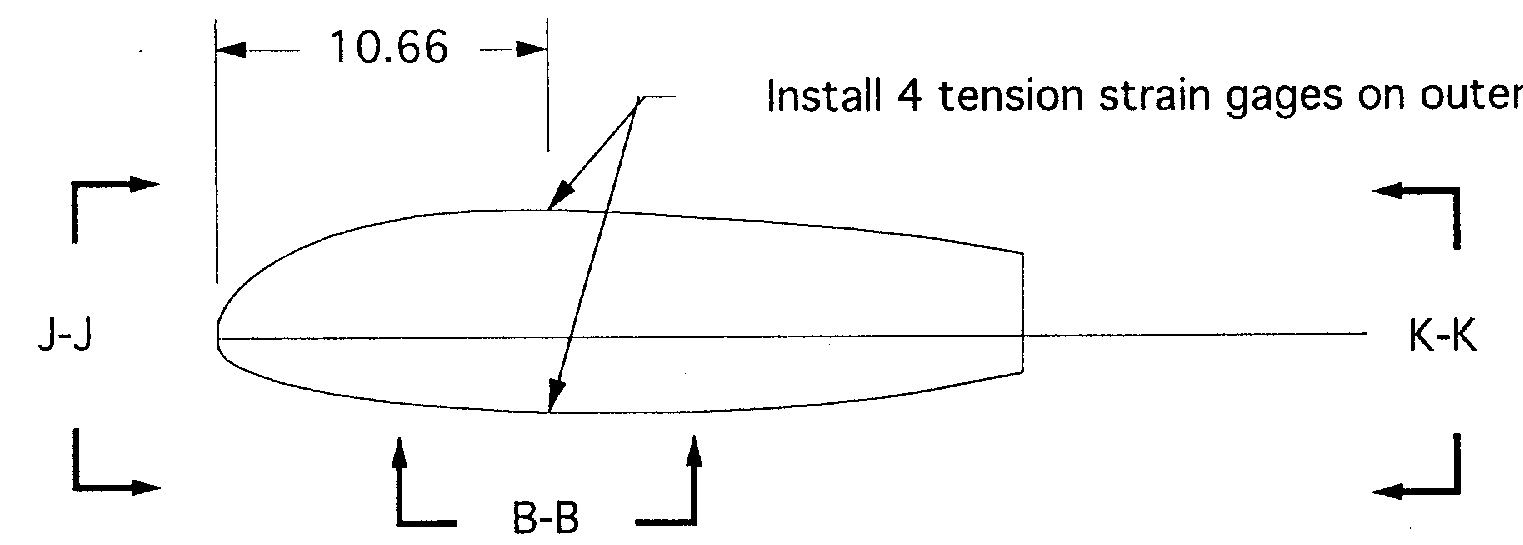

Station 732

Toward HP Side Leading Edge

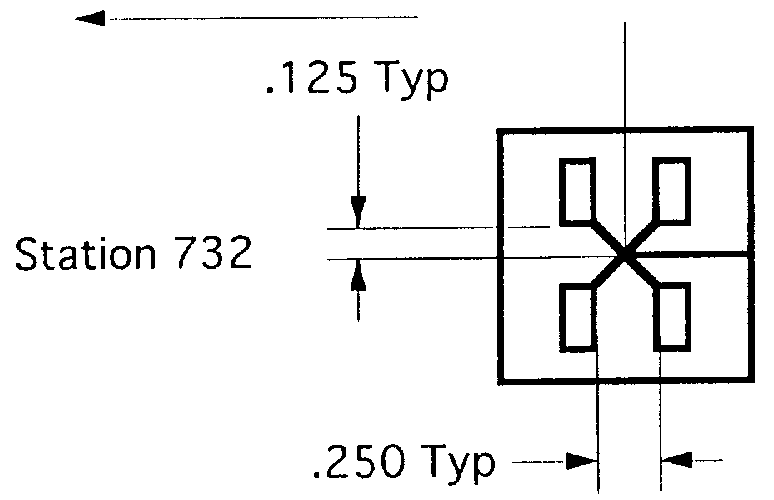

Detail J-J $8 \times$ Scale Rotated 90 Deg for clarity

STRAIN GAGE DETAILS, Station 732

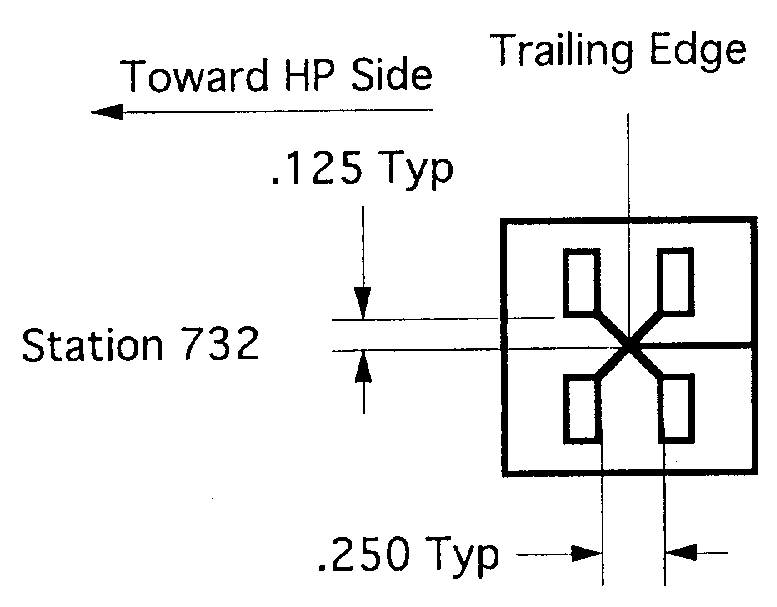

Detail K-K

$8 \times$ Scale

Rotated 90

Deg for clarity
Toward LE $\quad 10.66$ " from LE

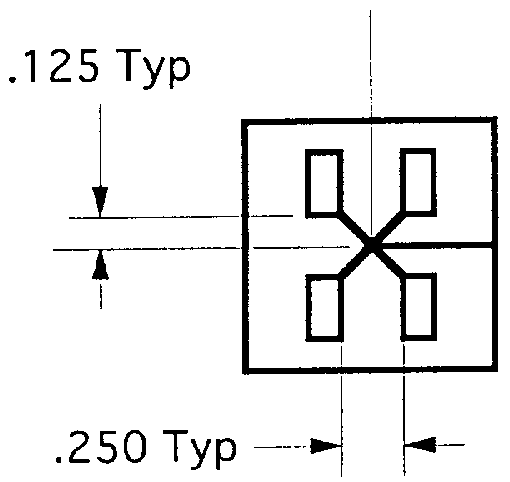

Detail B-B

$8 \times$ Scale 
Notes:

1) Remove all paint and prepare surface within a 2 " circle of the installation site.

2) Tension Gages should be installed with $1 / 4$ " clearance between gages.

3) Gages should be installed 1/8" on either side of the site.

4) Wiring will run aft along the chord line and into the cavity for hookup.

5) The four gages each side will be electrically connected to form a balanced bridge.

6) All leads should be routed toward the trailing edge by way of the Low Pressure side. Bond all leads to external surfaces with epoxy, fairing smoothly to skin. 
Makani Uwila Power Corporation

TASK 2 REPORT

Hawaii Zuteck Rotor Project

APPENDIX X-II

SAFE OPERATING PROCEDURES 


\section{Hawaii Zuteck Rotor Project}

Safe 0perating Procedure

for the

Hawaii Zuteck Botor Project

at

Site 9,

Kahuku Hills, Hawaii

under NREL Subcontract \# HC-2-11101-4,

Task \# WE 129201 
SOP Page 2

July 23, 1993

\section{1) Introduction}

The safety and well being of those at the Kahuku wind farm site are of the utmost importance to management. We make every effort to insure that all operations are safely carried out. The safety issues related to our project at this site are primarily those of any operating wind farm. These include the possibility of injury or death from unauthorized operation or entry in the turbines. Other hazards include falls, electric shock and traffic accidents. These, and others are described in more detail below.

2) Description of Hazards

Operation of a wind farm involves the hazards that do not ordinarily occur in office jobs. These hazards include:

A) Electrical Hazards.

Electrical hazards are hazards of electrical shock caused by contact, or close prosimity to, electric voltage or current sources. These hazards could result from falling power lines, exposure to electrical circuits with high potential, and faults while using power tools and equipment.

B) Fall Hazards.

Fall hazards are hazards resulting from exposure to heights that could involve injury or death should the persons movement not be restricted in a vertical direction. Fall hazard exposure results from working outside of nacelles of wind turbines, in man baskets either inside or outside of turbines, from ladders, scaffolds, or other high platforms, crossing over gaps between pieces of equipment (such os 
the nacelle to blade crossing at MOD-5B or the spinner plate to HPU support in the Westinghouse machine) or any other equipment or building that increases a workers height above the ground.

c) Fire Hazards.

Fire hazards expose workers to excessive heat, smoke or open flame due to combustion of objects in and around the wind farm. Structure fires, brush fires, automobile fires and turbine fires are all possible exposure sources for workers. These fires can be ordinary combustibles, liquid or solid petroleum products or electrical sources.

D) Falling Object Hazards.

Falling object hazards involve objects striking or nearly striking a person or other object after falling from above. Anywhere there are objects above a person there is danger of an injury caused by these hazards. Special attention should be paid to the possibility of objects falling from running wind turbines and objects falling from active work areas overhead. Objects separating from wind turbines in operation are especially hazardous because of the additional velocity imparted to such objects due to the rotation of the machine. Ouerhead work areas are dangerous because of the movement of objects by crews overhead.

E) Mechanical Motion Hazards.

Mechanical motion hazards are defined as dangers arising from the movement of parts in and around the turbines. Employees can be injured by contact with these parts or if their clothing or hair are caught in these parts. These injuries could also result from the improper or careless use of power tools.

F) High Pressure System Hazards.

High pressure system hazards involve exposure to gases and fluids pressurized for energy transfer. These include hydraulic 
systems operating as high as 3000 psi and nitrogen gas systems operating as high as 2500 psi. The two main hazards are spray, where a leak creates a high pressure stream capable of penetrating or cutting skin, and suffocation, where a high pressure gas leak causes rapid orygen displacement.

G) Chemical Hazards.

Chemical hazards are those that would result from exposure to chemicals used on the site. Most chemicals used at HERS are minimally hazardous and all are clearly labeled with OSHA certified symbols.

H) Transportation Hazards.

Transportation hazards are those involving vehicle accidents. The wind farm occupies land used for training by the U.S. Armed Forces. Uehicular traffic is sometimes heavy.

3) Handling Precautions.

A) Electrical Hazards.

There are significant high voltage electrical shock hazards to most work on the wind farm. To minimize this hazard, HERS requires that all personnel working on electrical circuits be fully trained in electrical safety and first aid for electrical shock victims. Further, all potential high voltage (greater than 480 vAC) shock hazards are guarded by automatic or manual cutouts that must be engaged before allowing access to the high voltage area. HERS requires that, whenever possible, two opens on all phases of an electrical line isolate live high voltage lines from a work area. Further, one of these opens shall be visually verifiable. A non-contact voltage detector (ticker) is available on site and shall be used to determine the state of a line before work is performed on that line. Lockouts and tags shall be placed on all open switches so that those working on the line are the only ones able to close the switch. 
SOP Page 5

July 23, 1993

For circuits of lesser voltage, certification is still required. The ticker is capable of locating live lower voltage $A C$ lines and shall be used when needed. All AC circuits shall be shielded from accidental contact.

B) Fall Hazards.

HERS recognizes and trains personnel to avoid fall hazards in and around the turbines. Each person working around the turbines is required to understand and train for the possibility of a fall. All personnel are required to undergo yearly certification on safety and fall hazard avoidance, including the use and maintenance of fall arrestors, proper rigging of fall arresting equipment and common fall hazard situations around the farm.

C) Fire Hazards.

Fire is a very serious hazard in a wind turbine as it is possible to have the fire between the workers and an exit. HERS trains all personnel in fire prevention and the use of fire extinguishing equipment as a means of escape from the turbine. Specific evacuations plans with contingencies are reviewed with the staff on a regular basis.

D) Falling Object Hazards.

Most work areas in the turbines are enclosed to naturally minimize the danger of falling objects. If the crew foreman determines that there is a significant danger of falling objects, hard hats and other protective equipment shall be worn by all personnel within that work area and signs shall be posted indicating the protective equipment required.

E) Mechanical Motion Hazards.

Mechanical motion hazards are addressed by shielding or 
SOP Page 6

July 23, 1993

guarding rotating equipment that could be contacted by personnel working in the area. Wind farm rules prohibit entry into the nacelle of a running wind turbine under normal operational conditions. Variance from this rule requires management approval and a review of the mechanical motion dangers present in the nacelle when the turbine is running. In addition, personnel are required to certify on a yearly basis their understanding and ability to work around mouing machinery.

All personnel shall be certified in the safe use of power tools before being allowed to use such tools.

F) High Pressure System Hazards.

High pressure system hazards require training and common sense to auoid. All personnel are required to review the hazards of working with high pressure systems on a regular basis, including the cutting and oxygen displacement capabilities of these systems. All work with high pressure systems requires previous certification and annual recertification.

G) Chemical Hazards.

Training in chemical hazards is carried out during our annual first aid training. Eye washes are provided in each first aid kit ( 2 per turbine) and a sink and rinse area are provided in the warehouse.

H) Transportation Hazards.

The posted speed limit on all roads on the wind farm is $15 \mathrm{MPH}$ and all personnel are regularly instructed to follow this limit. They are also instructed to use extra caution on the roads when there are military units training in the area. Military Police patrol the site from time to time to insure the road safety rules are enforced.

4) Operational Procedures:

All personnel will be trained in the proper operation of the 
emergency facilities at the wind farm before they are allowed access to the turbines. Training includes the use of the emergency stop buttons, bedplate stop switches and other means of safely securing the turbines. The general emergency plans are reviewed with the staff on a regular basis. More specific training will be provided during orientation of anyone who is temporarily on the site.

\section{5) Authorized Personnel:}

Only those certified by HERS shall be authorized to operate, troubleshoot, maintain, or conduct testing on any of the machinery or equipment on the site. Certification shall indicate management confidence, as demonstrated in training and testing to the satisfaction of management, that the person is competent and capable of performing the task(s) in a safe and knowledgeable manner. Anyone performing tasks for which they are not certified, unless directly supervised by HERS personnel who are certified in that task, for the purposes of training, shall be subject to disciplinary action, or in the case of those not employed by HERS, ejection from the site and referral to their employer for disciplinary action.

\section{6) Personnel Training:}

All HERS personnel are required to train and certify on all equipment for which they have been hired to operate to the extent of their job requirements, as set forth in their job descriptions. Those who are unable to certify may face disciplinary action for nonperformance. The same requirements and procedures shall be enforced for all other personnel on site who are authorized to work on HERS equipment. The specific standards for each certification are available to all personnel. These may be changed at any time, possibly requiring recertification, at the discretion of management.

\section{7) Environmental}

All hazardous wastes shall be disposed of in accordance with City, State and Federal law. Most wastes will be in the form of used 
SOP Page 8

July 23, 1993

petroleum based products which shall be deposited in the waste oil tanks provided at the warehouse for that purpose. This waste oil shall be removed from the site by certified oil disposal companies.

\section{8) Emergency Notification:}

All personnel shall have, within easy reach, a radio and/or telephone at all times. In emergency cases, every effort will be made to notify management of the situation as soon as possible.

Specifically, for the case of fire, the fire department shall be notified as to the type, location, and size of the fire. The fire department can be reached from any phone on the Westinghouse site by dialing 911 on any phone. All personnel shall use judgement and common sense in determining their safety and capacity to extinguish the fire.

Personnel must recognize that their first responsibilities in a fire are their lives and those of their fellow workers. Fire extinguishers located around the site, especially those located in the turbines, are intended primarily to aid in the escape efforts of personnel in a fire situation. Always leave a way out when fighting a fire.

Management shall be notified of all injuries requiring treatment beyond basic first aid as soon as possible. All medical emergencies requiring more than on-site first aid shall be taken to Kahuku Hospital Emergency hoom or Kaiser Clinic in Kahuku for initial care. If an ambulance is required, (keep in mind that it takes at least 20 minutes to arrive at the wind farm) call 911 from any site phone and request one. Arrange for someone to meet the ambulance at Charlie Gate.

\section{9) References}

The following are included as references for this safety plan and should be referred to whenever a question of safety or rules is encountered.

Hazard Communications Program 
SOP Page 9

July 23, 1993

Operations and Maintenance Manual for the Westinghouse WWG0600, vol. 1-11

Occupational Safety and Health Standards, State of Hawaii, DOSH. 3 volumes. 


\section{Section 6}

\section{Hawaii Zuteck Rotor Project \\ Phase II Follow-Up}

"Hawaii Zuteck Rotor Project, Final Flap Actuation System Configuration Overview"

by M. D. Zuteck

August 18, 1998 


\title{
Hawaii Zuteck Rotor Project Final Flap Actuation System Configuration Overview
}

\author{
M. D. Zuteck
}

August 18, 1998

In the process of finalizing the design details for the flap control system based on linear electric actuators and synthetic line mechanical links, a tradeoff between a line link and a gas shock for movement in the stop direction was undertaken. The initial plan called for line links in both the power and stop directions. This system had the advantage that large forces and direct position control could be applied in the llaps up direction needed for stopping. Ilowever, this system required dual line runs from root to each flap, and would also require very careful set-up to get the right working tensions in the lines. Loss of pre-load due to small amounts of creep was seen as a possibly significant maintenance item, which could lead to softened control and reduced margin against flutter.

Using gas shocks on the stop side of the system required only a single run of line from the root to each llap segment, and greatly reduced the complexity of the line system, both at the root end, and in the cavity just inboard of the flaps. Because the line working tension was set by the gas shock, a small amount of line stretch was a non issue with this system, and a possibly fussy maintenance item was eliminated. The gas shock also provided a built-in limit for the maximum rate at which the flap would be pulled toward stop. Overall, this design was seen as having lower cost, lower complexity, less maintenance, and more robust practicality in operation. It was a step closer to a possible commercial flap system, and that was judged sufficient motivation for adopting it as the linal design choice.

Figure A1 shows the final link design in schematic form. The linear electric actuator provides the force needed to pull the flap to the chosen operating position. The block system within the outboard blade cavity provides the force multiplication needed to match the actuator to the requirements of each flap segment; 2:1 for the inboard llap, and 3:1 for the outboard flap. For each flap segment, a single gas shock provides both the working preload, and a mechanical force which drives the flap toward the stop position. Note that in the operating position, the actuator must carry both the airload and the gas shock forces, so its operating loads are somewhat higher than they would be for the dual line system. This is not a practical problem, because the increase in required actuator force is modest, and mounting the actuators at the root easily provides enough room for actuators of sufficient power. However, this is a tradeofl inherent in the chosen configuration which does not exist for the dual link design. 


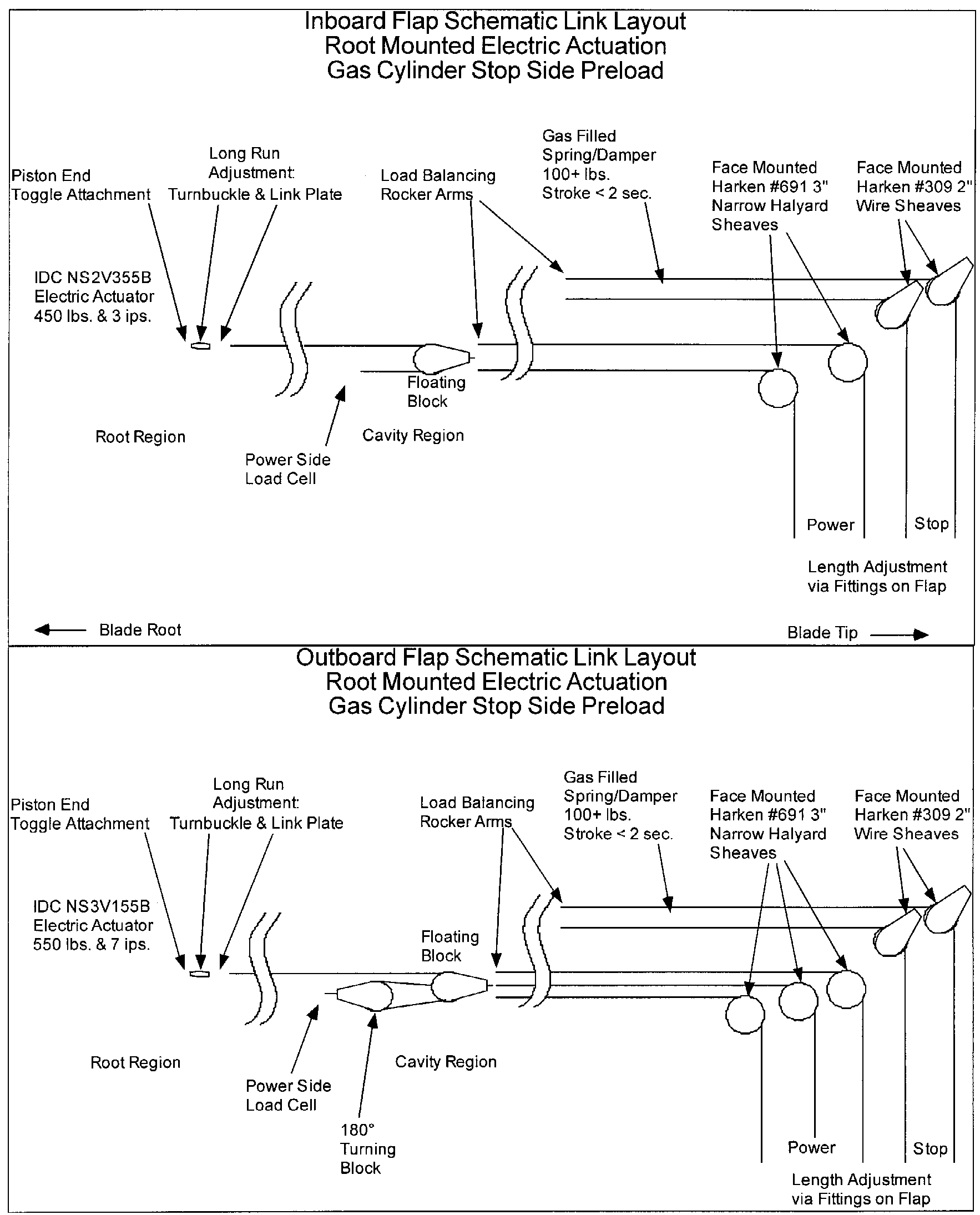

Figure A1 - Flap Actuation System Schematics 


\section{Actuation System Hardware Details}

\section{Root Mounted Actuators}

Photograph P1 shows the actuator mounting arrangement at the blade root. The mounting region was created by sawing a flat plane onto the inboard trailing edge of the blade. This was then reinforced and widened by bonding an FRP plate onto it. The actuators are mounted at the inboard end of this region, with the movable shafts pointed outboard. Attached to the tip of each actuator shaft is a fork and clevis, which mates to a turnbuckle and pinned link adjuster. In a mature system, with well understood long term line stretch behavior, a single turnbuckle or pinned adjuster should be sufficient, but for a research system, it was judged prudent to provide some extra adjustment range by including both, since the cost was insignificant, and there was room to do so easily.

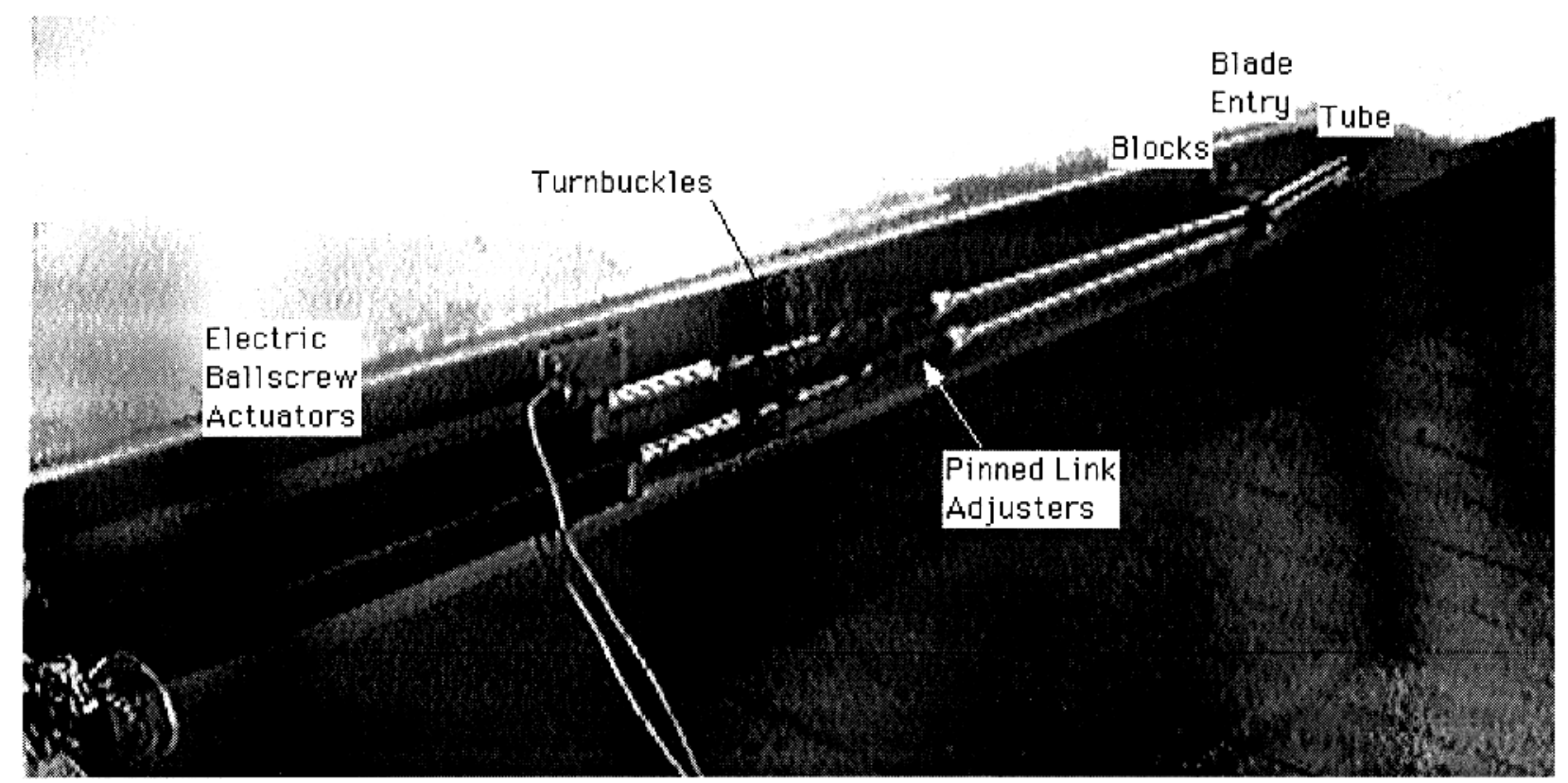

Photograph P1: Inboard Blade Hardware

Outboard of the actuators is a pair of turning blocks, mounted side by side in a single set of brackets. These blocks turn the lines through a small angle so they can pass into and through an entry tube which takes them inside the blade, in line with the block system in the outboard blade cavity. This tube is a single large PVC pipe bonded into the trailing edge laminate, which will not abrade the synthetic lines should contact occur. The alignment and clearance is such that this would not normally happen, even with the blade bent due to operating loads, but occasional contact due to vibration of the lines is a possibility. As a final detail, there are two white plastic fittings just outboard of the pinned link adjusters. Their function is to prevent the line being lost into the blade, should the line be accidentally dropped while the pinned adjusters or turnbuckles are disconnected. 
The actuators do not mount directly to the FRP reinforcement, but rather to a pair of FRP plates as are shown in photo $\mathrm{P} 2$. These plates are supported by steel studs bonded directly into the thick aft blade laminate, and provide the ability to precisely align the actuators with the line system by setting the position of the nuts that capture the plates. This arrangement makes it possible to minimize any undesired side loadings that could substantially reduce the ballscrew life, since the product data indicates that ballscrew life can be sensitive to shaft lateral loading. While the highest operating loads will occur with the shaft drawn inward toward its strongest position, it was nonetheless chosen to provide this adjustment since it was rather easy to do so.

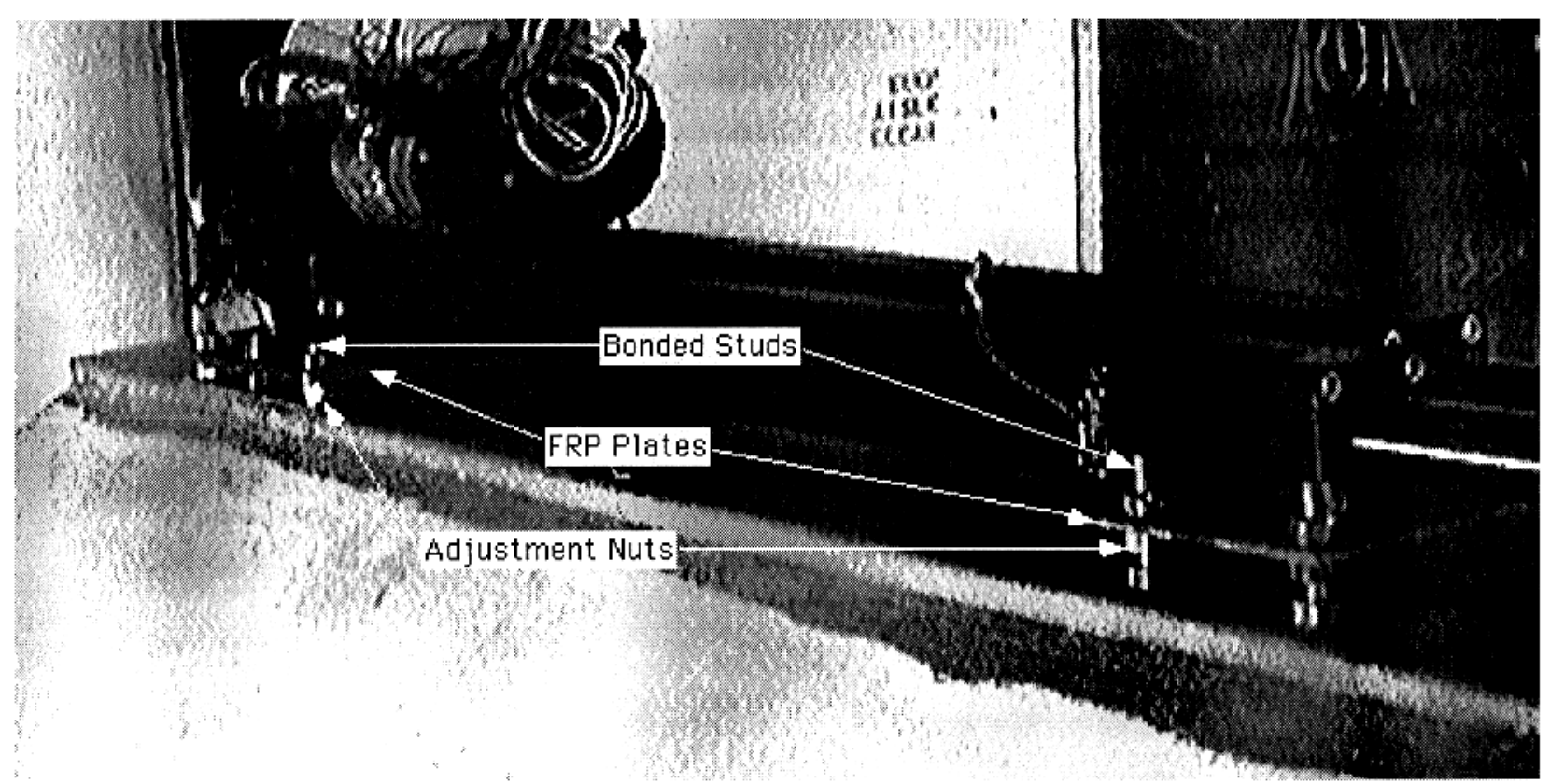

Photograph P2: Actuator Mounting and Alignment Hardware

\section{Outboard Blade Cavity Hardware}

One of the primary functions performed by the hardware within the outboard blade cavity is multiplication of the forces supplied by the lines running from the actuators, with a 2:1 ratio for the inboard flap, and 3:1 for the outboard flap. This matches the lower force, longer stroke from readily available electric ball screw actuators to the higher force, shorter range movement needed by the flaps. This also allows the use of a smaller diameter line for the run from the actuator to the cavity, which is lighter, less expensive, and has better vibrational damping. Use of force multiplication within the cavity also makes the link stiffer by the multiplication ratio, providing more accurate flap control with more resistance to flutter. A direct line link without force multiplication within the outboard cavity is certainly possible, and should be reconsidered because of its simplicity, once operational data is obtained with the present system. For the initial research however, the present higher stiffness system was judged to be more appropriate. 
Photo P3 shows the floating blocks within the cavity that provide the force multiplication function.

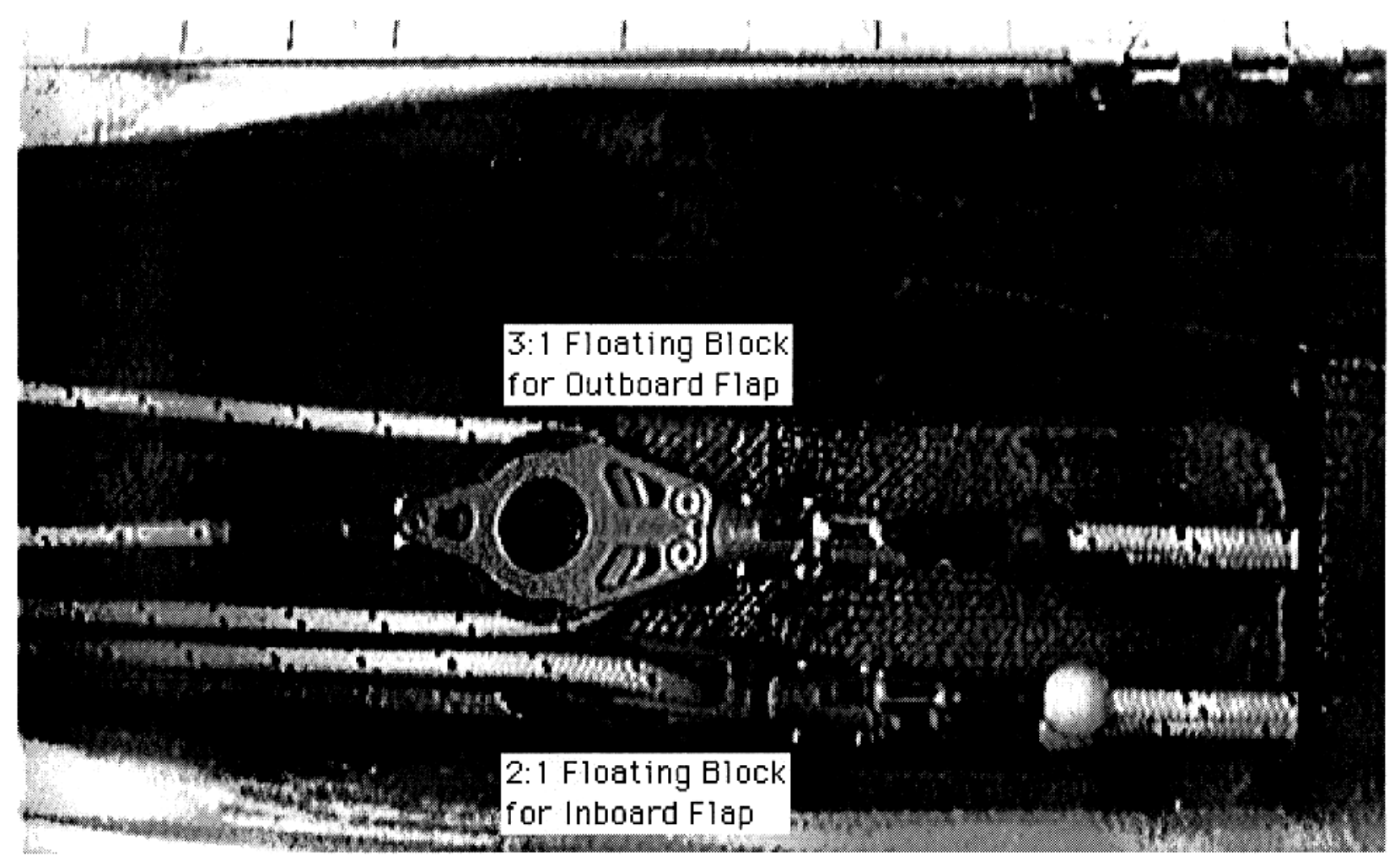

Photograph P3: Floating Blocks within Outboard Blade Cavity

Another function of the cavity hardware is to provide load measurements for the actuation lines for each flap. These measurements could have been made at the actuators, but the long run of line to the flaps would attenuate any high frequency vibrations that might be present. Also, due to centrifugal force acting on the lines, placing the load cells closer to the flaps provides a more direct measurement of the true flap control forces. For these reasons, the load cells were placed within the outboard blade cavity, as shown in photo P4. The turning blocks which guide the long run of line to the force multiplication blocks are also seen in this view. 


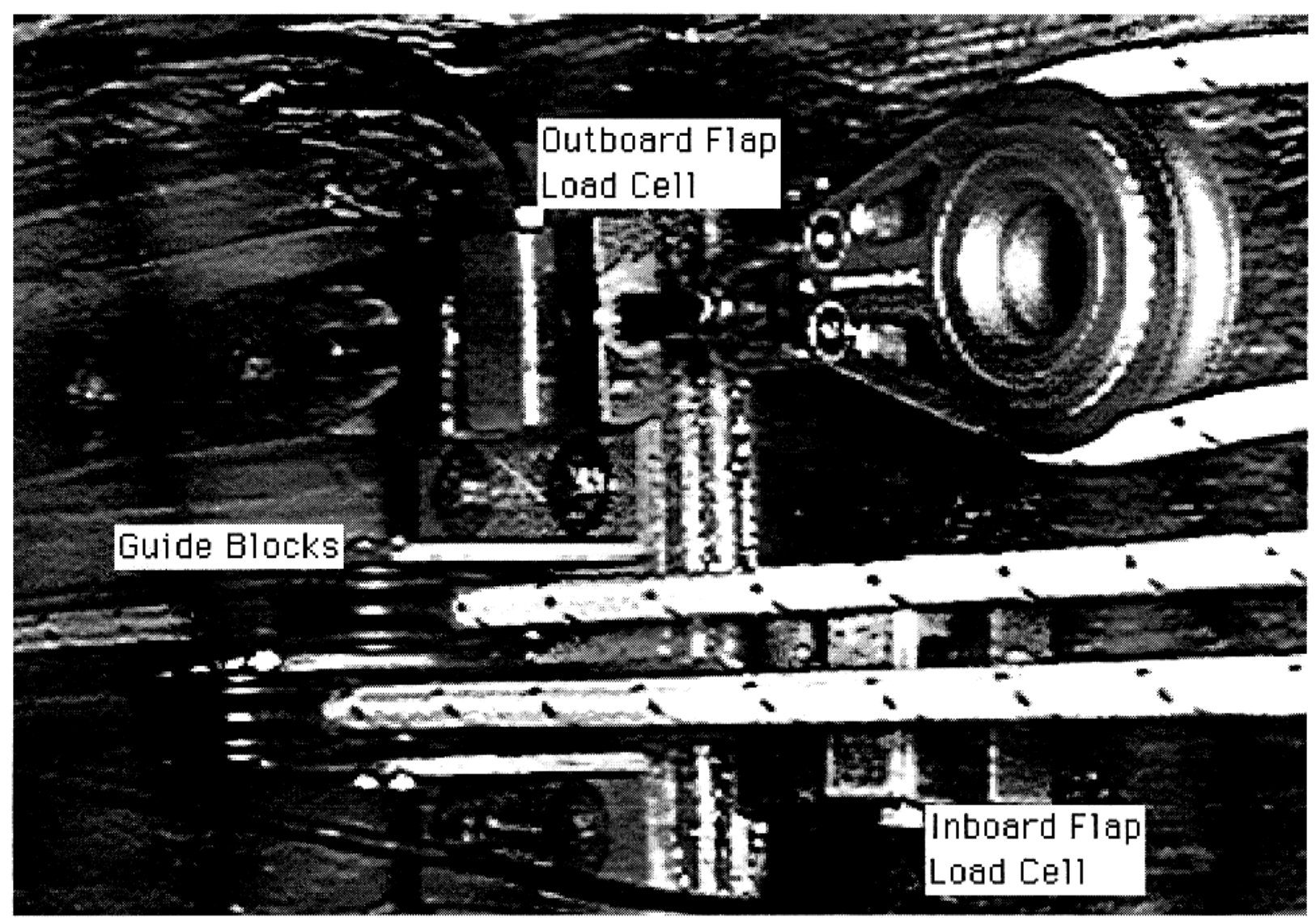

Photograph P4: Load Cell and Guide Block Layout

Another major function perform by the hardware within the cavity is to split the forces so they can be distributed to multiple attachment points on the flaps. The primary driver for this arrangement was to demonstrate the practicality of redundant line links and attachment points to the flaps. As shown in photo P5, rocker plates are used to balance the forces to the individual lines: three for the outboard flap, and two for the inboard flap. If one of the line links should be severed or become detached, its flap will still be restrained, once a small amount of movement to take up the added slack has occurred. Since the flap system will automatically be driven toward stop by the aerodynamic and gas shock forces, this redundancy may eventually be judged to be unnecessary, and a simpler connection could then be used. It can be noted in photo 5 that each line link is provided with a stopper ball, so that it can't drop into the tube during disassembly for maintenance, or if the attachment is broken during operation. This again demonstrates practical, low cost solutions to issues which could arise in commercial application. 


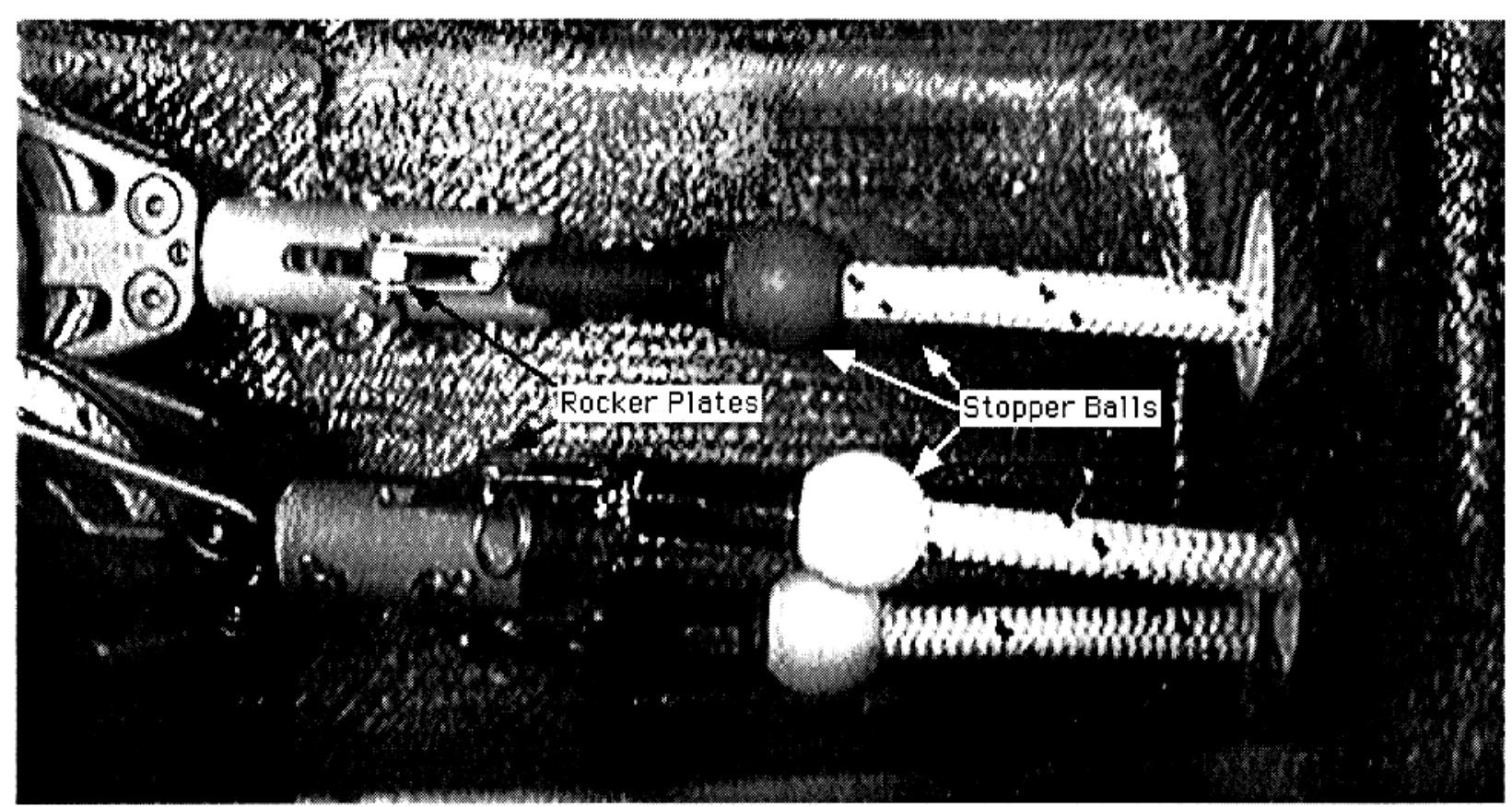

Photograph P5: Rocker Plate and Stopper Detail

\section{Gas Shock System}

The gas shocks provide mechanical damping of the flap motion, and a gas driven spring force which propels the flaps in the stop direction. In normal operation, the flaps already have a large moment in the stop direction because the hinge location is well forward of the aerodynamic force. If an overspeed occurs, the increase in this unbalanced aerodynamic force can overcome the actuator, and backdrive the system to safety, even if a stop command is not given by the system control software. The primary function of the gas shock is to take the flap the rest of the way to the stop position once the rotor speed has dropped, and to hold it there when the rotor is stopped. It also provides preload to the control line links, so that slack cannot occur and cause imprecise flap control.

The gas shocks are mounted with their pistons facing inward. Photo 6 shows the fork fitting at the end of the piston, which carries a rocker plate connected to two control lines. The rocker plate balances the forces on each line, and allows for a small amount of differential motion due to the different flap leading edge radius at each line attachment point. Again a major driver in the decision to use dual control lines was the desire to demonstrate the practical ability to provide redundancy. While it is not known or anticipated that a loss of this control link would lead to a dangerous turbine condition, this redundancy is readily provided at very little cost. 


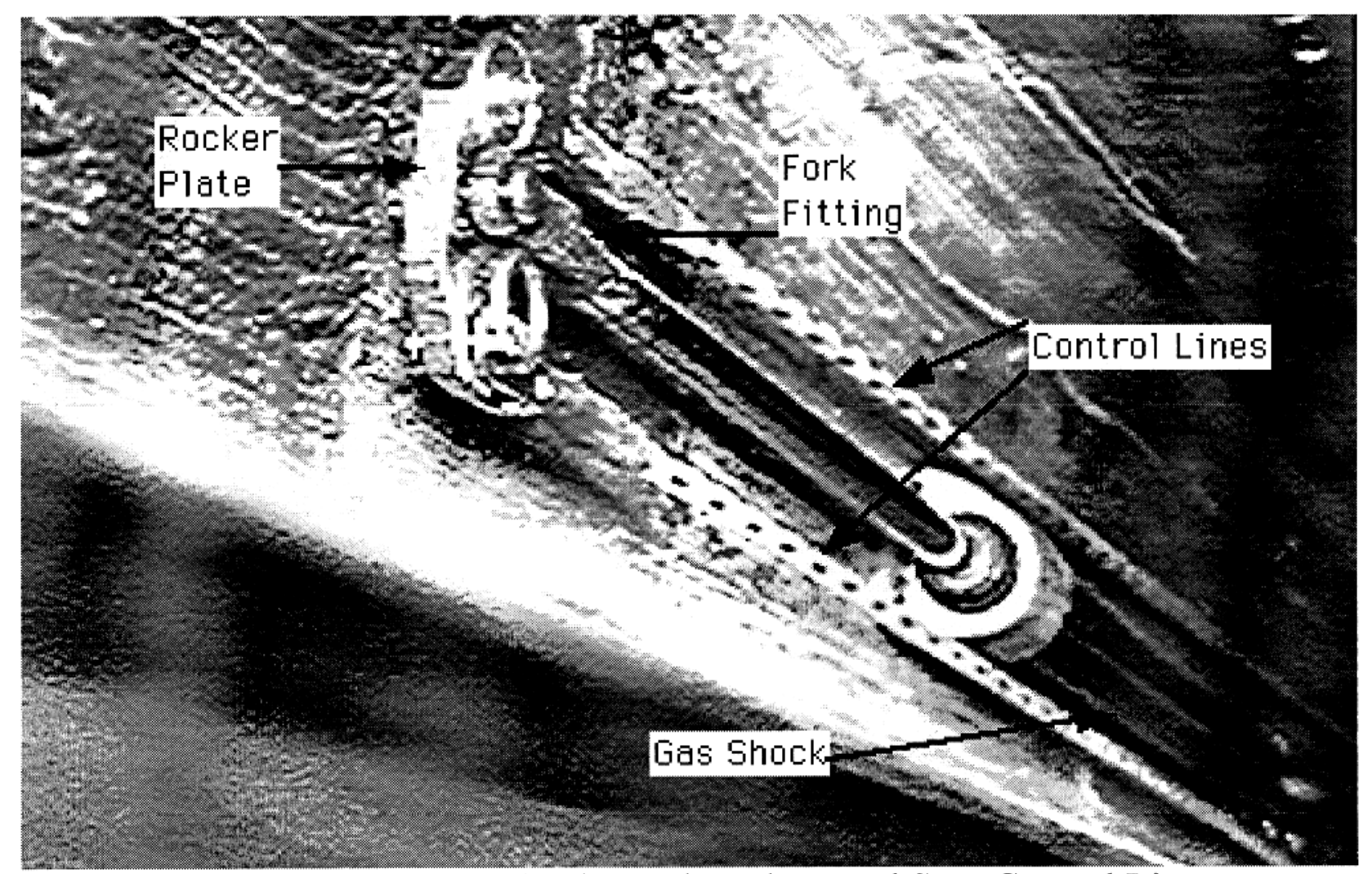

Photograph P6: Gas Shock, Rocker Plate, and Stop Control Lines

It should be noted that there was some question if the gas shocks were better mounted with pistons facing inward or outward. Facing them inward prevents the oil from leaking past the seals, because centrifugal force keeps it at the other end of the cylinder. The only concern with this choice is that if the turbine were to run for a very long time without stopping, the seals might become dry and wear rapidly. This was not judged to be a likely concern, but in the absence of engineering data suitable for resolving the issue, the cylinder retention has been designed so that the cylinder can be turned around with the piston then facing outward. No modification to the hardware is required to make this change; the various components simply have to be swapped end for end and the cylinder re-installed. This is entirely unlikely to be an issue in research use. If the system is commissioned to run long periods of substantial power generation so that some practical durability data can be obtained, then this built in feature might be useful. In any event, it was easily provided.

\section{Power Side Control Lines \& Attachment}

Photo 7 shows the power side attachment fittings on the outboard flap. These are standard pinned adjusters which provide a few few inches of adjustment right at the line to flap attachment points. This adjustment is provided to center the rocker plates properly within their range of rocking motion, and to allow proper distribution of forces between the attachment points. These fittings also serve to distribute the load over a large area of the flap structure. Since these fittings 
will mostly follow in the wake of the control lines, it was not thought to be necessary to provide a highly aerodynamic design. However, if they prove to be a source of noise, it should be apparent that more aerodynamic fittings could be fabricated and substituted.

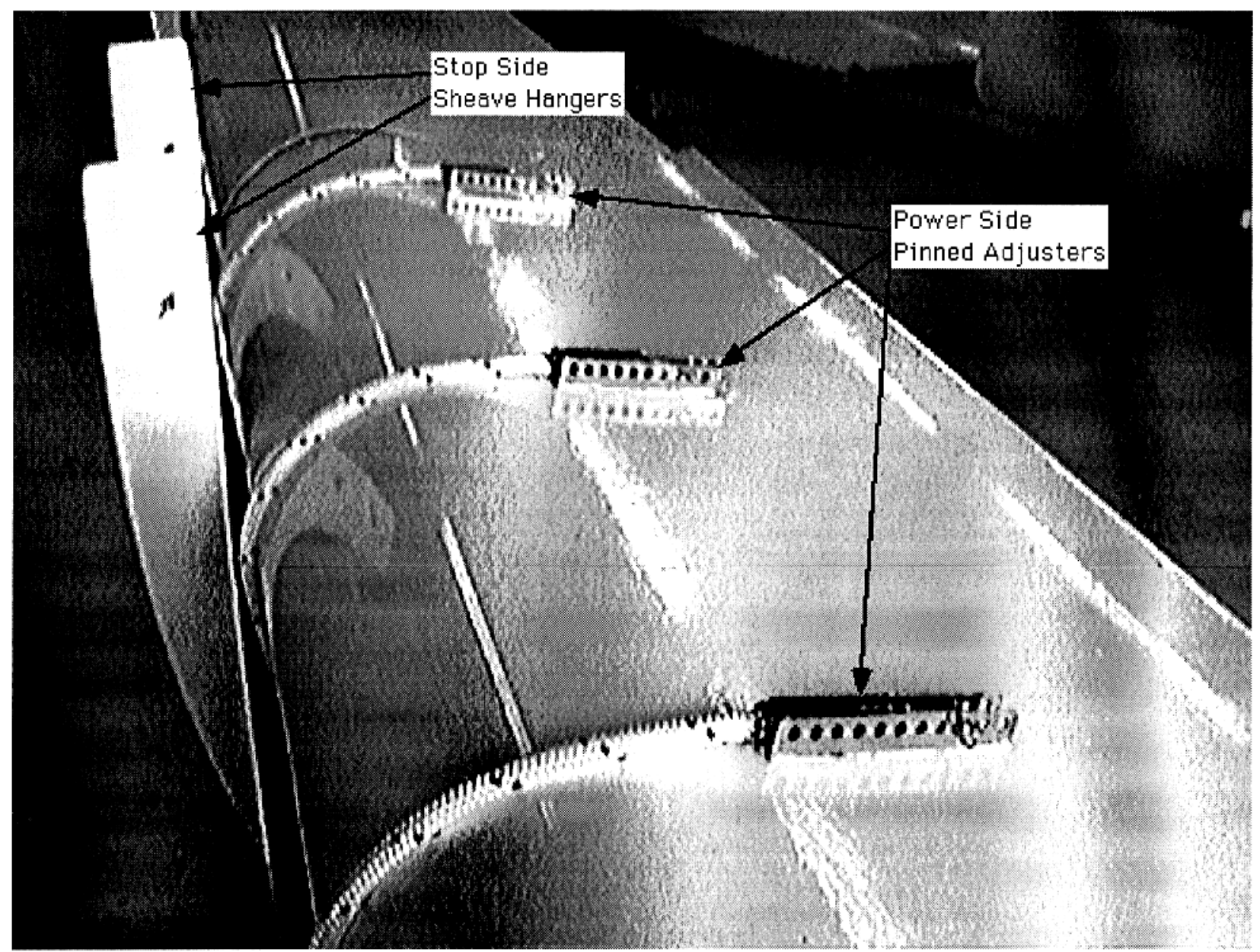

Photograph P7: Pinned Adjusters and Sheave Hangers

Photo 8 shows one of the exit blocks which feed the large diameter control line out from its guide tube and through the aft web so that it can exert its pull on the leading edge of the flap. There are three lines for the outboard flap, and two for the inboard one. Due to the different flap areas, aerodynamic loadings, and leading edge radii, the loadings on the lines and blocks are nearly equal for both flaps, as a matter of design choice. This eliminates the need for different parts for different locations, and would allow a common maintenance and replacement interval in commercial service. Each block is easily remove for examination or replacement via a single mounting bolt. Of course, a commercial version of the system might employ a single flap with one block and attachment point if the possible power production and redundancy advantages of a two element flap system did not justify the added cost. Research objectives dictated multiple flaps; the current system demonstrates they can be provided without unreasonable complexity. 


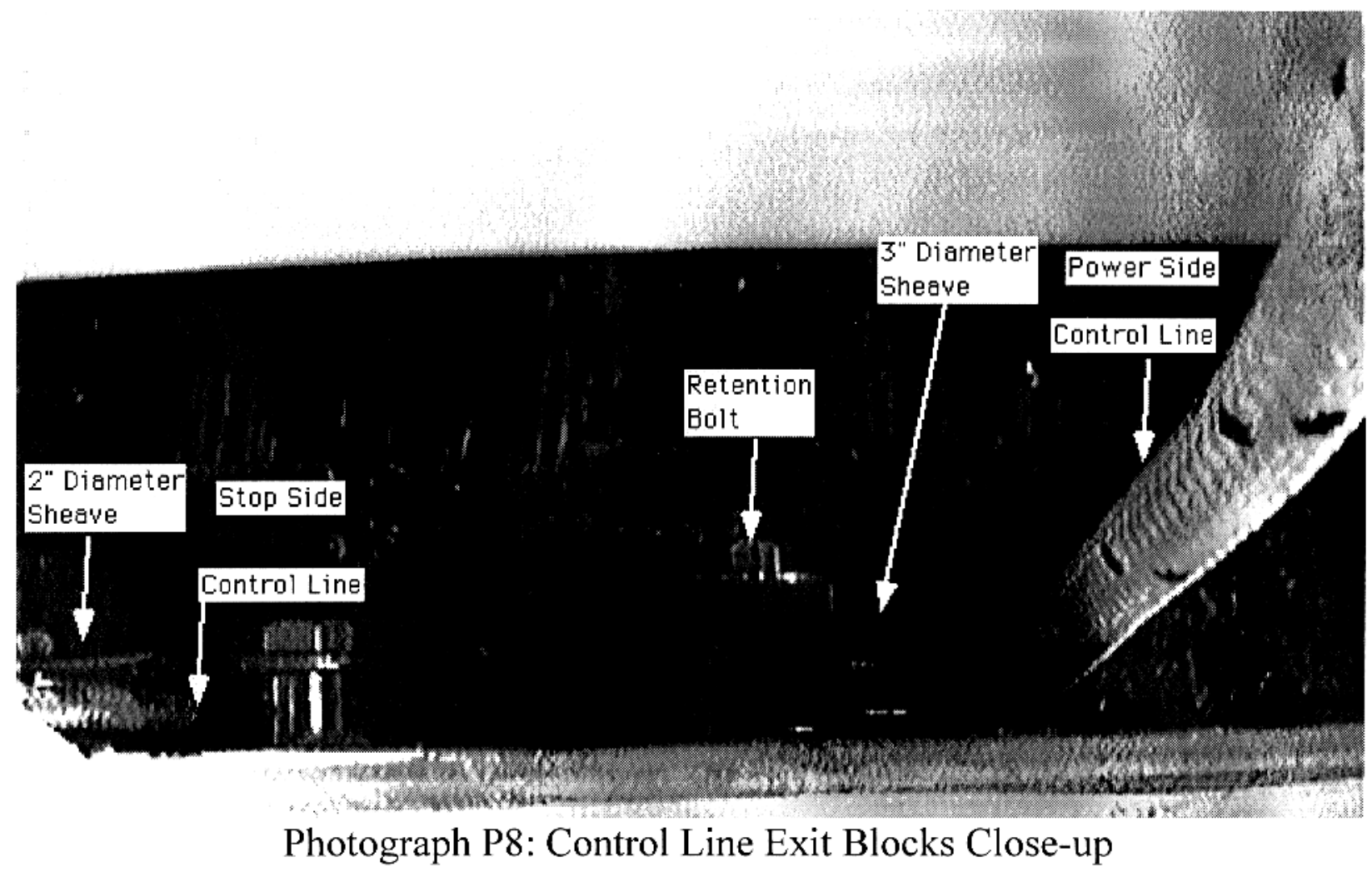

\section{Stop Side Control Lines \& Attachment}

The control lines for the stop side run only a short distance from the gas shocks to the points where they pull on the flaps, and both the shocks and the spanwise line runs are entirely within the cavity forward of the flap leading edge radius. The gas shock can be visually inspected by opening the flap sealing strip, without having to remove the flap.

Because the stop side lines must pull the flap in the stop direction, it is necessary to lead the control line aft past the flap leading edge so it can do this. That is accomplished by means of special structures called "sheave hangers", which position a turning block far enough aft to accomplish this purpose. As seen in photo 7, these structures look a bit like the hinge fairings on aircraft flaps. They are made hollow with two side plates to provide room for the turning sheave, and a path for the control line. They are bonded to the main blade structure, and are faired to a trailing edge point for minimum noise and drag. In the maximum lift flap position, they fit snugly against the flap surface for minimum noise and drag.

Photo 9 shows the fittings which attach the stop side control lines to the flap. These are made of sheet FRP, with the control line bonded into a slot cut in the pointed end of each triangular shaped tab. A layer of fiberglass is added top and bottom at the time of bonding to entirely surround the line, and thereby add more strength. These end tabs are secured to the upper surface of the flap leading edge, where they are entirely out of the way, and where there is 
plenty of material to accept the screw fasteners. This location also provides considerable range of final position, which can be used to fine adjust the rocker arm orientation and gas shock extension.

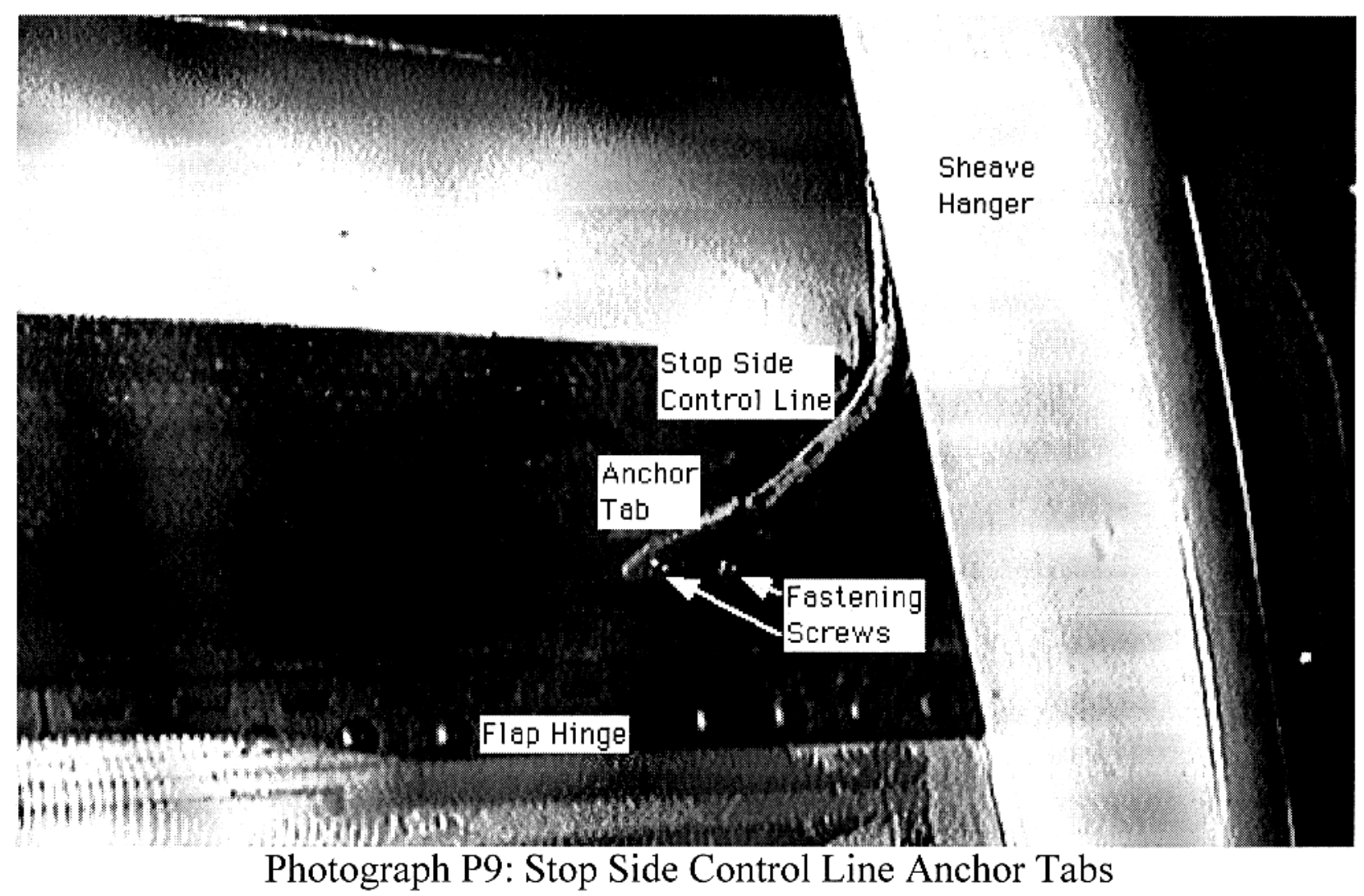




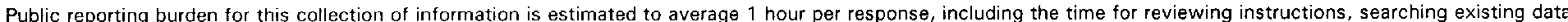

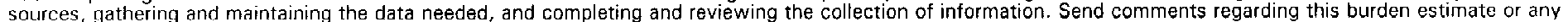

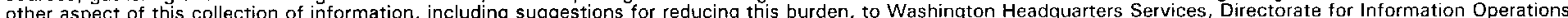

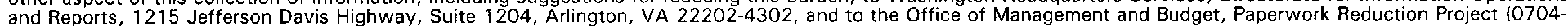
0188 ). Washington, DC 20503

\begin{tabular}{l|l|l} 
1. & $\begin{array}{l}\text { 2. REPORT DATE } \\
\text { September } 1998\end{array}$ & $\begin{array}{l}\text { 3. REPORT TYPE AND DATES COVERED } \\
\text { Subcontractor Report }\end{array}$ \\
\hline
\end{tabular}

4. TITLE AND SUBTITLE

Hawaii Zuteck Rotor Project: Compilation of Project Reports

6. AUTHOR(S)

M.D. Zuteck, W. M. Miller

7. PERFORMING ORGANIZATION NAME(S) AND ADDRESS(ES)

M.D. Zuteck

MDZ Consulting

931 Grove

Kemah, Texas 77565

9. SPONSORING/MONITORING AGENCY NAME(S) AND ADDRESS(ES)

National Renewable Energy Laboratory

1617 Cole Blvd.

Golden, CO 80401-3393
5. FUNDING NUMBERS

C:

TA: WE901410

8. PERFORMING ORGANIZATION REPORT NUMBER

11. SUPPLEMENTARY NOTES

12a. DISTRIBUTION/AVAILABILITY STATEMENT

National Technical Information Service

U.S. Department of Commerce

5285 Port Royal Road

Springfield, VA 22161

10. SPONSORING/MONITORING AGENCY REPORT NUMBER

SR-500-26086

\section{ABSTRACT (Maximum 200 words)}

Summarizes project to design and build aileron retrofit blades for a $600 \mathrm{~kW}$ upwind, teetered rotor, full-span pitch control, horizontal-axis wind turbine.

14. SUBJECT TERMS

wind energy, rotor, aileron, horizontal-axis wind turbine 12b. DISTRIBUTION CODE

\begin{tabular}{|c|c|c|c|c|c|c|c|}
\hline 17. & $\begin{array}{l}\text { SECURITY } \\
\text { CLASSIFICATION } \\
\text { OF REPORT } \\
\text { Unclassified }\end{array}$ & 18. & $\begin{array}{l}\text { SECURITY } \\
\text { CLASSIFICATION } \\
\text { OF THIS PAGE } \\
\text { Unclassified }\end{array}$ & 19. & $\begin{array}{l}\text { SECURITY } \\
\text { CLASSIFICATION } \\
\text { OF ABSTRACT } \\
\text { Unclassified }\end{array}$ & 20. & $\begin{array}{l}\text { LIMITATION OF ABSTRACT } \\
\text { UL }\end{array}$ \\
\hline
\end{tabular}

